The University of Michigan Institute of Science and Technology Series 



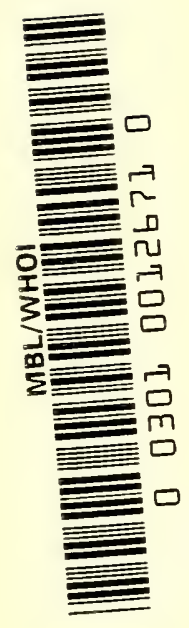




THE NATURE OF BIOLOGICAL DIVERSITY 
The University of Michigan

Institute of Science and Technology Series

\author{
ALLEN - The Molecular Control of Cellular Activity \\ ALLEN - The Nature of Biological Diversity \\ LILLER - Space Astrophysics
}




\section{The Neture of BIOLOGICAL DIVERSITY}

\section{Edited by}

John M. Allen

Associate Professor of Zoology

The University of Michigan

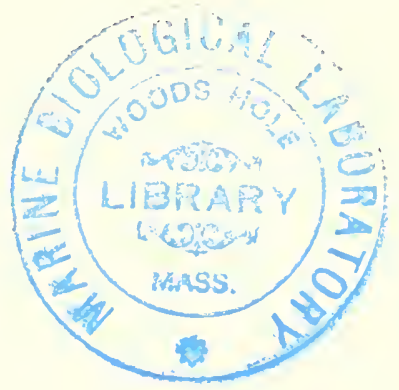

McGraw-Hill Book Company, Inc.

NEW YORK SAN FRANCISCO TORONTO LONDON 


\section{THE NATURE OF BIOLOGICAL DIVERSITY}

Copyright (c) 1963 by the McGraw-Hill Book Company, Inc. All Rights Reserved. Printed in the United States of America. This book, or parts thereof, may not be reproduced in any form without permission of the publishers. Library of Congress Catalog Card Number 62-20182 01078 


\section{Preface}

The papers contained within this volume are the result of a series of leetures held at The University of Michigan in the spring of 1961. under the auspices of it Institute of Seienee and Teehnology.

Of the several areas of inquiry that are germane to an understanding of biological phenomena. one of the more challenging is that which attempts to define the factors responsible for the diversification of eellular strueture and function. In planning the leetures from which this volume is derived, wr felt that examination of the elements learl. ing to the diversification of biologieal systems from a broad rantage point might yield a degree of synthesis to an area which is fraught with as much variation in its approaches as the systems which it attempts to investigate. This volnme deals nearly exelusively with the development of heterogeneity at the cellular and subcellular level, for elucidation of the problems involved will come largely from these areas of investigation which are basieally biochemieal and molecular in their philosophy.

In pondering the general problem of diversifieation in biologieal systems. we arrive at the realization not only that the properties of cells are the result of a long history of organie evolution hut also that prebiological evolution has placed basic restrictions upon what cells may beeome and what they may do. These restrietions of eour:e, relate to the properties of the molecules available for biologieal use. Thus, in any general discussion of diversification, an examination of the origin of organic moleenles makes a logieal starting point. This is the topie which has been ehosen to introduce the subjeet. From thipoint an examination of ways in which molecules may interact to yield biologieally useful energy needed for cell maintenance may he considered. Perhaps the most informative system in this respeet is the evolution of the photosynthetie meehanism.

Cell diversification depends upon the variety of eatalytic and structural proteins from which the eells are falmicated. These ilspects of the problem are examined in three chapters dealing with bioehemieal 
vi Preface

evolution, the origin of speeific proteins, and the nature of catalytic proteins. The maeromolceular aspeets of these processes are examined in chapters dealing with cellular organization and the genetic control of cellular organization, with protozoa as a model system. The final chapters of this book attempt to illustrate the ways in whieh eellular interactions and cellular products modify the processes of molecular diversifieation.

Throughout these pages we have tried to disseet the fabrie of moleeular and cellular interaction which lead to the bewildering array of biological complexity confronting us. We hope this collection of papers will lend perspective to this area. In some small measure we feel we have accomplished this.

I wish to thank the contributors to this volume who gave so freely and graciously of their thoughts and time. Thanks are also due Drs. Wilbur Ackermann and M. J. Coon of The University of Michigan, who spent much time in planning the lecture series, from which this book is derived.

John M. Allen 


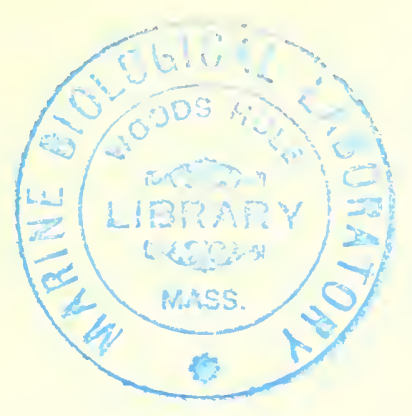

\section{Contents}

PREFACE

v

CHAPTER

1 THE ORIGIN OF ORGANIC MOLECULES

Harold C. Urey

2 EVOLUTION OF PHOTOSINTHETIC MECHANISMS Melvin Calvin

3 BIOCHEMISTRY AND EVOLUTION Ernest Baldwin

4 THE NATURE AND DIVERSITY OF CATALITIC PRO. TEINS Paul D. Boyer

5 THE ORIGIN OF SPECIFIC PROTEINS

Clement L. Markert

6 DIVERSITY AT THE SUBCELLULAR LEVEL AND ITS SIGNIFICANCE Keith R. Porter

7 DOES PREFORMED CELL STRUCTURE PLAY AN ESSENTIAL ROLE IN CELL HEREDITY?

Tracy M. Sonneborn

8 MICROENVIRONMENTAL INFLUENCES IN CITODIFFERENTIATION Clifford Grobstein

9 DIFFERENTIATION AND MORPHOGENESIS IN INSECTS Carroll M. Williams

10 GROWTH AND DIFFERENTIATION IN THE NERV. OUS SYSTEM 

THE NATURE OF BIOLOGICAL DIVERSITY 



\title{
The Origin of
}

\section{Organic Molecules}

\author{
Harold C. Urey
}

School of Science and Engineering University of California, San Diego

La Jolla, California

Darwin and Wallace proposed the theory of evolution almost simultaneously and quite independently. They and their numerous followers of the past century have demonstrated that, given an organisun of the most primitive type, all the species of today and of past geological periods could and did evolve from such cells. WTe are heginning to understand the processes by which inherited characteristics are carried from generation to generation by means of deoxyribonueleic acids, and also we understand how variations in species of animals and plants occur. Many details remain, but the broad outline has become clearer during recent years and decades. Also, we find marked biochemical similarities between all living things, indieating that they are all part of a single evolutionary process. These fundamental hiochemieal processes were established in the distant past before the time of the oldest fossils, namely, some 500 million or more years ago.

At least after the development of sexual reproduction, evolution must have occurred by mutation in one individual, it is true, but the 
characteristic must have been segregated from a community. It seems likely that precellular evolution also involved the segregation of chemical constituents from many sources.

The complexity of living organisms astounds all students of biology, and the more knowledge the olsserver has the more astounding to the facts appear to be. Is it not true that the development of a particular minute drop of clear protoplasm, such as a fertilized egg, into a sea urchin and nothing else is one of the greatest wonders of which we have knowledge? Yet the study of the compounds of carbon, nitrogen, oxygen, and hydrogen shows us that a very great varicty of these compounds is possible. Two illustrations of the varieties of the molecules can be given. The human egg contains strands of total length of about 1 meter long of deoxyribonucleic acid containing about $10^{9}$ units, each of which can be chosen in four different ways. The number of possible molecules becomes $4^{109}$, which is an immense number. To specify a human being at each moment of its existence requires less specific information; much redundancy is possible and surely exists. Again the number of possible proteins consisting of, say, 170 amino acids of 20 kinds is very great. If one of each kind were placed in a cubical box, the length of the edge of the box would be 10 raised to nearly the 50 th power light-years. Not all the possible protein molecules exist now in the observed universe nor could they have existed during the last 4.5 billion years.

Natural phenomena are very complex in all their various manifestations. We can follow in considerable detail the more simple and isolated examples of these phenomena, for example, many chemical reactions and structures, the structure of atoms and the nuclei of atoms, and the gross structure of stars and galaxies of stars. The details of natural phenomena exceed in complexity the complexity of structure of the human brain, and we cannot follow these except in an approximate way. But we can say something about the comparative complexities of the chemistry of the carbon, nitrogen, oxygen, hydrogen compounds and those of other elements. I shall state my conclusion categorically in this way. There is no known chemistry of other elements which approaches in ordered complexity that of these four elements, and we know enough of the chemistry of all the elements that we can be certain that no other such chemistry exists. Only these clements supply such a complexity of compounds and chemical reactions that we are forced to conclude that only the chemistry of these elements could supply the complexity of structure and behavior which we recognize as those of living things. A system of life based on other 
elements would necessarily be so vastly simpler in behavior that we would not recognize it as such.

The liquid in which all terrestrial life exists is water. It is interesting to inquire whether other liquids might be suitable. Only two seem possible candidates, namely, ammonia and hydrocarbons. It is difficult to imagine cireumstances that would supply liquid ammonia to a planet without water being present, hut its chemical properties might not rule it out. The hydrocarbons might be present on a planet hut the generally slow reactions occurring in liydrocarbon solvents look less likely as substitutes for moderately lively reactions of living things.

Living organisms do grow in petroleum products, though these organisms are of the hydrophilic variety and depend for their energy on the oxidation of petroleum by atmospheric oxygen. Free oxygen should be nonexistent on a planet with excess hydrocarbon rather than an excess of water. The sulfur deposits of the world have been produced by the reduction of $\mathrm{CaSO}_{4}$ by petroleum through the action of baeteria, but again sulfate has been produeed on earth by oxidation due to free atmospheric oxygen. These arguments may not exclude the possibility of life on a planet having excess hydrocarbon componnds but no oxidizing atmosphere, and any conclusion to this effeet may only indicate a prejudice arising from our terrestrial experience. It seems likely to the writer that only a water solvent could lead to any reasonable approximation to compounds and chemical reactions of sufficient complexity to be regarded as constituting a living organism.

\section{Primitive conditions on the earth}

Hydrogen is the most abundant element in the cosmos. In particular the sun contains 80 per cent $\mathrm{H}_{2}$, and it can be confidently supposed that the earth and other planets evolved from matter in which hydrogen was equally abundant initially. Also, carbon is reported to be about equally as abundant as oxygen. The abundances of some of the relevant elements in solar and terrestrial material are given in Table 1.

It is evident that solar material is highly reducing, with ahout 1.100 times as many atoms of hydrogen as of oxygen, and that the relative abundances of these elements are quite different in terrestrial matter at the present time. Meteoritic matter is in general very reducing also, i.e., it contains iron in the elementary and ferrous states. (However, the carbonaceous chondrites contain carbon compounds which are partially oxidized and also highly oxidized sulfur as magnesium sul- 
fate.*) The abundances of some elements in the terrestrial surface regions are given also in Table 1 . It will be noted that hydrogen is present mostly in oxidized form as water and that carbon and nitrogen are far less abundant than oxygen in surfaee water and even less abundant relative to oxygen in igneous roeks. Terrestrial surface carbon is present mostly as carbonates, i.e., in the highest oxidation state. If one added a small amount of hydrogen to the earth, one would expect that earbon and nitrogen would be converted in time to methane and ammonia and all sulfates would be reduced to sulfides.

Table 1. Atomic abundances of some elements relative to oxygen

\begin{tabular}{lccc}
\hline Element & Sun & $\begin{array}{c}\text { Earth's atmosphere } \\
\text { and oceans }\end{array}$ & $\begin{array}{c}\text { Earth's } \\
\text { igneous rocks }\end{array}$ \\
\hline $\mathrm{H}$ & 1.100 & 2 & $4.4 \times 10^{-2}$ \\
$\mathrm{C}$ & 0.57 & $* 2.1 \times 10^{-2}$ & $9.1 \times 10^{-4}$ \\
$\mathrm{~N}$ & 0.105 & $3.4 \times 10^{-3}$ & $1.1 \times 10^{-4}$ \\
$\mathrm{O}$ & 1 & 1 & 1 \\
$\mathrm{Mg}$ & $2.75 \times 10^{-2}$ & $9.4 \times 10^{-4}$ & $3 \times 10^{-2}$ \\
$\mathrm{P}$ & $2.4 \times 10^{-4}$ & $5.8 \times 10^{-8}$ & $1.3 \times 10^{-3}$ \\
$\mathrm{~S}$ & $2.2 \times 10^{-2}$ & $5.0 \times 10^{-4}$ & $5.6 \times 10^{-4}$ \\
$\mathrm{~K}$ & $5.5 \times 10^{-5}$ & $1.75 \times 10^{-4}$ & $2.3 \times 10^{-2}$ \\
$\mathrm{Ca}$ & $1.55 \times 10^{-3}$ & $1.8 \times 10^{-4}$ & $3.1 \times 10^{-2}$ \\
\hline
\end{tabular}

* The carbon abundance is that of the sedimentary rocks relative to oxygen in the oceans. The abundances of the mineral elements in sedimentary rocks are similar to those in igneous rocks.

sources: Sun: L. Goldberg, E. A. Müller, and L. H. Aller, Astrophys. J., Suppl. Ser. 5:1-138 (1960). Earth: K. Rankama and T. G. Sahama, Geochemistry, University of Chicago Press, Chicago (1950).

It is evident that two important processes from the standpoint of the present discussion have oceurred on the earth and also on Mars and Venus. (1) The more volatile fraction of solar matter has been lost to a high degree, including the elements $\mathrm{H}, \mathrm{N}, \mathrm{C}$, and $\mathrm{O}$, and the inert gases. (2) The surface regions of these planets have become highly oxidized. The first process is veiled in the obscurity of the earth's origin. Since any discussion of the process would earry considerable doubt and would be very long and involved, it will not be treated here. The second proeess is well understood. Oxidation of the earth is probably continuing at the present time and is due to the escape of hydrogen from the earth into space. The same process ean reasonably be supposed to have occurred in the case of Mars and

* E. Du Fresne, Dissertation, University of Chicago, 1960. 
Venus. It is most improbable that lydrogen is now escaping from the major planets. The general course of oxidation of earlon and nitrogen expected is shown in Table 2. The componnds listed are only the mo-t simple examples. Many complex CNOH compounds exist in which the oxidation states of $\mathrm{C}$ and $\mathrm{N}$ lie between the lowest and higle-t oxidation states. (The oxidation state is nsually defined hy counting oxyen as -2 and hydrogen as +1 and making the carbon and nitrogen states such that the molecule is nentral. As is well known, the oxidation states are not always uniquely determined.) The general course of

Table 2. Oxidation states

\begin{tabular}{lllll}
\hline $4-$ & $2-$ & 0 & $2+$ & $4+$ \\
$\mathrm{CH}_{4}$ & $\mathrm{CH}_{3} \mathrm{OH}$ & $\mathrm{CH} O$ & CHOOH & $\mathrm{CO}$ \\
$3-$ & $1-$ & 0 & Higher oxidation \\
$\mathrm{NH}_{3}$ & $\mathrm{NH} O \mathrm{OH}$ & $\mathrm{N}_{2}$ & states & \\
\hline
\end{tabular}

chemical change on the earth and other terrestrial planets has been from the more reduced to the more oxidized condition, i.e., from left to right in the table. It is evident that a favorable condition for the existence of eompounds sueh as those required for living organisms would be present during this oxidation proeess.

\section{The escape of hydrogen from the carth and inorganic roactions inrolred}

It is possible to estimate the conditions for the escape of hydrogen from the earth rather plausibly, though hardly with certainty. The escape conditions have been given in considerable detail by Trey (1959). Jeans derived the formula for the escape of planetary atmospheres. Its application to the earth indieated a los of hydrogen from the earth considerably larger than conld be aceomted for by the oxidation of surface elements by the oxy gen left behind in the process. Harteck and Jensen showed that diffusion was important and suggested a diffusion layer at the tropopause. Subserfuent work slowed that circulation occurred through this layer and Urey snggested that the diffusion layer was at the top of the atmosphere." The rate of escape is determined by diffusion in this layer and the rate is proportional to the surface hydrogen pressure, which at present is $10^{-6}$ atmosphere. The present rate was caleulated as $10^{7}$ atoms see ${ }^{-1} \mathrm{em}^{-2}$. This is not a highly precise value. It is probable that the rate of escape

* See Bates and McDowell (1957) for a disussion of the escape problem for $\mathrm{He}^{3}$ and $\mathrm{He}^{4}$. 
differs with time of day and the latitude. If this rate continued throughout $4.5 \times 10^{9}$ years, the loss would amount to the hydrogen from only $20 \mathrm{~g} \mathrm{~cm}^{-2}$ of water. In order to account for the oxidation of carbon, ammonia, sulfide, and some ferrous oxide, Miller and Urey estimated that probably 1,500 times as much hydrogen must have escaped and hence that the hydrogen pressure must have been some $1.5 \times 10^{-3}$ atmospheres during much of geologic time and the total water decomposed abont $3 \times 10^{4} \mathrm{~g} \mathrm{~cm}^{-2}$ or about one-tenth of the present surface water. " It is reasonable to suppose that hydrogen would be more abundant in an atmosphere that did not contain free oxygen and that it was the appearance of this oxygen which decreased the hydrogen abundance and initiated the present rate of loss.

If hydrogen were present at these comparatively high pressures, it is necessary to ask whether it would interfere with other chemical facts. Carbon dioxide reacts with silicates to give limcstone and silicon dioxide, and at the same time hydrogen reacts with carbon dioxide to form methane and water. If the carbon dioxide is destroyed by the second reaction until its pressure becomes lower than that required to precipitate calcium carbonate, the first reaction cannot proceed. Since very ancient limestones are known, this would be impossible. Miller and Urey (1959) showed that these conditions can be met satisfactorily. They also found that nitrogen would be present as $\mathrm{NH}_{4}+$ ion if the hydrogen pressure were the assumed value. This study showed that the necessary escape of hydrogen was possible, that calcium carbonate could be formed, and that reduced nitrogen could be present in the oceans. Such a study does not prove that the conditions did exist but only that they are not inconsistent with observations.

\section{The production of carbon compounds}

As a first approximation, it is reasonable to assume that the chemical elements will be present in nature in chemical compounds which are thermodynamically stable under the existing conditions. It is well known also that deviations from this condition are so very common as to be almost universal, though such deviations are usually not large. But we may well review briefly some general facts about the stability of carhon-hydrogen-oxygen compounds. The simpler componnds of

\footnotetext{
* There are indications that deuterinm is more abundant in the ocean than in juvenile water by some 4 per cent. This indicates that hydrogen has been lost to a larger extent proportionally than has deuterium. The observations are not inconsistent with the assumptions of Miller and Urey. See N. Kokubu, T. Mayeda, and H. C. Urey (1961), Geochim. et Cosmochim. Acta, $21: 247$.
} 
this kind are all unstable with respect to the completely oxidized and reduced condition. Thus at $25^{\circ} \mathrm{C}$ the following reactions all proeced toward the right-hand side.

$$
\begin{aligned}
4 \mathrm{CH}_{3} \mathrm{OH} & \rightarrow 3 \mathrm{CH}_{4}+\mathrm{CO}_{2}+2 \mathrm{H}_{2} \mathrm{O} \\
2 \mathrm{CH}_{2} \mathrm{O} & \rightarrow \mathrm{CH}_{4}+\mathrm{CO}_{2} \\
4 \mathrm{HCOOH}_{4} & \rightarrow \mathrm{CH}_{4}+3 \mathrm{CO}_{2}+2 \mathrm{H}_{2} \mathrm{O}
\end{aligned}
$$

At least for many other carbon compounds, similar statements are true. Compounds of carbon in intermediate oxidation states such as those common in living organisms are unstable even in the absence of hy. drogen or oxygen. It is also true that even small pressures of hydrogen will lead to reactions to produce the completely reduced state of carbon, and that no carbon dioxide would be produced. Also oxyen will burn up all these compounds at ordinary temperatures given sufficient time with or withont suitahle catalysts. What we note is that the compounds of which living organisms are composed are unstable. This is necessarily true, for otherwise no metabolism in either fer: mentative or oxidative organisms would occur. But this emphasizes that during the evolution of the most primitive living organism, as well as during the lives of well-organized living things. a continuous and effective sonrce of cnergy must be present.

We can estimate the sources of energy arailable today with some precision, as listed in Table 3 . Certain of these can be climinated

Table 3. Present sources of energy areraged over the earth

\begin{tabular}{lc}
\hline \multicolumn{1}{c}{ Source } & $\begin{array}{c}\text { Energy, } \\
\text { cal } \mathrm{cm}^{-2} \mathrm{yr}^{-1}\end{array}$ \\
\hline Total radiation from sun & 260.000 \\
Ultraviolet light & \\
$\lambda<2,500 \mathrm{~A}$ & 570 \\
$\lambda<2.000 \mathrm{~A}$ & 85 \\
$\lambda<1.500 \mathrm{~A}$ & 3.5 \\
Electric discharges & +4 \\
Cosmic rays & 0.0015 \\
Radioactivity (to $1.0 \mathrm{~km}$ depth) & 0.8 \\
Volcanoes & 0.13 \\
\hline
\end{tabular}

immediately from the list of effective supplies. Radioactivity is of no importance now except that it may and probably docs produce detrimental mutations as well as an occasional useful mutation. Pota-imm exists in the bodies of all living organisms but its radioactivity sup- 
plies no effective energy for these metabolic processes. The radioactivity of the rocks is unavailable because it is much too violent in character and because it is largely dissipated within the rocks. Cosmic rays are unimportant, as can be seen from the table.

Electrical energy of lightning is too violent to be of direct use, but it does produce some compounds of nitrogen which are useful.

Volcanic heat is of no value today as a source of energy for metabolic process and was probably of minor or in fact negligible importance in the past because of its violent and destructive character and its very sporadic appearance. What is needed for the evolution of life as well as its maintenance is a steady source of energy which will be maintained over billions of years.

Living things require compounds of certain kinds which contain greater quantities of energy than do the degradation products. The particular thermodynamic function that measures the spontaneous character of chemical reactions at constant temperature and pressure is the Gibbs free energy. In any spontaneous reaction this function decreases. Hence, living organisms of the animal or saprophytic plant type must be supplied with chemical compounds of higher free-energy content than the compounds which they discard. In some way free energy must be supplied to these waste products in order that they can be reconverted into the food chemicals again. Such free energy can be supplied by high-energy sources such as sunlight, radioactivity, electric discharges, etc. It could be supplied from heat sources, providing a suitable heat engine operating between high- and low-temperature heat reservoirs is available in accordance with the second law of thermodynamics. Merely high-temperature regions such as water pools alone, supplied by volcanoes or hot springs, are not sufficient to accomplish this. In considering this problem of the energy source for chemical evolution of life, these requirements of thermodynamics should be kept in mind. Though warm water may have accelerated reactions between compounds with suitable freeenergy content, warm water alone cannot provide the compounds of high free-energy content.

At present the source of energy is sunlight in the red end of the spectrum, which is absorbed by chlorophyll. However, in prebiological times before the appearance of chlorophyll, ultraviolet light, absorbed in the atmosphere to produce high-energy compounds which in turn were transferred to the oceans, must have furnished most of the free energy required for prebiological evolution. As Table 3 shows, there is only a small fraction of the energy in the solar spectrum below 
$2,000 \mathrm{~A}$, but it is larger in amount than all nonradiant sources of energy. It is evident also that the appearance of relatively simple carbon-oxygen-bydrogen compounds would extend the region of ab. sorption into the 2,000 to 3,000 A region where much larger amounts of energy are available. However, even after 4.5 hillion years, living organisms are using only a small fraction of all the cnergy of sunlight.

\section{Miller's experiments}

Miller's synthesis of carbon compounds from simple substances is too well known to require any serious review. The conditions used would not be those used today for the same experiments. It was supposed that the primitive atmosphere contained an appreciable concentration of hydrogen. The high atmosphere of the earth is at some $2000^{\circ} \mathrm{K}$ or even more, as was shown to be true by Spitzer (1952), and under these conditions elementary hydrogen would be lost very rapidly. Hence today experiments omitting hydrogen as such would appear more appropriate. Also it should be noted that cleetric discharges were used only beeause they were easy to provide and not because it was supposed that lightning was the primitive source of energy. It was expected that the electric discharge would activate molecules in a way that would be similar to that produced by ultraviolet light. Table 4 gives the list of substances produced by Miller in one of his experiments. For the first time weighable amounts of substances present in living organisms or readily produced from their

Table 4. Yields from sparking a mixture of $\mathrm{CH}_{4}, \mathrm{NH}_{3}, \mathrm{H}_{2} \mathrm{O}$, and $\mathrm{H}_{2} ; 710 \mathrm{mg}$ of carbon was added as $\mathrm{CH}_{4}$

\begin{tabular}{lclc}
\hline \multicolumn{1}{c}{ Compound } & $\begin{array}{c}\text { Yield, } \\
\text { moles }\left(\times 10^{5}\right)\end{array}$ & Compound & $\begin{array}{c}\text { Yield. } \\
\text { moles }\left(\times 10^{5}\right)\end{array}$ \\
\hline Glycine & 63. & Succinic acid & 4. \\
Glycolic acid & 56. & Aspartic acid & 0.4 \\
Sarcosine & 5. & Glutamic acid & 0.6 \\
Alanine & 34. & Iminodiacetic acid & 5.5 \\
Lactic acid & 31. & Iminoacetic-propionic acid & 1.5 \\
$N$-Methylalanine & 1. & Formic acid & 233. \\
$\alpha$-Amino-n-butyric acid & 5. & Acetic acid & 15. \\
$\alpha$-Aminoisobutyric acid & 0.1 & Propionic acid & 13. \\
$\alpha$-Hydroxybutyric acid & 5. & Urea & 2.0 \\
$\beta$-Alanine & 15. & N-Methyl urea & 1.5 \\
\hline
\end{tabular}


tissues were secured. They were not optically active and a number of unidentified sulustances were produced.

These experiments were repeated and extended by others, notably by Abelson (1957) in this country. Also the more difficult experiments using ultraviolet light have been done and very similar results obtained. Abelson's experiment showed that various mixtures always gave amino acids if the mixture was reducing, i.e., if excess hydrogen was present in amounts over that required to form water, and that amino acids were not produced if the mixture was on the oxidizing side, i.c., if free oxygen or its equivalent was present. We can conclude that it is most improbable that life would appear in an oxidizing atmosphere. In particular, if all life were destroyed on earth, the oxygen of the atmosphere would probably disappear by combining with earbonaceous compounds. The amount of reduced carbon in living organisms and in soils is very small but the great deposits of shales contain some 10 or 12 times as much carbon as could be oxidized by atmospheric oxygen. This would he hrought only very slowly into contact with atmospheric oxygen, and hence the atmosphere would probably remain somewhat oxidizing. Life would probably never evolve again on this planet if it were completely destroyed. Also, if a planet evolved into the oxidized state hefore well-organized life had appeared, it is probable that no life would evolve on that planet.

Miller's experiments and those of others who have extended this work carry us only a very small way along the long and involved road to the origin of well-organized life. There are many elementary problems which might be mentioned at this point, but possibly one of the most puzzling and also most essential is the introduction of phosphate into effective organic compounds. All inorganic phosphorus compounds are highly unstable except the phosphates, and the calcium, magnesium, and ferrous phosphates are highly insoluble in water (see Table 1). These are mentioned particularly because calcium and magnesium are present in water solution, i.e., in the oceans, as bicarbonates and hence phosphates would be precipitated. In the absence of elementary oxygen, ferrous iron would also be present. Probably organic compounds of some kind which are able to hold phosphate in solution existed in the primitive oceans.

In general, living organisms are excellent chemists and they have found routes for metabolic process which are beautifully adapted to their needs. The production of proteins, chlorophyll, enzymes, and the intricate replicative systems are amazing trimmpls of the most skillful of eliemists. The mind of man will be able to follow these to some extent in the future. 


\section{Development of orher planets}

It is evident that the processes outlined above could occur on other planets than the earth. But first, nearly all of the solar components of gases must he lost and then conditions must be such that hydrogen can escape at a sufficiently slow rate for the synthesis of very complex carbon compounds to occur. It is possible and indect proluable that this has occurred very generally throughout the entire universe, and it is possible that it has occurred on hoth Venus and Mars. At present both these planets have carbon in the highly oxidized state of carbon dioxide in their atmospheres. though elementary oxyen has not heen detected in either; on the other hand. neither has the highly reduced form of carbon, namely. methane. been detected.

The atmosphere of Venus contains about $1 \mathrm{~km}$ atmosphere of carbon dioxide above the cloud layer. Aside from a very small amount of water vapor, no other gas has been, detected with certainty in its atmosphere. Several explanations have been offered for the presence of large amounts of carbon dioxide in spite of the affinity of carbon dioxide for silicate rocks which favors its presence as limestone of dolomite. (1) The surface of the planet is arid so that crosion is negligible; hence contact between the gas and solid rocks is incffective and an equilibrium condition is not approximated. (2) The surface of the planet is covered by occans and again effective contact is not possible. (3) An excess of carbon dioxide exists such that all surface silicates have been converted to carbonates and the atmospheric carbon dioxide remains in the uncombined state. (4) The temperatures helow the atmosphere are so high that the equilibrium pressure is much higher than that appropriate to the earth. The surface temperatures as reported at present are consistent with the first and third alternatives only. It has also been suggested that an excess of hyrlocarbons exists and that the surface is covered with oceans of petroleum-like compounds. The temperature in the high atmosphere from infrared measurements is reported to be some $-40^{\circ} \mathrm{C}$. From the intensities in the rotational spectrum of visible carbon dioxide bands. the temperature is observed to be some 10 or $15^{\circ} \mathrm{C}$. But the intensity of the radiation in the centimeter wavelength region indicates temperatures in the region of $300^{\circ} \mathrm{C}$. It appears that the first two temperatures must be characteristic of some layers in the atmosphere above the clouds, and the last temperature is generally thought to be that of thr solid surface. Sagan (1961) has given reasons for helieving that a very effective "greenhouse effect" due to carbon dioxide and water may account for this high temperature. If these high temperatures 
do obtain, no life can exist on Venus at the present time. In the past, liquid water may have existed on the planet, the pressure of carbon dioxide may have been low, and hence the greenhouse effect may have been less, the temperature lower, and living organisms may have been present. It would be magnificent had life developed but disappointing if it should liave been destroyed.

Mars is a very different planet. It has a thin atmosphere with a pressure at the surface of about one-sixth that of the earth. Carbon dioxide is present, but oxygen has not been detected. The atmosphere is probably mostly nitrogen. It extends to a great height because of the low gravitational field. It is most probable that both hydrogen and oxygen can escape from the planet and hence that the planet may have had extensive oceans in the past. Glaciers would appcar to have been probable in this case, but just because the rocks were covered by them carbon dioxide may not have reacted with the rocks effectively and the greenhouse effect may have raised surface temperatures above the very bleak ones that obtain at the present time. Life may have evolved on this planet and in spite of the very arid and cold conditions it may persist to the present time. Carbon dioxide is present as shown by its absorption bands. Water is probably present as indicated by the polar frost caps and the morning haze, but the estimated amounts in the atmosphere are very small. It is probably escaping from the interior because both hydrogen and oxygen should escape at such rates that the observable water would be lost in less than $10^{6}$ years and hence atmospheric water must be continuously replaced.

Life may be present on Mars and its origin would be similar to that outlined for the earth. The changes of color with the seasons, the persistence of the gray areas in spite of dust storms, and, as Sinton (1957) has recently observed, the presence of faint absorption bands, which can be ascribed to the $\mathrm{CH}$ band in the light reflected from the gray areas, indicate that life may be present. The proof that this is true would be the most magnificent scientific datum of the twentieth century and would justify all the effort of the space programs of the world. It would substantiate the beliefs of the many students of this subject, namely, that life will evolve when conditions are appropriate in many other places of the universe and that life on earth is not alone in this vast expanse of space that extends for billions of light years in all directions.

\section{Teferences}

Abelson, P. H. (1957), Ann. N.Y. Acad. Sci., 69:276.

Bates, D. R., and M. R. C. McDowell (1957), J. Atmospheric \& Terrest. Phys., 11 : 200. 
Miller, S. L., and H. C. Urey (1959), Science, 130:245.

Sagan. C. (1961). Science. 133:849.

Sinton, W. (1957). Astrophys. J., 126:231.

Spitzer, L. (1952), Atmospheres of the Earth and Planets, ed. by G. P. Kuiper, University of Chicago Press, Chicago.

Urey. H. C. (1959), Handbuch der Physik, 50:363ff. 



\title{
Evolution of
}

\section{Photosynthetic Mechanisms*}

\author{
Melvin Calvin $\dagger$ \\ Department of Chemistry and \\ Lawrence Radiation Laboratory \\ University of California, Berkeley, California
}

\section{Introduction}

I have found the planning of today's discussion to be particularly difficult, perhaps the most difficult one that I have ever undertaken. The reason for this, I consoled myself, lies in the very nature of the evolutionary process itself. In physical science (and particularly in mathematical sciences) we are accustomed to a single sequence of events, in which each idea is precursor to the next, and one gradually develops a whole pattern of thought - a whole notion from beginning to end-in a single sequence. Those of you who are more faniliar with the way biological material has evolved will know that this is not really the way the living organism can be described in its evolutionary

* The preparation of this paper was sponsored by the U.S. Atomic Energy Com. mission.

$\dagger$ Research Professor of Chemistry, 1960-1961, in the Miller Institute for Basic Research in Science, University of California, Berkeley. 
history. The problem with which I am dealing, the problem of photosynthesis, is especially difficult to trace.

It turns out, as I shall try to point out in more specific detail as we go along, that the evolution of photosynthesis entails the fusion of a number of quite independent threads of evolution at some point in time to give rise to the modern process and the modern apparatus as we know it. In trying to describe that sequence of events, I find myself greatly increasing my respect for the novelist who writes historical novels. You know how he does it: He has many chains of events, giving rise to a particular incident at the end, or perhaps at the beginning of the novel, and he is very skillful at starting each of these threads and jumping from one thread to the next, bringing them along so they all come together at the right time and in the right place. I haven't yet been able to do that, and what I am going to have to do is to jump back and forth anong the varions evolutionary threads that are involved here, which ultimately fuse together to give rise to the very complex process of photosynthesis. The story may appear, therefore, more confused than it really is, since I must jump back and forth between separate evolutionary threads and try to indicate their points of fusion.

\section{Modern Photosynthetic Processes}

With this apology, let us begin our study of the evolutionary history of photosynthesis by first describing what we think we know of the modern process toward which we must eventually come. Most of you know that photosynthesis is the process by which living organisms are able to transform electromagnetic energy into chemical energy by inducing the reaction between carbon dioxide and water to evolve molecular oxygen and reduced carbon:

$$
\mathrm{CO}_{2}+\mathrm{H}_{2} \mathrm{O} \stackrel{h \nu}{\rightarrow}\left(\mathrm{CH}_{2} \mathrm{O}\right)_{n}+\mathrm{O}_{2}
$$

This is the overall process of photosynthesis which has long been recognized as a process for transforming electromagnetic energy, here represented by the quantum, into chemical potential, represented by oxygen in the elementary form and the elements of carbon and hydrogen largely in the oxidation level of carbohydrate. ${ }^{1,2,3}$

If this were all that we know about the process of photosynthesis, we would be hard pressed to try and predict an evolutionary history which might give rise to this process. Fortunately, in the last decade or two we have learned perhaps more about the process of photo- 
synthesis from this point on than in the previous hundred year-. This was the stage that was available to us roughly one humbed years ago. Only slow progress was made in increasing the chemical knowledere of photosynthesis until just prior to World War 1l-beginuing in the middle thirties and then going on after the war at an increasingly rapid rate.

What do we know today about the process of photosynthesis? Rather than try to give you a history of how the knowledge has evolved, I am going to (1) put down some of the establisherl things that we know about photosynthesis, represented by the overall reaction, (2) then see which organisms perform this process, (3) then determine what the biological apparatus is within some of the organisms (as far as we can do it), and (4) finally go further on down to the molecular level. You see, the question of the evolution of a process of this sort also raises others: What level shall we deal with? Shall we deal with photosynthesis at the level of the whole organism, the level of the cell. the level of subcellular particles, the level of the macromolccules, or the level of the small substrate molecules that are involved? We should, in fact, deal with all of these, if possible, but this is another complication which makes the organization of such a discussion as this extremely difficult. I am going to try to pick up two aspects of it, the mechanism itself on the substrate, and possibly submolecular level, and the apparatus on the subcellular, or macromolecular level.

\section{Nature of the organisms}

I hardly need review for you the nature of the organisms which are capable of performing the process of photosynthesis. Quite obviously, the higher green plants, such as a wheat field or a forest, do this on a grand scale. There is, however, a whole set of other organisms besides the higher green plants which are able to do this, or parts of it, and they represent an important part of the biological scheme of things in the course of our study. These are the marine algae; both the green and the red ones are important in terms of the amount of carbon which is turned over on the surface of the earth per year, as the algae represent the largest single plant family involverl in this turnover. Then, there is another group, the blue-green algae. which appear to be more primitive organisms which are capable of doing the entire process of photosynthesis, that is, reducing carbon and evolving oxygen. And, finally, we come to the bacteria. both the green and the red, which are capable of performing part of this conversion 
process. The bacteria can transform electromagnetic encrgy into chemical energy, but not with the evolution of oxygen. They usc other reducing agents than water in order to reduce the carbon and therefore they produce other oxidants than oxygen. But the bacteria are able to capture electromagnetic energy from the sun and transform it into chemical potential.

Thesc classifications of organisms really constitute the whole gamut of biological diversity, as far as $I$ an aware of it, which can do all, or some, of this conversion (energy manipulation) process; they all can do the crucial part of it-the quantum absorption and the quantum conversion.

\section{Mechanism of the Photosynthetic Process}

\section{A. The path of carbon in photosynthesis}

Let us see what we know about the mechanism of the process of photosynthesis itself. Part of this knowledge is a result of the tracer work which was mentioned earlier, ${ }^{1,2,3}$ beginning before the war. My colleaguc, Sam Ruben, began this work, using radioactive carbon-11. Right after the war in 1945 we took it up again, using carbon14. labeled carbon dioxide, to examine the sequence of events and determine the sequence of compounds involved in the transformation of $\mathrm{CO}_{2}$ into carbohydrate. The answer to these questions is now available to us, and we can draw a rather complete road map of the reduction of carbon dioxide. (A simplificd version of the carbon reduction cycle is shown in Fig. 1.) The first step in the photosynthetic carbon cycle is the carboxylation of a sugar, ribulose diphospliate, to give phosphoglyccric acid, and this, in turn, can now be reduced to triose phosphate using some kind of reducing agent as well as some pyrophosphate-containing compound. The triose phosphate then goes through a series of rearrangements to produce ribulose diphosphate again, and the carbon cycle can continue.

The light is required to produce these two agents: a reducing agent, here represented by $[H]$ and a particular (pyrophosphate-containing) phosphorus compound (which we shall mention in a moment) to help the reducing agent in the reduction process. This particular phosphorus compound scems to be adenosine triphosphate (ATP) which contains a pyrophosphate linkage. This is of great importance and will be discussed in detail later on.

The major point that $I$ want to introduce at this stage is the idea that the reduction of carbon dioxide through the carbon cycle and 
the whole sequence of enzymatic reactions that are involved in this reduction are dark reactions. Once we have available the products of the light reaction, namely, a reducing agent and some type of "high energy" phosphate, the whole carbon cycle can be operated and car-

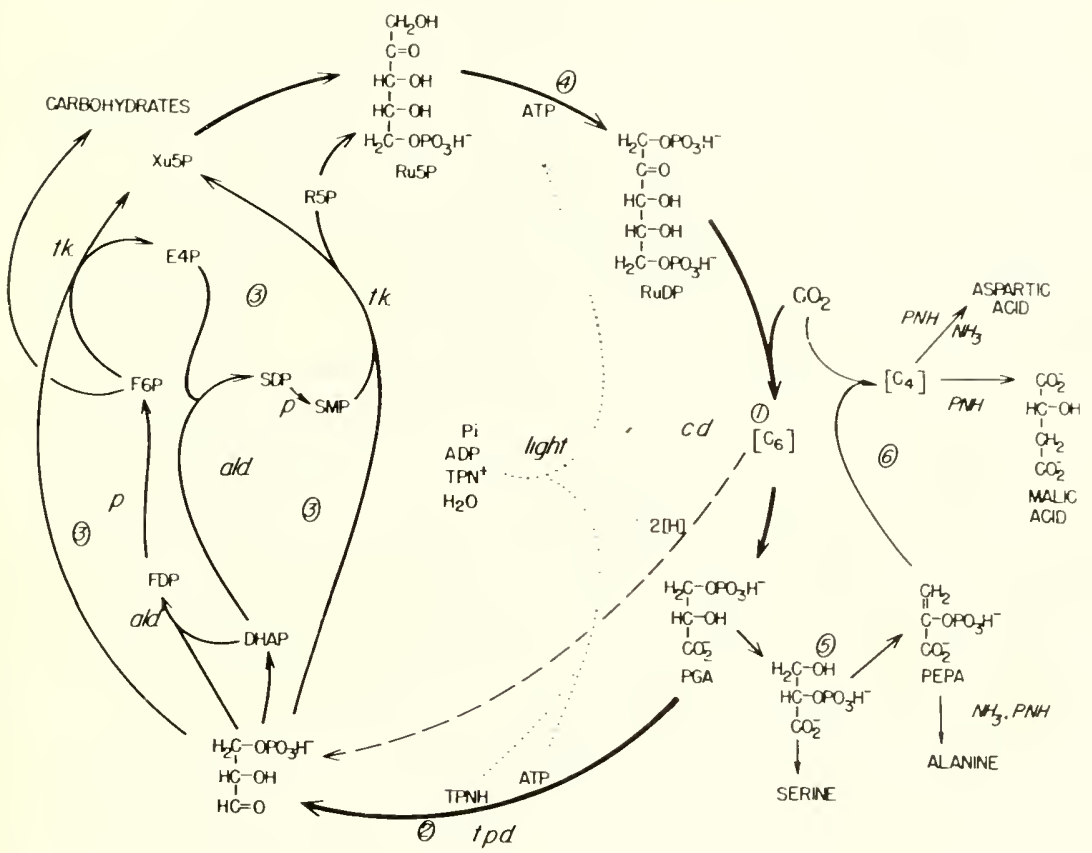

FIG. 1. Carbon reduction cycle (simplified version): (1) Ribulose diphosphate reacts with $\mathrm{CO}_{2}$ to give an unstable 6-carbon compound which splits to give two 3-carbon compounds, one of which is 3-phosphoglyceric acid. The other 3-carbon compounds might be either 3-PGA, as it is known to be in the isolated enzyme system, or some other 3-carbon compound such as a triose phosphate (dashed arrow). (2) PGA is reduced to triose phosphate with ATP and TPNH derived from the light reaction and water. (3) Various condensations and rearrangements convert the triose phosphate to pentose phosphates. (4) Pentose phosphate is phosphorylated with ATP to give ribulose diphosphate. Further carbon reduction occurs via conversion of PGA to phosphoenolpyruvic acid (5) and carboxylation (6), to form a 4-carbon compound (probably oxaloacetic acid). Reactions leading to the formation of some of the secondary intermediates in carbon reduction are also shown.

bon can be taken from $\mathrm{CO}_{2}$ into a varicty of compoumls, among then sugar. The sugar can be taken out of the eycle. Every time the cycle turns six times, for example, we can take out a hexose sugar molecule and still have the cycle molecules left. This, indeed, is what happens. 
We recognize also that all of the 11 enzymes that are involved in these transformations in the earbon reduction cycle are to be found nearly everywhere widely distributed in the biological world-not linited solely to organisms which are converting solar energy, but also in organisms that have nothing whatever to do with the photosynthetic process. It therefore secms quite clear that at least this sequence, that is, the carbon reduction sequence, undoubtedly evolved in a separate chain of evolutionary events having little or nothing to do in the early stages with the electromagnetic energy conversion process itself. ${ }^{+}$The eleetromagnetic energy conversion process appears to produce in a primary act, or very close to it, two materials, a reducing agent and a pyrophosphate linkage, which can then run the carbon reduction cycle.

We can already see the two quite independent evolutionary streams which were joined only very recently in evolutionary history to produce the modern green plant., ${ }^{5,6}$ The carbon reduction system was one independent stream. These streams will, of course, break up into finer parts as we go along, but this is our beginning.

\section{Bb. Ruantum concersion in photosynthesis}

Let us now return to the photochemical process itself. Having separated out the carbon reduction system as a distinet evolutionary stream, I am going to leave it since there is nothing unique about it for plotosynthetic organisms except the combination of the product of the light reaction with a certain collection of enzymes, all of which can lie found, either separately or in various combinations, in nonphotosynthetic organisms. 8,9 Therefore, the carbon reduction cycle had a separate evolutionary history until the recent times.

Let us now see what more we can say ahout the quantum conversion process in photosynthesis. We can say a good deal about it, although not nearly as much as we can about the carbon reduction process. We do not have anywhere near the detailed knowledge of the quantum conversion process that we do of the carhon reduction process. Figure 2 represents the structural formulas of the two molecules which we believe to be essential for running the photosynthetic carbon reduction cycle. (There are undoubtedly others of which we are still unaware required for oxygen evolution as well.) To run the carbon cycle we need the reducing agent, which is a pyridine nucleotide in its reduced form. An adenine and pyridine moicty are tied together by two ribose sugars and a pyroplosphate link to give the molecule known as diphosphopyridine nucleotide. Actually, in photosynthesis 
it seems that there is a molecule very similar to this, but involving another phosphate group on one of the ribose molecules. and so l shall actually use the triphosphopyridine nucleotide in its redured form as the structural formula for the reducing atent which is required to run the carbon reduction cycle.

The possibility exists that still another, and perhaps more specifie, reducing agent might be used by photosynthetic organisms in the reductive splitting of the initially produced carboxylation product

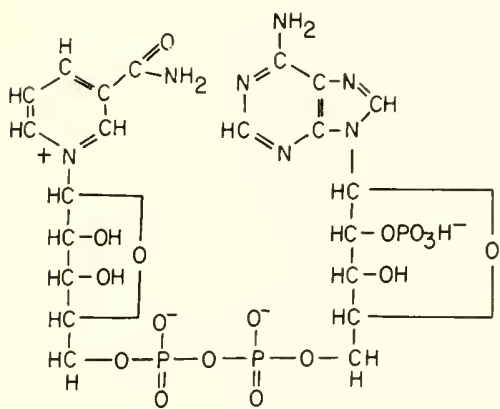

TRIPHOSPHOPYRIDINE NUCLEOTIDE (OXIDIZED FORM) (TPN')

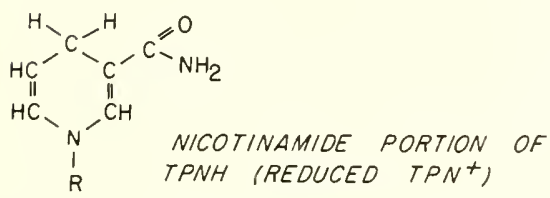

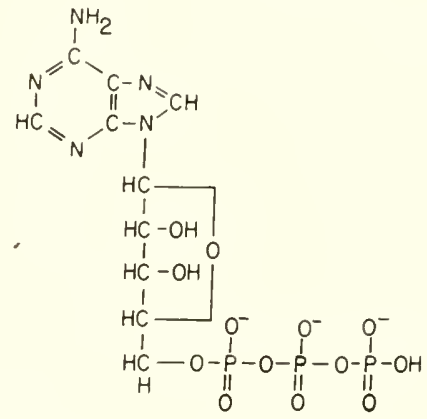

ADENOSINE TRIPHOSPHATE (ATP) IN ADENOSINE DIPHOSPHATE (ADP), TERMINAL PHOSPHATE IS REPLACEO BY $-\mathrm{OH}$

FIG. 2. Structural formulas of triphosphopyridine nucleotide and adenosine triphosphate. two of the agents required to run the photosynthetic carbon cycle.

(Step 1, Fig. 1).10 If so, it is almost certainly as gool a reducingr agent as TPNH and may or may not be structurally and kinetically related to it. If such a specific photosynthetic reducing agent functionin green plants, it will, in all probability, have been a late addition in the evolutionary development of a higher efficiency, since we al. ready know that the cycle can operate through TPNH.

The other molecule which is essential for ruming the evele and which clearly must come somewhere from the photochemical reaction is the adenosine triphosphate (ATP). Here, there are two pyrophosphate linkages, and the important one for our purposes is the ter- 
minal pyrophosphate link (Fig. 2). These are the two molecules that are required in order to move the cycle around, and clearly these must be manufactured as a result of the photochemical transformation.

How much do we know about how the photochemical transformation manufactures those two substances? Here, we are not so thoroughly informed, but a good deal, nevertheless, is known and some of it is of considerable importance in guiding our thinking as to what the evolutionary relationships between the photosynthetic equipment and other equipment of living organisms might be.

\section{Photoinduced Redox System}

The principal photochemical reaction we now know is, first, the absorption of light by chlorophyll to produce some kind of an exeited chlorophyll, either a molecule or molecular aggregate. (I don't mean this to be a separate chlorophyll molecule in solution, but simply the chlorophyll as it exists in the photosynthetic equipment of the organisms.) This electronically excited molecule must then undergo some kind of transformation; for example, it may react with another molecule or molecules to produce a separation of an oxidant from a reductant. ${ }^{11,12}$ I am using this language first because of a bit of confusion that has arisen in the meaning of these terms. The oxidant will eventually become molecular oxygen; the reductant will eventually become a reduced compound, pyridine nucleotide. The pyridine nucleotide, together with the ATP, for which we have not yet described a formation mechanism, will then go on to drive the carbon cycle.

Oxidant and reductant are the chemists' terms for what happens after the excited chlorophyll loses its energy to some molecule, or collection of molecules, if any redox system is directly involved. The biologist has been accustomed to writing these two things in different terms. Following van Niel, ${ }^{13-16}$ he has generally associated the term $M$ (Fig. 3) with water and has called the oxidant ([O] in Fig. 3) hydroxyl, or $[\mathrm{OH}]$, but he has been very careful to put a bracket around it. (Those of you who know what the meaning of a bracket is will understand the significance of this; when you see a biochemist putting a bracket aromel something of this sort it means that he doesn't really know what he is talking about. It is a general representation, not a chemical formula.) The reductant ([R] in Fig. 3), according to the biologists, has licen called [H] (hydrogen), and this had led many to suppose that the primary process of quantum conversion involves the spliting of the water molecule itself. What is meant by the van Niel 
theory. at least in elemical terus. is the ereation of a reductant of some general charaeter, whose nature we do not know. and of an oxidant. also of some general character whose nature we do not know as yet. These two things are both very closely associated with and must ultimately come from water, as given by the stoichionetry of the primary reaction of photosynthesis in the first place.

In more recent years, still another terminology has entered into this discussion and it comes from quite a different source. The physieist has called the reductant the "electron" and what is left after you

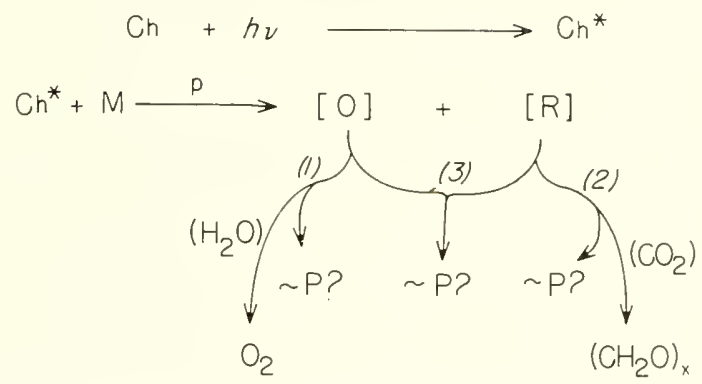

FIG. 3. Simplified photosynthesis scheme. The quantum is first absorbed by the chlorophyll molecule: then something happens ( $\mathrm{p}$ for primary) to the excited chlorophyll to produce two chemical species, $[O]$ and $[R]$. for example, which can go on, one of them [O] to become molerular oxygen in some way (1). and the other one $[\mathrm{R}]$ leading to the redurtion of $\mathrm{CO}$ to carbohydrate (2). Along these two routes, various other energy-containing species may be created (ATP or $\sim P$ ). ATP would be an energy-storage product. This may be created on either, or both, sides. There may be back reaction (3) between the oxidants and reductants. which also could create products of higher energy. The obvious one here is, of course. the pyrophosphate linkage in ATP.

take an electron away from a molecule is called a "hole." 17 These are the physicists' terms for the same phenomenon. You nust not become confused about the terminology becanse all of these-oxidantreductant, hydroxy-hydrogen. electron-hole-are different name- for essentially the same thing. What we are trying to do now is to discover exactly the best way to deseribe these things in ultimate and intimate detail.

I introduce the terminology of the physicist because in the last few years we have learned a number of the reactions of exeited chlorophyll and one of them is an electron transfer reaction which i- ol)servable speetroscopically. An electron is transfered from iron in the divalent state to give iron in the trivalent state, $18,19.20,21.22$ with the 
electron located in an as yet unknown place. It is an important recognition that this phenomenon occurs and occurs very quickly after the chlorophyll absorbs the light.* The excited chlorophyll in some way is able to extract an electron from the ferrous iron compound, at present associated with the chlorophyll in modern organisms in the form of cytochrome, to produce the ferricytochrome and an electron in some molecules as yet undesignated. ${ }^{19,24}$ This appears to be an important connection between a molecule that is unique to photosynthetic plants, namely, chlorophyll, and certain kinds of molecules which are not unique to photosynthetic plants, namely, the iron cytochromes (iron hemes). The iron hemes have universal distribution and this is an important fact to remember.

In addition, we now know that electrons must ultimately find their way to pyridine nucleotide, which picks up a proton from the water, making reduced pyridine nucleotide. The oxidized iron, or something close to it, will eventually take electrons from water, giving rise to the ferrous iron and molecular oxygen.

At the same time that all these things are happening, somewhere along the line, either on the way from the intermediate oxidant to oxygen (reaction 1, Fig. 3), or on the way from the intermediate reductant to the pyridine nucleotide (reaction 2, Fig. 3 ), or, perhaps, in a recombination reaction in which the electron falls back into the hole (reaction 3, Fig. 3 ), we also create adenosine triphosphate. The ATP is designated by $\sim P$ ?, which represents "high-energy phosphate" linkages. The reactions in Fig. 3 indicate possibilities only, and not knowledge of three different ways (places) in which pyrophosphate could be created: (1) The fall of the intermediate oxidant toward oxygen; (2) the fall of the intermediate reductant (pcrhaps a sulfhydryl group) to the pyridine nucleotide which would, perhaps, give rise to pyrophosphate; or (3) perhaps the energy of recombination of the hydrogen-hydroxyl (electron-hole), which could also give rise to a number of pyrophosphate linkages.

\section{Photoinduced Dehydration}

A more profound departure from the basic redox primary photo process is possible, particularly in the light of the recently indicated 25

* A recent modification ${ }^{14}$ of the van Niel generalization inserts a ferrocyto. chrome ahead of the water molecule as the primary electron donor to the excited chlorophyll, hut it does not specify the primary fate of the excited electron which must be removed from chlorophyll. The oxidized cytochrome is presumed capable of oxidizing water to oxygen, with the concomitant formation of ATP, a suggestion similar to that of Bassham ${ }^{23}$ and corresponding to reaction 1 in Fig. 3. 
reversibility of at least some of the steps of oxidative phosphorylation. Thus, there is evidence that in mitochondria it is possible to produce the reaction

$$
\begin{aligned}
& \mathrm{Fe}^{1 \mathrm{I}} \text { (eytochrome) }+1 / 2 \mathrm{DPN}+(n) \mathrm{ATP} \rightarrow \\
& \mathrm{Fe}^{111}(\text { cytochrome })+1 / 2 \mathrm{DPNH}+(n) \mathrm{ADP}+n \mathrm{Pi}
\end{aligned}
$$

If an independent (nonredox) method of dehydration could be found for producing ATP according to the reaction,<smiles>O=P([O-])(O)O[PH3+]</smiles>

then both ATP and TPNH could be photoprodueed without ealling upon a photoinduced direct electron transfer reaction.

We already have a precedent for the idea that an optically excited pi-electron system can have an increased affinity for water leading to its hydration by an only very slowly reversible process so that energy may be trapped in this manner. ${ }^{26}$<smiles>O=c1cc[nH]c(=O)[nH]1</smiles><smiles>O=C1CC(O)(O)C(=O)N1</smiles>

For example, if the 9.10 enol in chlorophyll were to ard orthophosphate (when excited), an enol phosphate could be produced, which presumably would le eapable of phosplorylating ADP to make the required ATP. ${ }^{27}$ Part of this would then be used to reverse the DPNH-eytochrome reduction to produce the ultimately necessary separation of oxidant and reductant (water splitting) recunired for $\mathrm{G}_{2}$ production and $\mathrm{CO}_{2}$ reduction.

The not inconsiderable difficulty with such a plan as this is the necessity for producing a good many more than one ATP for each quantum absorbed by chlorophyll. Even if a way of circumventing this difficulty were found, it remains fairly clear that such a device 
would be a rather recent evolutionary addition to an already highly developed biosynthetic energy-manipulating system.
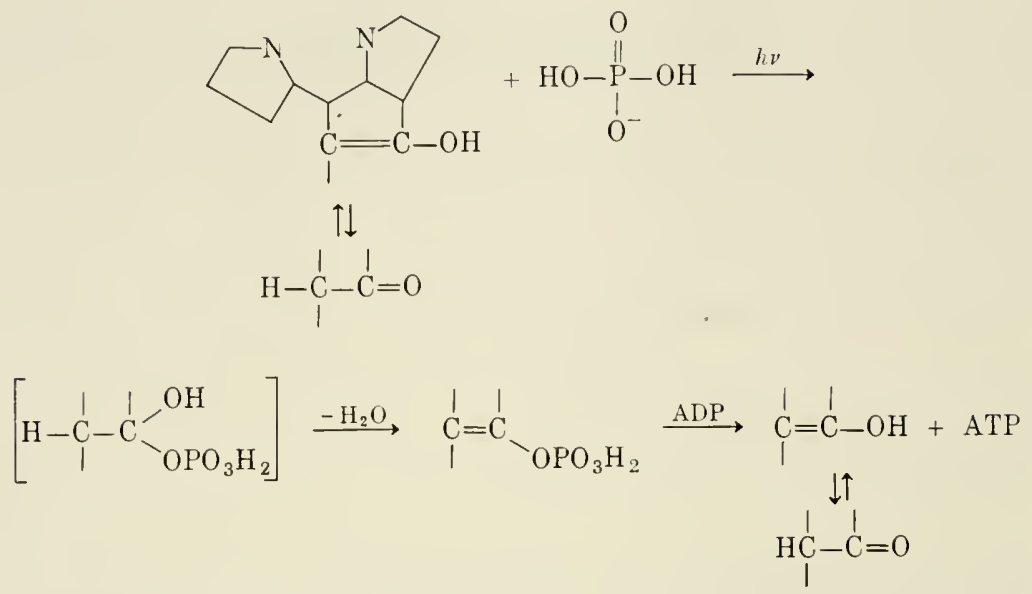

\section{Pyrophosphate Linkage in Nonphotosynthetic Processes}

The appearance of pyrophosphate linkage in a variety of organisms is well known. In practically all organisms, there are mechanisms for producing ATP which do not involve photosynthetic mechanisms at all. One of them is a reversal of one reaction in which ATP is used in the photosynthetic cycle (triose phosphate dehydrogenase). By rumning the reaction backward (Step 2, Fig. 1) one ean make ATP. A more important source is a reaction which apparently involves iron-the cytochromes, involving also the oxidation and reduction of the pyridine nucleotide. The two reactions together are involved in the ereation of ATP in nonphotosynthetic organisms. This process of the oxidation of pyridine nucleotide by the passage of electrons from pyridine nucleotide back to oxygen through the iron cytochromes, with the concomitant formation of ATP, is known as oxidative phosphorylation. It leads to the ereation of more ATP than does the substrate oxidation process. The return of a photoexcited electron of chlorophyll through all or part of a similar chain could produce the necessary ATP (see Fig. 3).

Thus the ereation of both the reduced pyridine nucleotide and the ATP are not nnique to photosynthetic processes. These processes also occur in nonphotosynthetic organisms. ${ }^{6}$ We know something about 
how pyridine nucleotide is created, but we know relatively little alout how ATP is ereated in oxidative phosphorylation in which the elertrons pass from reduced pyridine nucleotide through iron back to oxygen. This is one of the major problems of energy transformation in all biological organisms.

We have now split up the photo process of photosynthesis into two other streams of evolutionary development, the stream which gave rise to pyrophosphate (ATP) and the stream which gave rise to pyridine nucleotide. Neither of these necessarily involves the photo process directly. This learls us to the conelusion that the appearance of the photo reaction, or the coupling of the photo reaetion. with the ereation of ATP and of redueed pyridine nucleotide was a very late thing in the evolutionary seheme. ${ }^{4}$ You see that we are foreed, now, to consider the question of the origin of life in diseussing the origin of photosynthesis. We cannot dodge that issue, and we are indeed considering it and doing so in a much more sophisticated way than has been possible up until recent times.

I shall indicate some of the states that we need, in order to try to focus your attention on the separate evolution of mechanisms for making ATP. mechanisms for making the molecules which are involved in the creation of ATP today, mechanisms for creating pyridine nucleotide, and, finally, how the light-capturing molecule, chlorophyll. may have appeared and was coupled to the other energytransforming processes. This is really the story in prineiple, and I now want to go through it quickly and try to give you some idea of how I think these things might have oceured.

\section{Erolution of the Phatesymthetie Apparatus in the Green Plant}

Figure 4 shows the apparatus in the green plant (the chloroplasts) which is responsible for performing the process of photosynthesis. It is perhaps necessary to say a few words here about the relationship of the tangible physical material that performs photosynthesis as it ean be seen on the subcellular. but still visible, level. I shall then discuss the macromolecular level (where this apparatus cannot yet he scen), and, finally, go to the smbstrate level where we can again deal with things in a chemieal way.

Three different kinds of chloroplasts are shown in Fig. 4, illustrating the highly ordered array of layers in all of the three types of organisms: a unicellular green alga, a blue-green alga which does not have 

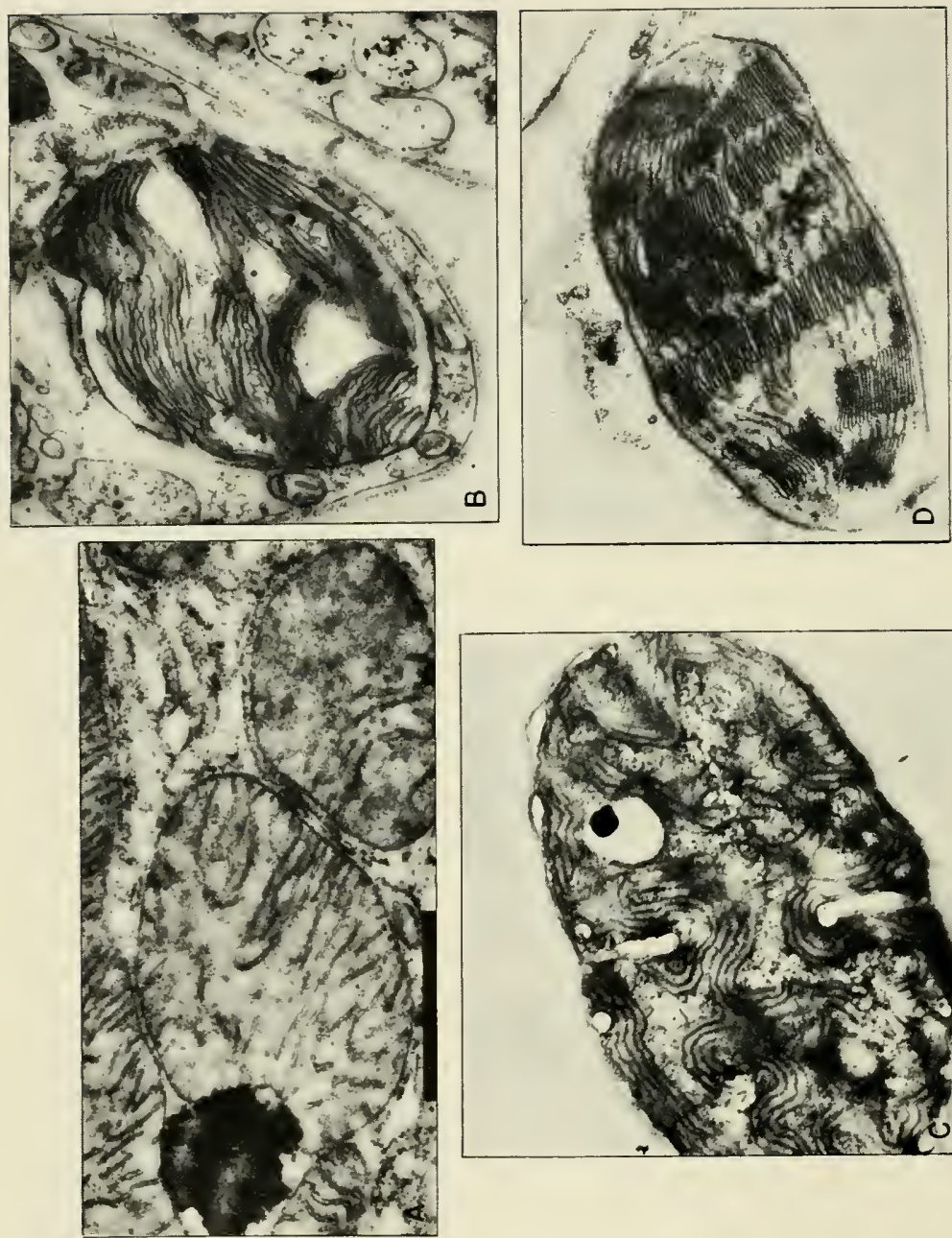

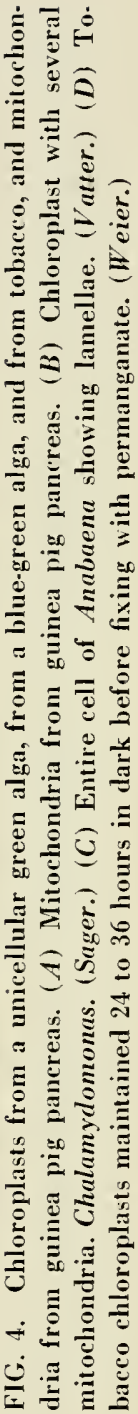


a chloroplast (the layers are still present, however, winding their way in and out through the entire cell), and a chloroplast from a higher plant (tobaceo) showing the layering of the green matrial very clearly. The layers (lamellae) themselves are constructed of arrays of macromolecular subunits which we now think we can see." 9 Figure 5 gives a model for chloroplast lamellar structure and Fin. 6 is an electron micrograph of frozen dried spinach chloroplast supernatant.

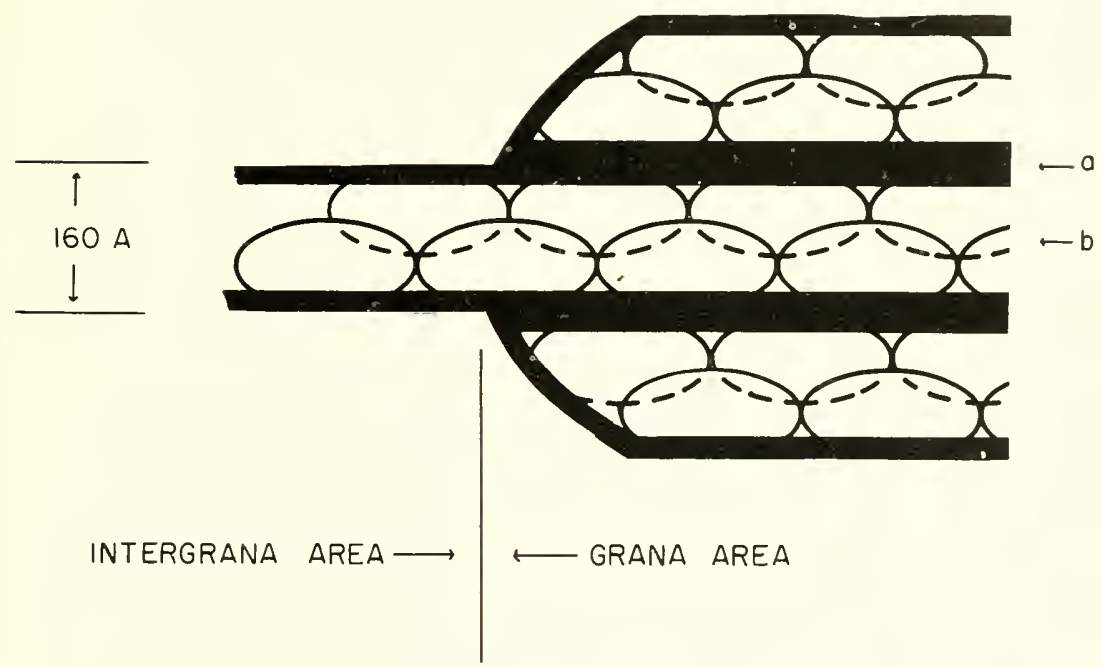

FIG. 5. Model for the lamellar structure within a spinarh chloroplast: (a) Osmium-staining layer of the lamellar strurture. Thickness $30 \mathrm{~A}$ in the intergrana regions and $60 \mathrm{~A}$ in the grana regions. (b) Particles forming the granular inner surface of the two layers making up the lamellar structure. The parking of oblite spheres would not be as simple as illustrated. since the central axis of both layers would not be in the same vertical plane shown here.

Figure 4 shows the high degree of order in the chloroplasts, and, furthermore, that this high degree of order exists in other elements in the cell, such as the mitochondria, which perform other functions (formation of ATP by oxidative phosphorylation of pyridine nucleotide).$^{29}$ The purpose of Fig. 4 is to show the similarity of structure between the photosynthetic apparatus and matcrial which is not photosynthetic, and to show also that it is a highly ordered array in all eases. This highly ordered array must be achieved in some sy-tematic way from molecules which themselves are ordered hy virtue of the atoms of which they are made. 


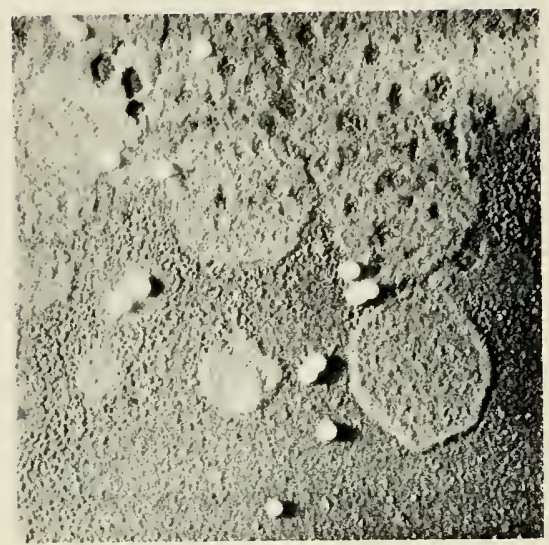

FIG. 6. Frozen dried spinach chloroplast sonicate; 880 A diameter PSL (polystyrene latex) markers.

\section{Chlorophyll structure}

The actual detailed structure of the one molecule unequivocally associated with the capture of light and its transformation, i.e., chlorophyll, is shown in Fig. 7. This shows the structure of some of the different kinds of chlorophyll that are known: The first is protochlorophyll, which appears in etiolated plants grown in the dark. When such plants are placed in the light, the protochlorophyll is converted to chlorophyll. The principal difference between protochlorophyll and chlorophyll is the addition of two extra hydrogen atoms at the double bond in ring D. Bacteriochlorophyll is the molecule which is responsible for the capture and conversion of light in the purple and green bacteria; it differs from green plant chlorophyll in having a second, dihydropyrrole ring in it.

We must devise some way of making those ordered chloroplast structures which were seen in Figs. 4, 5, and 6, and we must envisage some way of evolving this particular molecule, chlorophyll, belonging to the general class of tetrapyrrollic substances known as porphyrins. These two things-ordered array within the cells and the development of chlorophyll itself-are two essential features of our evolutionary scheme for the process of photosynthesis.

The structural feature, the appearance of order and structure, is something common to the evolution of all living organisms, and belongs to the general discussion of how ordered structures may be evolved from nonliving materials. This is really part of the problem of the origin of life. 

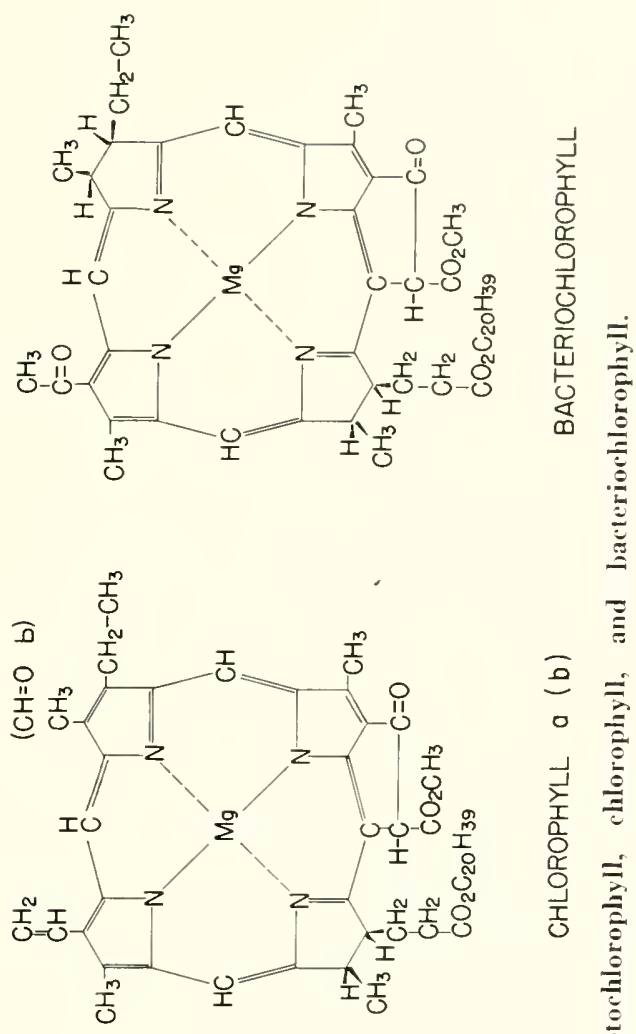

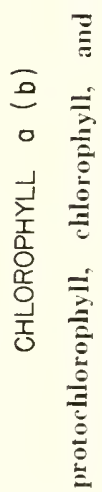

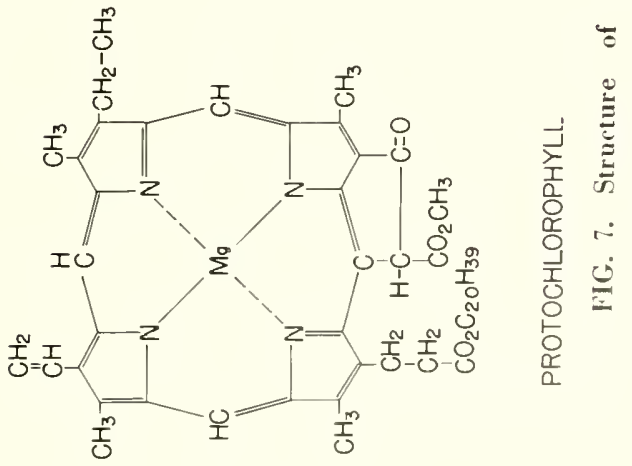




\section{Chemical Evolution}

I wish to discuss briefly the beginnings of chemical evolution, starting with the molecules of the primitive atmosphere being subject to a primitive photosynthesis, using the far ultraviolet or radiation from the radioactivity of the earth's crust to transform them. The earliest molecules on the surface of the earth were those shown on the top row of Fig. 8. particularly methane, ammonia, and water. If these molecules are subjected to radiation of energy great enough to break the bonds of carbon-carbon, carbon-hydrogen, hydrogen-hydrogen, nitro-

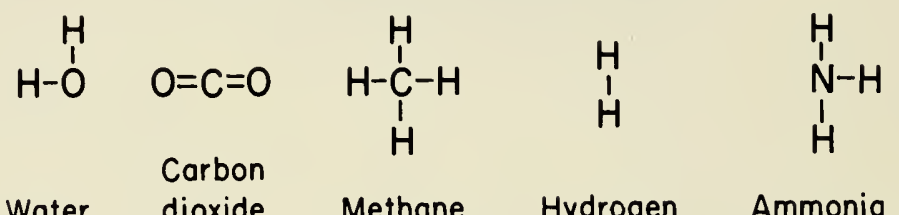<smiles>O=CO</smiles>

Formic acid<smiles>CC(=O)O</smiles>

Acetic acid<smiles>O=CCCC(=O)O</smiles>

Succinic acid

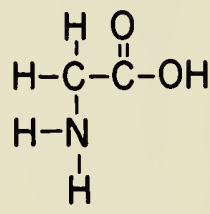

Glycine

FIG. 8. Primeval and primitive organic molecules.

gen-hydrogen, hydrogen-oxygen, which can be done by ionizing radiation, ${ }^{30}$ such as the beta rays of potassium- 40 which are plentiful in the earth's crust, or with ultraviolet light of wavelengths shorter than $2,200 \mathrm{~A},{ }^{31}$ then the atoms which are so formed may reorganize to form more complex molecules, a few of which arc shown on the bottom row of Fig. 8. You already recognize these molecules as being the present-dlay substrate materials (formic acid, acetic acid, succinic acid, and glycine) upon which all living organisms operate. Glycine, shown here, is the only nitrogen-containing compound in the bottom row of Fig. 8, and it is the simplest of the amino acids, of which the proteins are constructed. By exchanging one of the carbon-bound hydrogen atoms of the glycine for any of a group of other atoms, some 20 different amino acids can be built up. 
In the first experiment of this type in 1950, in which we used the cyclotron as a source of ionizing radiation, ${ }^{30}$ we started with $\mathrm{CO}_{2}$, hydrogen, and water, and were able to get, by random transformation processes, reduced carbon compounds such as formic acid, acetic acid, and succinic aid. In later experiments, in which ammonia was addled to the initial mixture following Miller, ${ }^{32}$ glycine was obtained. Still more recently (in the last three or four months) we have performed this experiment again, but instead of depending upon ordinary analytical methods to find these randomly occurring compounds, we have used carbon-14 labeled methane in the primitive gas mixture, thus providing radioactive carbon atoms which could be followed around. The discharge from a 5-Mev electron linear accelerator was passed throngh the mixture of methane, ammonia, and water, and we took the water solution containing the product from this bombardment and spread it out on a piece of filter paper in a systematic way. ${ }^{33}$

Figure 9 shows the results of one of these bombardment experiments. It is a photograph of the darkened x-ray film which results when a paper chromatogram containing radioactive products is placed on top of an x-ray film. Wherever there is a black spot on the film a particular compound has been located. We can tell what the nature of the compound is by where it is located on the film with respect to its origin. All the different nonvolatile radioactive compounds which result from one particular bombardment are shown in Fig. 9, and about a dozen compounds have separated out.

We have been able to identify in this way some half dozen compounds, * including adenine, glycine, alanine, and various other amino acids and sugars, some fatty acids and some hydroxy acids-the very things of which today's living matter is composed. One of the compounds, representing about 60 per cent of the total, is urea. We find in neutral and acidic fractions a large number of compounds, including lactic acid and sugars. You can also see that alanine and glycine represent a very small amount of the total. Down in the lower center of the chromatogram are the nucleosides and further up are the bases. There are present in this irradiated mixture adenine, cytosine, guanine, thymine, and perhaps other as yet undeternined bases. Thus, such random processes as these may give rise to all the simple compounds that are needed by present-day living organisms. ${ }^{34,35}$

Having made these simple compounds (particularly the amino acids) by the random methods, we can build them up into proteins

* HCN was identified in the aqueous solution by a separate procedure. 
in various ways. Aside from the more or less laborions and specific methods involving speeial protective or activating groups, at least two simpler methods, possibly applicable to primitive conditions, have been successfully demonstrated in the laboratory recently. The first involves heating amino acid mixtures in molten glutamic acid together with some polyphosploric acid to produce a mixed polypeptide resembling protein. ${ }^{36}$ The second involves heating the anino
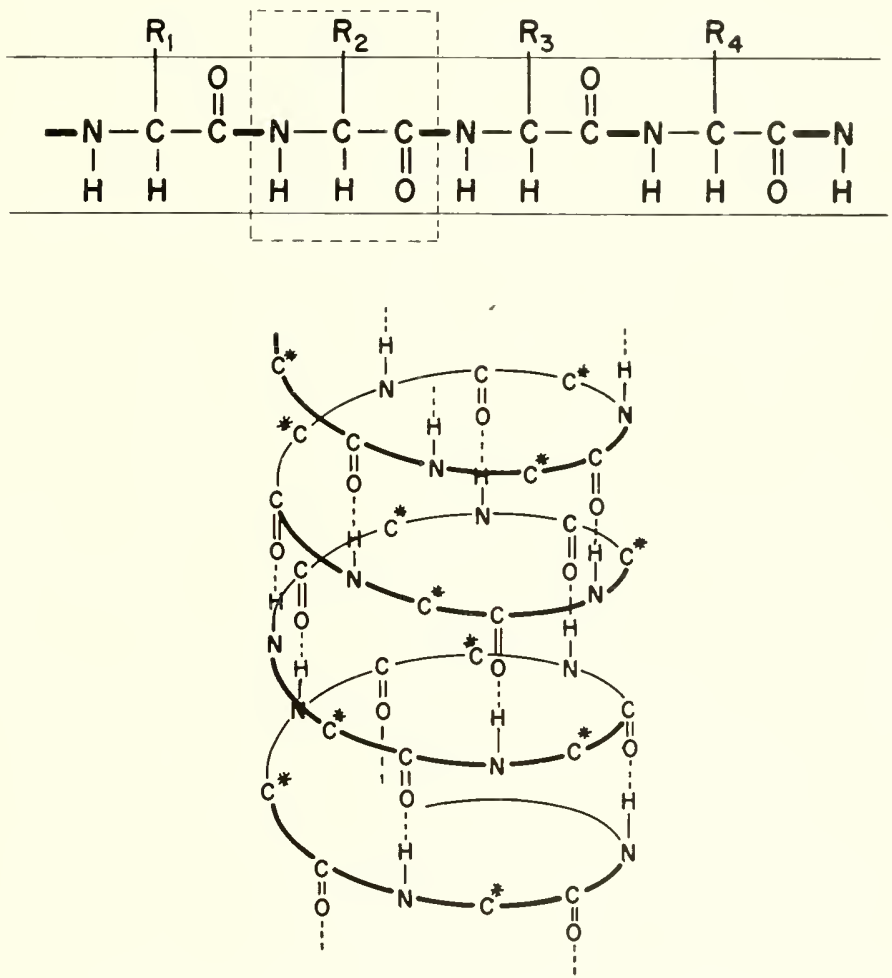

FIG. 10. Protein structure. Simple structural principles. Variety of chemical reactivity.

acid in an aqueous ammonia solution to produce a polypeptide of intermediate size. ${ }^{3 i}$

The proteins themselves ean take on a specific structure which is shown in $\mathrm{Fig}$. 10. The protein is a combination of amino acids. and the helical strueture is built in into the linear array of the amino aeids beeause of the partieular arrangenent of earbon. hydrogen. 
nitrogen, and oxygen atoms in such a chain. Figure 11 shows how the helical structure can take on visible order. The upper photograph is an electron micrograph of single filaments of protein which is a component of collagen. When the protein filaments aggregate, as shown in the lower photograph, they do so in a specific ordered array because of the particular arrangement of amino acids in the proteins. Here you can begin to see the appearance of the visible order that must be generated to create mitochondria, chloroplasts, and other subcellular particles. This generation of order is, of course, common to all living things and is not unique to photosynthesis. One can gen-
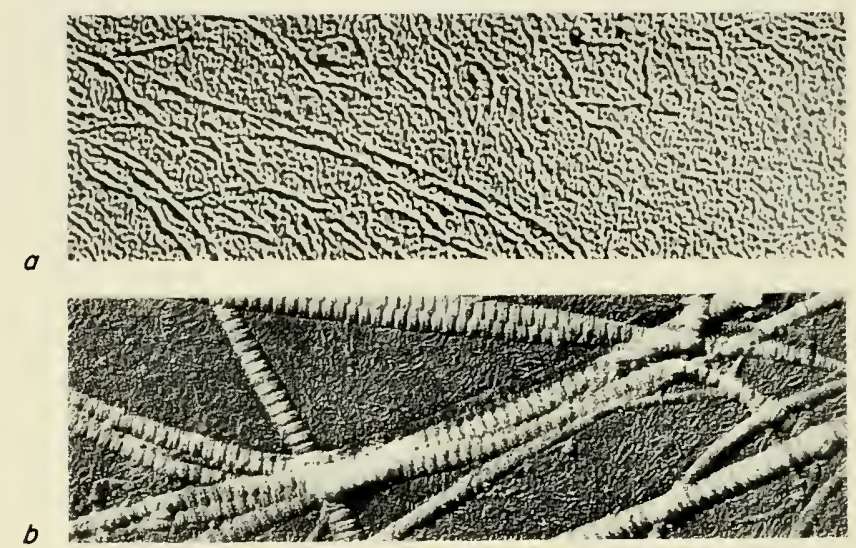

FIG. 11. Electron micrograph of collagen filaments. (a) Filaments of collagen, a protein which is usually found in long fibrils, were dispersed by placing them in dilute acetic acid. This electron micrograph, which enlarges the filament $\mathbf{7 5 , 0 0 0}$ times, was made by Jerome Gross of the Harvard Medical School. (b) Fibrils of collagen formed spontaneously out of filaments such as those shown above when 1 per cent of sodium chloride was added to the dilute acetic acid. These long fibrils are identical in appearance with those of collagen before dispersion.

erate order, beginning from the primitive molecules of the early earth's atmosphere (Fig. 8), throngh proteins (Figs. 10 and 11) into the subcellular material itself (Fig. 4).

\section{Development of IRudimentary Catalysts}

Let us now turn to the question of the generation of the porphyrins, which seem to be central not only to the capture of light as represented by chlorophyll but to the appearance of adenosine triphos- 


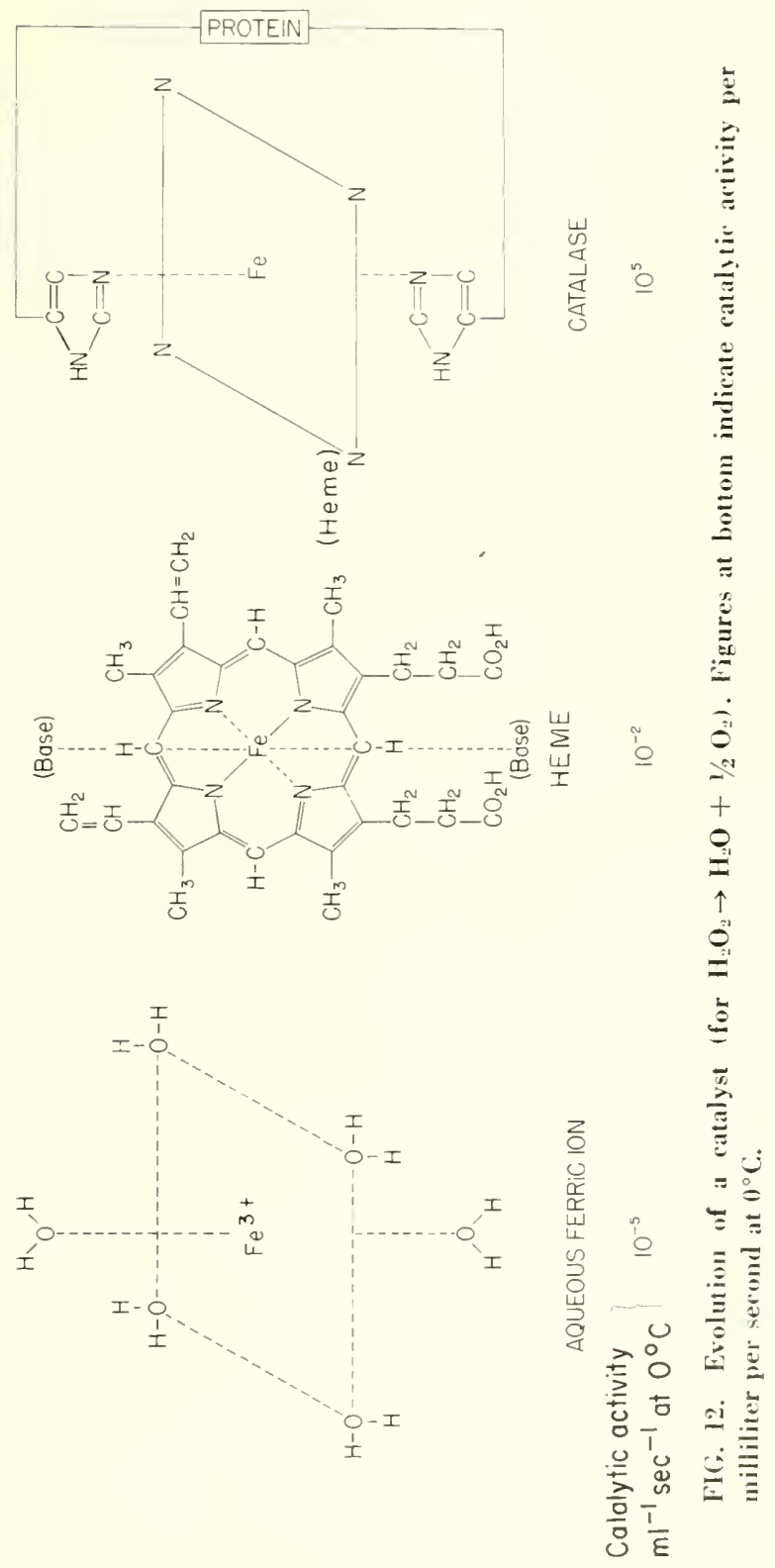


phate in present-day organisms and perhaps to the appearance of ATP in primitive organisms as well.

Figure 12 shows that, starting with the primitive function of iron for the decomposition of hydrogen peroxide, which will be formed in the seas either by ultraviolet radiation or by $K^{40}$ radiation, the iron catalysis can be improved by a factor of 1,000 if it is built into a porphyrin. If we now transform this iron further by encasing the heme into a folded protein and make the molecule of catalase, the catalytic function is improved by another factor of 10 million for this particular peroxide decomposition reaction. ${ }^{35}$

This fact is of great importance because I believe that peroxide appeared in the primitive seas of the earth at the very earliest stages as a result of both the ultraviolet radiation at the top of the atmosphere and of the potassium-40 radioactivity in the earth's crust. This peroxide can now serve as an evolutionary selection pressure ${ }^{38}$ to improve the catalytic function of iron from the bare iron to the iron heme to the iron heme-protein combination.

The way in which this can occur is shown by having a look at the way in which hemes are synthesized by modern living organisms (Fig. 13). We start with succinic acid and glycine, which were made by random synthesis from the primitive earth's atmosphere, and by combining these two substances, we make the alpha-amino-beta-ketoadipic acid which then decarboxylates to give the delta-amino-levulinic acid, two of which can combine to form the heterocyelic pyrrole ring. Then there follows a series of oxidation and condensation steps to give rise to the tetrapyrrole ring. ${ }^{39}$ This reaction is a spontaneous one which involves a number of oxidation steps, several of which are almost certainly catalyzed by iron. The oxidation is achieved either by oxygen or peroxide under the influence of iron and presumably better achieved by iron in a porphyrin than by bare iron. Therefore, once the porphyrin is formed, more of it will be formed because of this autocatalytic self-selection mechanism..$^{4,7}$

\section{Pyrophosphate formation}

This idea is important because the mechanism of the formation of pyrophosphate seems to involve the oxidation of iron. In the last few months, we have been able to demonstrate that one can generate pyrophosphate in aqueous media by simply allowing hydrogen peroxide to oxidize ferrous iron in the presence of orthophosphate. ${ }^{40}$ In 


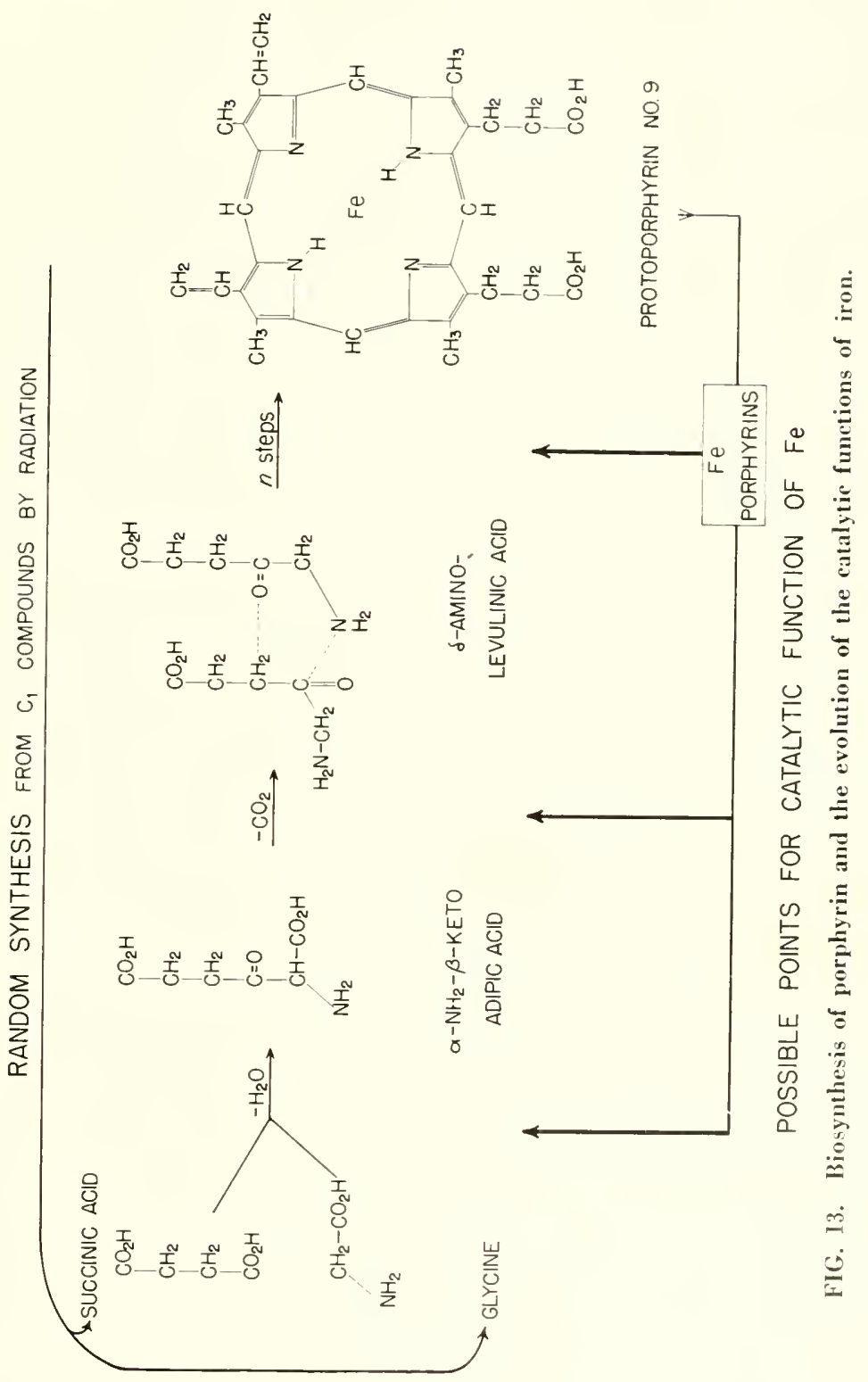


this reaction, a certain amount of orthophosphate is converted into pyrophosphate. The reaction may be written as follows:

$$
{ }^{*}\left(\mathrm{Fe}^{++}+\mathrm{H}_{2} \mathrm{PO}_{4}^{-} \longrightarrow \stackrel{\stackrel{\mathrm{O}}{\|}}{\longrightarrow}\left(\mathrm{Fe}^{\mathrm{II}}-\mathrm{O}-\underset{\mathrm{O}}{\mathrm{O}}-\mathrm{O}^{-}+\mathrm{H}^{+}\right.\right.
$$

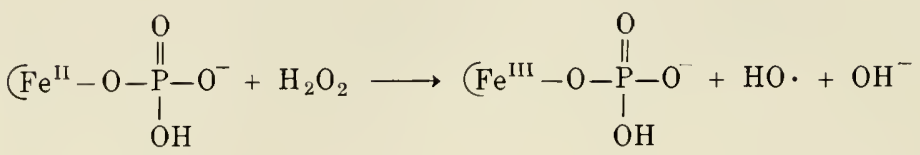

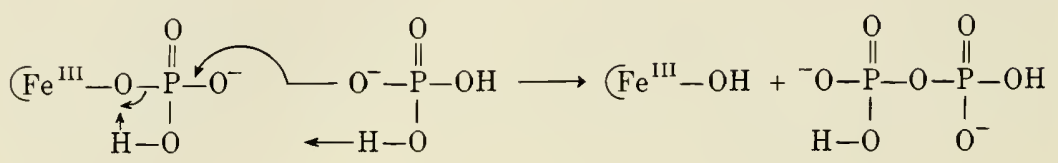

* The half circle around the iron symbol is introduced to represent any other coordinated atoms or groups.

I believe this to be evidence of the primitive way in which the highly evolved oxidative phosphorylation which takes place today began. The complexing of phosphate by ferrous iron, followed by the withdrawal of an electron from the ferrous iron to make ferric iron, the elimination of a water molecule to make pyrophosphate, reduction of the ferric iron to ferrous, completes a cycle for the formation and the liberation of the pyrophosphate linkage. This is now demonstrated in a simple system, and $I$ think it will not be long before we will be able to demonstrate it in the highly evolved iron systems that are used in oxidative phosphorylation, both in plants and in animals, and which are also used in photosynthetic phosphorylation probably in a similar manner.

You ean see here a driving force which will give rise to the porphyrin molecule. The driving force is the peroxide present in the ocean and the usefulness of transforming orthophosphate to pyrophosphate in aqueous solutions so the pyrophosphate can then be used to assist the combination of amino acids to make proteins. This was the evolutionary sequence which gave rise first to the porphyrin and second to a mechanism for manufacturing pyrophosphate.

\section{Coupling}

As yet we have suggested no mechanism for using light to perform these processes. All that would be required in the later stages is to 
find a way of removing the electron from the iron, not with hydrogen peroxide but with light, in order to couple the photochemical reaction to what we now know to be nomphotochemical processes.

I think this event happened very late in the evolutionary seheme, and the evidence for it lies in the fact that the chlorophyll molecule is today manufactured by a sequence of reactions almost identical with the seqnence of reactions used to manufacture the hene, but just before the iron is put into the heme, a branching occurs, leading not to heme but to the chlorophyll molecule in which magnesium is situated (Fig. 14). I think the reason for that reaction is, first, that the

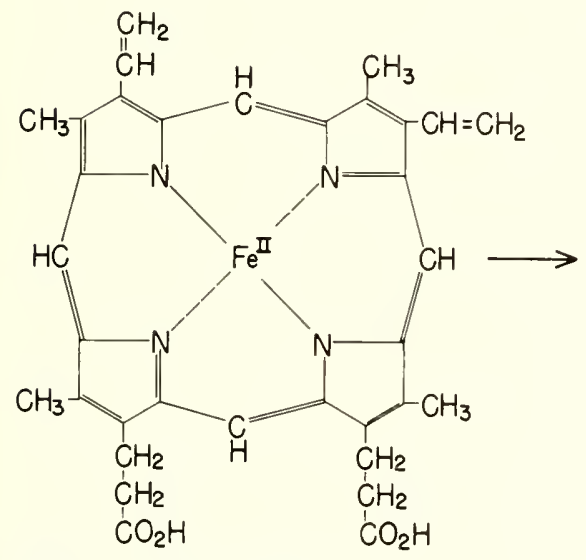

HEME (as in hemoglobin ond cytochrome)

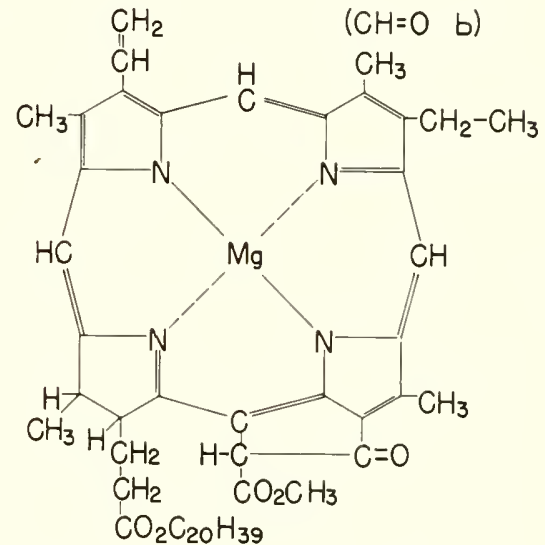

CHLOROPHYLL a

\section{Fe - PROTOPORPHYRIN NO.9}

FIG. 14. Structural relations between heme and chlorophyll.

light-absorbing ability of the heme itself is very poor. Although heme is red, it does not have anywhere near the light-absorbing capacity of chlorophyll, and one of the reasons for the evolutionary selection of magnesium chlorophyll (magnesium chlorin) is the fact that the absorption of light by a magnesium chlorin is several thonsand times greater than that of the iron porphyrin. Secondly, something very special about the electronic structure of the magnesium and of the packing together of the chlorophyll molecules in a erystal lattice, leading to the separation of electrons from the chlowophyll ${ }^{\mathrm{H} 1}$ is better achieved by the chlorin than it is by the porphyrin. Finally if the dehydration-phosphate activation idea (by the 9-10 enol of 
chlorophyll) turns out to play a role, we would then have a third powerful selective factor favoring the chlorophyll structure.

The mechanism and the detailed chemical and physical reasons for this obvious advantage of the chlorophyll over the porphyrin remain for the future to discover.

\section{IReferences}

1. J. A. Bassham and Melvin Calvin, The Path of Carbon in Photosynthesis, Prentice-Hall, Inc., Englewood Cliffs, N.J. (1957).

2. J. A. Bassham and Melvin Calvin, The Photosynthesis of Carbon Compounds, W. A. Benjamin, Inc., New York (1962).

3. J. A. Bassham, Photosynthesis, J. Chem. Education, 36:548-554 (1959) ; J. A. Bassham and M. R. Kirk, New aspects of photosynthesis, J. Chem. Education, $38: 151-154$ (1961).

4. M. Calvin, Evolution of enzymes and the photosynthetic apparatus, Univ. Calif. Radiation Lab. Rept UCRL-3915 (Aug., 1957). Also, M. Calvin, Evolution of enzymes and the photosynthetic apparatus, Science, 130:1170-1174 (1959).

5. M. Calvin, Chemical evolution and the origin of life, Idea and Experiment, vol. 2, no. 4 (June, 1953).

6. M. Calvin, Chemical evolution and the origin of life, Am. Scientist, 44:248-263 (1956).

7. M. Calvin, Round trip from space, Evolution, 13:362-377 (1959).

8. G. Milhaud, J. P. Aubert, and J. Miller, Le métabolisme du carbone dans le chimioautotrophie, Compt. rend., 243:102 (1956).

9. R. C. Fuller and M. Gibbs, Aberrant patterns of some photosynthetic enzymes, Plant Physiol., 31, Suppl.: xxi (1956).

10. J. A. Bassham and M. R. Kirk, Dynamies of the photosynthesis of carbon compounds. I. Carboxylation reactions, Biochim. et Biophys. Acta, 43:447-464 (1960).

11. M. Calvin, Some photochemical and photophysical reactions of chlorophyll and its relatives, Light and Life Symposium, Johns Hopkins Press, Baltimore (1961), pp. 317-355.

12. M. Calvin, Quantum conversion in photosynthesis, J. Theoret. Biol., 1:258-287 (1961).

13. C. B. van Niel, Evolution as viewed by the microbiologist, in The Microbe's Contribution to Biology, Harvard University Press, Cambridge, Mass. (1956), pp. 155-176.

14. R. Y. Stanier, Photosynthetic mechanisms in bacteria and plants: development of a unitary concept, Bacteriol. Rev., 25:1-17 (1961).

15. D. I. Arnon, Cell-free photosynthesis and the energy conversion process, Light and Life Symposium, Johns Hopkins Press, Baltimore (1961), pp. 489-564.

16. D. I. Arnon, Conversion of light into chemical energy in photosynthesis, $N a$ ture (London), 184:10-21 (1959).

17. M. Calvin, The photosynthetic carbon cycle, J. Chem. Soc., 1956:1895-1915. M. Calvin, Photosynthesis, in Radiation Biology and Medicine, ed. by W. D. Claus, Addison-Wesley Publishing Company, Reading, Mass, (1958). M. Calvin, Energy reception and transfer in photosynthesis, Rev. Mod. Phys., 31:147-156 
(1959). M. Calvin, Free radicals in photosynthetic systems, Rev. Mod. Phys.. $31: 157-161$ (1959).

18. H. Lundegardh, On the oxidation of cytochrome f hy light. Physiol. Pluntarum. 7:375-382 (1954). H. Lundegardh. Spectrophotometric investigation on enzyme systems in living objects. IV. Kinetics of the stearly state, Biochim. it Biophys. Acta, 35:340-353 (1959).

19. M. D. Kamen, Comments on the function of heme proteins as related to primary photochemical processes in photosynthesis. Light and Life Symposium. Johns Hopkins Press, Baltimore (1951), pp. 483-488.

20. B. Chance and Lucille Smith. Respiratory pigments of Rhodospirillum rubrum, Nature (London), 175:803-809 (1959). Lucille Smith, Reactions of cytochrome pigments in photosynthetic bacteria. Light and Life Symposium, Johns Hopkins Press, Baltimore (1961), pp. 436-442.

21. B. Chance and M. Nishimura, On the mechanism of chlorophyll cytochrome interactions: The greater insensitivity of light-induced cytochrome oxidation in Chromatium, Proc. Nat. Acad. Sci. U.S., 46:19-25 (1960).

22. W. Arnold and R. K. Clayton, The first step in photosynthesis: Evidence for its electronic nature. Proc. Nat. Acad. Sci. U.S., 46:769-776 (1960).

23. J. A. Bassham. Energy utilization through coupled systems, Radiation Research, Suppl. 2:497-502 (1960).

24. M. D. Kamen, in Enzymes: Units of Biological Structure and Function, Academic Press, Inc., New York (1956), p. 483.

25. B. Chance, Energy-linked cytochrome oxidation in mitochondra, Nature (London), 189:719-725 (1961).

26. D. Shugar and K. L. Wierzchowski, Reversible photolysis of pyrimidine derivatives including trials with nucleic acids, Biochim. et Biophys. Acta. 23:657-658 (1957). D. Shugar and K. L. Wierzchowski, Photochemistry of nucleic acids. nucleic acid derivatives and related compounds, Postepy Biochem., 4:213-296 (1958).

27. H. H. Wasserman and David Cohen. l-Alkoxyvinyl esters of phosphoric acids as phosphorylating agents, J. Am. Chem. Soc.. $82: 4435-4436$ (1960).

28. R. B. Park and N. G. Pon, Correlation of structure with function in Spinacea oleracea chloroplasts, J. Mol. Biol., 3:1-10 (1961).

29. M. Calvin, From microstructure to macrostructure and function in the photosynthetic apparatus, Brookhaven Symposia in Biology, $11: 160-180$ (1958).

30. W. M. Garrison, D. C. Morrison, J. G. Hamilton. A. A. Benson. and M. Calvin. Reduction of carbon dioxide in aqueous solutions by ionizing radiation. Science, 114:416-418 (1951).

31. W. E. Groth and H. v. Weyssenhoff. Photochemical formation of organic compounds from mixtures of simple gases, Planetary Space Sci.. 2:79-85 (1960).

32. S. L. Miller. Production of some organic compounds under possible primitive earth conditions. J. Am. Chem. Soc., $67: 2351-2361$ (1955). S. L. Miller and I1. C. Urey, Organic compound synthesis on the primitive earth. Science, 130:245251 (1959).

33. C. Palm and M. Calvin, Primordial organic chemistry. I. Compoundo resulting from the irradiation of $\mathrm{C}^{14} \mathrm{H}_{4,} \mathbf{J}$. Am. Chem. Soc., 84:2115 (1962). See also Irratdiation of methane, ammonia. hydrogen and water, Univ. Callif. Radiation Lah. Rept. UCRL-9519 (Jan. 31, 1961).

34. For a more complete discussion of the subject of chemical evolution and the 
44 The Nature of Biological Diversity

origin of life, see M. Calvin, Chemical Evolution, Condon Lectures, Oregon State Board of Higher Education, Univ. of Oregon Press, Eugene (1961).

35. M. Calvin, The chemistry of life. 3. How life originated on the earth and in the world beyond, Chem. Eng. News, 39:96-104 (May 22, 1961).

36. S. W. Fox, K. Harada, and A. Vegotsky, Thermal polymerization of amino acids and a theory of hiochemical origin, Experientia, 15:8I-84 (1959). S. W. Fox, How did life begin? Science, 132:200-208 (1960).

37. J. Oró, Direct synthesis of polypeptides. I. Polymerization of glycine in aqueous ammonia, Arch. Biochem. Biophys., $93: 166-171$ (1961).

38. R. Gerschman, Oxygen effects in biological systems, Proc. 21st. Intern. Physiol. and Pharmacol. Congress (1959), pp. 222-226.

39. D. Shemin, Biosynthesis of porphyrins, Harvey Lectures, 50:258-281 (19541955).

40. J. A. Barltrop, Private communication. 


\title{
Biochemistry and
}

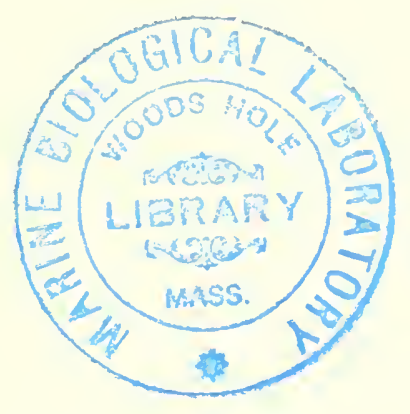

Evolution

\section{Ernest Baldurin}

\author{
Department of Biochemistry \\ University College, University of London
}

As N. W. Pirie (1937) has written, "Life' and 'Living' are clearly words that the scientist has horrowed from the plain man. The loan has worked satisfactorily until comparatively recently. ... Now. however, systems are being discovered and studied which are neither obviously living nor obviously dead, and it is neeessary to define these words or else give up using them and coin others." With the discovery that viruses are crystallizable nucleoproteins, it began to be necessary for the first time to realize that there is no fundamental gap between what is living and what is not. The effects on biological thinking have been profound and far-reaching. The origin of life, formerly no more than a pseudo problem upon which time, energy, ink, and paper had been most generously-and uselessly-lavished, now became a true and a real problem, worthy at last of serious scientific consideration.

The origin of life has become something to be sought in times far remote from our own-at some early time in terrestrial history. Already many stimulating essays on this important matter have been written, speculation has abounded, and a major symposium las been 
held in Moscow (Oparin, 1957) with distinguished scientific contributors from all over the world.

H. C. Urey, among others, has written at length about the origin of the earth and of its early atmosphere, and has concluded that this was originally a reducing rather than the oxidizing medium it is today (Urey, 1959). It has been pointed out that ultraviolet and other forms of radiation, acting upon this primitive atmosphere, must probably have led to the syuthesis of large quantities of small-molecular organic compounds and the production of what has been called a "primordial soup."

Miller (1957) has shown-and his observations have been repeatedly confirmed-that among the products of irradiation of gaseous mixtures approximating in composition to that of the earth's primitive atmosphere glycine, formic, acetic, and succinic acids appear in high yields, together with a remarkably assorted collection of other organic materials (Table 1). It can hardly be without significance that even today these are still the starting materials for the biosynthesis of many elaborate compounds-acetate for the synthesis of fatty acids, sterols, and steroids, and glycine and succinate for that of porphyrins.

The gap between this stage in chemical evolution and the eventual emergence of the first organized, self-replicating system is a difficult one to bridge in the present state of knowledge. It has been said that, given enough monkeys, enough typewriters, and enough time, one of the animals would eventually produce a typescript of all Shakespeare's sonnets. There seems to be no reason why this should not be true. Equally, given a large enough number of small molecules as letters of a biochemical alphabet and a few billion years to do it in, there seems to be little reason why random permutations and combinations should not eventually lead to the production of some primitive kind of organized system possessing potentialities for self-replication, survival, and eventual evolution.

No doubt the monkeys would have produced some other interesting documents in the course of their efforts, documents corrcsponding to other kinds of organized systems; systems that failed to stand up to alterations in a constantly changing external enviromment, and which subsequently died out and left no trace.

Possibly these random processes were less random than the aimless and totally undirected performance of the monkeys because, as Calvin (1957) has pointed out, autocatalysis and catalysis by simple inorganic compounds or heavy metals may have played a large part, not only in the synthesis of new and more elaborate molccules, but also as a sclective and therefore directive agent. There may well have 
been still other chemieal counterparts of natural seleetion, so that the production of large-molecular compounds and their oreanization into a primitive form of living stuff was, in some degree. perhaps a rather less improbable performance than the writing of Shakespcares sonnets.

Table 1. Products of irradiation of a mixture of $\mathrm{II}_{2}, \mathrm{CH}_{4}$, and $\mathrm{NII}_{3}$ (spark discharge)

\begin{tabular}{|c|c|c|c|}
\hline \multirow[b]{2}{*}{ Compound } & \multicolumn{3}{|c|}{ Yield, moles $\cdot 10^{5}$} \\
\hline & $\begin{array}{l}\text { Spark. } \\
\text { run } 1\end{array}$ & $\begin{array}{l}\text { Silent. } \\
\text { run } 3\end{array}$ & $\begin{array}{l}\mathrm{N}_{2} \text { run, } \\
\text { run } 6\end{array}$ \\
\hline Glycine & $63 .(2.1)^{*}$ & $80 .(.46)^{*}$ & $\mathrm{I} 4.2(.48)^{*}$ \\
\hline Alanine & 34. & 9. & 1.0 \\
\hline Sarcosine & 5. & 86. & 1.5 \\
\hline$\beta$-Alanine & 15. & 4. & 7.0 \\
\hline$\alpha$-Aminobutyric acid & 5. & 1. & - \\
\hline N-Metlylalanine & 1. & 12.5 & - \\
\hline \multicolumn{4}{|l|}{ Acids: } \\
\hline Aspartic & 0.4 & 0.2 & 0.3 \\
\hline Glutamic & 0.6 & 0.5 & 0.5 \\
\hline Iminodiacetic & 5.5 & 0.3 & 3.9 \\
\hline Imino-acetic-propionic & 1.5 & - & - \\
\hline Formic & 233. & 149. & 135 \\
\hline Acetic & 15.2 & 135. & 41. \\
\hline Propionic & 12.6 & 19. & 22. \\
\hline Glycolic & 56. & 28. & 32. \\
\hline Lactic & 31. & 4.3 & 1.5 \\
\hline$\alpha$-Hydroxyloutyric & 5. & 1. & - \\
\hline Succinic & 3.8 & - & 22. \\
\hline Urea & 2. & - & 2. \\
\hline Methylurea & 1.5 & - & 0.5 \\
\hline Sum of yields of compounds listed. \% & 15 & 3 & 8 \\
\hline
\end{tabular}

* Per cent yield of glycine based on carbon placed in the apparatus as methane. SOURCE: Miller (1957).

Supposing, then, that the period of ehemieal evolution gave rise to some organized system possessing the potentialities for what may be called "life," as we use the word in its everyday connotation. and organie evolution could begin. To our knowledge and undertanding of this latter process hiochemistry can contribute nuch: hence the title of this essay, "Biochemistry and Evolution"-a challenging title for any biochemist and above all for one who professes an interest in its comparative aspects.

Nearly 25 years ago the present anthor wrote a little book (Bald- 
win, 1937) whose only claim to lasting distinction was probably the foreword contributed to it by Sir Frederick Gowland Hopkins. In that foreword he gave the following text: "I venture to think that productive thought in biochemistry . . ealls for the widest possible survey of life's manifestations. Onc of its ultimate tasks is to decide on what, from the chemical standpoint, is essential for these manifestations as distinet from what is secondary and specifie." Comparative biochemistry is indeed concerned as much with resemblances as it is with differences, and the further biochemical research progresses, the more does it appear that living organisms closely resemble each other at the molecular level, no matter what their strueture, mode of life, or environment. It is as though there is some fumdamental struetural and netabolic ground plan to which all kinds of living things conform. If we could but strip away everything that is secondary and specific and leave this ground plan revealed and naked, we should very probably have a fair idea of the struetural and metabolic make-up of the earliest forms of anything that would be called "alive" by present-day standards. Further back than this, perhaps, we could not go; but that is a problem for the future rather than for this time and place. In writing here about evolutionary diversity the existence of a fundamental ground plan is taken for granted. It is assumed, moreover, that the features of this fumdamental plan were laid down very early in the evolution of modern living forms and that they correspond to a common starting point for evolntionary divergence and differentiation.

J. B. S. Haldane (1937) once wrote that: "Our final theory of evolution will see it largely as a biochemical process." Now if, as seems generally to be believed, evolution has proceeded by a long series of individual mutations, and if, as there is every reason to think, individual mutations, or at any rate their consequences, are open to investigation along biochemical lines, we are also bound to believe, again with Haldane, that "future interpretations of genetics will be largely expressed in hiochemical terms." Biochemical genetics is now a large and important branch of biochemical inquiry. Moreover, it is well documented (sce, for cxample. Haldane, 1954).

If we accept the notion of a fundamental ground plan-and all modern biochemistry seems to point in this direction-and if we suppose that this ground plan was laid down early in the course of biological time, it would seem probable that mutant forms could only be viable if the underlying mutations were consistent with the maintenance of the primary, basic, and fundamental pattern. Moreover, when at a later stage a number of consistent and specific arlaptational super- 
structures had been built up on the fumdamental plan, further mutations would only be viable if they were consistent with the fundamental plan itself and with the maintenance of everything that had already been superadrled to the system. Something of this kind must surely be at the bottom of the fact that the vast majority of random mutations are lethal.

When we eome to study spontaneous or artificially induced nutations in modern organisms, ranging from Neurosport to man himself. it seems an almost invariable rule that each mutation that turns up results in either the loss or some unfarorable modification of at least one enzyme.

There is an abundance of evidence for this; inlerited metabolic disorders such as phenylketonuria, alkaptonuria, hemophilia, and the like have long been known (see Garrod, 1909). Another well-known example on the evolutionary scale is the serial loss of uricolytic enzymes among vertebrate animals (Baldwin. 1949: Florkin, 1949). Fishes in general possess urico-oxidase, allantoinase, and allantoicase, but in some groups and families allantoicase has already disappeared. At the other end of the scale, most mammals possess urico-oxidase but lack allantoiease and allantoinase. Finally, among the primates, even urico-oxidase has been lost.

These last-mentioned enzymes are concerned only with end prodnets of metabolism. If, however, the lost or altered enzyme is one that plays an integral part in intermediary metabolism and normally catalyzes the conversion of $A$ into $B, A$ will tend to accumulate in the cells and the organism thenceforward will be able to survive only in media in which $B$ is present and available. A familiar example is found in a mutant of Escherichia coli, which lacks the enzyne that converts 4-amino-5-iminazole-carboxamide-ribosyl-5'-phosphate into inosinic acid (Gots, 1953 ).

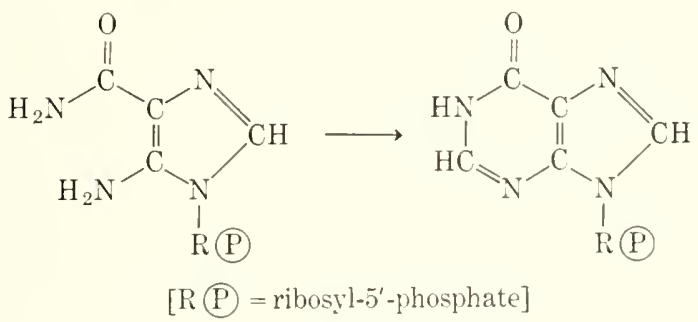

This is an important step in the biosynthesis of purines and their nucleotides and was our first clue to the nature of the synthetic mechanism. 
A mutation of this kind is likely to result in the restriction of the mutant to certain very circumscribed habitats, habitats in which the necessary metabolite can be found ready made. Further stepwise mutations may result in the loss of ability to produce yet other metabolites and the habitats available become even more restricted. This can lead in the end to the grossest kind of parasitism, especially among bacteria, and it is very possible that symbiosis and frank parasitism may be the end results of similar, serial loss mutations in animals as well.

Among bacteria at any rate, loss of synthetic ability is often a stepwise process and can lead to the most exacting of nutritional requirements; many amino acids and a larger or smaller number of accessory growth factors are often required, and these can sometimes only be found in the tissues or tissue exudates of a specific living host. Such is the case in Streptococcus haemolyticus for example, one of the most exacting organisms known. A case that has been studied in much detail is that of cocnzyme A synthesis by bacteria. Requirements for the total synthesis of this substance (see Table 2 and Fig. 1) have been established (Snell, 1956).

Table 2. Biosynthesis of coenzyme A by bacteria

\begin{tabular}{ll}
\hline \multicolumn{1}{c}{ Organism } & \multicolumn{1}{c}{ Requirement } \\
\hline Corynebacterium diphtheriae & B-alanine \\
Lactobacillus bulgaricus & pantetheine \\
Lactobacillus casei & pantothenic acid \\
Acetobacter suboxydans & pantoic acid \\
Treponema pallidum & pantetheine-4'-phosphate \\
\hline
\end{tabular}

SOURCE: Snell (1956).

Yet advantageous mutations, which are probably much less frequent, have clearly taken place over and over again; indeed they have formed the ultimate basis of all adaptation and consequent evolutionary progress. It would seem, however, that among mutations leading to gain, as judged by advantages of survival value, some seem to be more probable than others.

One outstanding example of a gain mutation that seems to be of a rather probable character is the invention of hemoglobin, by far the commonest of the four known respiratory pigments (Lemberg and Legge, 1949). We can say "proballe" because, unlike chlorocruorin, hemcrythrin, and hemocyanin, hemoglobin has turned up over and over again without the slightest reverence for taxonomy; it crops up 
here and there all over the animal kingdom, in many members of many invertebrate groups as well as in vertelorates generally. Keilin suggested many years ago that the formation of hemoglobin is due to modifications (presumably mutational) in the enzymatic machinery ordinarily involved in the prodnetion of the eytochromes. Presumaly $b$ or $c$ are the components concerned, since their hemes are very closely related to that of hemoglobin itself. This scems to be confirmed by the comparable fact that chlorocruorin, which oceurs only in a small group of so-called ehlorhemid worms, carries a heme very similar to and possibly identical with that of cytochrome $a$.

According to all available evidenee, different hemoglobins possess a common heme, and the species-specific differences existing between

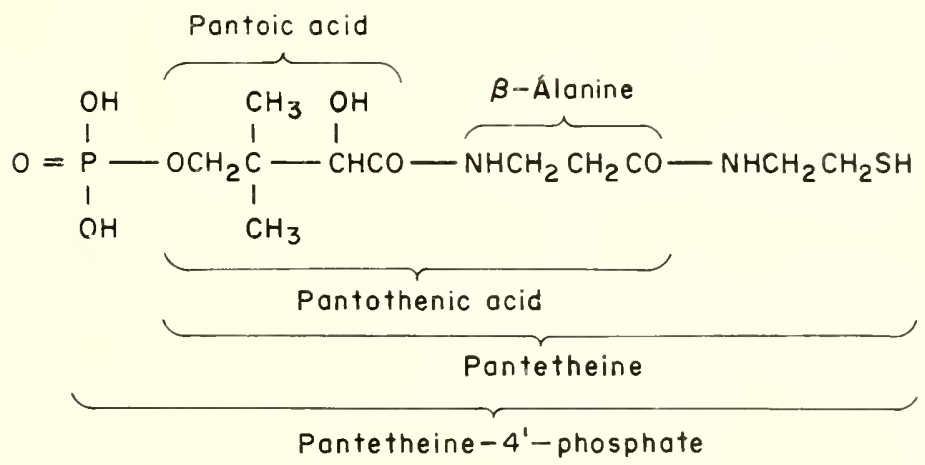

FIG. 1. Requirements for coenzyme A synthesis by bacteria (see also Table 2).

them reside entirely in the globin part of the molecule. But this may be too narrow a view, for there may well be mutant forms of globin as indeed there are among humans. About two dozen or so human variants are now known (Prankerd, 1961) and what seem to be quite trivial differenees from the purely chemical standpoint may have important physiological results: sickle-cell hemoglobin differs from normal in only one of the 300 amino acid units in each half molecule (Hunt and Ineram. 1959). In sickle-cell hemoglobin, valine replaces glutamic acid. while in hemoglobin $C$ the place of glutamic acid is taken by lysine. These and other differences are summarized in Table 3. Small though the chemical differences between the normal and sickle-cell hemoglohins may seem on the surface. individuals carrying two sickle genes commonly die, often in infaney. from the .consequent anemia. Here we have what was originally an arlvanta- 
geous mutation operating through a further mutation to a disadvantageous outeome.

In what has just been said it would appear that the invention of hemoglobin is eertainly a gain event on the whole, for with its acquisition many animals were enabled to penetrate into regions which they could not otherwise have occupied, and were assured of a more abundant supply of oxygen and a consequently greater potential activity, even in their normal habitats. Subsequent mutations in the human race-and there surely must be others elsewhere among animals - seem to have had only indifferent consequences in some cases (hemoglobin $\mathrm{C}$ ), while others have been well on the way toward being lethal (hemoglobin $\mathrm{S}$ ).

Table 3. Chemical differences between normal and abnormal hemoglobins

\begin{tabular}{cll}
\hline Hemoglobin & Structural characteristics & Chain in which structures occur \\
\hline $\mathrm{A}$ & Val.his.leu.thr.pro.glu.glu.lys. & N-terninal sequence of $\beta$ chain \\
$\mathrm{S}$ & Val.his.leu.thr.pro.val.glu.lys. & N-terminal sequence of $\beta$ chain \\
$\mathrm{C}$ & Val.his.leu.thr.pro.lys.glu.lys. & N-terminal sequence of $\beta$ chain \\
$\mathbf{G}_{\beta}$ & Val.his.leu.thr.pro.glu.lys.lys. & N-terminal sequence of $\beta$ clain \\
$\mathrm{E}$ & Gly.gly.lys.ala.leu.gly. & Peptide in $\beta$ chain \\
& (Lys. replaces glu. of Hb-A) & \\
I & Try.gly.asp.val.gly. & Peptide in $\alpha$ chain \\
& (Asp. replaces lys. of Hb-A) & \\
\hline
\end{tabular}

SOURCE: Prankerd (1961).

Any discussion of the speeies-speeifieity of proteins leads one into deep waters, for relatively little is known even today about the detailed ehemieal strueture of these materials. However, insulin is a protein of fairly small molecular size and of which the strueture is preeisely known through the brilliant work of Sanger and his coworkers (Brown, Sanger, and Kitai, 1955; Harris, Sanger, and Naughton, 1956). They have shown that insulin is species-speeific and have discovered the precise nature of the differences between a number of different insulins. Some of their results are summarized in Table 4. All this demonstrates that it is possible to have a number of sulsstances which, though ehemically different, nevertheless possess identical physiological or pharmacological aetivity.

Relatively little is known about the comparative side of enzymology, though important advances have been achieved in elucidating the structure of ribonuelease (Anfinsen \& White, 1961). An interesting point of a somewhat different kind is that, as is now well known, 
Table 4. Species-specificity of insulin
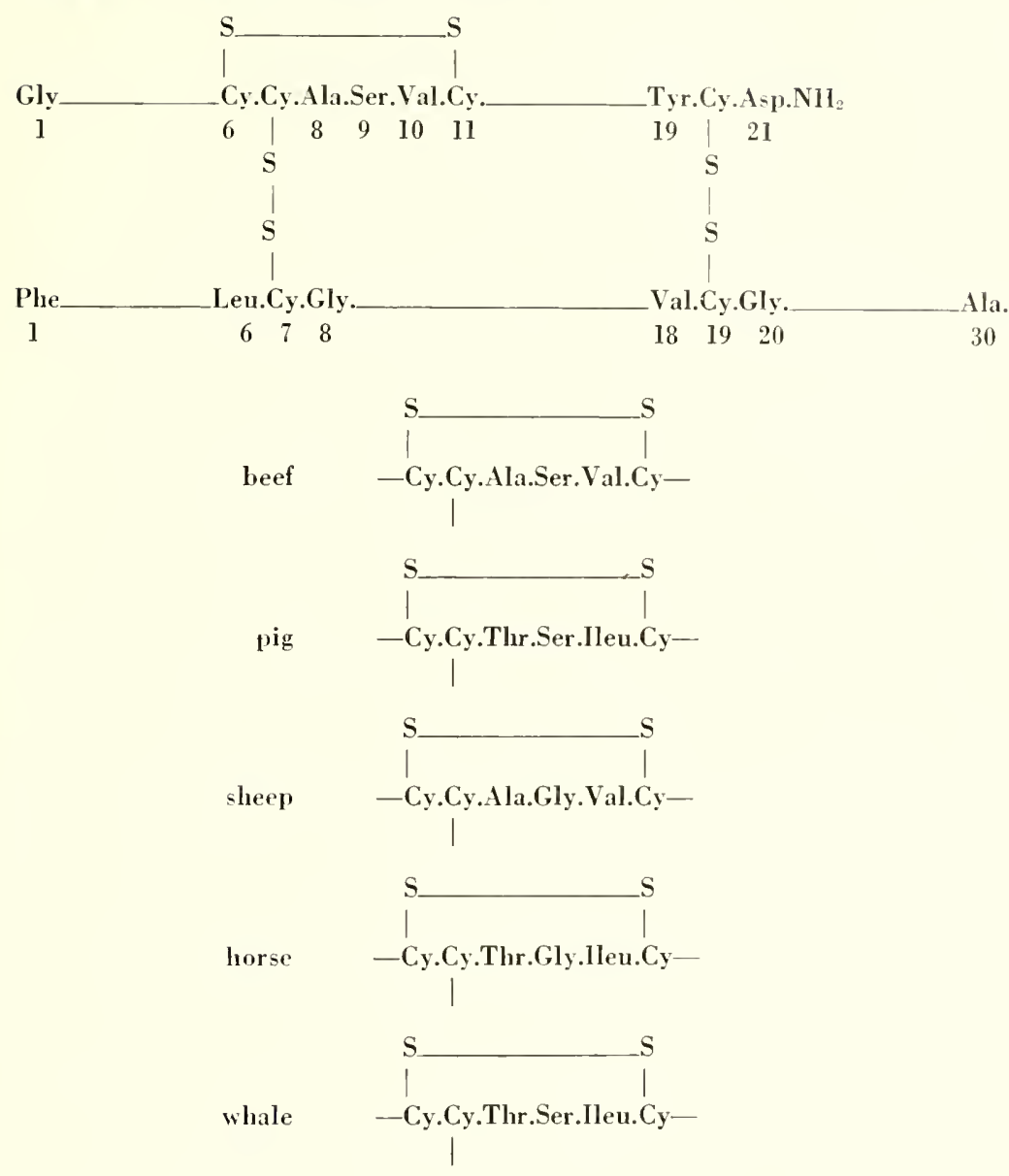

Above, an abbreviated formula of beef insulin.

Below, points of difference between insulins of several species.

Sounce: Brown. Sanger, and Kitai (1955): Harris. Sanger, and Naughton (1956).

the intracellular eathepsins of animals are not only qualitatively but also quantitatively homospecific with the extracellular peptidases, suggesting that the extracellular peptidases of today had their evolutionary origin in intracellular enzymes.

Other macromolecules are not much more rewarding as things stand at present. Lipids have much in common in all animals, in plants, and in bacteria. Polysaccharides, apart from the remarkible 
specialized substances produced by the tubercle organisms and the blood group polysaccharides, have much in common. Cellulose occurs widely in plants and occasionally in animals, especially in the tunicates, but we know little about its fine structure. Chitin occurs in many invertebrates, but even its structure is still not precisely known. Galactogen, a major constitnent of the eggs and albumin glands of certain snails, is uncommon; indeed it is uncommon if only in that about one in every seven of the constituent galactose units consists of the L- instead of the usual D-isomeride (Bell and Baldwin, 1941). Glycogen, the commonest of animal polysaccharides, somewhat resembles the amylopectin component of the plant starches yet differs somewhat according to its source, but the differences are not chemically very remarkable. Glycogens from various sources give different colors with iodine, ranging from zero to the well-known portwine coloration, probably reflecting differences in chain length and degree of branching. However, it is difficult to know what chain length means in molecules which are continuously changing as new units are constantly added or removed. These are essentially dynamic, everchanging, and thoroughly recalcitrant molecules.

So far we have mainly considered some variations on some one or other of a few general themes. But it happens from time to time that the comparative biochemist comes across substances that appear at the time of their discovery to be uniquely confined to particular groups or species. Galactogen, for example, is known to be present in the eggs and albumin glands of Helix pomatia, $H$. aspersa, and Limnaea sp. and might have been thonght to be a characteristic feature of gastropod mollusks, but it could not be detected in the eggs of Aplysia punctata, a marine gastropod, nor in those of the cephalopod, Sepia officinalis (Baldwin, unpublished). Maybe it will turn out to be a feature of pulmonates as opposed to operculates, but too few species of either have as yet been studied.

The trouble here is, as has often been pointed out, that comparative biochemistry has not in the past heen comparative enough, and, until it becomes so, it behooves us to be wary of associating this or that substance too closely with some one or other particular group of animals. A recent example of this is the case of homarine. First discovered in lobster muscle by Hoppe-Seyler (1933), it has now been found to be a very widely distributed constituent of invertebrate materials and may, for all we know to the contrary, occur in vertebrate tissues as well. It had indeed already been found in two other phyla, viz., in Arbacia sp. by Holtz, Kutscher, and Thielmann (1924) 
and in Arca noae by Kutscher and Ackermann (1933)), but was wrongly identified as the isomeric trigonelline at the time.

Distribution studies have in the past been one of the more popular kinds of comparative biochemistry, but they have been too few and too far between. Classical examples are those of Kutscher and Ackermann (1933a, 1936). As an illustrative example here we nay review work done on the distribution of the phosphagens, with which the author has some personal acquaintance.

Work in this field began with the discovery by Eggheton and Eggleton (1928) that although creatine phosphate occurs widely in vertebrate muscles, it is absent from those of invertebrates. Meyerhof (1928) found that, among invertebrates, arginine phosphate replaces the creatine compound. This pioneer work was soon followed up on a much larger number of species by Needham, Needham, Baldwin. and Yudkin (1932) and gave results which led them to believe that they had important evidenee concernirg the origin of vertebrates. A!l the invertebrates examined contained what appeared to be arginine phosphate, with notable exceptions in certain echinoderms (later confirmed by Baldwin and Needham, 1937). In certain echinoids both phosphagens were found to coexist. The same results were found in a hemichordate (Balanoglossus salmoneus) and it seemed that the results fitted in with Bateson's theory of the origin of vertebrates, i.e., that they arose through an echinoderm-hemichordate route.

In all this there was a certain element of fortune. If this work had

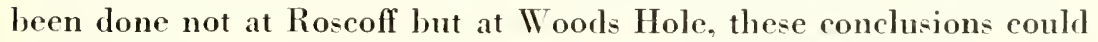
not have been reached because the echinoid and hemichordate studied later at Woods Ilole by Baldwin and Yudkin (1950) prover to contain only one phosphagen each-arginine phosphate in Arbaria pustulosa and the creatine compound in Saccoglossus kovcalevshii.

The work of Baldwin and Yudkin (1950) was mainly levoted to a study of the phosphagen of marine annelids and was prompted by the somewhat atypical hehavior of the presumptive areinine phosphate of certain annelids studied hy Needham, Needham, Bahlwin. and Yudkin (1932) and by the work of Arnold and Luck (1933), according to whom several species of marine annelids contain no arginine whatsoever.

The presence of new phosphagens among the annelids was demonstrated and it was shown that none of them is identical with arginine phosphate. One of the new substances was tentatively irlentified as creatine phospliate. but its positive irlentification only eame later on with the work of Roche and his colleagues (Roche. Thoai, Garcia and 
Robin, 1952; Thoai, Roehe, Robin, and Thiem, 1953a, b, c; Thoai and Robin, 1954a, b; see also Ennor and Morrison, 1958). In addition to ereatine phosphate, moreover, Roche's group identified two further new phosphagens, one based on glyeocyamine and another on taurocyamine. Yet another new hase, lombriein, was sul,sequently diseovered in earthworms and it seems prohable that yet another is<smiles>CC1CCCCC1CNC(=N)N</smiles>

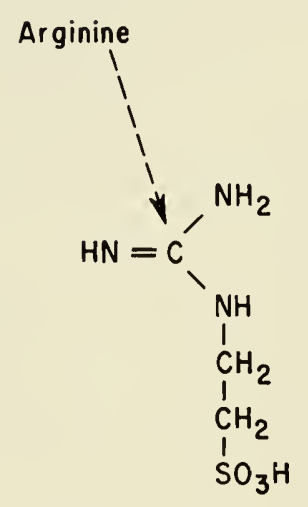

Taurocyomine
Glycocyamine

Creotine

FIG. 2. Relationships of guanidine bases of animal phosphagens: (1) Transamidination of glycine; (2) transmethylation of glycocyamine; (3) transamidination of tanrine.

present in leeches. The formulas of these bases are shown in Fig. 2. Evidently, then, the annelids are a particularly versatile group.

The discovery of ereatine phosphate in worms upset earlier ideas ahout vertebrate evolution, even though something could still be salvaged from the wreek. But perhaps the most interesting aspect of Roehe's series of studies was that glycocyamine, known for many years as a metabolic intermediate between arginine and creatine, occurs in certain annelids. There secms here to be an evolutionary sequence; 
arginine in many marine inverteloates, leading to glycoryamine in some annelids and thence on to creatine in other annelid species. Perlaps the time has come to reexamine the echinoderms and protochordates in case this intermediate stage has been promerved for w there too.

The discovery of taurocyamine was interesting inasumble at transanidination is a fairly rare event. Longest known is the tran-for of the amidine gromp from arginine to glycine, yielding ellyoryamine. It seems likely that taurocyanime arises ly a similat tran-for from arginine to taurine, for taurine is wirlely distributed in ihe animal kingdom and oecurs in remarkal,ly large quantities in certain nollusks, e.g., Abalone (Schmidt and Watson, 1918) and, more intere-ting, in at any rate some annelirl worms (Kurtz and Luck. 1935). So, discoveries of this comparative kind ran sonsetimes and sometling to the vast and everegrowing hody of general hiochemistry. Another example that comes 10 mind is the discovery of octopine in cephatr. porl mollusks (Morizawa, 1927) and in some lamellihranchs and gastropods (Jrvin and Wilson. 1939). This substance appeared to give promise of restriction to eertain fairly sharply defined woups of animals, but later turned ont to be very closely allied to the intermediate compounds formed in the probalbly miversal proress of transamination.

As time goes on, then, more and more of the supposedly scoondary and specific features of particular eroups or species tend to berome incorporated into some more general plan, and examples conld lor multiplied considerably. It may well be, indeed, that as romparative hiochemistry becomes more comparative. more and more of the odfl. peeuliar, and apparently restricted phenomena known today will prove to he widely and in some instances perhaps ever universally distributed, perhaps even as parts of the fundamental metabolis ground plan. Even the production of larwe amount of steam-volatile fatty acids by parastic worm- (Ascris lumbricoides) (Moyle and Baldwin, 1952), long thought to be mnique. at least amone animalfinds a close parallel in the production of -imilar acid- hy the artion of ruminant symbionts upon eellulose (MeAnally and Phillipson. 1944), luut this does not seem by any means a widespreal of fumlamental phenomenon.

At this stage two general comments may he marle: firt. that wre are inclined to study too few species and are tempted to draw too farreaching conclusions from too little evidence. For thi- we late to blame sometimes ourselves. sometimes shortane of fund-. and somp. times the weather, especially at marine stations. Secondly, and this 
must he emphasized, no matter what animal or animals we choose to study, there is always a possibility or even a likelihood that we shall stumble across some hitherto unknown phenomenon of general or even fundamental importance.

However, not the whole of comparative biochemistry is in quite this unsatisfactory state. Often facts are scrappy and unsatisfactory because too few species have been studied, but sometimes fairly thorough, systematic studies have been carried ont. For example, starting with the work of Städeler and Frérichs in 1858, evidence has accumulated that the elasmobranch fishes, but not the teleosts or any other group, elaborate urea as their principal nitrogenous excretory end product. This is true also of the holocephalians, which are usually regarded as an aberrant elasmobranch group, so that biochemistry and taxonomy run hand in hand in this case. The function of the urea, long debated, seems now to be certain. It plays a most important role in osmotic regulation in these fishes (Smith, 1936). Here a striking biochemical peculiarity can be correlated with a specific function in a particular kind of environment.

On a smaller scale, urea formation features also in the dipnoan fishes (Smith, 1930). But when the swamps they inhabit dry up in the dry season, the formation of ammonia-important while they have water to live in-is wholly suppressed in favor of urea production. In this case urea formation evidently represents a specific device for the detoxication of ammonia, and without some such mechanism the lungfishes would have little or no chance of survival through their periods of estivation.

A substantially similar case is found in the horned toad, Xenopus laevis. This animal, by all taxonomic standards, is a perfectly good amphibian, but it is one of a number of amphibians that have made a secondary and permanent return to the water. In the ordinary way the bulk of its waste nitrogen is excreted as ammonia, but some urea is nevertheless formed as evidence, presumably, of a truly amphibious ancestry (Balinsky and Baldwin, 1961). It is said that Xenopus can survive periods of estivation during the dry season, and a number of experiments in which specimens were kept under mildly damp instead of wholly aquatic conditions have proved that this animal, like the lungfish, switches over to large-scale urea production under these conditions (Balinsky, Cragg, and Baldwin, 1961). Like the lungfish emerging from estivation, Xenopus excretes large amounts of accumulated urea when returned to water after being kept out of water for some days (Table 5). Here it seems that these are comparative data of real significance, even though the number of species involved 
is small. But of course it would be well to have the results either confirmed or contradicted by investiwations on otler species witl similar habits and habitats.

Table 5. Nitrogen excretion of Xenopns in water after 19 days in damp (not wet) conditions.

\begin{tabular}{rcc}
\hline \multirow{2}{*}{ Days in water } & \multicolumn{2}{c}{ Percent of total N as } \\
\cline { 2 - 3 } & Ammonia & Urea \\
\hline 3 & 17 & 66 \\
5 & 22 & 66 \\
10 & 56 & 35 \\
17 & 82 & 8 \\
\hline
\end{tabular}

sotrce: Balinsky, Cragg. and Baldwin (1961).

The results so far mentioned fit in with much other information so precisely that we may perhaps be excused for seeming to jump to conchusions over only one or two speeics. The basic fact hehind all this is that ammonia, familiar enough as a household article, is nevertheless extremely toxic, as was conclusively shown by Sumner many years ago. No animal, probably. could survive for long on dry land without having some means of converting ammonia into a more imnocuous material such as urea. Indeed, Xenopus apart, all the anuran amphibians so far examined excrete ahout 80 per cent or more of their waste nitrogen as urea lsee Table 6), and the habit

Table 6. Nitrogen excretion of amphibians: Anura

\begin{tabular}{llcc}
\hline \multirow{2}{*}{ Amphibian } & Habitat & \multicolumn{2}{c}{$\begin{array}{c}\text { Per cent of } \\
\text { lotal N as }\end{array}$} \\
\cline { 3 - 4 } & & Ammonia & Urea \\
\hline Xenopus laevis & $\mathrm{FW}$ & 65.5 & 21.4 \\
Rana esculenta & $\mathrm{FW} / \mathrm{T}$ & 7.8 & 74.8 \\
R. temporaria & $\mathrm{FW} / \mathrm{T}$ & 7.0 & 78.7 \\
Hyla arborea & $\mathrm{T}$ & 4.3 & 83.8 \\
Bufo calamita & $\mathrm{T}$ & 5.3 & 86.9 \\
\hline
\end{tabular}

SOLnCE: Cragg. Balinsky, and Baldwin (1961).

of urea production has been inlerited by the mammals. inchuling even those primitive forms that still lay egge (Cragg. Batinshy. and Baldwin, 1961). However, the majority of the reptiles, together with 
the birds, produce not urea but uric acid as an alternative way of detoxicating ammonia. But from some reptilian groups interesting facts of probable evolutionary significance have emerged (Cragg, Balinsky, and Baldwin, 1961). We know little about the crocodiles and alligators except that ordinarily they live in water and excrete nitrogen mainly in the form of ammonia (Table 7). One would like to know what happens during their overland treks in search of new haunts when the water dries up in the dry season. It should be possible to do "desiccation" experiments similar to those tried on Xenopus.

Table 7. Nitrogen excretion in crocodilian reptiles

\begin{tabular}{lccc}
\hline \multirow{2}{*}{ Reptile } & \multicolumn{3}{c}{ Per cent of total N as } \\
\cline { 2 - 4 } & Ammonia & Urea & Uric Acid \\
\hline Alligator mississipiensis & 75 & 6 & 13 \\
Caiman crocodilus & 58 & 6 & 15 \\
Crocodylus niloticus & 66 & 5 & 21 \\
\hline
\end{tabular}

SOUrCE: Cragg, Balinsky, and Baldwin (1961).

It is among the tortoises and turtles-perhaps the most primitive reptilian group-that the most interesting results have emerged, though the number of species used was only eight. Three groups have been studied by Moyle (1949), one of which lives an amphibious life and never goes far from the water (Table 8). In these the major end product is urea, inherited presumably from ancestral amphihians. A second group comprises two species that, like Xenopus, have made a secondary and apparently permanent return to fresh water. Here

Table 8. Nitrogen excretion in chelonian reptiles

\begin{tabular}{llccc}
\hline \multirow{2}{*}{ Reptile } & \multicolumn{2}{c}{ Habitat } & \multicolumn{3}{c}{ Per cent of total N as } \\
\cline { 3 - 5 } & & Ammonia & Urea & Uric acid \\
\hline Kinosternon subrubrum & Aquatic & 24.0 & 22.9 & 0.7 \\
Pelusios derbianus & Aquatic & 18.5 & 24.4 & 4.5 \\
Enyys orbicularis & Amphibious & 14.4 & 47.1 & 2.5 \\
Kinixys erosa & Land near water & 6.1 & 61.0 & 4.2 \\
K. youngii & Land near water & 6.0 & 44.0 & 5.5 \\
Testudo denticulata & Swamps & 6.0 & 29.1 & 6.1 \\
$T$. graeca & Dry land & 4.1 & 22.3 & 51.9 \\
T. elegans & Very dry land & 6.2 & 8.5 & 56.1 \\
\hline
\end{tabular}

SOURCE: Moyle (1949). 
ammonia sometimes predominates among the nitrogenous excreta, with urea still playing a substantial part. This seems to inclicate a reversion toward wholly aquatic habits, but the persistence of urea production gives present evidence of a one-time truly amplibious or terrestrial past.

The third group comprises three species within a single genus, Testudo. In the swamp-dwelling $T$. denticulata the picture is similar to that found in the other amphibions species. In $T$. graeca, however, a substantial excretion of uric acid makes its appearance and finally. in the desert-living $T$. elegans, wea no longer appears in more than trivial amounts and urie acid is responsible for practically all the nitrogen accounted for.

In fairness to Moyle, it should he pointed out here that there were a number of analytical difficulties in this work largely because many of these animals have a habit of exereting a good deal of only partially digested food that is not removed by the usual deproteinization pro. cedures, but even so the results do appear to be pretty clear-cut. It certainly seems that in this group of reptiles we have a series of eases which sum up the biochemical steps which were probahly entailed in the evolution of the modern snakes, lizards, and birds. Starting from an amphibious stock of urea producers, they took to progressively drier and drier surroundings, making use at first of the mechanisms they already possessed by reason of their ancestry. Eventually the advantages of uric acid became apparent-its extreme insoluhility. the fact that it is relatively innocuons and that little water is required for its excretion-and gradually, probably step by step, there came the switchover from the formation of urea to that of urie acid. This. as Joseph Needham (1931) has argued, must also have tied up with the invention of impermeable eggshells and consequential changes in the conditions of embryonic life.

Before leaving these ehelonian reptiles, it must he mentioned that there are reports in the literature to the effect that the wholly marine turtles exerete only ammonia and no urea or uric acid worth mentioning. Does this mean, perhaps, that they never had an amphibious pliase and so had no use for urea, or that they returned to the water long, long ago and have now altogether forgotten how to make it? Evidently, there is still plenty of room for new work in this field.

From these studies on amphihia and reptiles some recent research has turned toward another problem of no small interest, viz., the nitrogen excretion of fishes. The positive results olstained by the author so far have been published (Baldwin, 1958, 1960). like much of the work already mentioned, lunt only a few of the negative ones 
have so far seen the light of day. However, there are some interesting possibilities from the viewpoint of evolution.

The nuterial nsed comprised a number of speeies of elasmobranchs which, as is well known, are large-scale producers of urea, and the primary problem is whether or not they make urea by the same route as that followed in mammals and amphibians. It is now widely though not quite universally believed that urea formation follows the pathways shown in Fig. 3. Carbon dioxide and ammonia in the presence of ATP and acetylglutamate give rise in some way that is still very obscure to carbamyl phosphate. Ornithine is transcarbamylated by earbamyl phosphate to give citrulline, which reacts then with aspartate, giving argininosuceinate. This last product is split into arginine and

\section{Mechonisms of ureogenesis}

(as generally accepted)

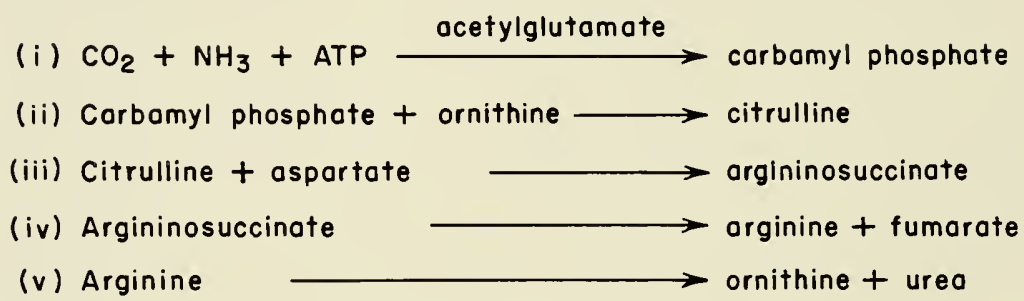

FIG. 3. Mechanisms of ureogenesis (as generally accepted).

fumarate and the arginine is hydrolyzed by arginase to give urea and regenerate ornithine, which can then be used over again. Most of the enzymes involved have been rather recently more or less purified and studied in considerable detail (see Brown and Cohen, 1960, for references). Their results were published a few years after our own work in this field began.

A number of interesting problems eame to mind at the start of this work. In the first place, while arginase is present in the livers of all urea-producing animals, it is normally confined to the liver. In elasmoloranchs, however, it is present in every organ in the body; it would be interesting to know whether, in view of its very great osmotic importance, urea might be made not only in the liver as is usually the case but in other organs as well. The whole business presents special problens because one is faced with the determination of small amounts of urea synthesis in the presence of some 2 to 2.5 per cent of 
preformed urea, but it has been possible to orercome this. first hy the use of well-washed tisue preparations and later (Josepll. unpub. lished) by the use of ion-exchange resins. A few experiments have heen done on urea synthesis in organs other than the liver but have led nowhere so far.

Hitherto it had been usual to think of urea production as a means of detoxicating ammonia, and as something that originated in animals at somewhere about the amphibian level of evolution. This attitude could accommodate not only the modern amphibia but also the lungfishes which, apart from the elasmobranchs, are the only group of fishes in which urea formation is a serious industry. Why, then, and at what stage in their history, did these wholly aquatic elasmoloranchs develop the machinery for making urea? It could, of course. be a matter of evolutionary convergence. Alternatively it could be, perhaps, as Romer and others have suggested, that the earliest ancestral fishes lived under conditions similar to those the lungfishes experience today, and that they all used urea as a means of survival. Later on, it could be argued, urea formation became redundant and disappeared from the majority of fishes. The elasmobranchs, it might he thought, had discovered its osmotic advantages in the meantime and retained the synthetic apparatus. If this were true, it might perhaps be anticipated that some vestiges of the one-time synthetic apparatus might be discovered in other kinds of fishes today, and new work is going on to look into this. In the meantime it is known that arginase is present in the livers of a considerable number of teleostean fishes, and that appreciable quantities of urea are often to be found in their excreta and even in their tissues. So this looks like a helpful line to follow up. Finally, there are still a few fishes that, morphologically speaking, have remained practically unchanged since the Jurassic, for example, Amia and Lepidostens. Polypterus is still with us but luas changed little since the Carboniferous or thereabouts. There are, too, the coelocanths. All these and many more would be well worth studying as potential sites of restigial urea-producing enzymes. So far the only information we have comes from Brown and Cohen (1960). who could find neither carloamylphosphate synthetase nor ornithine transearbamylase in Amia or Lepidosteus.

In the earlier part of our own work, we were able without difficulty to show that laboratory-synthesized carbanyl phosphate reacts with ornithine and gives citrulline, and that, in the presence of citrulline, aspartate, and ATP, urea is formed. If any of the reactants was omitted, urea synthesis stopped (Tables 9 to 11). All these results have since been abundantly confimed. So far there is obviously a close 
Table 9. Formation of citrulline from carbamyl phosphate and ornithine

\begin{tabular}{lc}
\hline \multicolumn{1}{c}{ Species } & $\mu$ mole citrulline/g powder \\
\hline$R$. productus (1) & 187 \\
$R$. productus (2) & 166 \\
H. californicus & 223 \\
M. californicus & 205 \\
G. marmorata & 166 \\
& \\
Reaction mixture: $0.1 \mathrm{ml} 0.1 \mathrm{M}$ ornithine; $0.2 \mathrm{ml} 0.2$ \\
M K-phosphate. buffer (pH 7.4$) ; 2.5 \mathrm{ml} 0.02 \mathrm{M} \mathrm{dilitl}$ - \\
ium carbamyl phosphate; $0.8 \mathrm{ml}$ water $0.5 \mathrm{ml}$ extract \\
of Type l powder. \\
Incubation: $30 \mathrm{~min}$ at $38^{\circ} \mathrm{C}$. Readings at $490 \mathrm{~m} \mu$.
\end{tabular}

SOURCE: Baldwin $(1958,1960)$.

Table 10. Formation of urea from citrulline and aspartate

\begin{tabular}{|c|c|c|c|}
\hline \multirow{2}{*}{ Species } & \multicolumn{3}{|c|}{$\mu$ mole urea/g powder } \\
\hline & Preformed & After incubation & Synthesized \\
\hline \multirow{2}{*}{ R. productus (1) } & $\int 126$ & 158 & 27 \\
\hline & $\{126$ & 178 & 52 \\
\hline \multirow{2}{*}{ R. productus (2) } & $\{95$ & 118 & 23 \\
\hline & $\{95$ & 121 & 26 \\
\hline \multirow{2}{*}{ M. californicus } & $\{74$ & 108 & 34 \\
\hline & 75 & 103 & 28 \\
\hline \multirow{2}{*}{ G. marmorata } & $\{123$ & 145 & 22 \\
\hline & $\{125$ & 159 & 34 \\
\hline \multirow[t]{2}{*}{ U. halleri } & $\{126$ & 158 & 32 \\
\hline & $\{127$ & 177 & 50 \\
\hline \multicolumn{4}{|c|}{ 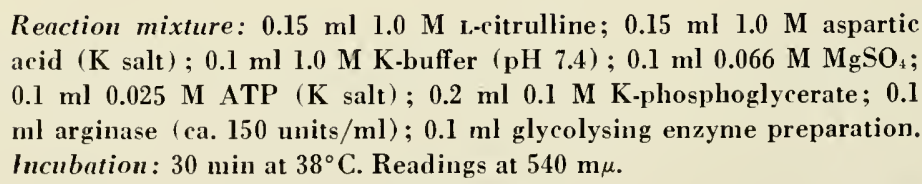 } \\
\hline
\end{tabular}

SOURCE: Baldwin $(1958,1960)$. 
parallelism between urea synthesis in these fishes, in amphibia, in chelonian reptiles, and in mammals. We have since done more detailed work on the stages between citrulline + aspartate and urea, and there is no doubt that the reactions take place in the usual way. But where we have completely failed in more than two years of concentrated work is in the biosynthetic production of carbanyl phosphate l,y elasmobranchs. We have used more delicate and refined methods for its detection, we have tried all sorts of conditions of temperature and $\mathrm{pH}$, we have tried putting in everything from sodium chloride to the proverbial kitchen sink, but still we have not been able to get a synthesis of carbamyl phosphate. Parallel experiments with rat liver,

Table 11. Formation of urea from citrulline and aspartate *

(M. californicus)

\begin{tabular}{lcc}
\hline Reactant omitted & $\begin{array}{c}\mu \text { mole urea/g } \\
\text { powder }\end{array}$ & $\begin{array}{c}\mu \text { mole urea formed } / g \\
\text { powder }\end{array}$ \\
\hline All & 75 & (Preformed) \\
None & 100 & 25 \\
Citrulline & 73 & -2 \\
Aspartate & 78 & +3 \\
ATP & 83 & +8 \\
Phosphoglycerate & 75 & 0 \\
Arginase & 100 & 25 \\
\hline
\end{tabular}

* $1 \mathrm{ml}$ enzyme and $1 \mathrm{ml}$ reaction mixture as for Table 10 . Incu. bation $30 \mathrm{~min}$ at $30^{\circ} \mathrm{C}$.

Source: Baldwin $(1958,1960)$.

frog liver, and slaughterhouse material produce carbanyl phosphate readily enough, but the elasmobranchs systematically refuse to do so. Brown and Cohen (1960) have since reported similar failures.

We shall not try to put any interpretation on these results except to say that there seem to be two possibilities. One is that we may he dealing with a case of evolutionary convergence. The other is that the scheme for urea synthesis on which we are working, and which is widely accepted, may be wrong. Bach. for example. has long maintained that there are more ways than one in which urea may be synthesized and it is even possible that, working on elasmohranch fishes, we may yet find out how urea is really synthe-ized in mammal..

The author was brought up to believe that the jol of biochemistry is to solve biological problems ly chemical methods, and he felt in 
preparing this essay that the task was, not so much to present new facts as to try to get a certain amount of perspective into the contributions that biochemistry, especially on the comparative side, can make toward the solution of evolutionary problems. Not unnaturally, most space has been spent on matters with which he has had a good deal of personal experience. An attempt has been made to point out some of the shortcomings and some of the dreams, trials, disappointments, and tribulations of a comparative biochemist. But in spite of all these it is still possible to believe that if the recent upward swing of interest in comparative biochemistry can be maintained, it will in the end prove its ability to make valuable contributions to that most biological of all biological theories, the theory of evolution.

\section{theferences}

Anfinsen, C. B., and F. H. White (1961), The ribonucleases: occurrence, structure and properties in The Enzymes, Academic Press, Inc., New York, vol. 5, pp. 95122.

Arnold, A.. and J. M. Luck (1933), Studies on arginine. III. The arginine content of vertebrate and invertebrate muscle, J. Biol. Chem., 99:677-691.

Baldwin, E. (1937), An Introduction to Comparative Biochemistry, lst ed., Cambridge University Press, London and New York.

(1949), An Introduction to Comparative Biochemistry, 3d ed., Cambridge University Press, London and New York, p. 65.

- (1958), Ureogenesis in elasmobranchs, Nature (London), $181: 1591-1592$. (1960), Ureogenesis in elasmobranch fishes. Comp. Biochem. Physiol., $1: 24-37$.

- , and D. M. Needham (1937), A contribution to the comparative biochemistry of muscular and electrical tissues, Proc. Roy. Soc. (London), B, 122:197-219.

- and W. H. Yudkin (1950), The annelid phosphagen: with a note on phosphagen in Echinodermata and Protochordata, Proc. Roy. Soc. (London), B, 136:614-631.

Balinsky, J. B., and E. Baldwin (1961), 'The mode of excretion of ammonia and urea in Xenopus laevis, J. Exp. Biol., 38:695-705.

$\longrightarrow$, M. Cragg, and E. Baldwin (1961), The adaptation of waste nitrogen excretion to desiccation, Comp. Biochem. Physiol., 3:236-244.

Bell, D. J., and E. Baldwin (1941), The chemistry of galactogen from Helix pomatia as a component of a polysaccharide of animal origin. J. Chem. Soc., 1941:125132.

Brown, G. W., and P. P. Cohen (1960), Comparative biochemistry of urea synthesis. 3. Activities of urea-cycle enzymes in various higher and lower vertebrates, Biochem. J., $75: 82-91$.

Brown, H., F. Sanger, and R. Kitai (1955), The structure of pig and sheep insulin, Biochem. J., 60:556-565.

Calvin, M. (1957), Chemical evolution and the origin of life, in The Origin of Life on the Earth, Rep. Internat. Symp., Publ. House, Acad. Sci. USSR, pp. 338-350.

Cragg. M., J. B. Balinsky, and E. Baldwin (1961), The comparative study of nitrogen excretion in some amphibia and reptiles, Comp. Biochem. Physiol., 3:227-235. 
Eggleton, P., and G. P. Eggleton (1928), Further observations on phosphagen, J. Physiol., 65:15-24.

Ennor, A. H., and J. F. Morrison (1958). Biochemistry of the phospliagens and related guanidines, Physiol. Rev., 38:631-674.

Florkin, M. (1949). Biochemical Evolution. Academic Press Ine. New York, pp. $45-47$.

Garrod, A. E. (1909), Inborn Errors of Metabolism. Oxforel Univer-ity Press, London and New York.

Gots, J. S. (1953), Oecurrence of 4-amino-5-iminazole carboxamide as a pentose derivative, Nature (London), 172:256-257.

Haldane, J. B. S. (1937), The hiorhemistry of the individual, in Perspectives in Biochemistry, Cambridge University Press, London and New York, pp. 1-10. (1954), The Biochemistry of Genetics. George Allen \& Unwin, Ltc.. London.

Harris, J. I., F. Sanger, and 11. A. Nanghton (1956). Species-differences in insulin, Arch. Biochem. Biophys.. 65:427-438.

Holtz. F.. F. Kutscher. and F. Thielmann (1924), Über das Vorkommen des Pflanzenalkaloids Trigonellin in der Tierwelt. Z. Biol., 81 :57-60.

Hoppe-Seyler. F. A. (1933), Über das homarin. eine bisher mnekannte tierische Base, Z. physiol. Chem., 222:105-115.

Hunt. J. A.. and V. M. Ingram (1959), A terminal peptide sequence of human haemoglobin. Nature (London), 184:640-64i.

Irvin, J. L., and D. W. Wilson (1939). Studies on octopine. III. The precursor of octopine in scallop musele. J. Biol. Chem., $127: 575-579$.

Kurtz, A. C., and J. M. Luck (1935). Studies on annelid muscle. I. Tanrine in Audoninia spirabranchus (Moore). J. Biol. Chem., $111: 577-584$.

Kutscher, F., and D. Ackermann (1933a). Comparative biochemi-try of the vertebrates and invertebrates, Ann. Rev. Biochem.. 2:355-376.

- (1933b). Úber das Vorkonmen von Betainen in der Archenmuschel, $Z$. physiol. Chem.. $221: 33-39$.

(1936), Comparative biochemistry of the vertebrates and invertebrates, Ann. Rev. Biochem.. 5:453-462.

Lemberg. R.. and J. W. Legge (1949), Haematin Compounds and Bile Pigments: Their Constitution, Metabolism and Function. Interscience Publishers. Inc.. New York. pp. 307. 309.

MrAnally, R. A.. and A. T. Phillipson (1944). Digestion in the ruminamt, Biol. Rev., $19: 41-54$.

Meyerbof, O. (1928). Ueber die Verbreitung der Argininphosphorsaüre, Arch. Sci. Biol. (Napoli), 12:536-548.

Miller. S. (1957), Formation of organir compounds on the primitive earth, in The Origin of Life on the Earth. Rep. Internat. Symp. Publ. House. Arad. Sci. TSSR, pp. 73-85.

Morizawa, K. (1927). The extractive sub-tances in Octopus octopodia. Acta. Schol. Merl., Univ. Kioto. 9:285-302.

Moyle, V. (1949), Nitrogenous excretion in chelonian reptiles, Biochem. J., $44: 581-584$.

, and E. Baldwin (1952). Volatile fatty acids of Ascaris lumbricoides from the pig, Biochem. J., $51: 504-510$.

Needham, J. (1931), Uricotelic metabolism and the evolution of the terrestrial egg. in Chemical Embryology. Cambridge University Press, London and New York. Vol. 2, pp. 1132-1145. 
D. M. Needham, E. Baldwin, and J. Yudkin (1932), A comparative study of the phosphagens, with some remarks on the origin of vertebrates, Proc. Roy. Soc. (London), B., $110: 260-294$.

Oparin, A. (ed.) (1957), The Origin of Life on the Earth, Rep. Internat. Symp., Publ. House, Acad. Sci. USSR.

Pirie, N. W. (1937), The meaninglessness of the terms life and living, in Perspectives in Biochemistry, Cambridge University Press, London and New York, pp. 11-22.

Prankerd, T. A. J. (1961), The Red Cell. An Account of Its Chemical Physiology and Pathology, Oxford University Press, London and New York, p. 136.

Roche, J., N. v. Thoai, I. Garcia, and Y. Robin (1952), Sur la nature et la répartition des guanidines monosubstituées dans les tissus des invertébrés. Présence des dérivés guanidiques nouveaux chez des Annélides, Compt. rend. soc. biol., 146:1902-1905.

Schmidt, C. L. A., and T. Watson (1918), A method for the preparation of taurine in large quantities, J. Biol. Chem., $33: 499-500$.

Smith, H. W. (1930). Metabolism of the lungfish, Protopterus aethiopicus, J. Biol. Chem., 88:97-130.

- (1936), The retention and physiological role of urea in the Elasmobranchil, Biol. Rev., $11: 49-82$.

Snell, E. E. (1956), Some aspects of vitamin and growth factor research, in Currents in Biochemical Research, Interscience Publishers, Inc., New York, pp. 87-114.

Städeler, G., and F. T. Frérichs (1858), Über das Vorkommen von Harnstoff. Taurin und Seyllit in den Organen der Plagiostomen, J. prakt. Chem., $73: 48-55$.

Thoai N. v., and Y. Robin (1954a), Métabolisme des dérivés guanidylés. II. Isolement de la guanidinotaurine (taurocyamine) et de l'acide guanidinoacétique (glycocyamine) des vers marins, Biochim. et Biophys. Acta, 13:533-536.

(1945b), Métabolisme des dérivés guanidylés. IV. Sur une novelle guanidine monosubstituée biologique, l'ester guanidino-éthylsérylphosphorique (lombricine) et le phosphagène correspondant, Biochim. et Biophys. Acta, 14:76-79.

Thoai. N. v., J. Roche, Y. Robin, and N. v. Thiem (1953a), Sur la présence de la glycocyanine (acide guanidyl acétique). de la taurocyamine (guanidyl taurine) et les phosphagènes correspondants dans les muscles des vers marins, Biochim. et Biophys. Acta, 11:593.

(1953b), Sur deux nouveaux phosphagènes: la phosphotaurocyamine et la phosphoglycocyamine, Compt. rend. soc. biol., 147:124I-1243.

- (1953c), Sur le phosphagène de Lumbricus terrestris sp., Compt. rend. soc. biol., $147: 1670-1672$.

Urey, H. C. (1959), The atmospheres of the planets, Handb. Phys., 52:363-418. 


\title{
The Nature and Diversity
}

\section{of Catalytic Proteins}

\author{
Paul ID. Hoyer \\ Department of Physiołogical Chemistry \\ University of Minnesota, Minneapolis, Minnesota
}

Most investigators, in considering the general topic of this lecture series, "The Nature of Biological Diversity." are likely impressed with both the breadth and the importance of the subject matter. I share such a view, and indeed find the subtopic to which my remarks are to be addressed, "The Nature and Diversity of Catalytic Proteins," to be a subject of wide scope. In part our awe of these topies. as scientists, reflects the wealth of experimental material to be considered. together with the recognition that the totality of our present information is meager compared to the seope of the subject, and. further. is to a large extent only descriptive and superficial. We lack the knowledge and the insight to develop the generalized concepts that will give colerence and understanding to the diversity encountered. In this presentation, an attempt will be made to give some important generalizations about enzymes that appear valid at this time. to point ont varions similarities and diversities which need further understanding, and to suggest some relation hips and generalizations which are indicated from present researeh derelopments. In illustration of 
some concepts or points, consideralle use will be made of data from our group at Minnesota because 1 am most familiar with them and can speak most freely of them, not because these data are necessarily the best to illustrate a partieular point.

From the viewpoint of an enzymologist, the most striking eharaeteristic of different living forms is not their diversity hut their similarity. Morphological and-functional differences among organisms and cells are large compared to ehemical differenees, and in particular, compared to differenees in cellular enzyme chemistry. Some generalizations about the nature of enzyme action, which are so well recognized that their importance may be overlooked, are as follows:

Catalytic proteins (enzymes) are found in all cells. This and the following generalization are alssolute in that no known exceptions have been found. Thus biologists would predict with a high degree of confidence that any living form found on earth would have enzymes in its cells.

All cells have in common some basic enzymic reactions. All known types of cells, including many diverse unicellular organisms, have enzyme systems for the formation and use of certain key chemieal substances, sueh as amino acids, partieular organic phosphates, and ribonucleic acids.

Various enzymic reactions have important common features of mechanism. The most prominent of these features is that enzymic eatalyses occur by speeific combination of the substrate moleeules with particular regions of the enzyme molecule. Possibilities of some other common features in finer details of mechanism will be examined later.

Enzyme cofactors have similar roles in different cells. This has been an important generalization in the elucidation of metabolic funetion of vitanins. Biochemists have frequently taken advantage of the knowledge that a cofactor role found with microorganisms will apply to larger, more eomplex forms in an identical manner or one whieh is closely related chemieally.

Among the implications of the first two generalizations are those related to the origin of life itself, and a few comments of a phylogenetie nature may be in order, partieularly in this day of interest in planets other than earth. Existence of living material withont the presence of eatalysts therein is difficult to visualize, but one may ask if the enzyme protein is the only possible way for a variety of eatalysts to be produced from ehemical elements. Are the properties of phosphate and phosphate compounds, and of nucleic acids such that 
other means of handling cellular energy and reproductive requirements are not possible? The enzymological unity of the forms of life we recognize might find its explanation in one of the following:

1. A common origin of all living cells. This is implieit in theories of the origin of life based on the oceurrence of at least one highly improbable event.

2. Given the changing chemical environment to which earth has been exposed, the development of life is a logical consequence. This implies that the basie chemistry common to various cells is unicpuely required for life under our present conditions.

3. Living forms with different chemical bases have existed on earth, but that form with a chemistry as ace hnow it today has, through adaptability, been the only form to survive.

Means are not at hand to distinguish among these or other possibilities, and it is not my purpose to dwell further upon such matters but to turn attention to certain questions for which pertinent information is at hand. Some questions about the diversity of enzymes to which the bulk of this lecture will be addressed are:

Do enzymes catalyzing the same or similar reactions in various cells have structural features in common? Features about which meager information is becoming available pertain to size, amino acid composition, amino acid sequences in catalytically important areas, and the relation of degradation and of modification of composition to eatalytic activity. In this lecture, some results on amino acids present at catalytic sites of hydrolytic enzymes and on degradation of enzymes in relation to activity will be presented.

Do enzymes from different sources catalyzing the same reaction do so by the same or similar mechanism? At this stage the answer appears to be yes for a number and perhaps for most enzymes. but with some enzymes there is strong suggestion that different mechanisms hold. Attention will be directed toward some results with aldolases, and with several types of enzymes involved in phosphorylation reactions.

Are there additional common features of enzyme mechanisms achich are as yet unrecognized? Sturly of mechanism has many levels. and as finer tetails of mechanism are revealed examination for possible similarities in the rhemistry of various caltalyes is in order. Some of our studies on syntheses coupled to ATP' cleavage have wiven indieations of previously unrecomized features of enzymic catalyes. and these implications. lowether with an anal- 
ogy between oxidative phosphorylation and muscle contraction, will be presented.

\section{Some relations of amino acid composition to activity}

Amino acid composition and partial or complete amino acid sequence studies have shown only small differences in proteins with a particular biological activity from different animal species, namely, with insulins, hemoglobins, and some pancreatic enzymes. Small but detectable differences in enzymes from one tissue have also been found and the recognition of such variants will likely increase as more discerning methods are applied. Markert has appropriately termed such closely related enzymes "isozymes" (1). The similarities of the protein structure of the same enzyme from different tissues is illustrated by the immunological cross reactions among various mammalian tissue lactate dehydrogenases (2), as well as various lactate dehydrogenases from a single tissue (1). Differences in composition are also shown by differences in catalytic behavior of purified lactate dehydrogenases from different tissues, as documented by Kaplan and coworkers (3). Such differences may have clinical use in identification of the source of an enzyme from its properties.

One aspect of amino acid composition of enzymes of particular recent interest has been the demonstration of the presence of a similar amino acid sequence near the reactive seryl residue of a variety of hydrolytic enzymes. Pertinent findings are summarized in Table 1.

Table 1. Amino acid sequences near reactive seryl residues of some hydrolytic euzymes

\begin{tabular}{ll}
\hline \multicolumn{1}{c}{ Enzyme } & \multicolumn{1}{c}{ Sequence } \\
\hline Trypsin & -Glycyl-aspartyl-seryl-glycyl- \\
Chymotrypsin & -Glycyl-aspartyl-seryl-glycyl- \\
Thrombin & -Glycyl-aspartyl-seryl-glycyl- \\
Elastase & -Glycyl-aspartyl-seryl-glycyl- \\
Liver aliesterase & -Glycyl-glntanyl-seryl-glycyl- \\
Pseudocholinesterase & -Glycyl-glutanyl-seryl-glycyl- \\
Bacterial proteinase & -Threonyl-seryl-methionyl-alanyl-
\end{tabular}

SOurces: Original data for the first six enzymes are cited in (4): the sequence for bacterial proteinase is given by Sanger and Shaw (5). 
Identification of the peptide containing the active seryl residue has been made by various groups, taking advantage of the basic observation of Jansen, Nutting, and Balls (6), showing that with inhibition by $\mathrm{P}^{32}$-labeled diisopropylphosphofluoridate (DFP), radioactive phosphorus became attached to an amino acid at the active site of ehymotrypsin. The occurrence of the same tetrapeptide sequence, glycyl-aspartyl-(or glutamyl) -seryl-glycyl- in the first six enzymes listed in Table 1 has given rise to the suggestion that such a secpuence plays an important role in the activation of the seryl hydroxyl group. That such a sequence is not essential, however. is shown by the recent work of Sanger and Shaw on a bacterial proteinase (5). The sequence they found (Table 1) hears no resemblance to that found in the other enzymes. Clearly more than one means is available for bringing about the participation of a seryl hydroxyl in a catalytic site of a lydrolytic enzyme. The occurrence of a similar sequence in the first group of enzymes may actually reflect some feature other than a basic catalytie requirement.

The probability that only certain regions of enzymes participate in the catalyses raises the question of whether considerable portions of the amino acid chain or chains might not be essential for catalysis, and, further, that much of the observed diversity of composition of enzymes catalyzing a particular reaction might reside in the apparently unessential portions of the protein. Our limited knowledge in this area allows no generalizations as yet. With two enzymes, papain and enolase, retention of activity after considerable degradation has been reported. Hill and Smith (7) renoved over one-half of the amino acid residues from papain of mol wt about 21,000 by the action of an aminopeptidase, with retention of full activity. Nylander and Malmström (8) similarly accomplished removal of about 150 amino acid residues of the yeast enolase molecule of mol wt about 66,000 from either the carboxyl terminus or from the amino terminus of the single peptide chain without activity loss. Some enzymes are much more sensitive to degradation, however. Thus bovine pancreatic ribonuclease of mol wt about 13,000 reversibly loses activity with removal of a 20 peptide unit from the anino terminus (9). In contrast to the results with papain and enolase, Drechsler, Boyer, and Kowalsky (10) reported a rather striking loss in catalytic activity and change in specificity of a comparatively large enzyme, rabbit nuscle aldolase. of mol wt 147,000, with removal of only three COOH-terminal tyrongl residues.

The modifieation of aldolase aetivity accompanying remoral of 
tyrosines is accomplished by incubating the crystalline aldolase with carboxypeptidase. The results of a typical digestion are shown in Fig. 1. With release of the tyrosines there is a parallel loss of activity, giving rise to a new species which has about 5 per cent of the original activity toward fructose 1,6-diphosphate as a substrate. This change in the aldolase molecule is not accompanied by any discernible change in its size or physical properties. Aldolase, which catalyzes the cleavage

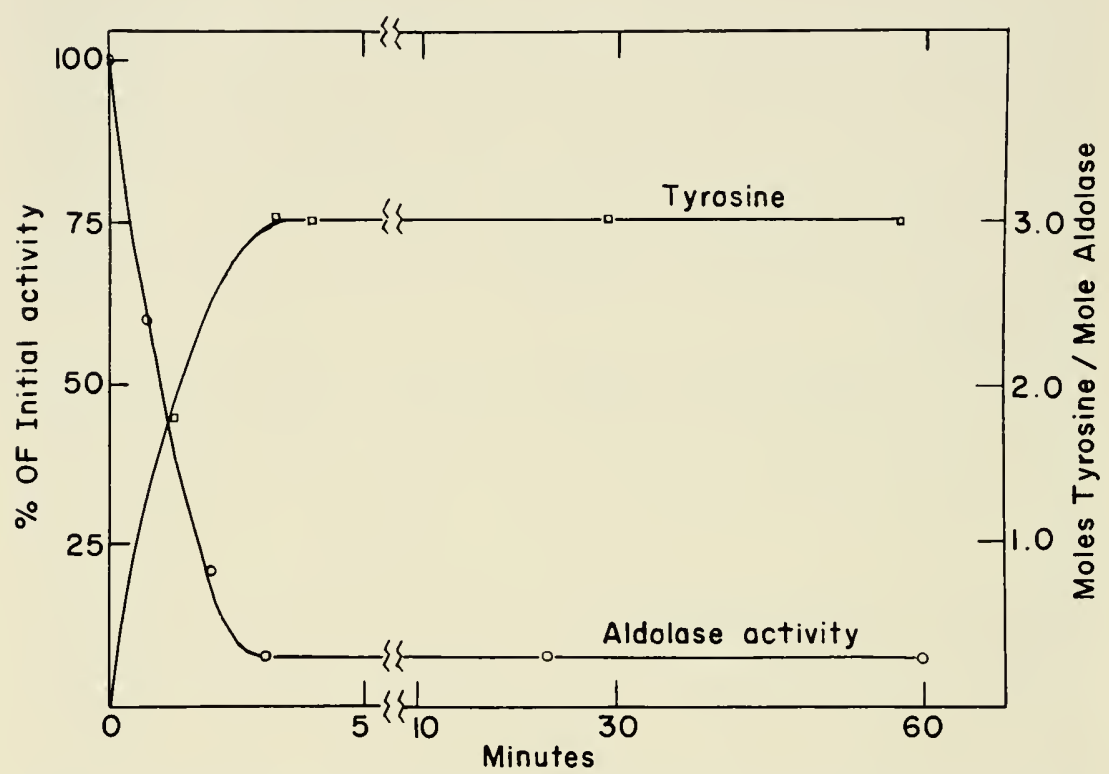

FIG. 1. Tyrosine release and activity loss accompanying carboxypeptidase digestion of rabbit muscle aldolase $(10)$.

of fructose 1,6-diphosphate to 2 triose phosphates, will also catalyze cleavage of fructose l-phosphate to glyceraldehyde and dihydroxyacetonephosphate. Surprisingly, the original weak catalytic activity toward fructose 1-phosphate is actually slightly increased after removal of the tyrosines. These and other aspects of aldolase action are of keen interest, but take us away from the main thread of our topic. A principal reason for giving the findings on aldolase degradation in this lecture is that they have served as the basis for some interesting comparative studies of aldolase by $\mathbb{W}$. J. Rutter at the University of Illinois. 


\section{Some comparisons of mustrle. lierer. and youst aldolases:}

The experiments on carboxypeptidase degradation of aldolace have. as indieated above. led to the recomnition that mucle and liver aldolase may have considerable structural and eatalytic features in common. Some of the characteristies of these two enzymes are summarized in Table 2. The two enzymes are similar in molecular size. number of - SH groups per mole. and ultraviolet absorption spectrum. Carboxypeptidase removes only one tyrosyl residue from liver aldolase, in contrast to the three COOH-teminal residues removed from muscle aldolase. The liver aldolase, before carboxypeptidase digestion,

Table 2. Comparative properties of muscle and lirer aldolases

\begin{tabular}{|c|c|c|}
\hline Property & Muscle & Liver \\
\hline Molecular weight & 150.000 & 159.000 \\
\hline -SH per mole & 28 & 29 \\
\hline $\begin{array}{l}\text { Tyrosines removed by } \\
\text { carboxypeptidase }\end{array}$ & 3 & 1 \\
\hline Activity $\frac{\text { fructose-di-P }}{\text { fructose-l-P }}$ & $\begin{array}{c}100 / 2.1 \quad \text { (Native) } \\
62.5 \quad(-3 \text { tyrosines) }\end{array}$ & $\begin{array}{c}10043 \text { (Native) } \\
40 ?(-1 \text { tyrosine })\end{array}$ \\
\hline Ultraviolet spectra & \multicolumn{2}{|c|}{ Enzymes have similar spectra } \\
\hline
\end{tabular}

SOURCES: Refs. 10. 11.

has a catalytic action on fructose 1.6-diphosphate and fruetose 1-diphosphate rather similar to that shown by muscle aldolase after carboxypeptidase digestion. Thus the prineipal differences in catalytic behavior between the two enzymes may rest in the presence of the two additional $\mathrm{COOH}$-terminal tyrosines in the muscle aldolase. In ardition to their indication of more structural relation between liver and musele aldolase than previonsly recognizerl, these studies are of interest in that they illustrate well the importance of mall differences in fine structure of a protein to its hiological activity.

In contrast to the similarity of liver and musele aldolase, yeast aldolase differs markedly from musele aldolase. Some characteristies of the yeast and muscle enzymes are summarized in Tal,le 3 . The netal requirements of the yeast enzyme and the inhibition by ehelating agents, not shown by the musele enzyme. are striking. In addition. the marked difference in the number and beharior of - SH groups. as well 
as other differences between the two enzymes, suggests that the enzymes have some important differences in the mechanism of their catalytic reactions. The situation is reminiscent of the familiar hiological truism about diversity, namely, "there is more than one way to skin a cat."

A number of other yeast enzymes have not been found to have the marked differences from their mammalian counterparts shown by the aldolases. Thus both liver and yeast alcohol dehydrogenases contain $\mathrm{Zn}$ as an essential component (14), and yeast and muscle glyceralde-

Table 3. Some characteristics of yeast and muscle aldolases

\begin{tabular}{ccc}
\hline \multicolumn{1}{c}{ Characteristic } & Yeast & Muscle \\
\hline $\begin{array}{l}\text { Metal requirement } \\
\text { Effect of chelating } \\
\text { agents }\end{array}$ & $\mathrm{Zn}^{++}, \mathrm{K}^{+}$ & None \\
- SH groups/mole & Inhibit & No effect \\
$\begin{array}{l}\text { Substrate effect on } \\
\text { p-mercuribenzoate } \\
\text { inhibition }\end{array}$ & $2-3$ & $27-28$ \\
\hline
\end{tabular}

SOURCEs: Refs. 11, 12, 13.

hyde-3-phosphate dehydrogenases appear to have an essential -SH group or groups at the catalytic site (15). A difference between yeast and mammalian lactate dehydrogenases deserves mention however, if only for its social implications. The yeast enzyme uses a flavin-containing cofactor, in contrast to the reaction of the mammalian enzyme, which uses diphosphopyridine nucleotide. Were it not for this difference, lactic acid and not ethyl alcohol would be expected as a principal metabolic product of yeast.

\section{Amino acid analog incorporation and activity}

An additional aspect of variation in composition as related to enzyme function comes from studies on the specificity of protein synthesis. Results and implications of recent researches are ably discussed in a review by Vanghan and Steinberg (16); studies of amino acid analog incorporation appear to be of particular pertinence. Various investigators working with bacterial systems have demonstrated that amino acid analogs may be incorporated into tissuc proteins in place of naturally occurring amino acids. Recently in our 
lahoratory Westhead has demonstrated sueh incorporation in a living animal, namely, that rabbits fed $p$-fluorophenylalanine show exten-ive incorporation of this amino acid analog into tissue proteins. There are clear indications, particularly with bacterial systems, that synthesis of proteins which are biologically inactive may be onc carse of the toxicity of the amino acid analogs. A few highly purified enzymes containing analogs have been isolated and their properties compared to their normal counterparts. Crystalline Bacillus subtilis $\alpha$-amylase containing considerable ethionine in place of methionine retains full activity (17), but replacement of around one-sixth of the phenylalanine residues by $p$-fluorophenylalanine results in 30 per cent loss of activity (18). Similarly, p-fluorophenylalanine incorporation into penicillinase gives extensive loss of activity (19). In contrast. Westhead (20) found that rablit aldolase with replacement of about one-fourth of the phenylalanine residues with $p$-fluorophenylalanine was indistingnishable from the normalenzyme in physical, chromatographic, and eatalytic properties. Variable effects of analog incorporation conld logieally reflect the importance of the resirlues being replaced to the catalytic site or essential structure of a given enzyme. The occurrence of such variability is of interest because it suggests that even selectivity for normal amino acids may be subject to error, and enzyme microheterogeneity might logically occur without primary genetic variation.

\section{The generality of cofactor function}

The similarity of the actions of vitamin-containing cofactors is quite well documented and inderstood. Also the role of divalent cations as an activator is well recognized. For example, every enzyme systcm reacting with ATP has been found to require a divalent cation, usually $\mathrm{Mg}^{++}$, for maximal activity. Some years ago. during a brief stay at the Marine Biological Laboratory at Woods Hole, I had occasion to study whether a less well understood cofactor requirement. namely, that of the monovalent cation $\mathrm{K}^{+}$, also appeared to be a general requirement for one enzyme from a variety of sources (21). The enzyme studied was pyruvate kinase, catalyzing the transfer of a phosphoryl group from phosphoenolpyruvate to ADP. The results obtained are summarized in Table 4 and show that. in all tissues and species tested, activation loy $\mathrm{K}^{+}$was demonstrable even withont dialysis of the tissue extract. With a freshwwater species, Anadonta, which has a characteristically low intracellular salt content, only a weak activation was demonstrable, however, without dialysis. Thus 
even in this species, $\mathrm{K}^{+}$appears to be required for pyruvate kinase activity hut in a considerably lower concentration than for the other tissues.

In aldition to the requirement of $\mathrm{K}^{+}$for pyruvate kinase from sources listed in Table $4, \mathrm{~K}+$ has also been shown to activate pyruvate

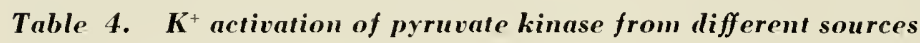

\begin{tabular}{|c|c|c|c|c|c|}
\hline \multirow{2}{*}{ Tissue used } & \multicolumn{2}{|c|}{ Activity * } & \multirow{2}{*}{ Muscle source } & \multicolumn{2}{|c|}{ Activity * } \\
\hline & $\overline{\mathrm{No} \mathrm{K}^{+}}$ & $\overline{+\mathrm{K}^{+}}$ & & $\overline{\mathrm{No} \mathrm{K}^{+}}$ & $+\mathrm{K}^{+}$ \\
\hline \multicolumn{6}{|l|}{ Rabbit } \\
\hline Heart & 15 & 100 & Skate & 5 & 45 \\
\hline Liver & 4 & 18 & & & \\
\hline Kidney & 1 & 6 & Fundulus & 2 & 65 \\
\hline Uterus & 3 & 18 & & & \\
\hline Brain & 14 & 70 & Limulus & 41 & 390 \\
\hline Dogfish & & & Pecten & 8 & 39 \\
\hline Body muscle & 8 & 230 & & & \\
\hline Stomach muscle & 6 & 25 & Thyone & 0.6 & 6 \\
\hline Brain & 7 & 110 & Phascolosoma & 0.1 & 2 \\
\hline \multirow[t]{2}{*}{ Tetrahymena } & 23 & 39 & Torpedo & 0.4 & 4 \\
\hline & & & Anadonta $\dagger$ & 26 & 39 \\
\hline
\end{tabular}

* $\mu$ moles pyruvate formed per $100 \mathrm{mg}$ tissue per 10 minutes.

$\uparrow$ Dialyzed.

SOURCE: Ref. 21.

kinase from yeast $(22)$ and from plants $(23)$. The $\mathrm{K}^{+}$activation thus appears to be a rather general phenomenon, suggesting cither an irreplaceable role for $\mathrm{K}^{+}$in the reaction mechanism or a close phylogenetic relationship of the various organisms.

\section{Mechanistic melarions of enzymess caralyzing similar reactions:}

Enzymologists have quite logically hased much of their work on the probahility that enzymes catalyzing similar reactions do so by similar mechanisms. Various examples could be cited; a particularly good one comes from the dehydrogenases linked to the cofactor, diphosphopyridine nucleotide. In all instances studied, the reduction of the cofactor occurs with a direct transfer of a hydrogen, probably as a hydride ion, from the substrate to the cofactor (24). Another 
example comes from the kinases which catalyze transfer of the terminal phosplioryl group of ATP to various acceptors. Studies in our laboratory (see ref. 4) and that of Mildred Cohn (25) have shown that in various kinase reactions, the catalysis occurs with a cleavage of the bond between the phosphorus atom of the group transferred and the oxygen atom linking the phosphory group to the rest of the rlonor molecule, and that the phosphoryl group is transferred without interehange of its oxygens with oxyens from water or substrates. Recently we have probed further the details of the pyruvate kinase and hexokinase reactions by study of the reaction kinetics and substrate binding (26). These and earlier studies have led to a concept of the catalysis as depicted in Fig. 2 for pyruvate kinase. The pattern given in this

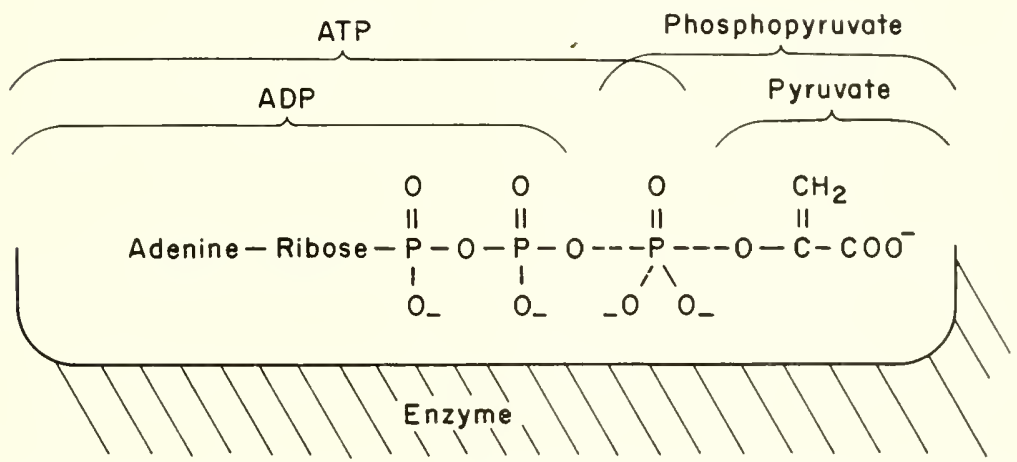

FIG. 2. A schematic illustration of substrate binding and a transition state for pyruvate kinase.

figure likely holds for other kinases as well. Simple hut important aspects are that ATP and ADP share a common binling site and pyruvate and phosphopyruvate another binding site. but that both ATP and phosphoenolpyruvate cannot be bound to the enzyme at the same time because of a common position at the active site for their transferable phosphoryl group.

An important feature of the catalysis by kinases. as indicated for pyruvate kinase in Fig. 2, is the transer of the phosphoryl group directly from the donor to the aceeptor; without formation of any phosphoryl enzyme intermediate. This is in contrast to the intramolecular phosphoryl transfer catalyzed by phosphoglunomulase. in which there is goorl evidence for a phosphoryl enzyme intermediate (27). Also. speculation has become common that many enzync re- 
actions involve function of discrete, covalently bound intermediates in their catalyses. Such is not the case with the kinases. Of the various experimental results pointing to the absence of a phosphoryl enzyme intermediate in the kinase reactions, results of one recent approach (28) may be of interest because they allow definitive conclusions and because they illustrate a simplicity of experimental design based on the use of comparatively large amounts of a given enzyme. The findings of such an experiment with pyruvate kinase are given in

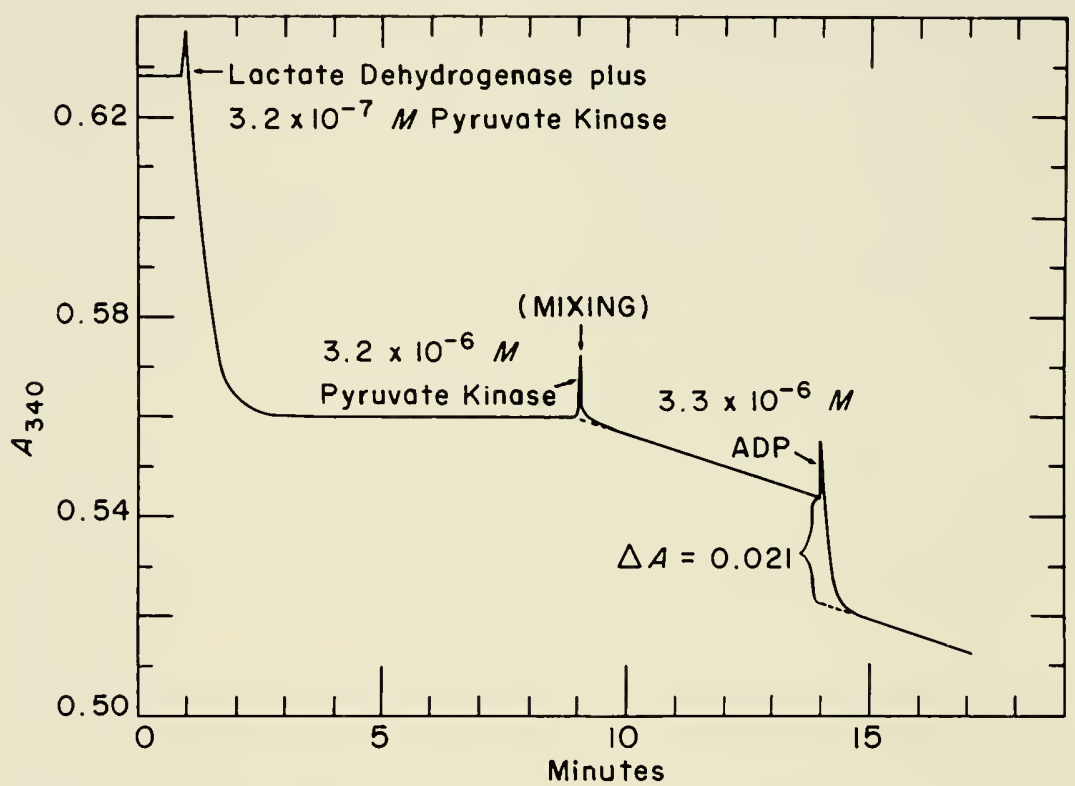

FIG. 3. Demonstration of lack of phosphoryl enzyme formation by pyruvate kinase.

Fig. 3. The system used is actually a sensitive test for formation of ADP. The initial reaction mixture contains phosphoenolypyruvate, ATP, and reduced diphosphopyridine nucleotide, together with small traces of ADP and pyruvate. Upon addition of catalytic amounts of pyruvate kinase and lactate dehydiogenase, practically all the ADP present is phosphorylated to give ATP through the pyruvate kinase reaction, with maintenance of a high $\mathrm{ATP} / \mathrm{ADP}$ ratio. The pyruvate formed from phosphoenolpyruvate oxidizes some DPNH, with a resultant slight decrease in absorbancy at 340 millimicrons. The absorbancy as measured on a sensitive recording spectrophotometer 
soon hecomes stable; the amounts of pyruvate kinase and lactate dehydrogenase present are sufficient to catalyze rapirl attainment of equilibrimm. At this stage a eomparatively large amount of pyruvate kinase is added. If any appreciable phosphoryl enzyme is formed from reaction of the enzyme with $\mathrm{ATP}$, the resultant $\mathrm{ADP}$ formation would give an immediate drop in absorbancy at $340 \mathrm{~m} \mu$; none such is de. tected. The continued slow decline represents a side reaction catalyzed by the very large excess of pyruvate kinase (26). The sensitivity of the system to ADP is indicated by the subsequent addition of an amount of ADP equivalent to about one-half of the concentration of active sites of the large amount of pyruvate kinase added. The results demonstrate clearly the lack of formation of phosphoryl enzyme even in the presence of all reactants and under conditions favorable to rapid net reaction.

(1)

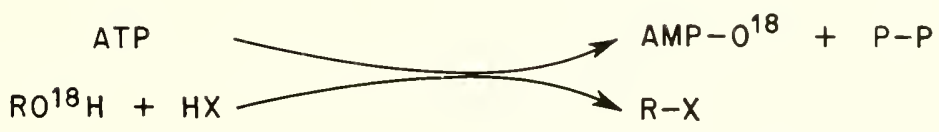

(2)

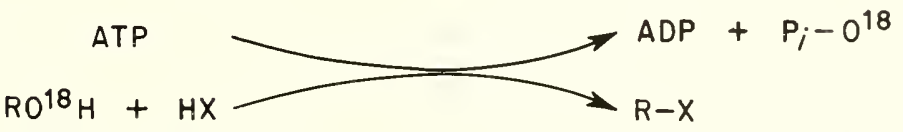

FIG. 4. The two general patterns for syntheses coupled to ATP cleavage.

The lack of phosphoryl enzyme formation as shown by Figr. 3 could result from the existence of the pyruvate kinase as a stable phosphoryl enzyme. If any such phosphoryl group participated in the catalysis. it would be rapidly replaced hy the phosphoryl group from ATP. This possibility is readily checked by the use of radioactive P32-labeled ATP. Such experiments rule out the formation of a stable phosphory? enzyme as a catalic intermerliate (28).

Other phosphorylation enzymes which have been of interest are those which eatalyze syntheses coupled to cleavage of ATP. The two patterns of ATP cleavage which have been found with this group of enzymes are indicated schematically in Fig. 4. Examples of this important type of reaction are the synthesis of aeyl coenzyme $A$ derivatives from fatty acids and coenzyme A. of glutamine from whitamate and ammonia, and of glutathione from its component amino acids. Studies with the stable isotope $O^{1 s}$ have shown that in such synthenes substrates and not water furnish the oxygen necessary for ATP 
cleavage, and that of the four possible modes of ATP cleavage leading to release of one or both of the terminal phosphoryl groups of ATP, only the two indicated in Fig. 4 occur $(4,25)$. Such results give further evidence of the mechanistic similarity of various enzymes catalyzing similar reactions.

One other aspect of the mechanism of enzymes catalyzing similar reactions deserving brief mention pertains to enzyme specificity. An unsettled question is whether enzymes catalyzing a similar reaction, but with marked differences in the degree of specificity, do so by a similar mechanism. Phosphatases are known, for example, with a high degree of specificity, such as a phosphatase which will remove the phosphoryl residuc only from the $5^{\prime}$ position of nucleotides. Other phosphatases are known with considerably wider specificity, ranging to the extracellular phosphatase from Escherichia coli, which Heppel (29) has found to have a remarkable ability to hydrolyze a wide variety of phosphate esters. Aside from their interest as examples of the variability of enzyme specificity, such findings need study and explanation on a mechanistic level.

\section{Possible generalidies for enzyme mechanisms}

Thus far students of enzyme mechanism have not uneovered any properties of the protein molecule which serve as a general basis for enzyme catalysis, and beyond the implications inherent in the participation of a beautifully spccific combination of enzyme and substrate, one rapidly enters an area of spcculation. With regard to thermodynamic considerations, perhaps the most important finding is that all enzymes appear to lower the energy of activation for the reaction. Some kinetic findings of possible importance to enzyme mechanisms in general have arisen from our studies of syntheses compled to ATP cleavage, and I would like to present some aspects of these researches.

In probing at the mechanism of glutamine synthetase, catalyzing

$$
\mathrm{ATP}+\text { glutamate }+\mathrm{NH}_{3} \rightleftharpoons \mathrm{ADP}+\text { glutamine }+\mathrm{P}_{i}
$$

the above reaction, studies of the rlynamic reaction rate at equilibrium were undertaken, that is, the rate of interconversion of reactants to products when no net reaction is occurring. Such rates are measurable by adding traces of isotopically labeled sulistrates to the reaction mixture at dynamic equilibrium. Somewhat to our surprise, we found marked inequalities in the isotopic exchange rates at equilibrium. Thus, with variations in equilibrimm conditions, the rate of inter- 
change of inorganic phosphate with ATP would he marle to be aloout equal, greater than, or less than the rate of interchange of glutanate with glutamine 130$)$. This led to some theoretical considerations of the factors governing reaction rates at equilibrimm. Some clear and useful concepts have emerged (31). With regard to the rhlutanine synthetase reaction, as depicted in Figr. 5. an explanation for the inequalities of exchange rates is forthcoming if the slow steps in the overall catalysis are not those in which covalent bonds are formed or broken. but those of release of substrates from the enzyme. Inequalities of exchange rates near equilibrium liave been demonstrated for the aldolase reaction as well (32). and studies with this and with dehydrogenase reactions are in progress at Minnesota. The experi-

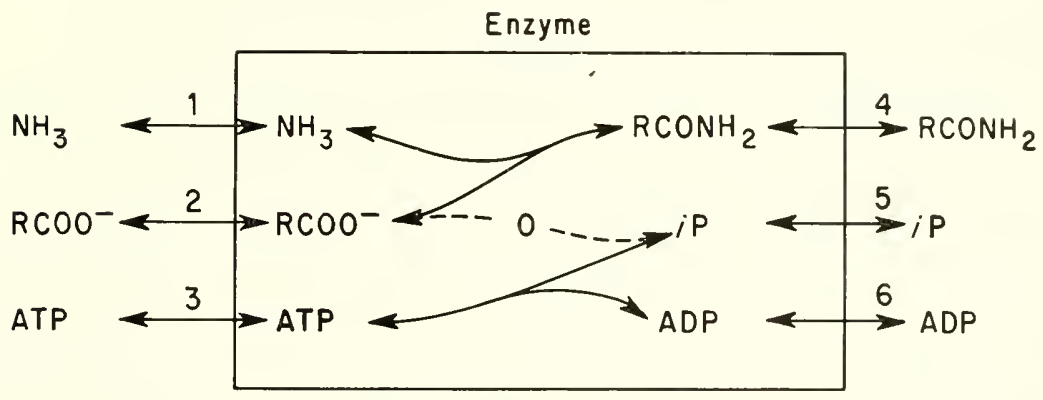

FIG. 5. A scheme for the glutamate synthetase reartion showing substrate binding and release steps.

mental results indicate that the taeit assumption frequently mate. that the slow steps in enzymic catalyses are those in which the covalent bonds are broken and formed, is open to serious question.

Recognition that there may be a considerable energy harier hetween the free and bound forms of substrates, taken lowetler with the remarkable specificity of enzymic catalyses. sugests that the important structural and electronic cluanges necessary for catalysis accompany the binding, and that reaction of the bound substrates occurs readily with little further clange in their position and properties. Sucl considerations lend support to the coneept of the synthetase and other enzymic reactions as concerted reactions (1.33). and actually give a simpler picture of the catalyis. Thi- maly lo illutrated with a typical synthetase reaction, the acctate thiokinase reaction, which also shows inequalities of sub-trate expluneres at equilibrium (30). In line with the above discussion. the arestate 
SCHEMATIC FORMATION OF ACETYL-COA WITHOUT ACETYL-AMP AS AN INTERMEDIATE

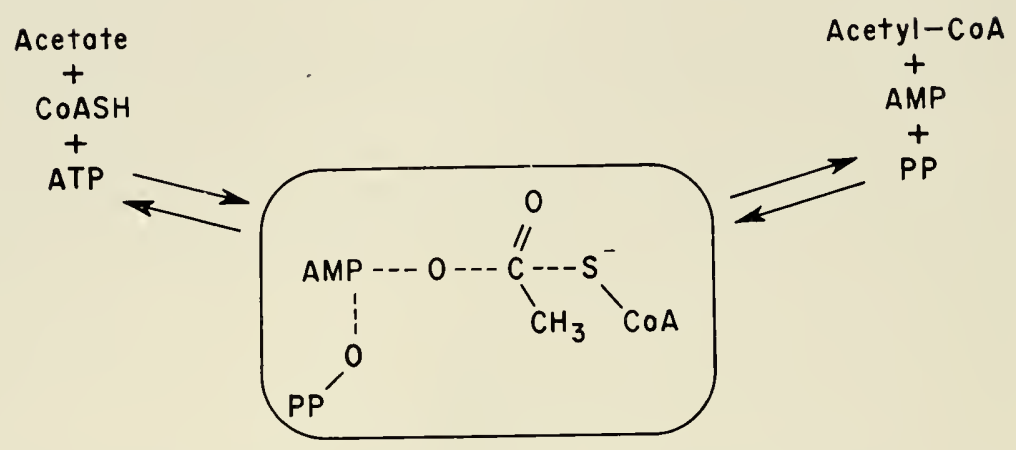

(Involves only one key transition state, without shift in reactant binding for catalysis)

FIG. 6. A scheme for the acetate thiokinase reaction with one key transition state.

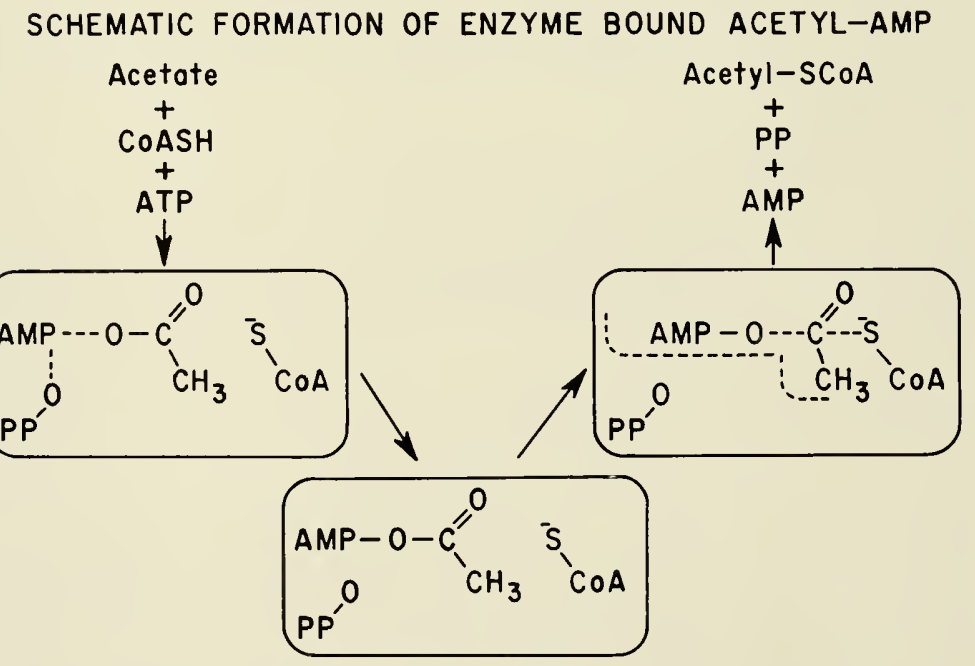

(Involves two key tronsition states with shift of position of bound reoctonts)

FIG. 7. A scheme for the acetate thiokinase reaction with two key transition states. 
thiokinase reaction can lie visualized as oceurring with participation of one key transition state, as depicted in Figr. 6. The reactants are bound in an activated form, and as the acetate carboxyl oxyen approaches the $\mathrm{P}$ atom of the ATP, the $\mathrm{S}$ of coenzyme $\mathrm{A}$ approaches the acetate carboxyl carbon, with the formation of the products in one concerted reaction. This is in contrast to the reaction as usually depicted with acetyl adenylate as a discrete intermediate (sce ref. 34). Participation of sueh an intermediate would appear to necessitate rather complicating shifts of the reactants during catalysis. An attempt to depiet this difficulty is given in Fig. 7. For discrete formation of acetyl adenylate, the $S$ atom of the bound and activated coenzyme A molecule must somehow be held away from the acetate carboxyl carbon, which would become increasingly susceptible to reaction as its oxygen departed for eleavage of the ATP. Then after acetyl adenylate had formed, a shift would need to oceur, to allow the coenzyme $A$ and acetyl adenylate to react.

The manner by which the synthetases and much simpler enzyme systems react is obviously far from settled. The recognition of substrate release as potential slow steps in the catalyses. together with other information, warrants the hypothesis that enzyme reactions in general may proceed through binding of reactants favoring reaction through one key transition state (4).

\section{A similurity of oxidutive phosphorylution and muscle contruction}

For a number of years our group has been interested in the basic problem of how oxidative enzymic reactions are coupled to formation of ATP, usually referred to as oxidative phosphorylation. Not being content with having one seemingly insoluble problem on our hands, we recently undertook some experiments related to muscle contraction. The divergence is not as wide as it might seem, and one principal reason for our interest in ATP eleavage by myosin and actomyosin was the finding by Levy and Koshland (35) that an unexplained oxygen exchange reaction accompanied the cleavage.

Several years ago in studies on oxidative phosphorylation by nitochondria, the discovery was made that the process was characterized by a rapid exchange of inorganie phosphate with ATP as well as a much more rapid exchange of phosphate oxygens with water. Typical results are given in Table 5. Such rapid exchange of phosphate oxygens is unusual, and one possible explanation may be the rapid formation and hydrolytic eleavage of a phosphorylated intermediate. 
Recent studies by Dempsey and Boyer (37) have shown that in the presence of ATP, myosin and actonyosin catalyze an exchange of oxygens of inorganic phosphate with those of water. One experimental result which led to these findings is depicted in Fig. 8. This figure

Table 5. Exchange reactions catalyzed by mitochondria capable of oxidative phosphorylation

(Overall: $\mathrm{ADP}+\mathrm{P}_{i} \underset{\text { oxidation }}{\stackrel{\text { substrate }}{\longrightarrow}} \mathrm{ATP}+\mathrm{HOH}$ )

\begin{tabular}{cc}
\hline $\mathrm{P}_{i}{ }^{32} \leftrightharpoons$ ATP exchange & $\mathrm{O}_{\mathrm{P}_{i}}{ }^{18} \leftrightharpoons \mathrm{HOH}$ exchange \\
\hline $13 \mu$ moles & $280 \mu$ moles \\
\hline
\end{tabular}

Mitochondria with $\mathrm{ATP}, \mathrm{P}_{i}, \mathrm{Mg}^{++}, \mathrm{K}^{+}$, at $23^{\circ}, 15$ minutes. No substrate and no oxygen uptake.

SOURCE : Ref. 36.

shows the time course of appearance of $\mathrm{O}^{18}$ from water into phosphate cleaved from ATP by actonyosin. The phosphate appearing in the initial part of the reaction contains only the one water oxygen expected from the hydrolytic reaction. With continued incubation, more than one water oxygen is found in the phosphate, suggesting a concentration dependent on exchange of phosphate oxygens of the medium with water oxygens. The experiments reported in Table 6 provide a con-

Table 6. P ${ }_{i}$ oxygen exchange during hydrolysis of ATP

\begin{tabular}{|c|c|c|c|}
\hline \multicolumn{3}{|c|}{$\mathrm{O}^{18}$ atom, excess, $\%$} & \multirow[b]{2}{*}{$\begin{array}{c}\mathrm{mM} \mathrm{\textrm {H } _ { 2 } \mathrm { O }} \\
\text { exchanged }\end{array}$} \\
\hline $\begin{array}{c}\mathrm{H}_{2} \mathrm{O} \text { of } \\
\text { medium }\end{array}$ & $\begin{array}{c}P_{i} \\
\text { added }\end{array}$ & $\begin{array}{c}P_{i} \\
\text { isolated }\end{array}$ & \\
\hline \multicolumn{4}{|c|}{ Actomyosin hydrolysis } \\
\hline 1.44 & 0.000 & 0.099 & 15.0 \\
\hline 0.00 & 1.005 & 0.817 & 15.0 \\
\hline \multicolumn{4}{|c|}{ Myosin hydrolysis } \\
\hline 1.44 & 0.000 & 0.090 & 14.0 \\
\hline 0.00 & 1.012 & 0.854 & 13.6 \\
\hline
\end{tabular}

SOURCE: Ref. 37 .

clusive demonstration that most, if not all, of the oxygen excluange accompanying ATP cleavage results from exchange of phosphate oxygens of the medium. In these studies, the exchange was measured both by incorporation of oxygen from $\mathrm{H}_{2} \mathrm{O}^{18}$ into phospluate as well 
as from the loss of $\mathrm{O}^{18}$ from $\mathrm{P}_{i}-\mathrm{O}^{18}$ to water. The results show that, within experimental error, the extent of exchange measured by the two approaches is equal and that therefore the species undergoing exchange is the inorganic phosphate of the medium. As with oxidative phosphorylation, such results suggest the reversible formation and hydrolysis of a phosphoryl derivative. The following points of com-

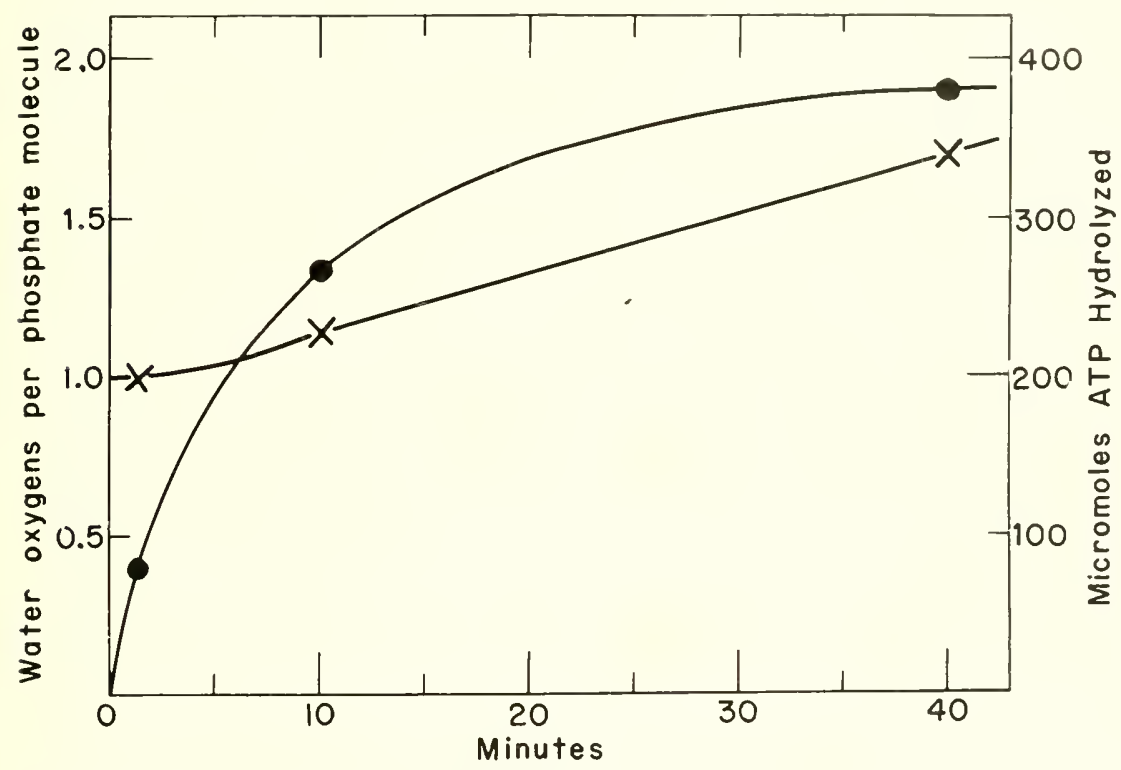

FIG. 8. The time course of appearance of $\mathrm{O}^{18}$ from $\mathrm{H}_{2} \mathrm{O}^{18}$ into phosphate cleaved from ATP by actomyosin (37).

parison of oxidative phosphorylation and of ATP cleavage by actomyosin and myosin emerge:

An unexplained exchange of inorganic phosphate oxygens with water oxygens oceurs, in both processes, possibly reflecting reversible phosphorylation.

Protein structure changes may accompany both processes. Possibility of structure change accoupanying electron transport is elearly indieated by the difference in structure of oxidized and reduced cytochrome $c$ as indicated by the difference in proteolytic digestibility (38) and as demonstrated by nuclear nagnetic resonance studies of Kowalsky (39) in onr laboratory. 
In one instance, ATP cleavage may induce structural change; in the other, structural change may induce ATP formation.

Past cxpcrience suggests that further work will likely show the last speculation to be invalid, but the possibility that such apparently diverse processes as oxidative phosphorylation and muscle contraction may have an important. common mechanistic feature is indeed an intriguing one.

\section{Genetic control of and induced change in the wature of enzymes}

A lecture under the heading of the nature and diversity of catalytic proteins would not be complete without some consideration of the factors governing the formation of enzymes. Two exciting areas of research are on the genctic control of the fine structure of enzymes and on the nature of enzymic changes which lead to resistance to antibiotics and anticancer agents.

As an example of genetic control of the fine structure of an enzyme, the excellent researches of Hotchkiss and Evans (40) may be cited. Concepts which have arisen from their work on the genetic modification of a pneumococcal enzyme involved in folic acid synthesis from $p$-aminobenzoic acid, are shown schematically in Fig. 9. Most of the studies of gene-cnzyme relationships have concerned all-or-none effects-either a particular enzyme is present or is absent in a given genetic strain. Hotchkiss and Evans have obtained strong genetic evidence that the difference in relative affinities for various analogs of $p$-aminobenzoate noted in their studies results from the variations in the fine structure of a single enzyme. They suggest, as noted in Fig. 9, that DNA controls not only the presence of the enzyme, but that variation in the fine structure of the DNA can result in variation in the enzyme as reflected by the change in inhibitory effects of chemical modifications of $p$-aminobenzoate. As noted by these observers, there will remain some doubt about the interpretation until purification of the enzymes involved can be achieved, but the way seems clear and the authors appropriately state, "It would be a challenging prospect to learn about the linear sequence of amino acids in a series of protcins which have such intercsting and characteristic properties in their native folded forms."

Problcms of keen fundamental as well as practical importance arise from consideration of the factors responsible for the develop- 
ment of resistance to antibiotics and to anticancer agents. Three means of development of resistance appear probable, as follows:

1. Gradual or sudden changes in key properties of an enzyme or enzyme system.

2. Changes in enzyme concentrations leading to altered routes of utilization of former lethal syntheses.

3. Exclusion of the agents from sensitive sites lyy perneability. binding, or other changes.

Comparative studies on highly purified enzymes from normal and resistant tumor cells or bacterial cells liave been extremly limited.

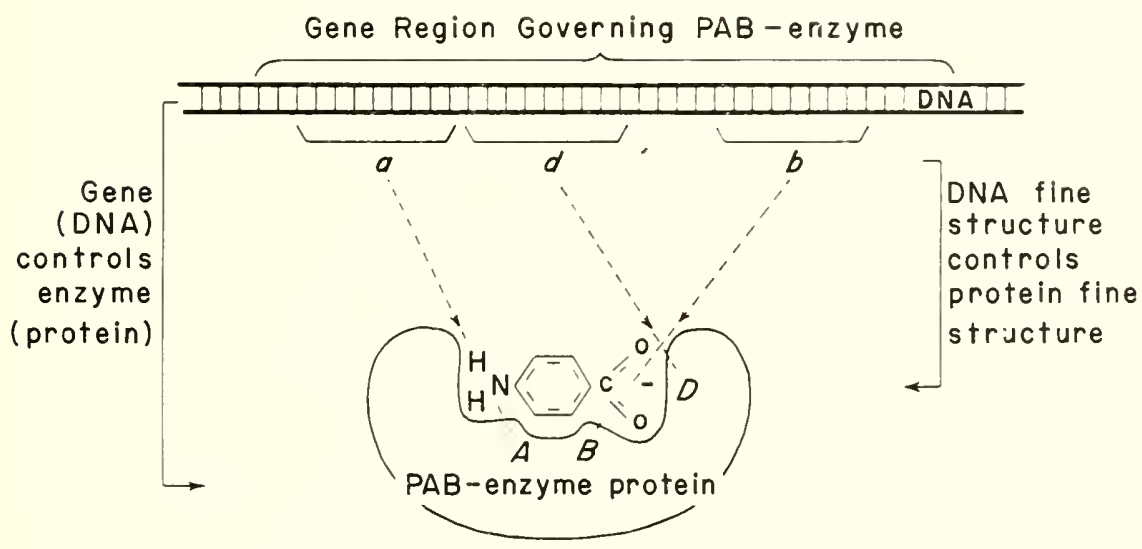

FIG. 9. Genetic control of fine structure of enzyme system using $p$-aminobenzoate (40).

In an important paper some years ago, Kulyowitz and Ott (41) found purified lactate dehydrogenase from normal musele and from the Jensen sareoma arising from musele to be closely similar if not identical in catalytic and immunologic properties. With further study of the biochemistry of eancer, an appreciation has developed that eancer cells, like bacterial cells, show a remarkable and dearly aloility to adapt to their cnvironment. Recent reviews. such as that of Anderson and Law (42), may be consulted for a summary of various findings. The data point unmistakably to the conchusion that resistance ean arise from change in the properties of certain enzymes, although in no instance to our knowledge has proof of such a cluange been documented with a purified enzyme. Some examples where a change in propertics of key enzymes is strongly indicatod inchule the 
resistance of Enterococcus stei to sulfonamide (43), and of Escherichia coli to Aureomycin (44). In the latter case, clectron-transport enzymes in cell-free extracts from resistant cells but not from nonresistant cells were demonstrated to be insensitive to added Aureomycin. Resistance of Erlich ascites cells to mercaptopurine and azaguanine has been associated with the loss of enzymes for conversion of these anticancer agents to their ribotides. $(45,46)$. However, even the decreased ability for ribotide synthesis from the anticancer agents may not be the only basis for resistance. Heidelberger et al. (47) have found that although the rate of conversion of fluorouracil to fluorodeoxyuridylate is decreased, the actual amount of fluorodeoxyuridylate prescnt is about the same in the resistant and normal cells, and the resistance was attributed to a decreased ability of the fluorodeoxyuridylate to inhibit the enzymes involved in thymidine synthesis. Increase in the amount of some enzymes may also be associated with resistance. For example, resistance to folic acid analogs in leukemia has been attributed to increased dihydrofolate reductase activity (48).

Differences in propertics of enzymes from a given microorganism or cellular strain may also be encountered in the well-known phenomenon of adaptative enzyme formation. In a valuable paper, Halvorson and his colleagues (49) have shown that a highly purified constitutive yeast $\beta$-glucosidase resembles very closely the induced enzyme present in a related species in physical properties and maximal reaction velocity, but that the inducible enzyme has an apparent Michaelis constant one-tenth that of the constitutive enzyme. The data suggest that the two enzymes differ in the fine structure near the catalytic site.

The present information about enzyme cliange in adaptation and development of resistance, although meager, is sufficient already to outline some fascinating but difficult problems ahead. As in many areas of research, the more important results and controlling factors may not be visualized at present or may be improperly conceived. Obtaining an understanding of the relations between structure change and the properties of a given cnzyme promises to be a challenging but rewarding task. The stepwise appearance of resistance in some cancer cclls suggests that there may be considerable randomness in the genetic control of finc structure of enzymes in all ccll populations, and thus that resistance might result from the continucd selection of the better adapted cells. On the practical sicle, one may even hope that our degrce of biochcmical crudition will increase to the point where we can, by planned development of resistance of a cancer cell to one agent, actually render it more susceptible to the action of another agent. 


\section{Conclusions:}

The audience is perhaps too well aware at this stage of the validity of a conment made at the beginning of this address, namely, that the topic under discussion is broad. Many other facets than these cited herein could be given for your consideration. In any event is is clear to the lecturer, and I hope to the audience. that the basis for the nature and diversity of eatalytic proteins is at best only partly understood. It must be emphasized that the oceurrence, properties, and meclianism of enzymes from widely different cells are more striking than the differences. In some instances, however, as with yeast and muscle aldolase, rather wide differences in mechanism do appear possible. With regard to enzyme meehanisms. continued search may reveal more basic and simplifying generalities underlying the behavior of enzymes. Some common mechanistic patierns already recognized have been discussed briefly, and possibilities of further generalizations have been mentioned. The problems sketchily outlined herein call for zealous application of man's ingennity. It is from the probing at and documenting of the diversitics of enzymes and their action that important generalizations about living processes will emerge.

\section{IReferencers}

1. C. L. Markert and F. Moller. Multiple forms of enzymes: tissue ontogenetie and species specific patterns. Proc. Nat. Acad. Sci. U.S., 45:753-765 (1959).

2. J. S. Nisselbaum and O. Bodansky, Reations of human tissue laetic dehydrogenases with antisera to human heart and liver lactic dehydrogenases. J. Biol. Chem., 236:401-404 (1961).

3. N. O. Kaplan. M. M. Ciotti. M. Hamolsky, and R. E. Bieber, Molerular heterogeneity and evolution of enzymes. Science, 131:392-397 (1960).

4. P. D. Boyer, Mechanism of enzyme artion. Ann. Rev. Biochem.. 29:15-14 (1960).

5. F. Sanger and D. C. Shaw, Amino-arid sequenee about the reactive serine of a proteolytic enzyme from Bacillus subtilis, Nature (London). 187:872-873 (1960).

6. E. F. Jansen, M. D. F. Nutting, and A. K. Balls, Mode of inhibition of elyymotrypsin by diisopropyl fluorophosphate. I. Introduction of phosphorus. J. Biol. Chem., 179:201-204 (1949).

7. R. L. Hill and E. L. Smith. IIydrolysis of merenripapain by leurine amino. peptidase without loss of enzymic activity. J. Biol. Chem.. 231:117-134 (1958).

8. O. Nylander and B. Malmströn. The degradation of yeast enolase with leucine aminopeptidase and earboxypeptidase without change in cnzymic artivity: N. and C-terminal residues of the enzyme, Biochim. et Biophys. Acta, 31:196-202 (1959).

9. F. M. Richards and P. J. Vithayathil, The preparation of -ubtilisin-modified 
ribonuclease and the separation of the peptide and protein components, J. Biol. Chem., 234 : 1459-1465 (1959).

10. E. R. Drechsler, P. D. Boyer, and A. G. Kowalsky, The catalytic activity of carboxypeptidase-dlegraded aldolase, J. Biol. Chem., 234:2627-2634 (1959).

11. O. C. Richards and W. J. Rutter, Studies on the properties and mechanism of action of various aldolases, Federation Proc., 19:86 (1960). W. J. Rutter, private communication.

12. R. J. Peansky and H. A. Lardy, Bovine liver aldolase. I. Isolation, crystallization, and some general properties, J. Biol. Chem., $233: 365-370$ (1958).

13. R. J. Peansky and H. A. Lardy, Bovine liver aldolase. II. Physical and chemical measurements on the crystalline enzyme, J. Biol. Chem., 233:371-373 (1958).

14. B. L. Vallee, Metal and enzyme interactions: correlation of composition, functions and structures, in The Enzymes, ed. by Boyer, Lardy, and Myrbäck, vol. 3, Academic Press, Inc., New York (1960).

15. P. D. Boyer, Sulfhydryl and disulfide groups of enzymes, in The Enzymes, ed. by Boyer, Lardy, and Myrbäck, vol. 1, Academic Press, Inc., New York (1959).

16. M. Vaughan and D. Steinberg, The specificity of protein biosynthesis, in $A d$. vances in Protein Chemistry, vol. 14, Academic Press, Inc., New York (1959), p. 115.

17. A. Yoshida and M. Yamasaki, Studies on the mechanism of protein synthesis incorporation of ethionine into $\alpha$-amylase of Bacillus subtilis, Biochim. et Biophys. Acta, 34:158-165 (1959).

18. A. Yoshida, Studies on the mechanism of protein synthesis; incorporation of p-fluorophenylalanine into $\alpha$-amylase of Bacillus subtilis, Biochim. et Biophys. Acta, 41:98-103 (1960).

19. M. H. Richmond, Incorporation of $\mathrm{DL} \cdot \beta \cdot$ ( $p$-fluorophenyl) $\left[\beta \cdot{ }^{14} \mathrm{C}\right]$ alanine into exopenicillinase by Bacillus cereus 569/H, Biochem. J., 77:121-135 (1960).

20. E. W. Westhead and P. D. Boyer. The incorporation of $p$-fluorophenylalanine into some rabbit enzymes and other proteins. Biochim. Biophys. Acta, 54:145156 (1961).

21. P. D. Boyer, The activation by $\mathrm{K}^{+}$and occurrence of pyruvic phosphoferase in different species, J. Cell. and Comp. Physiol., 42:71-78 (1953).

22. I. F. Seits, Role of potassium and ammonium ions in the transfer of phosphate from phosphopyruvic acid to the adenylic system, Biokhimiya, 14:134-140 (1949) ; Chemical Abstracts, 43:6281 (1949).

23. G. Miller and H. J. Evans, The influence of salts on pyruvate kinase from tissues of higher plants, Plant Physiol., $32: 346-354$ (1957).

24. B. Vennesland, Stereospecificity of hydrogen transfer in pyridine nucleotide dehydrogenase reactions, Federation Proc., 17:1150-1157 (1958).

25. M. Cohn, Mechanisms of enzymic cleavage of some organic phosphates, J. Cell. and Comp. Physiol., 54:17-32 (1959).

26. A. M. Reynard, L. F. Hass, D. D. Jacobson, and P. D. Boyer, The correlation of reaction kinetics and substrate binding with the mechanism of pyruvate kinase, J. Biol. Chem., $236: 2277-2283$ (1961).

27. J. B. Sidbury, Jr. and V. A. Najjar, Further studies on the mechanism of phosphoglucomutase; the phosphoenzyme bond, J. Biol. Chem., 227:517-522 (1957).

28. L. F. Hass, P. D. Boyer, and A. M. Reynard, Studies on possible phosphoryl enzyme formation in catalysis by hexokinase, pyruvate kinase, and glucose 6phosphatase, J. Biol. Chem., 236:2284-2291 (1961). 
29. L. A. Heprel. D. R. Harkness, and R. J. Hibmoe. A Study of the substrate specificity and other properties of the alkaline phosphatase of Escherichin coli. J. Biol. Chem., 237:841-846 (1962).

30. P. D. Boyer, R. C. Mill.. and H. J. Fromm, Hypotheses for and some kinetic studies with ghtamine synthetase and acetate thiokinase, Arch. Biorhem. Biophys., $81: 249-263$ (1959).

31. P. D. Boyer. Uses and limitations of masurements of rates of isotopir exphange and incorporation in catalyzed reactions. Arch. Biochem. Biophys., 82:387-110 (1959).

32. I. A. Rose. The mechanism of action of aldolase and the asymmetric labeling of hexose. Proc. Nat. Acad. Sri. U.S., $44: 10-15$ (1958).

33. J. M. Buchanan and S. C. Hartman, Enzymic reactions in the synthesis of the purines, Advances in Enzymol.. $21: 199-261$ (1959).

34. P. Berg. Role of magnesium in aretyl coenzyme A formation by aretothiokinare. Science, 129:895-896 (1959).

35. H. M. Levy and D. E. Koshland. Jr. Mechanism of hydrolysis of adenosinetriphosphate by muscle proteins and it relation to muscular contraction. J. Biol. Chem., 234:1102-1107 (1959).

36. P. D. Boyer, W. W. Luchsinger, and A. B.,Falcone. $\mathrm{O}^{18}$ and $\mathrm{P}^{32}$ exrhange reac. tions of mitochondria in relation to oxidative phosphorylation. J. Biol. Chem.. 223:405-421 (1956).

37. M. E. Dempsey and P. D. Boyer, Catalysis of an inorganic phosphate-11. $\mathrm{O}^{18}$ exchange by actomyosin and myosin. J. Biol. Chem., 236:PC 6 (1961).

38. M. Nozaki. T. Yamanaka. T. Horio, and K. Okuniki, Cytorhrome c. 1. Purification procelures and proteinase digestion of bakers' yeast cytochrome c. J. Biochem. (Tokyo), 44:453-464 (1957).

39. A. Kowalsky, unpublished.

40. R. D. Hotchkiss and A. H. Evans. Fine structure of a genetically modified enzyme as revealed by relative affinities for modified substrate. Federntion Proc.. 19: 912-925 (1960).

41. F. Kubowitz and P. Ott, Isolierung und Kristallisation eines Gärung-fermentes aus Tumoren. Biochem. Z.. 314:94-117 (1943).

42. E. P. Anderson and L. W. Law. Biochemistry of rancer, Ann. Rev. Biochem.. 29:577-608 (1960).

43. A. Wacker, A. Trebst, and H. Simon, Über den stoffweehsel des Sulfanilamids. $\mathrm{S}^{35}$ bei empfindlichen und resistenten Bakterien, Z. Naturforsch.. 12b:315-319 (1957).

44. K. Saz and L. M. Martinez, Enzymatic basis of resistance to Anreomycin. II. Inhibition of electron transport in Escherichio coli by Aureomyin, J. Biol. Chem.. 233 :1020-1022 (1958).

45. P. Reichard, O. Skold, and G. Klein. Possible enzymic mechanim for the development of resistance against fluorouracil in ascites tumors, Nuture (London). 183:939-941 (1959).

46. R. W. Brockman. L. L. Bennett, Jr.. M. S. Simpson. A. R. Wilsoll. J. R. Thomson. and H. E. Skipper. A mechanism of resistance to 8-azaguanine 11. Stullie's with experimental neoplasms, Cancer Research, 19:856-869 (1959).

47. C. Heidelberger, G. Kaldor, K. 1. Mukherjee, and P. B. Dannebrg. Sudies on fluorinated pyrimidines. Xl. In vitro sudies on tumor resitance. Cancer Ro. search, 20:903-906 (1960). 
48. D. K. Misra, R. H. Stewart, M. Friedkin, A. Goldin, and E. J. Crawford, Increased dihydrofolate reductase activity as a possible basis of drug resistance in leukemia, Nature (London), 189:39-42 (1960).

49. A. S. L. Hu, R. Epstein, H. O. Halvorson, and R. M. Bock, Yeast $\beta$-glucosidase: comparison of the physical-chemical properties of purified constitutive and inducible enzyme, Arch. Biochem. Biophys., $91: 210-219$ (1960). 


\title{
The Origin of
}

\section{Specific Proteins}

\author{
Clement Lo Markert
}

Department of Biology

Johns Hopkins University, Baltimore, Maryland

We are all aware of the fact that every field of biology, including molecular biology, contributes in some degree to our appreciation of biological diversity. Underlying the obvious diversity of living organisms is a fundamental uniqueness in the molecular composition of each individual. This uniqueness is based upon characteristic proportions of small molecules and, even more important, upon the specific structures of numerous macromolecules that compose essential parts of the metabolic machinery. Of all these macromolecules, perhaps the widest range of diversity is found in the proteins. The only other class of molecules of nearly equal significance is the nucleic acids-the raw material of molecular genetics. But even the nucleic acids are, in a fundamental sense, recognized principally through the proteins which they control. Just as nucleic acids have occupied the attention of geneticists, so have the properties and activities of proteins bern at the focus of much of the research in biochemistry. The extraordinary advances in each of these two fields, genetics and hiochemistry, and the remarkably fruitful collaboration between then in the study of 
protein molecules have nearly obscured another area of biology that is larger than either of them and, in fact, encompasses both. This is the area best described as developmental biology. I speak today as a devotee and representative of this area. We developmental biologists share with geneticists an interest in gene function, but in addition we are concerned with the regulation of gene function during development. We, like the biochemists, are also concerned with the properties of protein enzymes since the characteristics of differentiating cells are basically a reflection of the enzymes they contain. But going beyond the biochemists, we developmental biologists must also investigate the mechanisms responsible for initiating, regulating, or stopping protein synthesis in accord with the requirements of the developing cell. Developmental biology, even that portion which focuses on specific proteins, is vast and complex, and productive research in this area has not yet matched the size of the problems. Nevertheless, progress has been made and $I$ shall attempt to synthesize and interpret a variety of data collected from diverse fields but all bearing on the problem of the origin or synthesis of specific proteins in an organism. Genetics and biochemistry will necessarily make the major contributions.

The prevailing viewpoint today is that the primary structure of a protein-the linear sequence of amino acids-reflects a corresponding sequence of nucleotides in desoxyribonucleic acid (DNA) and ribonucleic acid (RNA). A growing body of evidence supports this view; in any event since a general correspondence between genes and proteins is well established, no extensive review of this area would be justified now. However, it may be useful by way of introduction to call attention to the evidence relating genes to the protein hemoglobin in human beings. This is a well-known and often-reviewed subject hut provides a good foundation for my later remarks.

\section{Hemoglobin synthesis}

Hemoglobin is a complex molecule consisting of four polypeptide chains. In the normal adult, two identical $\alpha$ chains combine with a pair of identical $\beta$ chains to compose the finished molecule, which thus may be written $\alpha^{2} \beta^{2}$. Now the $\alpha$ and $\beta$ chains are each under separate gene control and mutant forms of each of these two genes have been discovered. Individuals with sickle-cell anemia, for example, possess a mutant form of the $\beta$ gene and synthesize an altered hemoglobin molecule in which valine has replaced glutamic acid at onc position in each of the two $\beta$ chains (for review see Conference on 
Hemoglobin, 1958). This is exactly what we have learned to expect from the genetic control of protein synthesis; it tells us only that primary protein strueture is related directly to gene structure-presumably to the linear sequenee of nucleotides that make up the DNA molecule. Since the synthesis of hemoglobin occurs in the ribosones of the eytoplasm (Schweet et al., 1958) rather than on the chromosomes in the nucleus, the eode for hemoglobin synthesis must have been transferred from the DNA to the ribosome, perhaps by a messenger RNA. Within the ribosome, protein synthesis is probably organized as a cooperative enterprise in which ribonucleic acid and protein both perform essential functions. Hemoglobin synthesis thus sets forth in broad outline the essential features, as we presently understand them, of the genetic control of specific protein synthesis.

Much more interesting and significant from the viewpoint of developmental biology is the fact that the hemoglobin of the fetus and newborn is different from that of the adult human. This fetal hemoglobin, like adult hemoglobin, is composed of four polypeptide chains, but the two $\beta$ chains of adult hemoglobin have been replaced by two identical $\gamma$ chains, which differ significantly in amino acid composition from the $\beta$ chains (Schroeder et al.. 1961). This difference in primary protein strueture implies that a different nonallelic gene is responsible for the synthesis of the $\gamma$ polypeptides. Genetie evidence confirms this implieation. A fundamental principle of development is thus elearly shown by this example, namely, that the synthesis of a speeific protein in the appropriately differentiated cells of a metazoan is dependent upon the activation of the corresponding gene and not simply upon the mere presence of the gene. During the first stages of embryonic development, before the differentiation of erythrocytes, none of the genes for hemoglobin synthesis appear to be active though they are surely present in the cells of the embryo. Then, as erythroeytes begin to develop, the $\alpha$ and $\gamma$ genes are activated and fetal hemoglobin is synthesized. Later the $\gamma$ gene is suppressed and the $\beta$ gene activated, although for a time both function together, producing mixtures of adult and fetal hemoglobin.

With this example of hemoglobin in mind, we may now state the thesis of this lecture. During embryonic development the cells of an organism undergo a progressive differentiation during which they acquire a eharacteristic repertory of proteins, largely enzymatic, which are the products of genic activity. The appearance of a new protein in a cell is an indication that the gene for that protein has been aetivated in that cell. By the same token the disappearance of a protein indieates that the corresponding gene has bcen inhibited. 
Thus cell differentiation becomes simply an expression of an antecedent pattern of gene activation or inhibition. The central problem of developmental biology then becomes the problem of the control of gene function.

Some investigators would state the problem differently; they favor the alternative hypothesis that pictures all the genes as functioning continuously. The effect, or consequences, of gene activity in this view would be modified by the specific environment in which the gene was functioning. Thus different cells with identical arrays of functioning genes could be produced. Although this view is logically adequate, it confronts the cell with particularly difficult and complex probems of regulating metabolism. The simplest and most efficient control mechanism should, it seems, be directed toward turning the gene on and off rather than toward controlling the products of gene activity, for these products would be far more numerous and prone to migrate to many different positions in the cell.

\section{Melanogenesis}

Whatever the correct hypothesis of cellular differentiation may be, the various developmental and genetic aspects of the problem of cell differentiation are well illustrated during the development of the mammalian melanocyte (Markert and Silvers, 1955). The differentiation of an embryonic cell into a melanocyte requires a highly organized sequence of environmental stimuli. These successive stimuli transform the melanoblast into a cell with distinctive biochemical and morphological characteristics. According to the preferred view, these characteristics soon result in activation of the gene for tyrosinase synthesis. The enzyme tyrosinase is not only characteristic of melanocytes but is indispensable for the terminal stage of differentiation which results in the synthesis of melanin. Thus the origin of this specific protein (tyrosinase) is dependent upon two distinct but related processes-the transformation of an embryonic cell into a mature melanocyte and then the activation of the specific gene for tyrosinase synthesis. These sequential steps in melanocyte differentiation are normally controlled by many different gencs. We can recognize several of these steps because mutant genes affecting them have been discovered in a variety of animals, particularly mice. The abnormal effects of these mutant genes enable us to construct a partial picture of the normal activity of several genes involved in the differentiation of mouse melanocytes.

Two quite different kinds of melanocytes-epithelial and dendritic 
- occur in mice and in other vertebrates as well. Both types must have arisen from a common precursor cell at some early stage in embryonic development. The progeny of this cell later separated into two groups, each proceeding down its own distinct pathway of embryonic development. One group gave rise to the outer wall of the optic cup, which transforms into the pigmented retina. These are the epithelial melanoeytes. The other group gave rise to the neural erest, from which melanoblasts migrate to many different tissues, such as those of the hair follicles. In these terminal tissue sites they receive differentiating stimuli from the surrounding cells and are thus enabled to complete their transformation into mature dendritic melanocytes.

Gene-controlled metabolites from hoth the embryonic melanoblast and from the cells of the tissue environment are jointly required to bring a melanoblast to full maturity as a piomenied melanocyte. We might reasonably expect, therefore, that some genes affecting melanocyte differentiation would operate primarily within the melanoblast while others would be expressed in the cells of the tissue environment. This expectation is realized.

Since epithelial and dendritic melanocytes reside in quite different tissue enviromments, they commonly respond differentially to those mutant genes that operate through the tissue enviromment. For example, in mice carrying the gene for yellow hair, the dendritic melanocytes are induced to synthesize yellow pigment when in the hair follicles. but the epithelial melanocytes of the eye continue to make black pigment. The early steps in the differentiation of the two types of melanocyte can also be controlled by different genes.

Black-eyed white mice carry a gene that prevents the differentiation of all dendritic melanocytes while permitting the differentiation of the pigmented retina. Similarly the genes for eyelessness prevent the appearance of epithelial melanocytes while leaving unaffected the development of dendritic melanocytes. However, many genes affeet both types of melanocyte, particularly those genes which control the terminal stages of pigment formation. The albino gene, for example. suppresses melanin pigment formation in all melanocytes by preventing the synthesis of tyrosinase. Likewise the black or brown color of pigmented animals is determined by the same gene equally in both kinds of melanocytes.

Melanin pigment is produced in a complex cell organelle called a melanosome (Moyer, 1961). The development of melanosomes is an indispensable condition for the normal synthesis of the specific protein, tyrosinase. Apparently the protein fibrils of the melanosome are the exclusive sites of tyrosinase activity. Figure 1 shows a seruence 


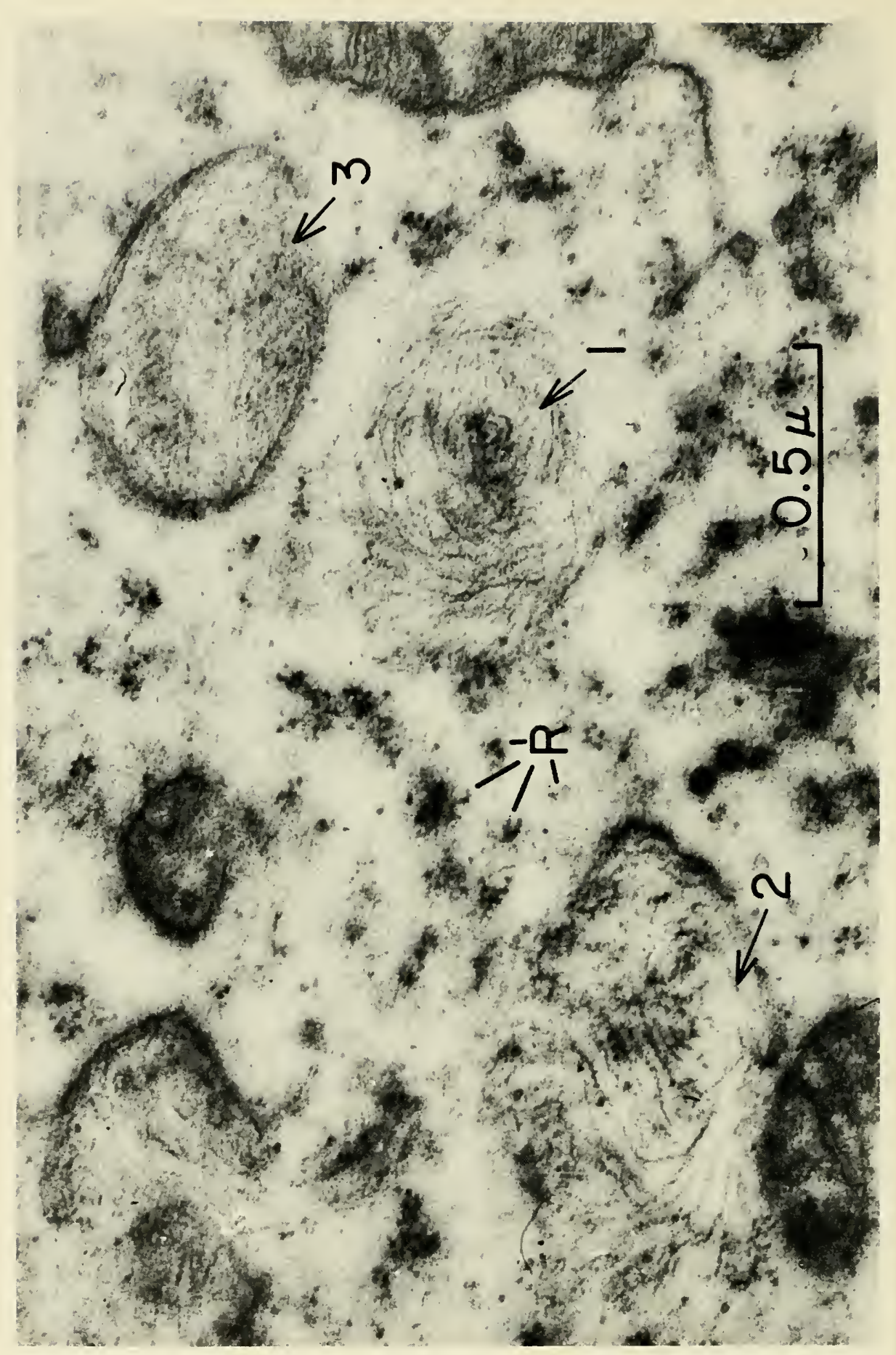


of developmental stages in the synthesis of a melanosome. 'These fibrillar structures have been found only in melanoblasts and presumably represent the response of the melanoblast to differentiating stimuli. Once the melanosome has been formed. it normally becomes pigmented by the deposition of melanin on the fibrils (Fig. 3) until the protein structure of the granule is completely obscured by melanin. However, the albino gene, which prevents tyrosinase synthesis (and thus melanin formation), does not prevent the appearance of unpigmented melanosomes (Fig. 4). The structural rletails of the melanosome are also under genetic control. The pink-eye gene brings about a disorganization of the protein fibrils of the melanosome (cf. Figs. 2 and 3 ) even though tyrosinase synthesis and pigmentation proceed in an essentially normal fashion. These observations on the ultrastructure of melanosomes and the differentiation of melanocytes lead to the general conclusion that the synthesis of a speeific protein during development requires a specific genc and the proper state of cell differentiation in order for the gene to be activated.

We have strong reasons for believing that the gene for tyrosinase synthesis is present in all the cells of a mouse, not just in the melanocytes. However, the gene reveals itself only in melanoeytes by the production of melanin. Recently, however (Peck, 1961), it has been possible to activate the gene for tyrosinase synthesis in cells that normally never give any evidence of possessing this gene in an active form.

The neural retina shares a common ancestry with the pigmented retina, hut the cells of the neural retina differentiate into sensory and nerve cells, presumably because of selective environmental stimuli that do not reach the pigmented retina. However, hy culturing the cells of the chick neural retina in vitro in isolation from one another, they can all be induced to manufacture pigment. This pigment passes the tests for melanin and is presumably synthesized through the catalytic activity of tyrosinase. These results obtained by Peck can best be interpreted as an abnormal activation of the gene for tyrosinase in cells that normally never have this gene in an active form. The word "normally" must be emphasized here, because an inherited disease of human beings known as retinitis pigmentosa is characterized by the formation of melanin-like pigment in the neural retina.

FIG. 1. Electron micrograph showing early stages in melanosome formation in the pigmented retina of a pink-eyed black embryonic mouse. Fixed in osmic acid. embedded in methacrylate, stained with nranyl acelate. Numbers indicate successive stages in melanosome development. $R$ indicates ribosomes. Mi mitochondrion. (Courtesy of Dr. Frank H. Moyer.) 
Is

finding

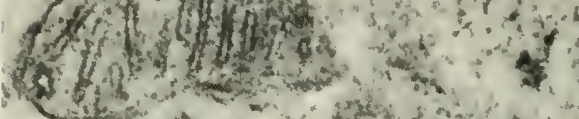

n.

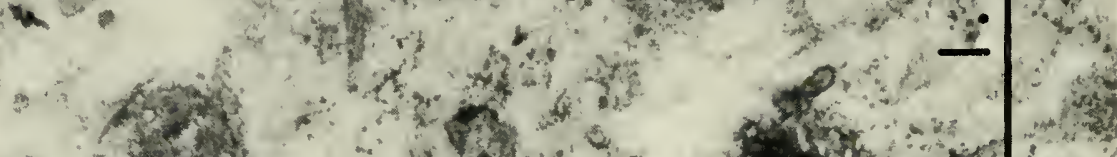
Nat $\cdots$

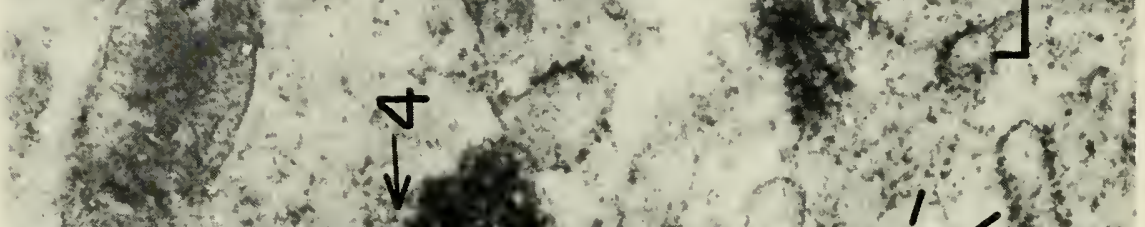

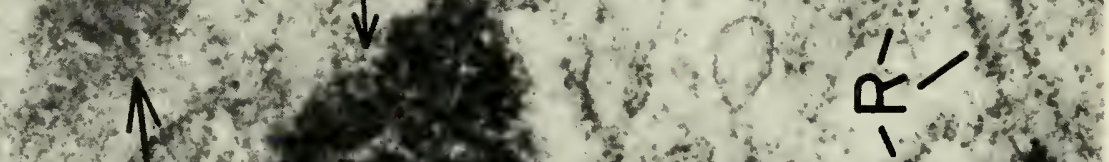

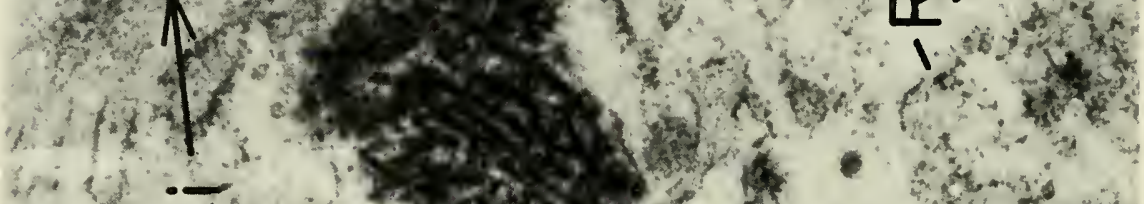

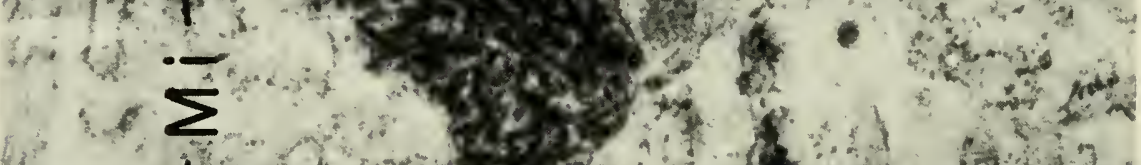

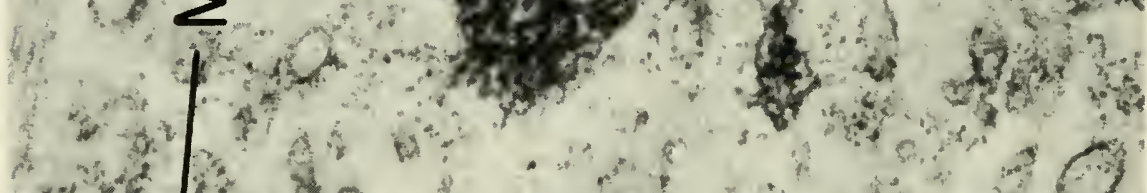

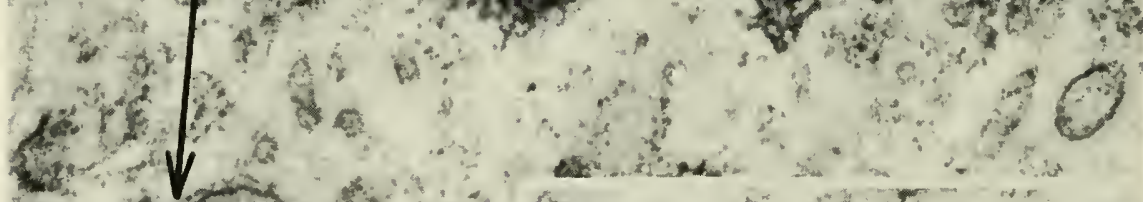
6.60000 ton $x+3$

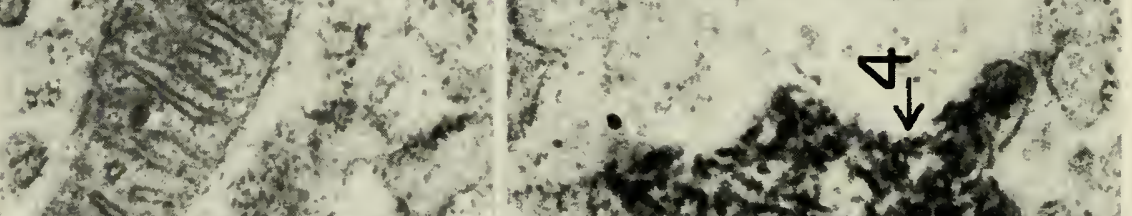

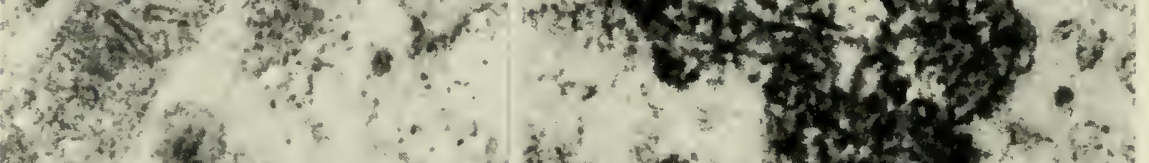

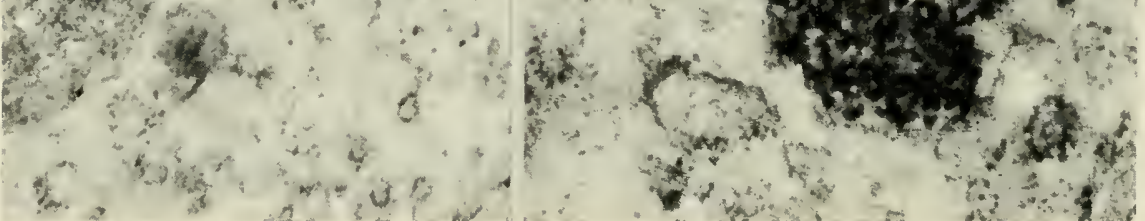


This disease leads to blindness and apparently represents al condition in which the gene for tyrosinase was abnormally provoked to activity.

The chick neural retina, which was cultured in vitro, had of course not been exposed to those stimuli that bring about melanosome formation in melanocytes. Nevertheless, pigment gramules superficially resembling those of melanocytes, as viewed with the light microscope, were formed. On examination with the electron microscope, however, these granules proved to be quite different in basic structure. Evidently the formation of pigmented melanosomes requires the integrated activity of several genes in addition to the one for tyrosinase. Any one of these genes functioning at the "wrong" time or in the "wrong" cell would probably lead to abnormal cell differentiation. Perhaps the most instructive inference that can be drawn from these experiments is that inactive genes in cells are not lost and may be abnormally aroused to activity by suitable stimuli that lie ontside the normal experience of the cell.

\section{Chromosomal differentiution}

If we are to understand the nature of cell differentiation, in fact, of all embryonic development, it is essential to elucidate the mechanism by which primary gene function is controlled. The previous observations on the role of genes in melanocyte differentiation and on the synthesis of tyrosinase have served to emphasize the critical dependence of gene activation on the physical-chemical composition of the cell. In view of the crucial importance of this subject, it is surprising that so few investigators have turned their attention to it. The problem is very difficult, of course, but some promising avenues of investigation have been opened. Before discussing these, it is desirable to empliasize that the genes are part of a chromosone in higher organisms-and the chromosomes are the most complicated organelles of the cell. In addition to desoxyribonucleic acid (DNA), the chromosomes contain protein in at least two general varieties, ribonucleic acid (RNA), polyamines, lipids, and perhaps other substances. From studies of viral genes (Cohen, 1957) we infer that DNA can function even though it is not integrated into complieated structures like chromosomes. What then is the function of these accessory substances

FIG. 2, Electron micrograph of pigmented retina of pinkeyed black mouse 13 days post partum. Fixed in osmic acid, embedded in EPON.812, stained with uranyl acetate. Note the disorganized arrangement of the fibrils and the irrogular hape of the melanosomes. This peculiar melanosome structure is an effect of the gene for pink-eye. (Courtesy of Dr. Frank H. Moyer.) 
of the metazoan chromosome? A plausible answer is that their role is primarily to regulate the function of the DNA-a regulation which becomes of eritical importance in all organisms composed of many diverse types of cells all equipped with the same set of genes.

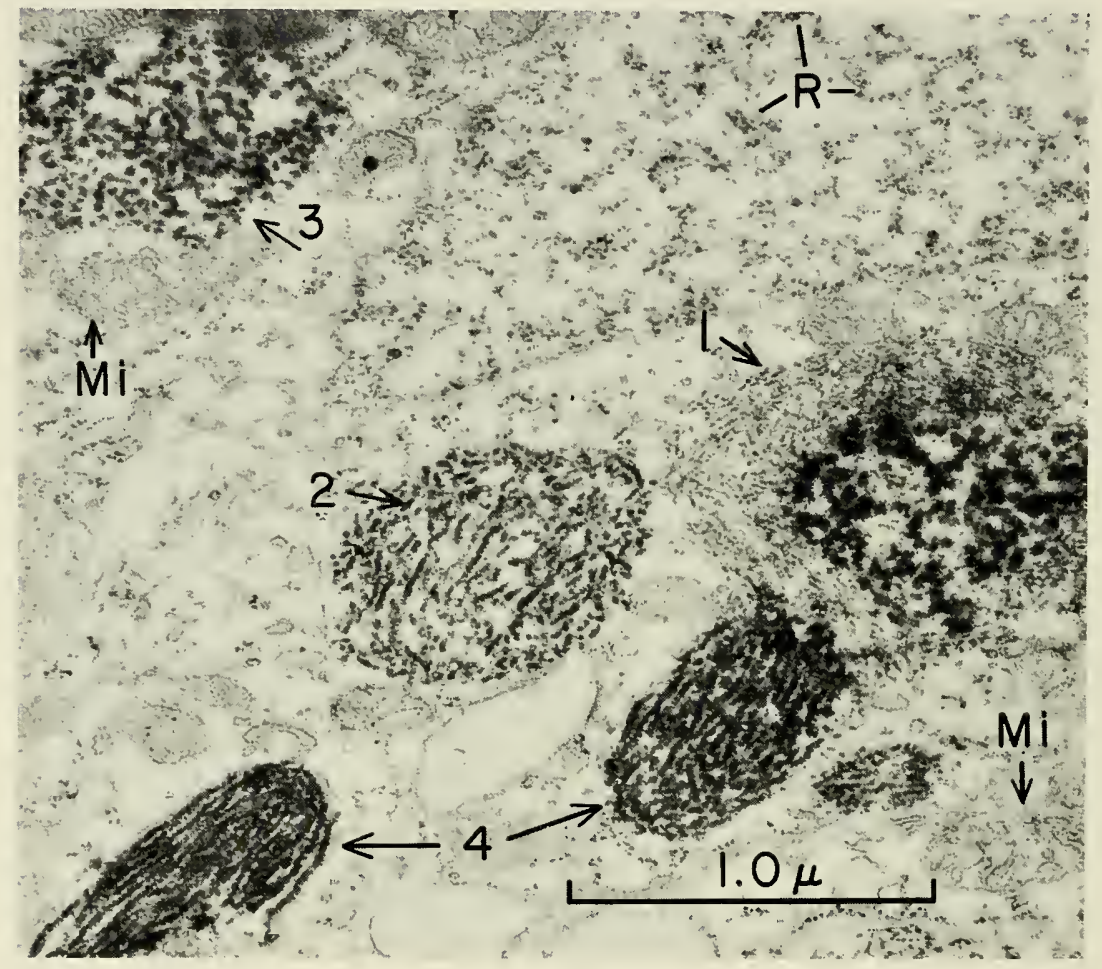

FIG. 3. Electron micrograph of pigmented retina of a C57 brown mouse 18.5 days in utero. Fixed in osmic acid, embedded in methacrylate, and stained with lead subacetate. Four stages in melanosome development are shown. Note the longitu. dinal (4) and cross sectional (3) cuts through the melanosomes. (Courtesy of Dr. Frank H. Moyer.)

Direct cytochemical investigations of chromosomes is one promising area of investigation. Recently Bloch and Hew (1960) have shown, in a eytochemical investigation of snail spermatogenesis, that the spermatocyte chromosomes contain histones with staining properties indistinguishable from other somatic tissues. As the differentiation of sperm proceeds, the somatic histone (lysine-rich) is replaced by 
an arginine-rich histone and later, in the sperm, by protanine. After fertilization, the protamine of sperm ehromosomes disappears and is replaced by faintly basic histones which differ from adult histoncs in their inability to bind fast green, and from protamines. both by their inability to bind eosin and also by their weakly positive reaction

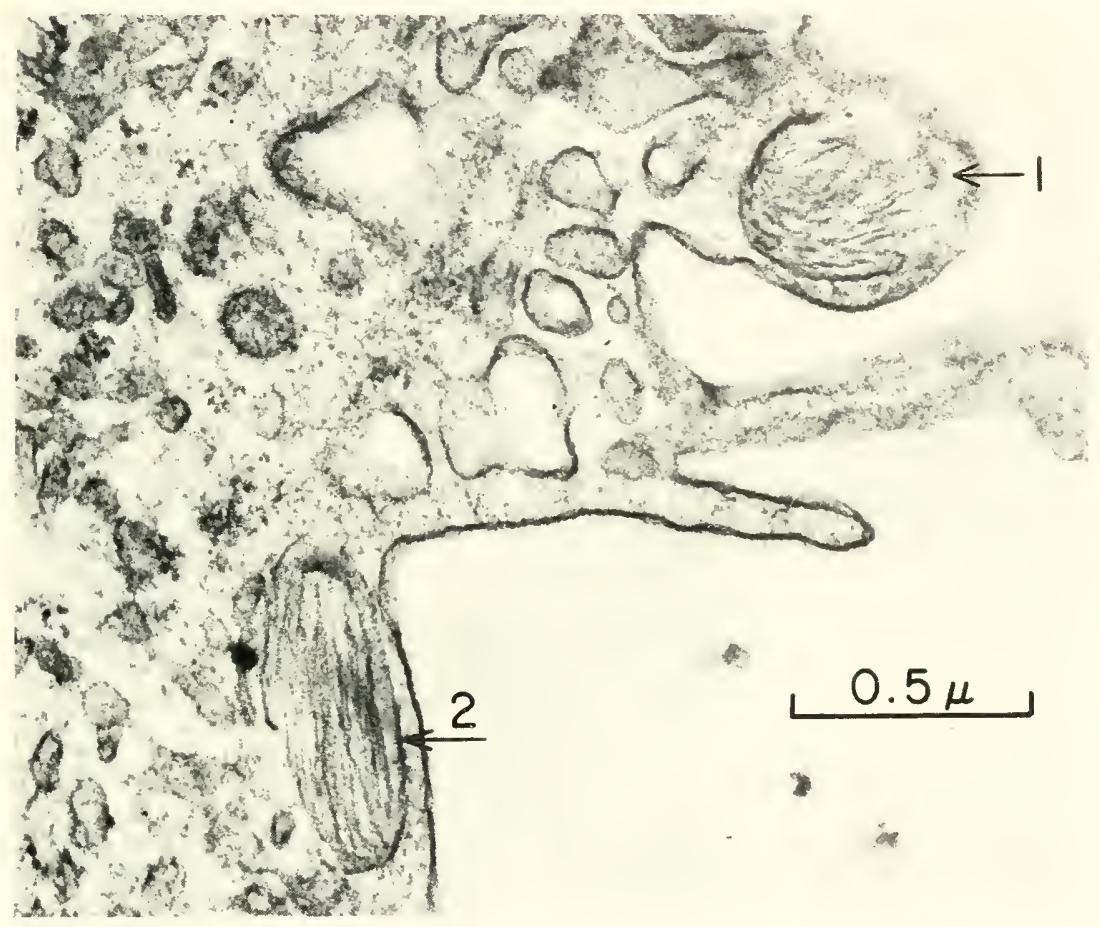

FIG. 4. Electron micrograph of "pigmented" retina of Swiss albino mouse. 15 days post partum. Fixed in osmic acid embedded in EPON-812, stained with uranyl acetate. Note the two nonpigmented melanosomes arrested at successive stages in development. No pigmentation of these melanosomes in albinos has been observed. (Courtesy of Dr. Frank H. Moyer.)

with bromphenol blue. These "cleavage" histones are found in both the male and female pronuclei, the early polar body chromosomes. and the nuclei of the eleaving egg and morula stages. During gastrulation the histone becomes indistinguishable from that of adult somatic cells. Before gastrulation much evidence suggests that the chromosomes are nonfunctional (Moore, 1955; Briggse et al., 1951). 
Further studies show that the cytochenical properties of nucleohistone in proliferating tissues differ from those found in physiologically active cells. Both the stainable phosphate groups of DNA and the stainable basic groups of histone decrease in nonreplicating cells, suggesting that these groups are masked by residual protein, which is known to increase in physiologically active cells (Alfert, 1958). In addition to pointing out the changing chemical composition of chromosomes during development, these and other studies also emphasize that chromosome replication is more than just DNA replication. The mininum replicating unit is nucleohistone (Bloch and Godman, 1955), but other constituents of chromosomes are also duplicated during mitosis, though less completely and less consistently. Presumably the variable constituents of chromosomes are the leading candidates for the role of differential gene activators or inhibitors, and thus we must look to protein or RNA. These constituents can be shown to vary in different cells at various stages in differentiation, but at this gross level of observation no correlation with the function of specific genes is possible. Among animals only the cliromosomes of Drosophila are well enough known to offer hope of identifying chemical changes at known genetic loci. In addition to the characteristic banded pattern of the giant chromosomes of Diptera, it has been known for many years that these chromosomes also exhibit localized areas of enlargement, or puffs (Beermann, 1959). These puffs (Fig. 5) are distributed along the chromosomes in distinctive patterns that are characteristic for the cell type and for the stage of its differentiation (Becker, 1959). They are commonly thought to indicate regions of heightened gene activity, but at any rate they are a clear indication of chromosome differentiation and may be related to differential gene function. Kroeger (1960) in a recent study sought to alter the puffing pattern experimentally. He simply placed nuclei from Drosophila salivary gland cells into cytoplasm taken from young embryos of two different ages. After incubation in this younger, less differentiated cytoplasm, the chromosomes of the nuclei were examined for their puffing pattern. His results (Fig. 6) may be summed up succinctly by stating that the puffing patterns changed and were characteristic for each cytoplasm. Some puffs regressed and new ones appeared. Thus the chemical environment of the chromosome elicits changes in chromosome morphology. The effective substances in Drosophila embryo cytoplasm are still unknown, but in another organism-the dipteran, Chironomus tentans-a specific substance has been shown to change chromosome puffing patterns. Clever and Karlson (1960) injected ecdyson-a hormone obtained from the pro- 


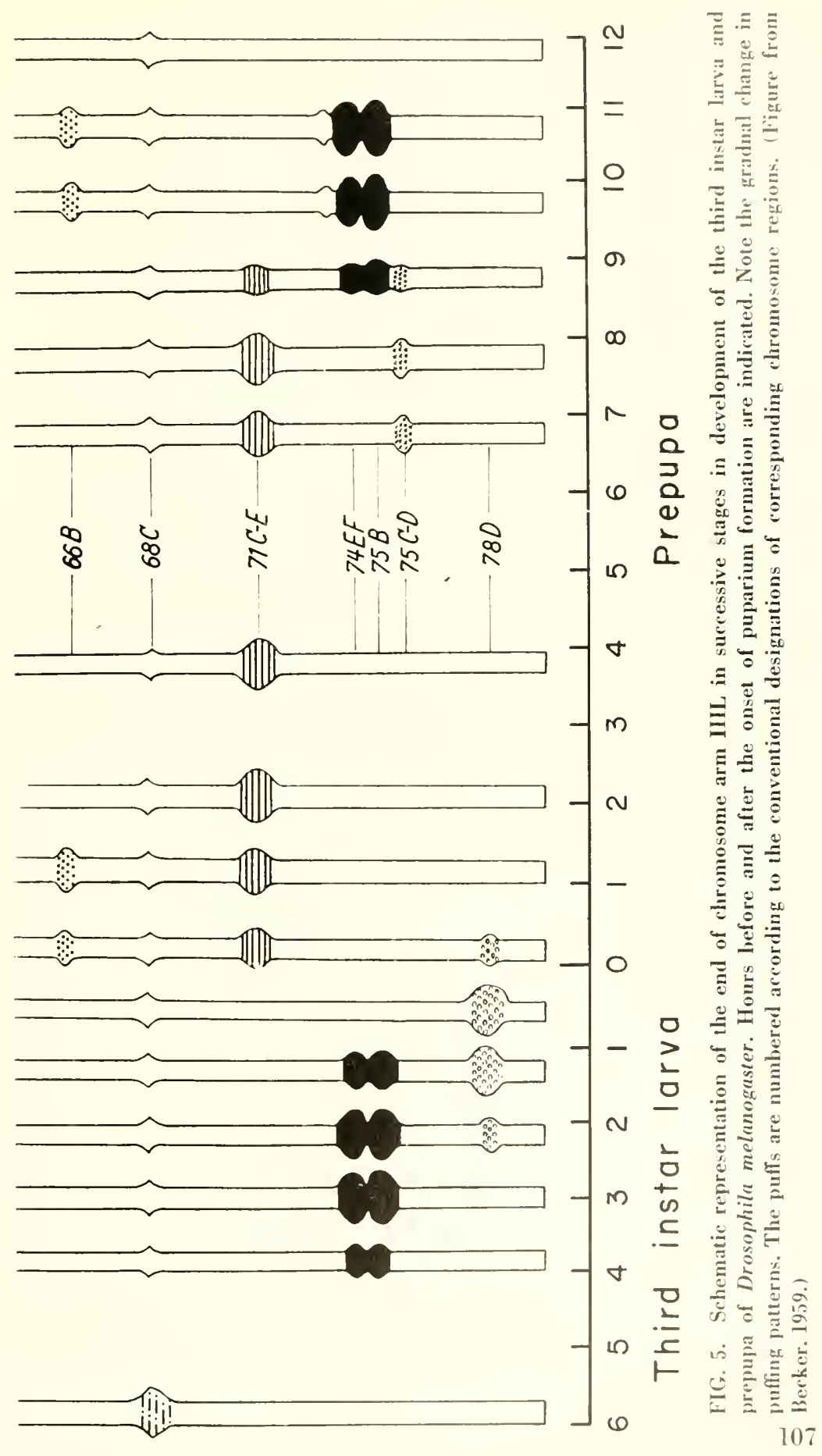


thoracic glands of insects-into the last instar larva of a chironomid. The hormone elicited one new puff and induced the disappearance of an old puff on one of the chromosomes. These changes normally oceur when the inseet metamorphoses. Thus the hormone eedyson, which stimulated metamorphosis, possibly achieves its effects, at least in part, by indueing elromosome differentiation which may manifest changes in gene function.

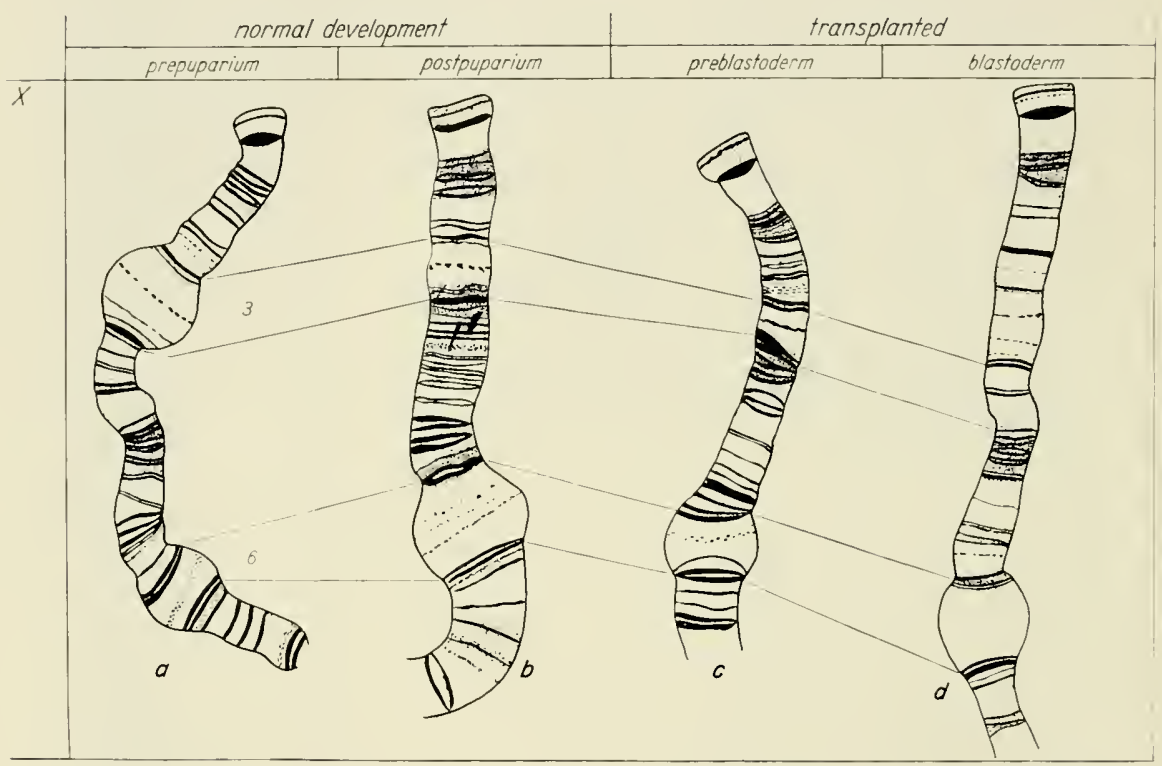

FIG. 6. Comparison of regions of salivary-gland chromosomes of Drosophila busckii at two stages in development and after incubation for 3 hours in cytoplasm from preblastoderm and blastoderm embryos. Note the clianges in puff development in regions 3 and 6 . (Figure from Kroeger, 1960.)

We saw previonsly, during the discussion of tyrosinase synthesis, that the response of a gene to activating stimuli is highly specific for the state of cell differentiation in mice, and probably in all organisms. Apparently substances from the cytoplasm enter the nucleus and induce changes in the structure and function of receptive chromosomes, as shown by the work on dipteran chromosomes. Except for ecdyson, the nature of these substances is completely unknown, but two leading candidates are proteins and ribonucleic acid or some combination between them. 


\section{Vuclear alitionmtiation}

Chemically induced chromosomal changes also seem to provile an explanation for the results obtained hy Moore (1960) in his transplantation of nuclei between two species of frog, Rana sylvatica and $R$. pipiens. Rana sylvatica eggs were fertilized by $R$. pipiens sperm and then the egg nucleus removed hefore fusion with the sperm nucleus could oceur. Such R. sylvatica egas equipped with haploid $R$. pipiens sperm developed into blastulas, but then development stopped. By the time of developmental arrest, the original sperm nucleus would have divided ahout 12 to 14 times and the arrested blastula would be composed of approximately 25.000 cells. Nuelei from such arrested blastulas may be transferred again to eggs of the foreign species. The same pattern of cell division and arrest of development at blastula will again occur. Since hybrid amphibian embryos commonly cease development as blastulas, this result is not surprising but it does demonstrate a nueleo-cytoplasmic interdependence. Most suggestive, however, is the discovery that nuclei after a period of residence in foreign cytoplasm were not immediately able to support normal development even when retransplanted to their species-specific cytoplasm. Serial transplantation of these nuclei for six generations produced only arrested blastulas just like those produced by the original hybrid combination. Nultiplication of the nuclei in foreign eytoplasm had evidently produced a persistent change. prohably in the chromosomes.

An attractive interpretation of these results is that replication of chromosomes in foreign eytoplasm leads to the attachment of foreign substanees to the chromosomes, thus preventing their normal differentiation and inhibiting their heterosynthetic functions. It is important to remember that chromosome replication during nuclear division involves more than just the DNA. Many replieations mixht he neeessary, therefore, in order for a chromosome to lose a component acquired during its residence in a chemically foreign environment.

These observations on the failure of ehromosomes to promote normal development after they had multiplied in foreign cytoplasm prompted us to test the hypothesis that cellular differentiation reflects an antecedent ehemical differentiation of the chromosomes. Our experimental design was simple to the point of being naive. Varions macromolecular fractions were prepared from the nuelei of adult frog-liver cells. These fraetions were dialyzed against a plysiological saline solution and then injected into fertilized eges of the sane 
species. Control eggs, injected with the saline solution alone, developed normally except for occasional alonormalities due to physical injuries produced by the injection procednre. However, eggs injected with several of the nuclear fractions exhibited a consistent developmental arrest at the hegimning of gastrulation. Cell division stopped in these arrested blastulas, but otherwise they appeared normal. Since

I. FERTILIZATION

2. INJECTION

3. ARRESTED BLASTULA

4. DISSOCIATION OF CELLS

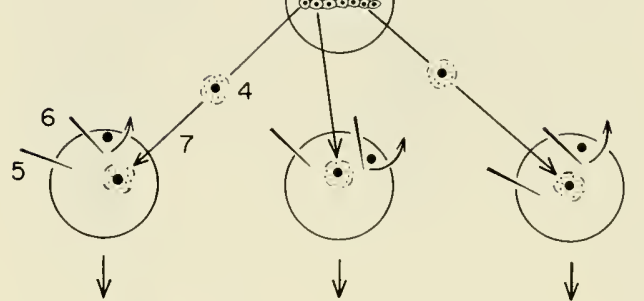

5. ACTIVATION

6. ENUCLEATION

7. NUCLEAR IMPLANTATION

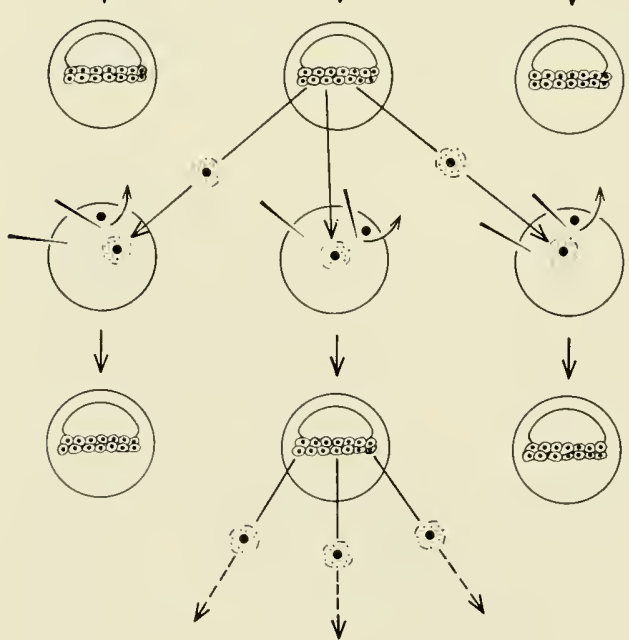

ARRESTED BLASTULA

(FIRST TRANSPLANT

GENERATION)

SERIAL TRANSPLANTATION OF NUCLEI

ARRESTED BLASTULA (SECOND TRANSPLANT GENERATION )

FIG. 7. Diagram of the procedure used in testing the developmental effects of injected protein fractions extracted from adult frog-liver nuclei. Nuclei derived from injected eggs were serially transplanted for seven generations. but each generation arrested at the beginning of gastrulation. 
several nuclear fractions produced these effects. we are not sure of the identity of the effective substances. although they appear to he nondialyzable proteins that are inactivated by prolonged heating. The most potent fraction is still active when diluted. so that it protein content is as little as 0.02 millimicrograms of protein per 0.1 microliter-the volume of the injected solution. Further dilution rendered this solution ineffective. During cell division the chromosones of injected eggs should have been frecly accessible to any injected substances. The very small quantity of injected material suggests a highly specific effect. Moreover, when nuclei from arrested blastulas were serially transplanted for seven generations (Fig. 7) to enucleated egis, the embryos that resulted invariably slopped developing before the onset of gastrulation (Markert and Ursprung, 1962). Since the effect was very characteristic and persistent through many nuclear divisions, it secms reasonahle to place the primary responsibility on the chromosomes. The belavior of these nuclei closely resembles that of the transplanted nuclei which multiplicd in foreign cytoplasm (Moore, 1960 , and indeed the chromosomes of the injected eggs were initially multiplying in "forcign" cytoplasm-a cytoplasm changed by virtue of the injected substances from the adult liver nuclei.

\section{Isozymes}

The discussion so far has hopefully revealed the importance of the cytoplasm in activating gene function, an event that is manifested in the synthesis of a specific protein. Is this then an inchsive description of the mechanisms underlying the synthesis of specific proteins? Probably not. Embryologists have often loosely spoken of molecular differentiation when they really meant the differentiation of cells as evidenced by the appearance of new proteins. However. we have recently become aware of a phenomenon that may be a valid example of a true molecular differentiation. Many investigators have shown that single enzymes commonly exist in multiple molecular forms or isozymes within the tissues or cells of a single organism (Markert and Moller, 1959). The isozymes of a single enzyme liave very similar catalytic properties but can nevertheless be distinguished from one another by their somewhat different physical properties. Usually chromatographic or electrophoretic techniques serve to separate isozymes from one another. These isozymes are not artifacts of analys but exhibit characteristic patterns of distribution in cacla tissue (Fior. 8). Horeover, the tissue patterns are species specific (Fig. 9). The characteristically different isozyme patterns of adult tissues must have 


\section{MOUSE TISSUES}

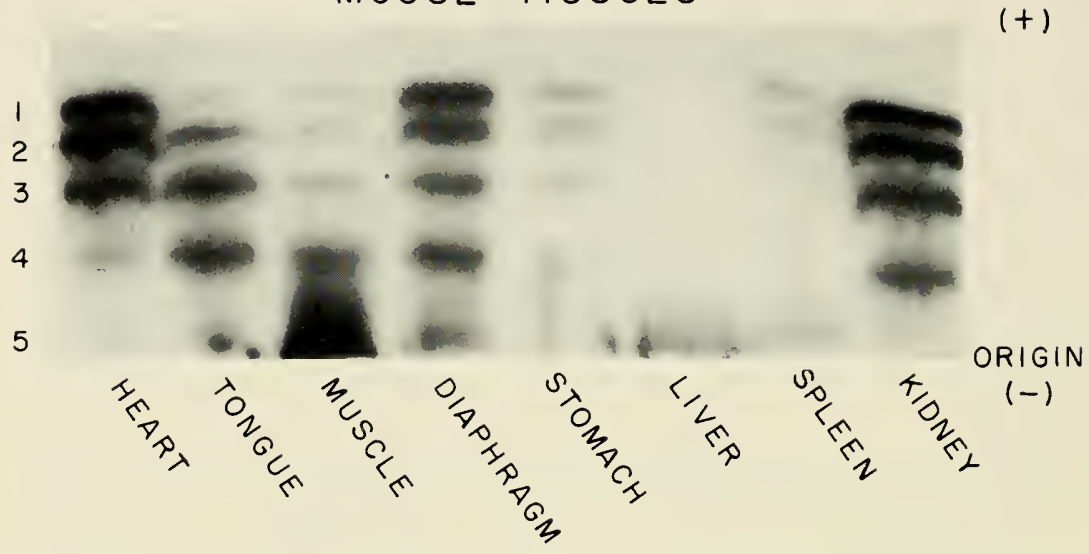

FIG. 8. Photograph of zymograms of lactate dehydrogenase isozymes from eight tissues of the mouse. Five isozymes are evident, most of which are found in most tissues. However, the relative concentration of the various isozymes differs markedly in the various tissues.

I SOZYMES

HEART LACTATE DEHYDROGENASE

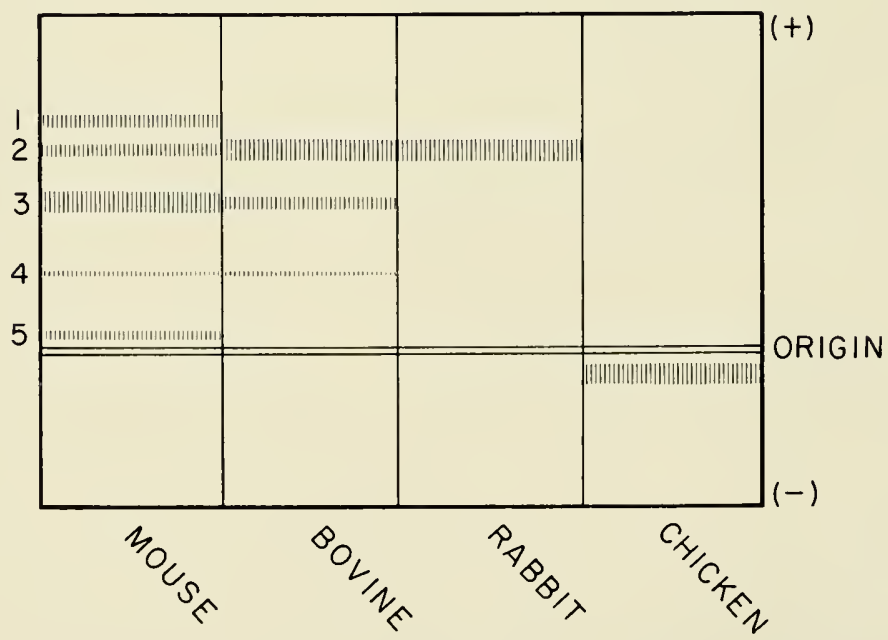

FIG. 9. Diagrammatic representation of zymograms of lactate dehydrogenase isozymes obtained from heart muscle of four species. Each species exhibits a characteristic pattern of isozymes. 
arisen during the course of cmbryonic development, and direct analysis shows this to be so. The adult pattern is the cnd product of a long sequence of gradual changes during ontogeny.

The existence of isozymes poses important problems for the origin of specifie proteins. Each isozyme may be the responsilility of one or two genes, or the several isozymes may represent modifications of a single gene product. The latter case would represent molecular differentiation. A fully satisfactory explanation for the origin of isozymes can scarcely be made until isozymic differences are related to molecular structure. At least five kinds of molecular changes may be invoked to produce different though closely related isozymes: Small changes in amino acid sequence, amidation of earboxyl groups, conjugation with small molecules, polymerization of different subunits, and changes in conformation achieved by folding the samc primary structure in different ways. All these possibilities have served to explain, with varying degrees of experimental support, the existcnce of numerous enzymes in isozymic forms. Polygenic control will clearly be indicated wherever isozymes are found to differ in primary structurc. Other distinctions are more plausibly attributed to modifications imposed secondarily upon a single basic gene product.

The esterase enzymes have been extensively investigated with reference to both ontogcnetic (Markert and Hunter, 1959) and genetic control (Wright, 1961). The esterases compose a large family of closely related but distinguishable enzymes. Each tissue of most animals that have been examined contains a characteristic repertory of these esterases in distinctive patterns of concentration. The patterns arise gradually during embryonic development. However, these different esterases are not all isozymes of one another. Wright (1961) has shown in an investigation of Drosophila enzymes that an esterase (Fig. 10) is present in position 4 in one strain and in position 5 in another strain. Hybrids between these strains have esterases in both positions. The genetic evidence strongly suggests that each of these esterases is controlled by an allele of a single gene: the heterozyote would then possess both esterases, as is apparent in the offepring from a cross between the two strains (Fig. 10).

In Wright's investigation no isozymes of esterase have yet heen identified, although the genetic control of specific protein -tructure is clearly demonstrated. Howcver, Allen (1960) has shown in Tetrahymena that the final structure of the molecule can also be the responsibility of cytoplasmic meehanisms encrging during the course of cellular differentiation. Allen's investigation demontrated that allelic genes control alternate groups of four csterases in Tetrahyment. 
The members of each group are distinguished from the members of the alternate group by a difference in charge, which ean plausibly be attributed to the substitution of a single amino acid in the primary protein produet of the gene. This produet would then be modified into four distinguishable esterases that are inherited as a group.

In a similar analysis of alkaline phosphatases in Escherichia coli, Bach et al. (1961) found five eleetrophoretically distinguishable forms

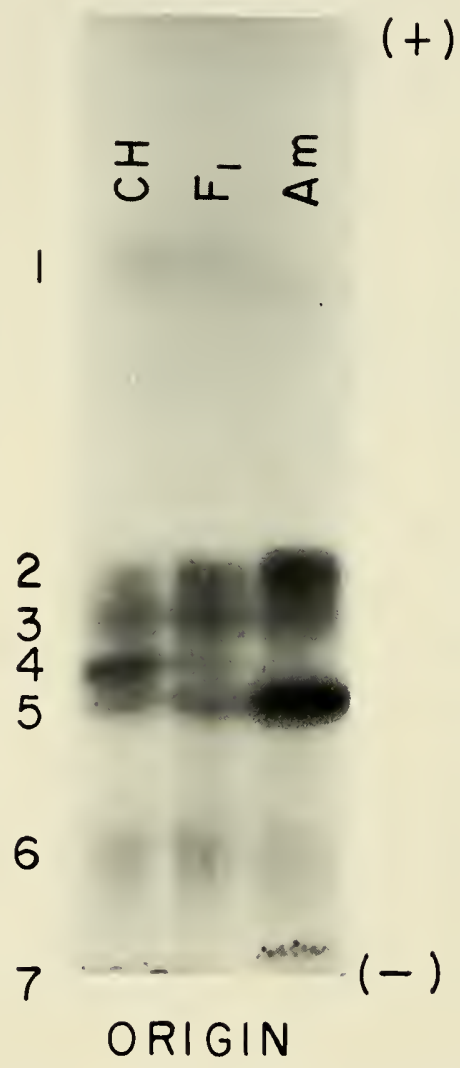

FIG. 10. Zymogram of esterases in Drosophila. Homogenates for each insertion were made from five adult male flies less than 24 hours old. Electrophoresis through the starch gel occurred for 6 hours at a voltage drop of $4 \mathrm{v} / \mathrm{cm}$ and a $\mathrm{pH}$ of 8.7 . Starch was made up in Tris buffer, $0.5 \mathrm{M}$. Alpha-naphthyl acetate was used as sub. strate and fast blue BB as dye coupler. Drosophila strain $\mathrm{Am}$ is highly inbred and shows an esterase at position 5 but not at position 4. Strain $C H$ is not homozygous but contains flies with esterases at positions 4 or 5 or both. When a strain $C H$ fly (with an esterase at position 4 but not 5 ) is crossed to strain $A n$, the $\mathrm{F}_{1}$ offspring all show esterases at both positions. 
of the enzyme. Several nutant strains continued to produce the sane number of phosphatases lut all the phosphatases were shifted in their electrophoretic mobility to the same extent. These result are consistent with the assumption that all five phosphatases are prorlucts of the same gene. Mutations in this gene learl to the production of an altered form of a single basic precursor molecule that is then secondarily modified into the five isozymes of alkaline pliospliatase. How ever, the quantitative proportions in which these isozyules are synthesized are elranged by growth in different media, and in effect, therefore, these different patterns represent different states of cell differentiation.

Extensive investigations (Markert and Appella, 1961: Appella and Markert, 1961) on the physicoehemieal properties of separated and recrystallized LDH isozymes from beef tissues have demonstrated that each of these isozymes is composed of four discociable polypeptide chains. These chains, like those of hemoglobin. may he encoded by two different genes. thus producing two kinds of polypeptides. Assortment of these two polypeptides in all possible combinations of four would yield the five LDH isozymes which are found in mouse ( $\mathrm{Fi}$ g. 8 ) and beef tissues. These isozymes would then be under polygenic control although the eytoplasm would doubtless play a role in assembling the finished tetramers in the proportions peculiar to each cell.

However, it is certain that varions isozymes may be converted into alternate isozymes by mechanisms resident in the eytoplasm of the cell. Kaji and collaborators (1961) have shown that one of the two major isozymes of yeast hexokinase may he converted into the other by treatment with trypsin or elymotrypsin in the presence of glueose. Presumably this conversion could also oceur in the cell. although a fixed ratio of the two isozymes is normally maintained within the yeast cell.

The origin of speeific proteins through nueleocytoplasmic meehanisms is also indicated by the work of Keck (1961) on two species of the giant single-celled alga, Acetabularia Aciculariu schenchii and Acetabularia mediterranea). By ingenious transplantation techniques. Keck combined the nuclei and eytoplasm of the two species in various proportions. Each species was shown to have a distinct acid phosphatase which could be readily identified by staining techniques after electrophoresis of a cell homogenate in a starch gel. The electrophoretic mobility of the med phosphatase was considerably greater. than that of the acic enzyme. Mixtures of homogenates from the two species showed two distinet luands after electrophoresis. In the graft combinations shown in Fig. 11, Keek discovered that the mod enzyme 
was, so to speak, dominant. That is, either the nucleus or the cytoplasm of med plants sufficed to establish the med phosphatase as exelusively characteristic of the hybrid plant. The acic enzyme rapidly disappeared from the graft combination at a rate far in excess of its

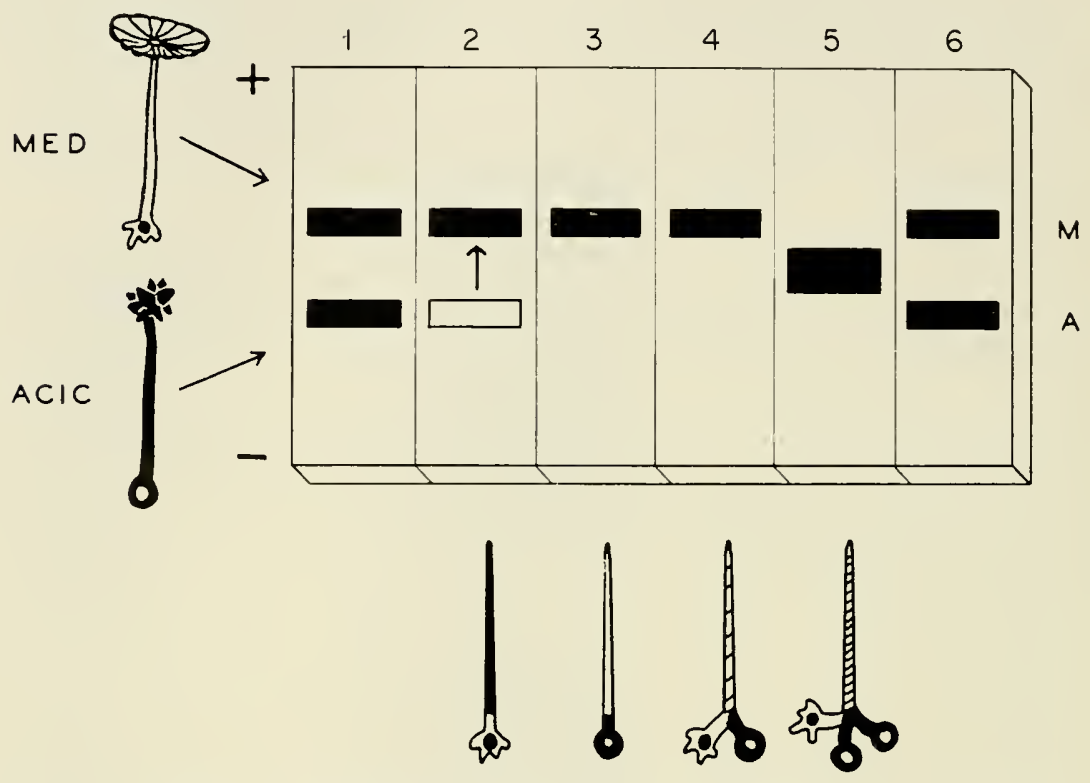

FIG. 11. Diagram of zymogram patterns of acid phosphatase in two species of Acetabularia. Each species contains a single acid phosphatase with a characteristic electrophoretic mobility in starch gel. Strips 1 and 6 show the pattern obtained from mixed homogenates of the two species. Strip 2 depicts the conversion of the acic enzyme to the med type when a med nucleus is substituted for the acic nucleus. Strip 3 shows that the med enzyme persists even after the med nucleus is replaced by an acic nucleus. Strip 4 shows that only med enzyme is found in hybrid cytoplasm regenerated in the presence of one nucleus from each species. Strip 5 shows the intermediate phosphatase band frequently observed when two acic nuclei and one med nucleus collaborate in the production of new cytoplasm. This band ap. parently represents an intermediate stage in the conversion of acic enzyme to med enzyme.

normal diminution in enucleated acic plants. This rapid disappearance suggests that some mechanism in the med cytoplasm converts the acic enzyme to the med type. This mechanism must be initiated by the nucleus because the med nucleus, by itself, is sufficient to bring about the conversion of acic phosphatase to the med type. An intermediate step in this conversion is visible after electrophoresis of graft com- 
binations containing two acic nuclei and one med nuclens joiner in a common cytoplasm. In this case, the productivity of the two acic nuclei is apparently so great that the med cytoplasm cannot complete the conversion of the acic cuzyme, hence an intermediate stage in the conversion accumulates and becomes visible.

The existence of numerous enzymes in isozymic forms requires us to seek an explanation in terms of physiological utility to the organism. One of the most attractive explanations for isozymes arises out of the work of Stadtman and his colỉaborators (1961) on the enzyme aspartokinase in Escherichia coli. This enzyme catalyzes the phosphorylation of aspartate by ATP and the resulting aspartyl phosphate serves as a precursor in the synthesis of the two amino acids, lysine and threonine. Both of these amino acids inhibit aspartokinase activity in extracts of $E$. coli. The inhibitions are additive and independent, suggesting that two different forms of aspartokinase are present. And indeed, hy ammonium sulfate precipitation two different isozymes were separated; one was inhibited by lysine, the other by threonine. Moreover, when $E$. coli is grown in the presence of $10 \mathrm{mM}$ L-lysine, the synthesis of the lysine-sensitive isozyme is completely represscd; thus the amount of the isozyme synthesized is adjusted to the physiological requirements of the organism.

Although both isozymes of aspartokinase carry out the same catalytic activity, the results of Stadtman et al. suggest that the isozymes may be located in different metabolic pathways, one leading to the production of threonine, the other to lysine. The behavior of the isozymes of aspartokinase suggests the following general hypothesis. Isozymes of any given enzyme carry out the same basic catalytic activity, but as parts of aifferent metabolic pathways. These metabolic pathways are either located in different parts of a cell or give rise to different end products. The gradual emergence during enbryonic development of specific isozymic patterns would then reflect the origin of distinct thougl related metabolic pathways.

In summary, the origin of specific proteins during development requires two basic interacting components-the genes and the cytoplasm. Genctic and biochemical evidence clearly demonstrates the role of genes in specifying the primary structure of proteins. lut the existence of isozymes also suggests a role for the cytoplasm in modifying at least the finer aspects of protein structure. Both the genes and the cytoplasm are brought to a state of active function hy as yet unknown mechanisms of cellular differentiation. The most fumbumental expression of this differentiation is the appearance of a new specific protein, which must be regarded as a product involvine the collaho- 
ration of genes and cytoplasm. During development, gencs and cytoplasm interact with one another to produce new patterns of active genes, which lead to the synthesis of new varieties of proteins and thus to an altered cytoplasm. This cyclic interaction makes possible progressive cell differentiation through the synthesis of new proteins and constitutes the foundation of all embryonic development.

\section{IReferences}

Alf ert, M. (1958), Variations in cytochemical properties of cell nuclei, Exp. Cell Research, Suppl. 6:227-235.

Allen, Sally Lyman (1960), Inherited variations in the esterases of Tetrahymena, Genetics, 45:1051-1070.

Appella, E., and C. L. Mlarkert (1961), Dissociation of lactate dehydrogenase into subunits with guanidine hydrochloride, Biochem. Biophys. Res. Commun., $6: 171-176$.

Bach, Marilyn L., E. R. Signer, C. Levinthal, and I. W. Sizer (1961). The electrophoretic patterns of alkaline phosphatase from various $E$. coli mutants, Federa. tion Proc., $20: 255$.

Becker, H. J. (1959), Die Puffs der Speicheldrüsenchromosomen von Drosophila melanogaster. I. Beobachtungen zum Verhalten des Puffmusters im Normalstamm und bei zwei Mutanten, giant und lethal-giant larvae, Chromosoma, 10 : 654-678.

Beermann, Wolfgang (1959), Chromosomal differentiation in insects, in Developmental Cytology, ed. by D. Rudnick, The Ronald Press Company, New York, pp. 83-103.

Bloch, D. P., and G. C. Godman (1955), A microphotometric study of syntheses of desoxyribonucleic acid and nuclear histone, J. Biophys. Biochem. Cytol., $1: 17-28$.

and early embryonic development in the pulmonate snail, Helix aspersa, J. Biophys. Biochem. Cytol., 8:69-81.

Briggs, Robert, E. U. Green, and T. J. King (1951), An investigation of the capacity for cleavage and differentiation in Rana pipiens eggs lacking "functional" chromosomes, J. Exp. Zool., 116:455-500.

Clever. U., and P. Karlson (1960), Induktion von Puff-Veränderungen in den Speicheldrüsenchromosomen von Chironomus tentans durch Ecdyson, Exp. Cell Research, $20: 623-626$.

Cohen, Seymour S. (1957), The biosynthesis of nucleic acids in some microbial systems, in The Chemical Basis of Heredity, ed. by W. D. McElroy and B. Glass, Johns Hopkins Press, Baltimore, pp. 651-685.

Conference on Hemoglobin (1958), Publication 557. National Academy of Sciences, National Research Council, Washington, D.C.

Kaji. A., K. A. Trayser, and S. P. Colowick (1961), Mnltiple forms of yeast hexokinase, Ann. N. Y. Acad. Sci., 94:798-811.

Keck, Konrad (1961), Nuclear and cytoplasmic factors determining species specificity of enzyme proteins in Acetabularia, Ann. N. Y. Acad. Sci., 94:741-752.

Kroeger, H. (1960), The induction of new puffing patterns by transplantation of 
salivary gland nuclei into egg cytoplasm of Drosophila. Chromosoma, 11:129 145.

Markert, C. L., and E. Appella (1961). Physicochemical nature of i-ozymes. Ann. N. Y. Acad. Sci., 94:678-690.

, and Robert L. Hunter (1959), The distribution of esterases in mouse tissues, J. Histochem. Cytochem., $7: 42-49$.

, and Freddy Moller (1959). Multiple forms of enzymes: Tissue. ontogenetir. and species specific patterns. Proc. Nat. Acad. Sci. U.S. 45:753-763.

- and Willys K. Silvers (1955), The effects of genotype and cell environment on melanoblast differentiation in the house mouse, Genetics, 41:429-450.

, and H. Ursprung (1962), Alteration of zygote chromosomes in Rana pipiens by injection of proteins from adult liver nuclei, Amer. Zool., 2:428.

Moore, J. A. (1960), Serial back-transfers of nuclei in experiments involving two species of frogs, Developmental Biology, 2:535-550.

- (1955), Abnormal combinations of nuclear and cytoplasmic systems in frogs and toads, Advances in Genetics. $7: 139-182$.

Moyer, Frank H. (1961). The developmental genetics of melanocyte differentiation analyzed with the electron microscope, Ph.D. Thesis. Johns Hopkins University.

Peck, David (1961), The role of tissue organization in the cytodifferentiation and metabolism of the embryonic chick neural retina, Ph.D. Thesis. Johns Hopkins University.

Schroeder, W. A., Richard T. Jones, J. Roger Shelton. Joan Balog Shelton, Jean Cormick, and Kathleen McCalla (1961). A partial sequence of the amino acid residues in the $\gamma$ chain of human liemoglobin F.. Proc. Nat. Acad. Sci. U.S., 47:811-818.

Schweet, R.. H. Lamfrom, and E. Allen (1958), The synthesis of hemoglobin in a cell-free system, Proc. Nat. Acad. Sci. U.S., 44:1029-1035.

Stadtman, E. R., G. N. Cohen, Gisele LeBras, and Huguette de Robichon-Szulmajster (1961). Feed-back inbibition and repression of aspartokinase activity in Escherichia coli and Saccharomyces cererisiae, J. Biol. Chem., 236:2033-2038.

Wright, T. R. F. (1961), The genetic control of an esterase in Drosophila melanogaster, Amer. Zool., $1: 476$.

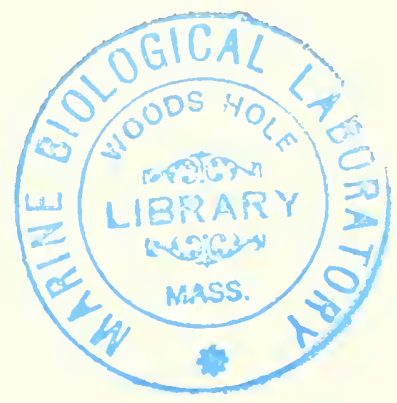





\section{Diversity at the Subcellular Level}

\section{and Its Significance}

Keilh IR. Porter

Biological Laboratories

Harvard University, Cambridge, Massachusetts

Diversity in the microsnopic anatomy of cells requires no exposition; it is illustrated in numerous histological and cytological treatises. There are in nature essentially as many distinct and separate forms of cells as there are tissues they comprise. Some kinds, especially cells performing similar functions, are remarkably alike in different animals or plants, but enough difference is usually apparent to permit their separation. That equal or greater variations wonld be apparent at the "subcellular," or "submicroscopic" level, seemed probablc but a more thorough investigation of the question was delayed pending the development of modern technics for electron microscopy. Now these procerlures have been quite widely applied and results of recent observations have not been surprising in the degrce of diversity they have depicted; it is, in other words, not greater than one might have expected. Diversity at submicroscopic levels naturally expands on the diversity evident at the microscopic because compartments of the cells which formerly appeared structureless now are lescribed in 
terms of fibrils, particles, and membranes of diverse organizations and dimensions.

More surprising perhaps than the variations in form revealed by subcellular explorations is the similarity displayed by structures formerly thought to represent diverse units of the cell. Thus it is that the modern cell biologist can relate structures formerly not apparently related. Generalizations encompassing the whole of metazoan cell structure, and including protozoans in some instances, may now be formulated, thus making much easier the task of elassifying the new fine-structure information. Simultaneously, there is provided through comparative eytology a clearer understanding of the relationships and functions of several of the newly defined systems.

It will be the purpose of this brief chapter to illustrate the diversity in form displayed by some of the subcellular components of cells, and to point ont the pervading similarities and structural associations which relate these components despite their apparent differences.

\section{Dirersity in miterehondria}

Variation in form at the subcellular level could, of course, be illustrated by comparing representatives of a number of intracellular structures. These might be fibrous, granular, or membranous in their basic structure. But possibly none is better for the purpose than mitochondria. These, as was well known from light microscopy, are universally occurring organelles of the cell. They contain enzymes for the complex series of reactions involved in oxidative phosphorylation in the production of energy-rich ATP. The electron microscope observations of Palade (1953) and of Sjöstrand (1953) about ten years ago on these organelles established the existence of a fairly complicated fine structure, which is uniform among the population in a single eell type but varies in different types (Figs. IA to $1 \mathrm{C}$ ). It was apparent, however, from these early studies that a hasic architecture was common to all mitoehondria (Palade, 1956a). Thus each of these organelles in its fully differentiated form possesses an external limiting membrane; inside this, and generally separated from it by space of about 8 millimicrons, there is an internal membrane which through various infoldings forms shelves, or cristae, as they came to be called. Observations made subsequent to this have not materially changed the picture. What has been revealed is a wide diversity of patterns displayed by the foldings or proliferations of the internal of the two membranes. These achieve a startling complexity in some cells, such as to make struetural analysis very difficult (Pappas and Brandt, 
1959). The central purpose of these variations secms to be to expose inereasing or decreasing areas of membranes to the structureles matrix of the mitochondrion (Figs. 1A to IC). Recently it has been found by Fernandez-Moran, in eollaboration with David E. Green, that the surfaces facing the matrix are construeted of small 100 A partirles. Since biochemical studies of these particles show then to contain all the functional enzymatic components of the electron transport chain. they are regarded as the ultimate unit or "elementary particle" of mitochondrial function (Fernandez-Moran. 1960). It will be valuable to apply similar methods of observation to a variety of mitochondria showing different levels of physiological activity.

\section{Variutions in cytoplasmir fine structero}

These struetural variations in mitochondria-an expression of diversity in the subcellular level-are now well known to students of cell fine strueture and deserve this attention only beeause they serve to illustrate how widely diverse morphologies can, upon analysis, be shown to represent variations on a simpler basic structure. Mitochondria, it must be admitted, present relatively minor problems of interpretation, compared with the whole eytoplasm of the cell. However, even the complexity and apparent diversity of this larger division responds to analysis if one recognizes the existence of separate and distinet systems which occur ubiquitously and ean properly be compared.

Some measure of the diversity one eneounters in the fine structure of eytoplasm may be gained from a linited survey of representative regions of a few diverse cell types. The range of variation shown is not descriptive of the enormous range one can find in nature, but it is illustrative without being so extreme as to make comparisons and correlations difficult. Figures 2 to 10 which follow are describerl and compared in the accompanying legends. 
FIG. 1A. A mitochondrion and surrounding cytoplasm from the liver cell of a bat (Myotis lucifigus). The structure, as is characteristic of liver cell mitochondria, shows few cristae ( $c r)$, which are paddle-shaped. It is evident that the total membrane surface of the cristae contiguous with the matrix $(m x)$ of the mitochondrion, is relatively small. This matrix, which is homogeneous and shows no evidence of patterned fine structure, makes up a large part of the mitochondrial content. The double membrane across the center of the mitochondrion is clearly an extension of the inner of the two membranes limiting the organelle, and may represent a stage in division of the mitochondrion (see Fawcett, 1955, for similar forms). The dense granules evident at various points in the structure are characteristic of many kinds of mitochondria; their function is unknown. Among mitochondria, these of liver cells display one of the simplest morphologies. Magnification: $36,000 \times$.

FIG. 1B. A group of mitochondria (sarcosomes) as found in cardiac muscle of the bat. It is clear at a glance that these mitochondria differ from those of liver in possessing many more cristae ( $c r$ ) and that the individual crista is much more extensive and more nearly partitions the interior of the organelle. The total membrane surface thus provided is much greater than in the case of liver mitochondria, but the volume of matrix materials is proportionately less. The structural features of these sarcosomes are characteristic of mitochondria associated with systems having large energy requirements. Presumably the production of ATP by such mitochondria is greater than in those of liver. The myofibrils are indicated at $m y$, the elements of the meager sarcoplasmic reticulum at $S R$, and $Z$ and $M$ bands of the sarcomere by $Z$ and $M$, respectively. The structure at the arrow is unidentified but appears to be continuous with the margins of one or two adjacent mitochondria. This cristae-rich variant on the morphology of the liver mitochondrion is one of the commonest. Magnification: $36,000 \times$.

FIG. 1C. A more unusual form of mitochondrion as found in Paramecium aurelia. The mitochondria here are limited by the typical double membrane, but are distinctive in possessing tubular cristae. These microelements have a diameter approximately equal to the thickness of cristae encountered in other mitochondria. The number of tubular cristae is obviously great and achieves a large contact surface between membrane and matrix. The dense granules in the cytoplasm surround. ing the mitochondria represent glycogen. (Courtesy of Giuseppe Millonig.) Magnification: $36,000 \times$. 

FIG. 2. A small region from the cytoplasm of a normal rat liver cell. A section of the margin of the nucleus $(N)$ is at the upper left. It is separated from the cytoplasm by the nuclear envelope (ne), which in the profile included within the section, shows several pores (arrows). Two structurally dissimilar membrane sys. tems doninate the fine structure of the cytoplasm. The most prominent of these. appears in long, slender profiles representing vertical thin sections through large lamellar vesicles 50 to 75 millimicrons thick. The membranes limiting these structures are studded with dense particles (ribosomes) and because of these this form of the endoplasmic reticulum is referred to as the rough ER (rer). Continuous with this rough form (see arrow for point of continuity), is another type of reticulum composed for the most part of tubules, interconnected in a three-dimensional lattice. In liver cells this agranular or smooth form of the reticulum (ser) is always associated with glycogen. The matrix of the cytoplasm in which these structures are embedded appears homogeneous although in some instances, even in liver cells, there is occasional evidence of bundles of fine, filamentous elements. Where the cisternae of the rough ER are cut obliquely, the distribution of ribosomes on their surfaces is depicted. Beside ribosomes not attached to membranes, the matrix con. tains resolvable glycogen granules $(g l)$, and sometimes ferritin particles. The liver cell, which has become a classical object for cytochemical investigations, has one of the nost complex of cytoplasms, related presumably to the complex physiolog. ical role of these cells. Nearly all the organelles and systems found in any cell are represented. It serves as a useful background for the somewhat simpler but diverse morphologies illustrated in the other figures. Magnification: $27,000 \times$. 


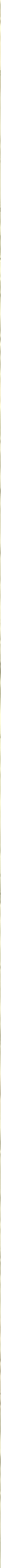


FIG. 3. The basal portion of a mucous neck cell from a gastric gland of the bat. The nucleus at the lower right contains the nucleolus $(n u)$ and is limited by the prominent nuclear envelope (ne). A mucous granule is shown at $m g$ and mitochondria at $m$. The cytoplasm of this cell is characterized by a prominent development of the rough form of the ER, (rer). The individual elements in the section appear as slender line-limited profiles representing sections through lamellar cisternae. The surfaces of these membranes facing the matrix of the cytoplasm are densely coated with ribosomes. This micrograph serves to illustrate a variant of the ER which is common in cells dedicated to the single task of protein synthesis. The total membrane surface for the support of ribosomes is large and the space within the system for the sequestration of the synthesized material is correspondingly extensive. Magnification: $30,000 \times$. 


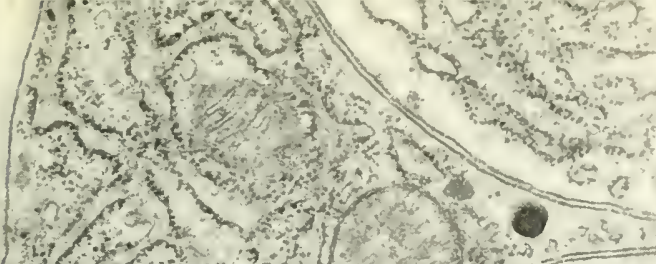

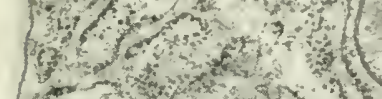

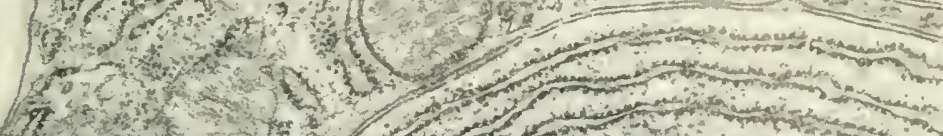

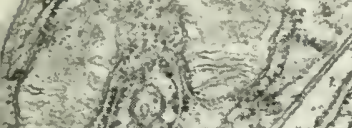

$f(0)$

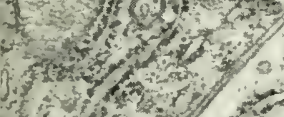

sond

$(10)$

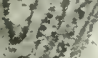

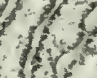

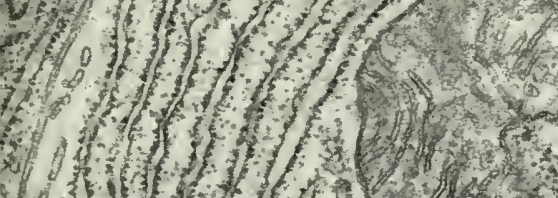

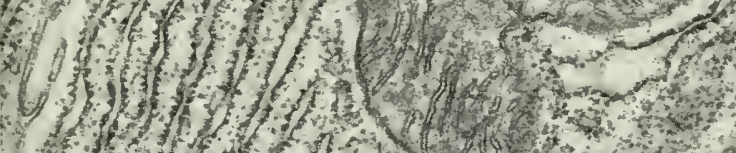

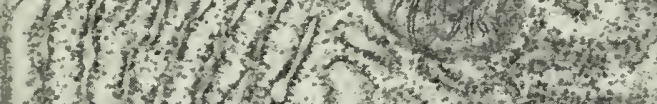

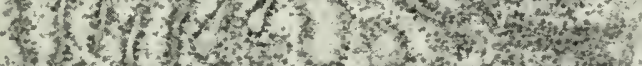

3.

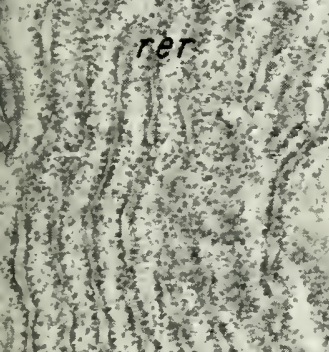

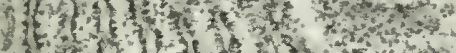

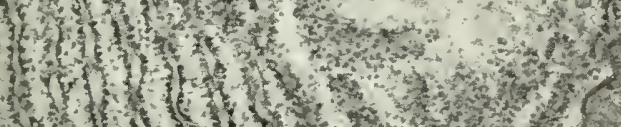

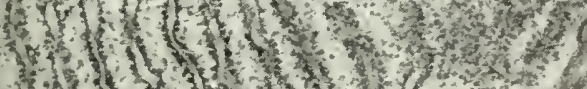

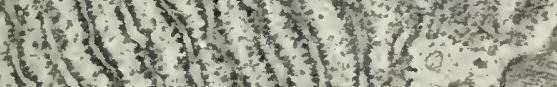

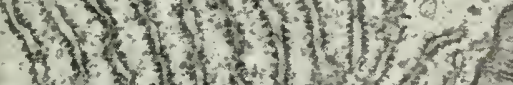

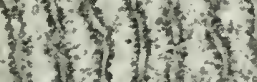

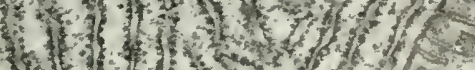

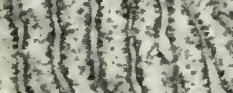

(1) 1 in

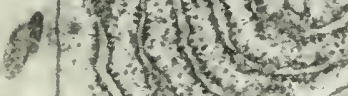

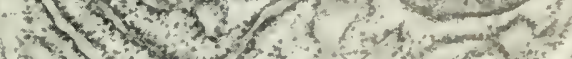

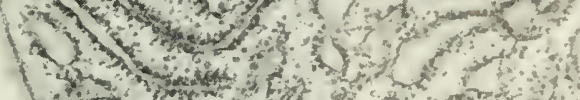

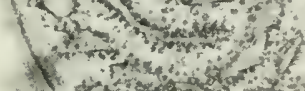

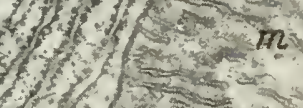

2

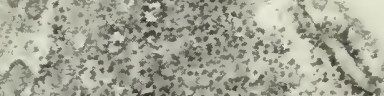

$m g$

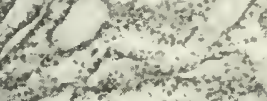


FIG. 4. Shows a portion of the cytoplasm of an epithelial cell in the intestine of the mosquito (Aedes aegypti). A part of a nucleus is shown at the upper left. The nuclear envelope is not unlike that found in other kinds of cells. The dominant element in the cytoplasm of this cell is again the rough form of the endoplasmic reticulum (rer). In its distribution and tendency to appear in clusters of lamellae, it resembles that found in the vertebrate liver cell. The smooth form of the reticulum (ser) is also represented in these cells and, as in liver cells, is closely asso. ciated with masses of glycogen $(g l)$. The Golgi $(G)$ is represented by separate stacks of laminate vesicles. Thus in a cell from a very different biological species, one finds a distinctive variant of the ER, but a variant which closely resembles that common to liver cells of other organisms. It will be interesting to learn whether these cells share any of the functions of liver cells. (Courtesy of Thomas F. Roth.) Magnification: $27,000 \times$. 
FIG. 5. Parts of three cells from the sporogenous tissue of the African violet (Saintpaulia ionantha). A nucleus $(N)$ with a prominent nucleolus $(m u)$ is shown at the upper left. Dense primary walls (cu) separate the cells and transect the image. The endoplasmic reticulum of these cells is made up characteristically of lamellar and vesicular elements. These are not organized into obvious patterns as in the case of the preceding cells, but seem instead to be more or less randomly distributed. Ribosomes are attached preferentially to the lamellar cisterna, but as is typical of undifferentiated and rapidly proliferating cells, the majority of the ribosomes $(r i)$ are free in the cytoplasmic matrix. Mitochondria are indicated at $m$, and smooth ER at ser. Here we encounter a morphology that is quite typical of embryonic or meristematic cells: an abundance of free ribosones and a sparse ER without obvious organization. (Courtesy of Myron C. Ledbetter.) Magnification: $35,000 \times$. 

FIG. 6. A small part of the cytoplasm of an epithelial cell from a gill filament of Fundulus heteroclitus. 'The cytoplasm is obviously packed with profiles of tubules joined together in a dense three-dimensional lattice. The membranes limiting these structures are free of particles and the whole system is properly interpreted as representing the smooth $\mathrm{ER}$ of this cell. In one place, marked by an arrow, there is a short profile of a lamellar vesicle studded with particles. These seem to be extremely rare and are the only representatives of the rough ER found in these cells.

The epithelial cell. of which a part is shown here, has been identified as a salt. secreting unit such as are regularly found in the gills of saltwater fishes. A similar pattern of ER development is common to cells of this type where they have been studied. Chloride-secreting, parietal cells of the stomach are quite similar (Sedar, 1961; Ito, 1961). A part of an adjacent epithelial cell, shown at the lower left, illustrates the diversity which may be evident between two closely associated units. Its cytoplasmic matrix is filled with fibrillar elements $(K)$, perhaps keratin in nature. Its mitochondria show fewer cristae than are found in the mitochondria of the salt cell, and the ER is represented by a relatively few profiles. Mitochondria are indicated at $m$, glycogen granules at gl. (Courtesy of C. Mrilliam Philpott.) Magnification: $48,000 \times$. 


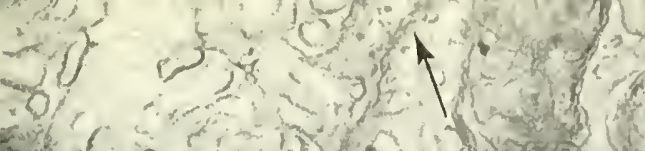

$3(0)=10$

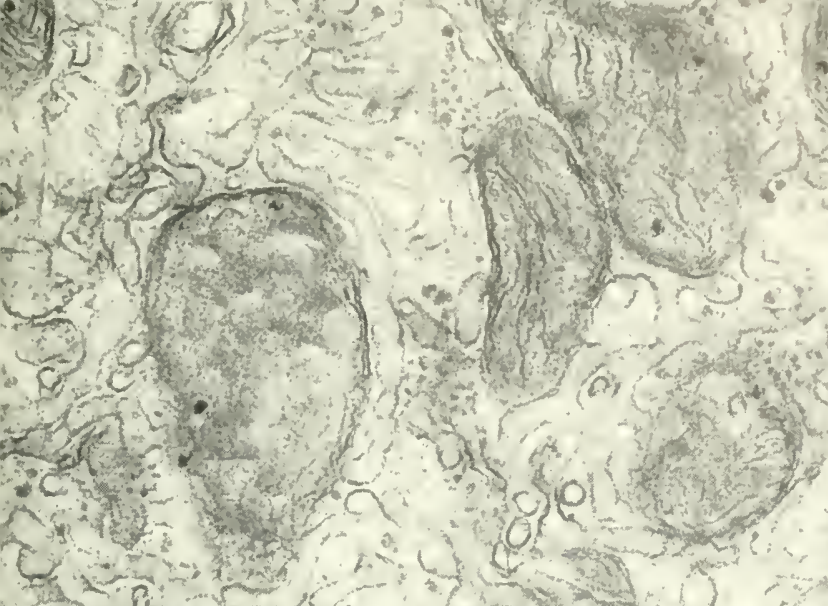

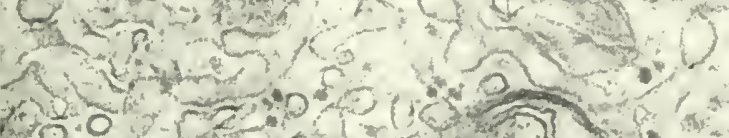
$9 \sqrt{7} \sqrt{6}$

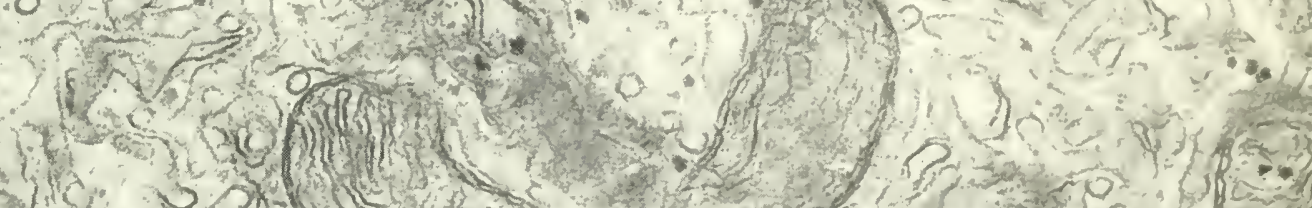

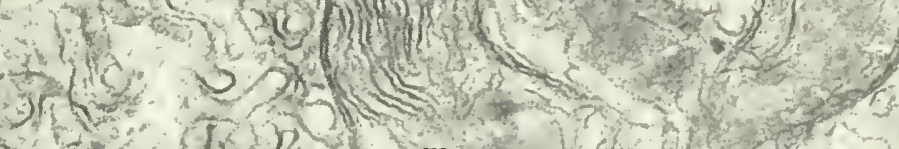

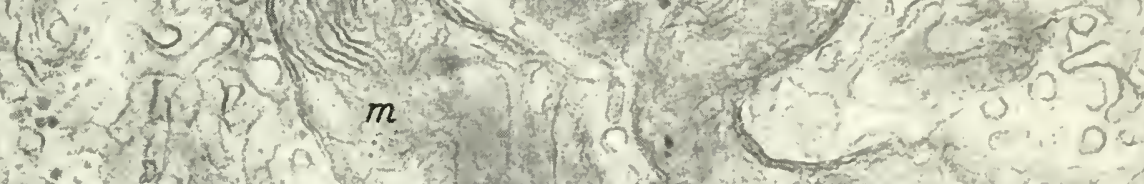
(2) 1.) Ne

als
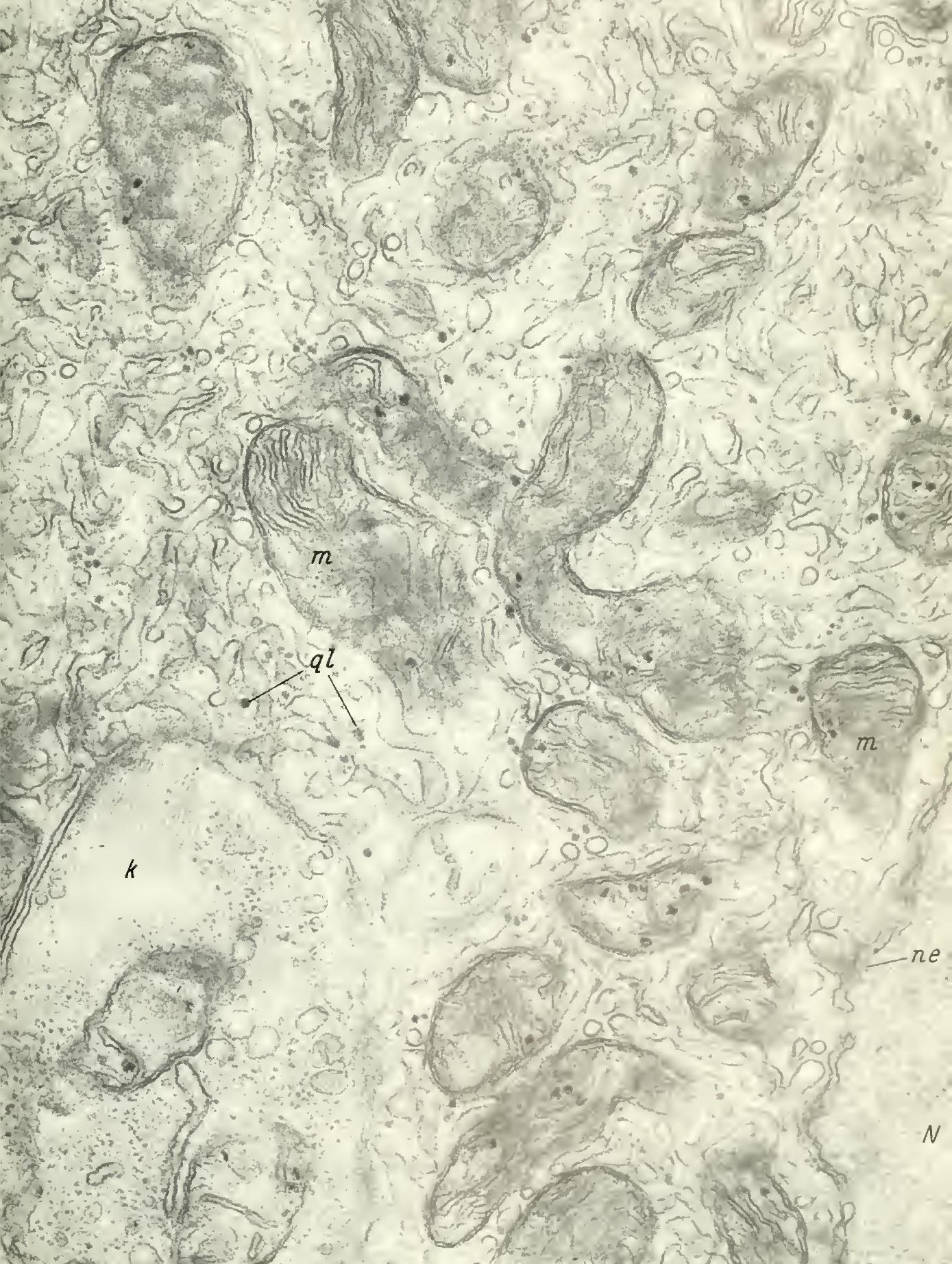
FIG. 7. A longitudinal section through a small part of a muscle fiber found in the myotome of a green frog (Rana clamitans) tadpole. The sarcoplasm between the myofibrils ( $m y$ ) is occupied by profiles of membrane-limited structures representing the ER of these cells. A face view of the system is shown at sarcomeres marked $\boldsymbol{X}$; otherwise images are profiles. It is obviously differentiated with respect to the adjacent sarcomeres of the myofibrils. At the level of the $Z$ band its continuity is interrupted by the interposition of small membrane-limited structures which appear to originate from the plasma membrane of the fiber (Snith, 1961; Porter, 196Ic). The intermediate vesicle, plus the two lateral vesicles on opposite sides of the $Z$ band, is the triadic ( $t r$ ) structure of earlier descriptions (Porter and Palade, 1957). A few particles of glycogen are scattered among the membranes. No ribosomes are attached to the membranes, hence they are properly classified as representing the smooth endoplasmic reticulum (ser) of the muscle cell.

Though appearing very different from that of other cells, the cytoplasm of the muscle fiber can be interpreted as one in which the fibrous elements of the cytoplasm are prominently developed and collected into large bundles. In spite of this exaggeratcd development of matrix components, the endoplasmic reticulum is not lost but is similarly crowded into the space between the myofibrils, presumably to perform a function in contraction and relaxation. (Courtesy of Clara Franzini.) Magnification: $50,000 \times$. 
FIG. 8. Parts of three cells on the epidernis of a larva of Amblystoma punctatum. The nucleus with a prominent envelope is shown at the lower right. The cytoplasm shows several profiles of the ER, some with particles attached (rer) and some separate, agranular profiles. The dominant feature of these cells is a large number of fine filaments representing the keratin component of the cells. These filaments, in places assembled in bundles $(K)$, occupy the continuous or matrix plase of the cytoplasm. The arrow marks a desmosome $(D)$, which represents a point of attachment between two adjacent cells; (is) indicates intercellular spaces.

This cell, which can be classified as a retaining or nonsecretory type of cell (Mercer, 1961) may ultimately show more and more keratin and less ER, until at the end of its differentiation it is practically free of ER except for the nuclear envelope. Magnification: $22,000 \times$. 
FIG. 9. A longitudinal section through a myelinated nerve fiber in the cortex of a rat. The matrix of the axoplasm in this and similar instances is characterized by the development of a large number of protein filaments ( $p f$ ), which represent a differentiation of the matrix (the keratin or myosin equivalent of this cell). These are arranged with their long axes parallel to the long axis of the fiber. The ER is represented by a very few membrane-limited profiles. The myelin sheath is shown at $m s$, and mitochondria at $m$. The surrounding tissue comprises numerous nonmyelinated fibers and dendritic nerve endings. (Courtesy of Giuseppe Millonig.) Magnification: $45,000 \times$. 

FIG. 10. Parts of two erythroblasts found in the embryonic liver of the rat. Nuclei are shown at $N$; the image of the one at the lower left includes a distinct envelope (ne). It is characteristic of these cells to show very few elements of the ER. The cytoplasmic matrix, on the other hand, is dominated by large numbers of ribosomes and between these an accumulation of material, probably hemoglobin. of lower density. As differentiation proceeds the ribosomes diminish in number, the reticulum disappears, and the matrix becomes uniformly gray. The nuclei are ejected. In this instance a nonfibrous component comes to dominate the cytoplasmic matrix as differentiation proceeds and the ribosomes and ER disappear. Mitochondria are indicated at $M$, the Golgi component at $G$, and centrioles at $C$. (Courtesy of $W$ in. centy Kilarski.) Magnification: 20,000×. 
It should be evident from this brief review of diversity in cytoplasmic structure that certain components recur, and that they appear as variants of a basic form. One can, for example, find in almost all cells some cvidence of fibrous structures in the continuous phase of the cytoplasm; ribosomes of nearly uniform size are present to greater or less extent in most instances; and finally, the cytoplasm shows multiple expressions of membrane-limited tubules and vesicles which seem to comprise a single system. In what follows this will be defined as a unit system of the cytoplasm and considered relative to its structural and functional diversity. There are certainly other components which could be used for the same purpose but which as yet have not been so completely analyzed for variations, occurrence, and function. The majority recur in all cell types and will of course come eventually to be understood. These include structures which are currently known as microbodies, lysosomes, multivesicular bodies, Golgi, and associated microvesicles.

The miscellaneous profiles of tubules and vesicles, which frequently appear to clutter up the cytoplasm, have been shown to represent parts of a continuous or intermittently continuous systen, commonly referred to as the endoplasmic reticulum, or ER (Porter and Thompson, 1948; Porter, 1953). As the technics of electron microscopy have improved over the past ten years, the image of this system has gradually cmerged from the optically empty ground substance of the cell, and it is now recognized as a commonly occurring component of the cytoplasm (Hagenau, 1958; Palade and Porter, 1954; Palade, 1955; Porter, 1961a).

The unit structure of this system can be thought of as a vesicular or tubular element which appears in a wide range of forms and dimensions. It is a membranc-enclosed space, usually showing no evidence of internal structure. When these conponent elements, which appear in thin sections as line or membrane-limited profiles, are followed through serial sections into the depth dimension, they are found to be, in most instances, part of a complex tridimensional reticulum which extends into all parts of the cell.

A further generalization which emerges from electron microscopy of many cell types is that the nuclear envelope is morphologically similar to the unit elements of the ER (Figs. 2, 3,5), and is found to be structurally continuous with the system at a number of points (Watson, 1955). It is proper, thereforc, to include the envelope and the cytoplasmic tubules and vesicles in a single system, the endoplas. mic reticulum, or ER. In support of these statements we note that the envelope consists of two membranes and an intervening space. 
The outer nembrane is studded with rihosomes, like rough cisternac of the ER, and the inner one is in intimate association with the peripheral chromatin of the interphase nucleus. The latter intimacy is such as to suggest an active and important physiologie exchange, or what have you between the envelope membrane and cavities and the genetie material of the nueleus. Perforations or fenestrae in the envelope connect, apparently without structural interception, the matrix of the cytoplasm and less dense nuclcoplasm of the nucleus and should provide for a free exehange of fairly larie molecules.

In some cells the endoplasmic reticulum is represented almost solely by the nuclear envelope, other parts having disappeared in the later stages of cytoplasmic differentiation (Fig. 10). In another and more commonly encountered structural expression or pattern, there are many lamellar sacs or cisternae in parallel array and this form corresponds to the strongly basophilie component of the cytoplasm long known as ergastoplasm. In other instances the system is represented by a three-dimensional lattice of particle-free tubules (Fig. 6) . The diversity of forms ranges widely between the extremes shown, for example, hy the cells of the vertebrate pancreas and the interstitial cell of the vertehrate testis. The interesting thing is that the structural pattern of the ER is constant (within limits) for any cell type and it is possible for the experienced observer to identify a eell on the basis of ER morphology alone. These patterns and their funetional relationships are discussed more fully below.

From these and other olservations on the morphology and variations in this system, it becomes evident that the ER is a complex, finely divided vacuolar system which ramifics and extends to all parts of the cytosome. It effectively creates in the cytoplasm a structureless and sometimes discontinuous internal phase separated by a membrane from the continuous phase of the cytoplasmie matrix. It has heen suggested, on the basis of these and related observations, that the ER provides for the channeled diffusion and serregation of metabolites. It is probable that the membrane is clectrically polarized. And eytochemical studics support the oft-expressed suggestion that the large surfaces of the system provide for the support and patterned disposition of enzymes within the eytoplasm.

\section{IDirersity in EIR patterns:}

One of the most striking features of this complex membrane-limited structure is its tendency to adopt similar patterns in cells of the same type. These patterns, it would seem, are determined by the macro- 
molecular composition and arrangement in the system itself rather than by an organization in the matrix, or continuous phase of the cytoplasm. The latter scens to display too much randomness in its behavior to support a patterned structure of this nature. Furthermore, the fragments of the ER which compose the microsome fraction, as isolated in sucrose, retain a form reminiscent of that of the intact system and this in the absence of the cytoplasmic matrix (Palade and Sickevitz, 1956). Hence it is reasoned that the system is to a degrec independently structured according to genctic information effective in any particular cell. Except that the expanse of this membranous system is greater than that encountered in mitochondria and chloroplasts, it is not more complicated or more incredible than the internal membrane systems of these smaller organclles. The ER, based on the nuclear cnvelope, pervades the whole cytoplasm; the cristae mitochondriales, only the cavitics of the mitochondria.

Beside heing constant for any single type of cell, these patterns are found to repeat to some degree in cells performing similar functions. It was in fact this tendency, brought to light by comparative cytology, which gave the first clues to the functional properties of these structures. Thus it was observed that the ER in cells engaged in the synthesis of protein for export is made up frequently of large, lamellar cisternae which are usually in parallel array (Dalton, 1951; Bernhard et al., 1952). And these cisternae always have dense $150 \mathrm{~A}$ particles attached to the outer or matrix surface of the limiting membranes (Palade, 1955b). This has led to the practice of referring to this form of the ER as rough or granular, as opposed to the smooth or agranular forms to be considered in greater detail in a succeeding section.

\section{The rough Ere}

This form of the ER refers not so much to patterning as it does to a particular characteristic of the component elements. In many instances, it is true, the particle-studded cistcrnae are arranged in stacks or are regularly spaced in parallel arrays which may occupy a large part of the cytoplasm. This is the ergastoplasm of classical cytology (Garnier, 1899). Thus one cxpects to find particles associated with this organization and form of the ER vesicle. There are, however, instances where parallel cisternae are particle-frec (Porter and Yamada, 1960), as also there are instances where particle-studded elements occur singly (Fig. 6). In general, however, the large flat cisternae of the ER are reserved for particle association and tend to show a degree 
of parallel close array. Thus such diversity of pattern as is displayed by this type of $\mathrm{ER}$ is in amount and degree of association rather than in the form of individual elements.

The function of this rough form has been more thoronglyly explored than any other form of the ER. As is well known, the combined evidence from cytochemistry, comparative eytology, histochemistry. and eytophotometry links the system to protein synthesis. This evidence has lieen so frequently reviewed that it needs no recital here (see, for example, Lotfield, 1957; Siekevitz and Palade, 1960 a. b). The important aspect of it to note for present purposes is that protein is synthesized in the particle or ribosome and is thence moved through the supporting membrane and segregated, or sequestered from the matrix of the eytoplasm to be transported toward export mechanisms represented usually by the Golgi component (Palade 1956b; Caro, 1961). Thus studies on protein synthesis have established functions for the membrane and cavity of the ER. functions of segregation and transport which might reasonably be extended to other forms of the system.

\section{The smooth or mgranular EIR}

As in the case of the rough ER, this represents a hasie form of the system rather than a distinctive pattern for any eell type. Also, as in the case of the particle-studded ER. the smooth appears more frequently in one form, that of slender tubules $(50$ to 100 millimicrons in diameter) arranged in a three-dimensional lattice. V'arions departures from this can be found, but the unit elements remain tubular or small vesicular (Fawcott. 1955: Porter and Bruni. 1959: Porter and Yamada, 1960; Christensen and Faweett, 1961).

The distribution of this type of ER among cells is less constant in its association with any single function than is the ease in the rough form. Thus it is not possible to say that the smooth ER is designed for steroid synthesis as opposed to protein synthesis for the rough ER, although it is customary for steroid-producing cells to show this type of ER. Christensen and Fawcett (1961). for cxample. have described the interstitial cells of the oppossum testis as showing only a smooth ER, in a close lattice. This they relate, by virtue of it occurrence in other steroid producers. as common to cells engaged in this activity. Biochenical studies by Lym and Brown (1958) point in the same direction. The inference is that enzymes active in steroid synthesis are associated with the microsomal membranes. A rery similar configuration is found in the pigment cells of the retina I Porter 
and Yamada, 1960). Its role here is not so easy to determine, but since these cells are deeply involved in supplying metaloolites to the adjacent photosensitive structures, it is probable that the system has some role in the interconversion of vitamin $A$ and retinene (Porter and Yamada, 1960). Several other examples of the involvement of the smooth ER in lipid metabolisn could be cited, but for our purposes here it seems more important to point out its association with other activities in other types of cells.

A striking example of the smooth endoplasmic reticulum is found in cells engaged in the concentration and secretion of a specific ion. Thus one finds unusual developments of smooth elements in oxyntic (acid-secreting) cells of the gastric mucosa in a variety of animals (Sedar, 1961). The concentration of these is especially striking near the free surface of these cells, where chloride ion is presumably being discharged into the gastric lumen. "Presumably" is inserted here because a direct demonstration of this phenomenon at the surface of oxyntic cells is still lacking. For present purposes the observation of special patterns and developments of the smooth ER in these acidsecreting cells is all that is stressed. Sedar speculates that substances normally foreign or injurious to the cytoplasmic matrix could be sequestered in the system prior to secretion.

Another chloride-secreting cell is encountered in the gills of saltwater fishes as well as in salt-secreting cells of other forms. In a recent study of these cells as encountered in the gill filaments of Fundulus, Philpott (1962) discovered compact reticula of smooth-surfaced ER. The extraordinary character of these is depicted in Fig. 6. The role of this system in chloride secretion is unfortunately not better understood here than in the case of the parietal cell, but the morphological association of the smooth ER with this type of cell is certainly indicative of some involvement (Philpott, $1962 \mathrm{a}, \mathrm{b}$ ).

Sequestration of small molecular species may be a function common to smooth forms of the ER. This is suggested in the chloride-secreting cells and also by a form of the smooth ER found in liver cells. In these latter, it is common to find a lattice-work of tubules associated with the large rosette granules of glycogen (Fig. 2). The amount of this in a cell seems to vary from time to time in direct proportion to the amount of glycogen. Structural continuities with the rough ER, which is more nearly constant in amount, are perfectly evident and this suggests that the smooth form may have its origins from the margin or edges of the rough form (Figs. 12 and 13). In its association with glycogen, the development of tubular and vesicular elements is 
such that the individual glyeogen particles are essentially locked or incapsulated by the smooth retienlum Ashford and Porter. 1961: Porter. 1961b). When glueose secretion is stimulated by grlucagon injection of the animal, the glyeogen disappears rapidly and concomitantly the tubules of the smooth ER dilate as though seyuestering the olucose. This interpretation is favored because at the same time, vesicles derired from the smooth reticulum acemulate at the basal and lateral eell surfaces and appear to fuse with the plasma menbrane, as though to discharge their contents. It is pertinent at least in this regard that glueose-6-phosphatase is localized in membranes of the microsomes. Other enzymes of the glycogenolytie sequence are apparently not associated with the membranes but are soluble or are part of the glyeogen gramules (Luck. 1961).

The liver eell is not the only instance where smooth and rough forms of the ER intermingle or are at least present in the same cell. Philpott (1962), reports the presence of both in the ehloride-secreting cells of Fundulus: Christensen and Fawcett (1961) in the interstitial cells; and Ito (1961) in the parietal cells of several forms. The extent to which the two systems are continuous in these latter instances is not indicated, but it is probable that the relationship found in the liver cell will eventually be demonstrated in these other forms.

A discussion of this smooth form of the endoplasmic reticulm would be incomplete withont some mention of the system found in striated muscle ( $\mathrm{Fig}$. 7). Here a continuous system of tubules and vesieles occupies the sarcoplasm between the myofibrils and differentiates into a pattern of organization which repeats with each sarcomere (Porter and Palade, 1957: Andersson-Cedergren. 1959; Faweett and Revel, 1961: Revel, 1962). This precise association with the contractile elements has convinced more than one olserver that the system must be involved in some phase of musele physiology. Thus the continuity of the system laterally in the musele fiber led to the early proposal that it might conduct the exeitatory impulse to the myofibrils located centrally within the fiber. sometimes at distances of 50 microns from the sarcolemma. More recently it has been recognized that one component of the system-the middle or intermediary element of the triad (Fig. 7), the T system of Anderson-Cedergrenis a derivative of the plasma membrane and hence a better candidate for lateral conduction (Smith. 1961; Porter, 1961e). This leares the sarcoplasmic reticulum, or SR-the smooth-surfaced reticulum of the muscle cell-with no assigned function. One might reason from the above-reported observations on the smooth ER of the liver cell that the 
systems may sequester glucose and transport it to the triad, or I-hand level, for glycolytic breakdown. Faweett and Revel have made the safe suggestion that the system "takes part in the synthesis of energy. rich compounds." But what role? Aetually there is fairly good evidence from eytochemical studies, in which isolated fractions of the smooth ER were examined (Museatello et al., 1961), that the membranes of the retieulum eontain a relaxing factor (the Marsh factor) which inhibits the ATP-ase activity of the myofibril. And there is further evidence (Ebashi, 1961; Revel, 1962) that the triadic element ean coneentrate $\mathrm{Ca}^{++}$, itself an inhibitor of the relaxing faetor. Thus one sees evolving a hypothesis that would involve the sareoplasmic representative of the smooth retieulum in musele relaxation.

This idea finds some support from comparative morphology of the $\mathrm{SR}$ in museles showing different rates of eontraction and relaxation. It is observed that museles which contract at extraordinarily high rates of frequeney, for example, the toadfish swim bladder (Fawcett and Revel, 1961), the ericothyroid muscle of the bat (Revel, 1962), the synchronous flight muscle of the dragonfly (Smith, 1961), and the extrinsic eye muscles of Fundulus (Reger, 1961), all show extraordinarily rich developments of the sarcoplasmie reticulum. Relatively slow museles, on the other hand, like cardiac musele, especially in the turtle (Faweett and Selby, 1958), show a minimal expression of the SR. It appears that the SR achieves its maximal development in museles where relaxation has to be achieved in a few milliseconds.

The association of the endoplasmic reticulum with intracellular fiber systems is not confined to the myofibril. Fauré-Fremiet et al., (1962) have recently drawn attention to its struetural involvement with the eontractile bundles of filaments in a Vorticella type protozoan. Though the extrapolation is tenuously supported, one can reasonably wonder if many of the motions of eells, especially those which mark the return of the eell to the relaxed or preferred form, may not depend upon the preferred pattern of the ER and the relaxing factors associated with its component elements.

In this article, repeated mention has been made of patterns in the ER. These may consist, as already indicated, partly of ribosome-associated elements and partly of partiele-free elements. In speaking of patterns, one refers to the relative amounts of these two forms, and their distribution with respect to one another and to the cell. Thus, although the cells of two salt-secreting organs may look alike in terms of smooth ER, they will differ enough in details of ER struetural design or pattern to make a separation of eleetron microseope images perfectly possible if not easy. 


\section{Medulations in EIR patterns}

When one speaks of these patterns in this membrane system, one refers of course to the preferred pattern in the normal cell. Modulations from this pattern are an expected part of the nomal functioning of the cell, and exaggerated expressions of this can be achieved by certain more or less synthetic devices.

It has been known for some time that the secretory cells of the seminal vesicle-along with several other epithelia-are responsive to hormonal control and show, as evidence of this, distinct microscopic changes. For example, under the influence of increased endogenous or exogenous androgen, these secretory cells increase in height and basophilia; whereas after castration both the height and basophilia greatly diminish (Moore, 1939). When these changes are examined for their fine-structural expression, it is discovered that in the castrate the number of vesicles and cisternae of the endoplasmic reticulum is drastically reduced ( $\mathrm{Figs}$. $11 \mathrm{~A}$ and $11 \mathrm{~B}$ ). The profiles representing the system retain an orientation with the long dimension parallel to the nuclear envelope, an organization or pattern which is characteristic of the normal cell. The volume of matrix material is possibly about equal to that in the control. The great difference then is in the volume of the ER and the surface area available for the support of ribosomes. In animals stimulated by exowenous androgens, the ER of the secretory cells shows the opposite response: it obviously proliferates to produce a system with dimensions in excess of normal. We find then a distinct and perhaps direct response in this system to the presence or absence of hormone (Deane and Porter, 1960). The response is not so much in a change of pattern as in area and volume of this functioning system. A morphological hypertrophy accompanies the functional stimulation, and the hypertrophy is limited to the system most clearly associated with the function. The modulation, which appears pronounced, is one of extent rather than design. Just how the hormone achieves this proliferation or where it lodges in the cell is a problem for future investigation.

A somewhat similar though less dramatic response is shown by the liver cells of the common fowl cockerel in response to estrogen stimulation. In this form, the materials for egg-yolk formation are synthesized in the liver. The greater activity of the hen's liver in this regard is expressed in a number of morphological features including a distinctly more extensive development of the endoplasmic reticulum. When a cockerel is injected with estrogenic hormone, lipoproteins and phosphoproteins associated with egg-yolk formation appear in 
1. pot

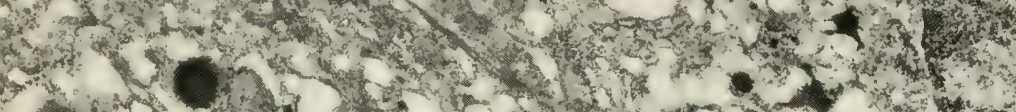
$29+x+10$ (1) $32 \times$

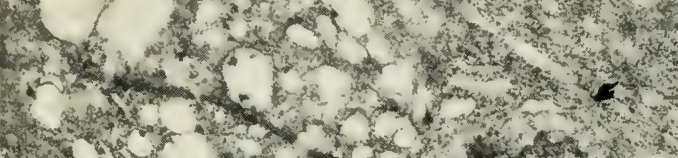

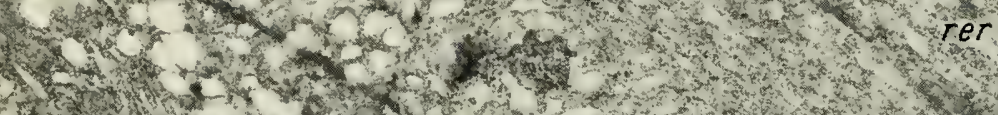

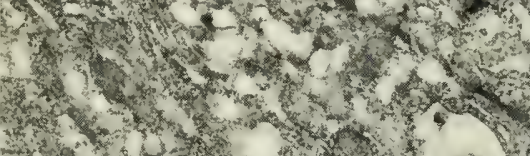

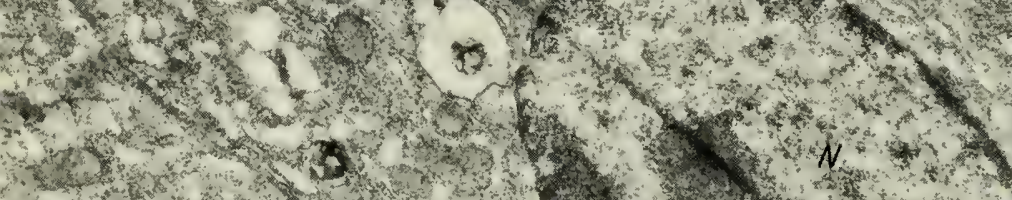

$A$

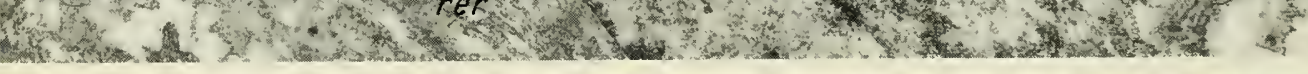

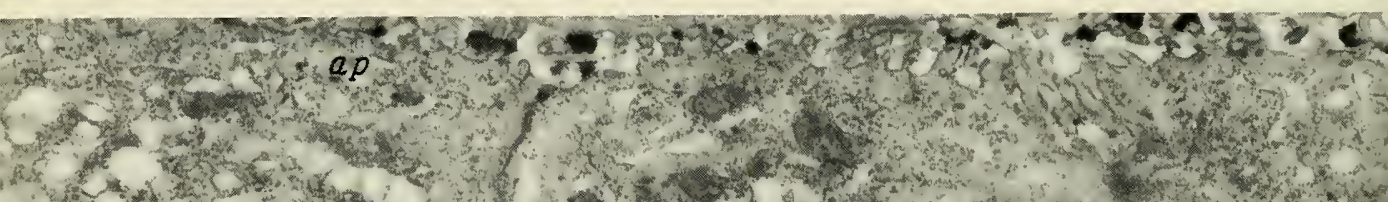

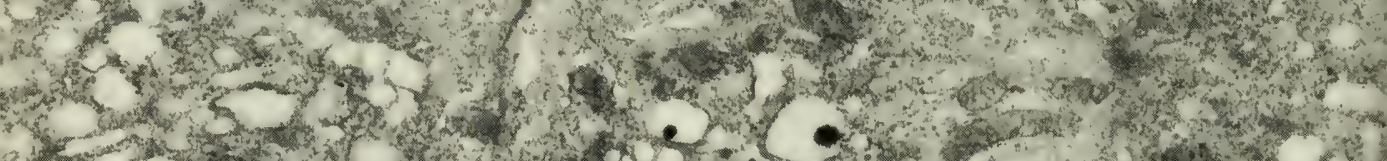

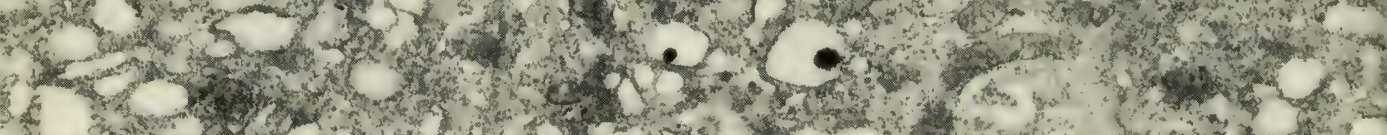

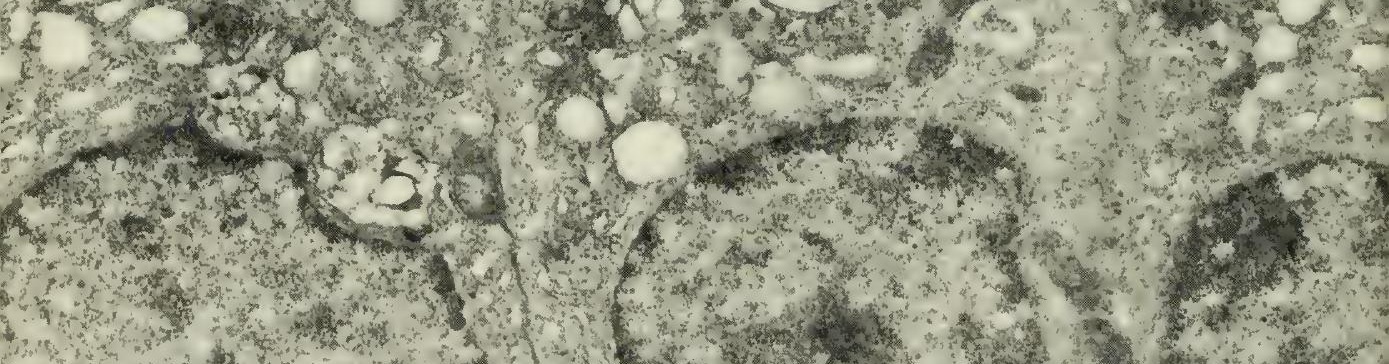

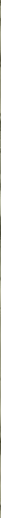


the blood plasma (Common et al., 1948: Sehjeide and Urist. 1956) and the liver cell approximates in its fine structure that of the hen. Among other things, the ER increases approximately two-to theefold (Figs. 12A, 12B). Here again. the pattern of organization remains much the same, with eisternae of the ER associated with mitochondrial surfaces; only the number of cisternae increases. which implies a corresponding increase in volume of the system and the area of its surface.

It is evident from the foregoing that some of the diversity cucountered at subcellular levels is controlled by extracellular factors. or factors of extracellular origin. Less dranatic are of course the natural variations that accompany the normal function. When, for example. a muscle fiber contracts. there are well-known alterations in the strueture of the fihrils: equally impressive but less well-known changes appear in the fine structure of the sarcoplasmic reticulum. The general pattern of organization shown by the SR of the relaxed fiber persists along with the sarcomeric organization of the fibrils. but the retails of fine structure of the system are radically and characteristically altered (Franzini and Porter, unpublished observations).

A better documented example is provided by the liver cell and its response to plasmaphoresis. It has heen repeatedly noted (Stenram. 1953: Lagerstedt, 1949: Glinos. 1958, that when an animal is deprived of plasma proteins through repeated bleerlings (and return of cells) the distribution of the basophilic material (the ergastoplasm) in the

FIG. 11A. Parts of two secretory cells of the normal mouse seminal vesicle. The hasal pole $(b p)$ is at the lower right, the apical (ap) at the npper left. The cytoplasm is filled with long profiles of the rough ER (rer) or ergastoplasm, with their long axes oriented parallel to the long axis of the cell. The larger spherical vesicles toward the apical pole are part of the Golgi complex.

The pattern of organization shown by the endoplasmic reticnlnm in these cells is characteristic of this tissue in the normal mouse and also in mice given exog. enous testosterone. Obviously the cisternae tend to enwrap the nuclens except at the basal pole. The irregular inside dimensions of the cisternae may reflect uneven accumulations of synthesized material. The limiting membranes of these cisternae are typically indistinct and densely packed with ribosomes. The total surface for ribosome association is relatively enormous (Deane and Porter. 1960). (Courtesy of Helen $\Pi$. Deane.) Magnification: $10,200 \times$.

FIG. 11B. Epithelial cells of the monse seminal vesicle as they appear two weeks after castration. They have obviously lost height and are not now tall and columnar as in Fig. 11A. Basal and apical poles are indicated. The change in volmme and height is reflected in. and is possibly due to a great reduction in the amount of ergastoplasm. The profiles of cisternae are still evident. The pattern of organization shown by these is the same as in the normal animal; only the long dimensions and total surface area have diminished. Magnification: 10,200×. 
cytoplasm is altered. The discrete chmps of densely staining material become less discrete and the components secur to become more diffusely distributed in all cells of the lobule as they are normally in cells bordering the portal areas. One might conchurle from this that rather pronounced changes would be found in the form and distribution of the rough form of the endoplasmic reticulum. Actually, when examined (Porter and Brumi, unpublished) in the electron microscope, the phenomenon is found to be referable to the distribution of mitochondria relative to the cisternae of the ER. In the relatively quiescent cell of the normal animal, the cisternae tend to appear in clusters of 8 to 12 units in parallel array (Figs. 13A and 13B). These would reasonably correspond to the discrete basophilic bodies of the light microscope image. In the plasmaphoresed animal, on the other hand, one finds these clusters of cisternae invaded by mitochondria and thus more widely separated (Fig. 13B) which, from an examination of adjacent thick and thin sections, can be seen to account for the diffuse basophilia of the stained cells. Thus in response to demands for increased synthesis of plasma proteins, the structural elements of the ergastoplasm take on a more intimate association with the mitochondria, presumahly for the ATP required. Here again it is to be noted that within the limits of this modulation, the pattern of organization exhibited by the ER departs from the normal only to admit the mitochondria to the intercisternal spaces in the otherwise characteristic clumps or clusters of cisternae.

\section{The ER in differentiation}

The diverse forms which have been described and illustrated here, and in most published descriptions of this system, are found in fully

FIG. 12A. Portions of two cells from a normal cockerel liver. The picture shows the typical form of the endoplasmic reticulum in the liver cells of this animal. Single cisternae with associated ribosomes are wrapped around the mitochondria. A few vesicles of the agranular type are mixed with the glycogen $(g l)$. Mirrograph from class project. graduate-student course in cell biology. Magnification: $20,000 \times$. FIG. 12B. Liver of cockerel 4 days following injection of estrogen. Among other changes induced by this treatment, there is a pronounced increase in the amount of the rough form of the endoplasmic reticulum. The cells come to resemble more closely those of the hen's liver, and the plasma requires lipoproteins and phospho. proteins found normally in the laying lien. These are synthesized for egg-yolk production. Thus exogenous estrogen induces marked proliferation of the rough ER. but the pattern of distribution and mitochondrial association remains similar to that in hen and cockerel. The nucleus is indicated at $N$, the mitochondria at $M$. spaces of Disse at $D i$, rough ER at rer. (Complete observations in press.) Magnification: $23.000 \times$. 
Diversily at the Subcellular Level and Its Significaner 157

or almost fully differentiated cells. In some instances, the most prom. inent expression of differentiation is to be found in the ER. In other instances this system fades to morphologieal insignificance as the cell differentiates - as for example, in erythroblasts (Fig. 10) or in cells of the epidermis (Fig. 8) (the retaining cells of Mercer, 1961). Regardless of the degree of its eventual involvement in the fine structure of the differentiated cell, it is a constant structural componcut of the undifferentiated cell. and it is a constant struetural component of the undifferentiated unit. It is represented from the bewinning of development by the nuelear envelope, and some evidence of it as a cytoplasmic structure is found as early as the two-cell stage (Sotelo and Porter, 1959).

Since electron microscope studies of differentiating cells are still rare (see Hay, 1958: Salpeter and Singer. 1960; Slantterback and Faweett, 1959; Wadlington and Perry, 1960; Bellairs, 1959), generalizations are hazardous. One gets the impression, hovever, that the system exists in embryonic cells as a relatively loose retieulum of tubular and vesicular elements (Fig. 5). Recognizable patterns of organization have so far been described only in the mature functioning cell.

\section{Conclusions:}

The paper has sought to remind the reader of the wide diversity of forms which may be found at the subcellular level of structure. These are all recognized as variations on a basic arehitecture found in the

FIG. 13A. Part of a normal rat liver cell, showing a morphology typical for cells around the central vein of the lobule. The parallel cisternae of the rough ER are closely packed in parallel array and in this form coincide with the discrete baso. philic bodies of these cells. The mitochondria normally retain a peripheral location relative to such clnsters. Adjacent areas, rich in glycogen, also show dense developments of the smooth reticulum. (For symbols, see Fig. 1.) Magnification: 18,000 $\times$. FIG. 13B. Area of liver cell similar to that in Fig. 13A. except that the animal from which this tissue was taken had been deprived of approximately $15 \mathrm{cc}$ of whole plasma within the 24 -hour period preceding sacrifice. The clange in fine structure of the ER reflects changes in the stained image in which, under the conditions of this experiment, the basophilic material appears in less discrete, more diffuse masses. This electron micrograph reveals that the cisternae in these rells are less rlosely arrayed and show a larger and less uniform intercisternal space; most ignificant of all. in accounting for the change in the light microscope image. the mitochondrit are here intermingled with the cisternae. Presumably the ER here is more active in the synthesis of plasma proteins, and the changes in fine structure reflect this fact. Despire the mitochondrial invasion, the general ER pattern. rharacteristic of rat liver cells, persists. (Symbols as for Fig. l.) Magnification: $18.000 \times$. 
cytoplasm of all cells (excepting bacteria and certain blucegreen algae). This includes a nuclear envelope in the form of a thin, menbrane-limited vesicle, perforated at numerous points in the surface. Many of the tubular and vesicular elements of the eytoplasin are apparently derivatives of or morphologically continuons with this envelope. These structures, along with mitochondria and other distinctive organelles, are bathed in the cytoplasmic matrix or continuous phase of the cytoplasm, which supports as well such resolvable differ. entiations as filaments or filurils, and particulates like ribosomes and ferritin. Diversity in the subcellular appearance of the cytoplasm is largely a reflection of the degree to which one or another of these structures dominates the picture.

Special attention has been directed to the diverse forms adopted by the complex membrane-limited system known as the endoplasmic reticulum. It was emphasized that this newly defined component of cells frequently appears in recomizable patterns in cells-patterns which are constant in differentiated cells of a single tissue type. From evidence available, one may conclude that the system functions in the sequestration and transport of products of synthesis, especially where these are destined for export from the cell. It supports on its surfaces the ribosomes as specific sites of synthesis and one may infer the same surface relationship holds for other enzymic dependent reactions. Thus the ER provides a patterned distribution of functions which extends to all parts of the cytoplasm and is integrated with the nucleus, Golgi. mitochondria, myofibrils, and other structures in support of normal, coordinated cell function. Modulations in the appearance of the system involve not so much a change of pattern as a change in quantity and surface area and minor relationships to associated cell components. The fluid anatomy of the system is cvidenced by these modulations. These various properties of the ER make it an excellent candidate for the role of cytoskeleton which Rudolph Peters (1956)

FIG. 14. A hepatoma cell with morphology typical for this transplantable tumor (a rapidly growing hepatoma known as the Dunning). There are many features of fine structure that one expects to see in tumor cells. The surface shows irregularities, in this instance like microvilli; the cytoplasmic matrix contains numerous free ribosomes; and the nitochondria $(m)$ are small and abnormal or inconpletely differentiated. The features of particular interest for this treatise are the extreme abnormalities of the ER. There are no lamellar cisternae such as one finds in the normal. Instead the system consists of irregular vesicles, with particles unevenly distributed ( $e r$ ). There is evidence of unusual extensions from the nuclear envelope (at arrows). The cell fails to store recognizable glyrogen; there is no system resembling the smooth ER of the normal cell. The endoplasmic reticulum in general is highly disordered. (Courtesy of Carlo Bruni.) Magnification: $15.000 \times$. 
postulated some years ago as required for the integrated behavior of cells-a patterned framework of surfaces and cavities upon which enzymes could be differentially distributed and within which metabolites and products of metabolism could be segregated.

With this thought in mind, it is interesting to look at cells in which at least one expression of normal integration-the capacity to form normal tissues - is lost. These are the cells of tumors.

Carlo Bruni and $I$ have in recent years been comparing the fine structure of rat hepatomas, possessing different growth rates, with one another and with that of the normal liver (Porter and Bruni, 1962). The hepatomas were all induced with chemical carcinogens, have gone through many transplantations, and are cytologically stable. In terms of fine structure, the cells of each tumor show characteristic features which have been constant during the period of study. A number of observations of interest could be mentioned, but in this connection it is important to note only that the structure of the endoplasmic reticulum is very abnormal (Fig. 14) and that the degree of departure from the normal is most pronounced in the more rapidly growing tumors. To what extent the lesions in the ER are involved in other manifestations of malignancy is hard to say, but, if in the normal the endoplasmic reticulum does play a role in the integrated biochemistry and physiology of the cell, the form it shows in these hepatoma cclls would not be expected to support that role.

\section{ITeferences}

Andersson-Cedergren, E. (1959), Ultrastructure of motor end plate and sarcoplasmic components of monse skeletal nuscle fiber as revealed by three-dimensional reconstructions from serial section. J. Ultrastruct. Res., 2, Suppl. 1.

Ashford, T. P., and K. R. Porter (1961), The response of hepatic cell fine structure to isolation perfusion, Proc. 1st Ann. Meeting Amer. Soc. Cell Biol., p. 10.

Bellairs, R. (1959), The development of the nervous system in chick embryos. studied by electron microscopy, J. Embryol. Exp. Morphol., 7:91-115.

Bernhard, W., F. Haguenau, A. Gautier, and C. Oberling (1952). La struture submicroscopique des elements basophiles cyloplasmiques dans le foie, le pancreas et les glandes salivaires, Z. Zellforsch. Mikroskop. Anat., Abt. Histochem., 37: 281-300.

Caro, L. G. (1961), Electron mieroscopic radio-autography of thin sections: the Golgi zone as a site of protein concentration in pancreatic acinar cells, J. Bio. phys. Biochem. Cytol., 10:37.

Christensen. A. K., and D. W. Fawcett (1961), The normal fine structure of opossum testicular interstitial cells, J. Biophys. Biochem. Cytol., 9:653-670.

Common, R. H., W. Bolton, and W. A. Rutledge (1948), The influence of gonadal hormones on the composition of hlood and liver of the domestic fowl, J. Endocrinol., $5: 263-273$. 
Dalton, A. J. (1951). Electron micrography of epithelial rells of the gantro-intentinal tract and pancreas, Am. J. Anat., 89:109-133.

Deane, H. W., and K. R. Porter (1960). Comparative study of "ytoplasmir haso. philia and the population density of ribosomes in the secretory cells of monse seminat vesicle, Z. Zellforsch. Mikroskop. Anat., Abt. Histochem.. 52:697-711.

Ebashi, S. (1961), Calcium binding activity of vesicnlar relaxing factor, J. Biochem. (Toliyo), $50: 236-244$.

Fanré-Fremiet, E., P. Favard. anıl N. Carasso (1962), Etude au microseope éleetronique des ultrastructures d'Epistylis anastatica. J. Hicroscopie. I :287-312.

Fawcett, D. W. (1955), Observations on the eytology and eleetron microseopy of hepatic celts, J. Nat. Cancer Inst. 15, suppl.:1475-1507.

—_ and J. P. Revel (1961), The sarcoplasmic reticulum of a fastacting fish muscle, J. Biophys. Biochem. Cytol., 10:89-108.

, and C. W. Selby (1958), Observations on the fine strueture of the turtle atrium. J. Biophys. Biochem. Cytol., 4:63-72.

Fernandez-Moran, H. (1960). Cell membrane ultrastructure. Low temperature electron mieroseopy and $x$-ray diffaction studies of lipoprotein eomponents in lamellar systems, Proc. Ann. Meeting Assoc. Res. Nervous Mental Diseases, Alhert Einstein College of Medicine. New York.

Franzini, C., and K. R. Porter (nupublished observations).

Garnier, C. (1899), Contribution à létude de la structure et du fonetionnement des cellules glandulaires séreuses. Du rôle de l'ergastoplasme dans la sícrétion, Thesis, Nancy, no. 50.

Glinos, A. D. (1958), The mechanism of liver growth and regeneration, in The Chemical Basis of Development, ed. by W. D. McElroy and Bently Glass, Johns Hopkins Press, Baltimore, pp. 1813-1839.

Hagnenau, F. (1958), The ergastoplasm: its history, ultra-trueture and biochemistry, Intern. Rev. Cytol., $7: 425-483$.

Hay. E. D. (1958), The fine strueture of blastemia cells of diffentiating rartilage in regenerating limbs of Amblystoma larvae. J. Biophys. Biochem. Cytol.. 4: $583-592$.

Ito, S. (1961). The endoplasmic retienlum of gastric parietal eells, J. Biophys. Biochem. Cytol.. $11: 333-347$.

Lagerstedt, S. (1949), Previons histological and eytochemieal investigations on changes in the liver cells in connection with protein assimilation. Section entitled: "Cytological Studies on the Protein Metabolism of the Liver in Rat," Acta Anat., 7, suppl. 9:1-112.

Lotfield. Robrrt B. (1957), The biosynthesis of protein. in Progress in Biophysics and Biophysical Chemistry. Pergamon Press. New York. vol. 8. p. 347.

Luck, D. J. L. (1961), Glycogen synthesis from uridine diphosphate glucose. The distribution of the enzyme in liver cell fractions. J. Biophys. Biochem. Cytol.. $10: 195-209$.

Lynn. Jr., W. S., and R. H. Brown (1958), The conversion of progesterone to androgens by testes, Biochem. J.. 232:1015-1030.

Nercer, E. H. (1961), Keratin and Keratinization. Pergamon Press. Nen lork. lp. $1-316$.

Moore, C. R. (1939), Biology of the testes, in Sex and internal secretions. 2d ed.. ed. by E. Allen, The Williams \& Wilkins Company. Baltimore. Pr. $353-451$.

Muscatello, U.. E. Andersson.Cedergren. G. F. Azzone. and A. vin der Decken 
(1961), The sarcotubular system of frog skeletal muscle. A morphological and biochemical study, J. Biophys. Biochem. Cytol., 10:201-218.

Palade. G. (1953), An elcctron microscope study of the mitochondrial structures, J. Histochem. Cytochem., $1: 188-211$.

(1955a). Studies on the ER. II. Simple dispositions in cells in situ, J. Biophys. Biochem. Cytol., $1: 567-582$.

(1955b), A small particulate component of the cytoplasm, J. Biophys. Biochem. Cytol., 1:59-68.

(1956a). Electron microscopy of mitochondria and other cytoplasmic structures, in Enzymes: Units of Biological Structure and Function, Academic Press, Inc., New York.

- (1956h), Intracisternal granules in the exocrine cells of the pancreas. J. Biophys. Biochem. Cytol., $2: 417$.

- (1956c), The endoplasmic reticulum. J. Biophys. Biochem. Cytol., 2, suppl.: 85-98.

- , and K. R. Porter (1954), Studies on the endoplasmic reticulum 1. Its identification in cells in situ, J. Exp. Med., 100:641-656.

and biochemical study. J. Biophys. Biochem. Cytol., $2: 171-200$.

Pappas. G. D., and P. W. Brandt (1958), The fine structure of the contractile vacuole in Ameba, J. Biophys. Biochem. Cytol., 4:485-487.

Peters, R. (1956). Hormones and the cytoskeleton. Nature (London), 177:426.

Philpott. C. W. (1962a). Teleost Osmoregulation: A comparative study of the fine structure of chloride cells in three species of Fundulus, Dissertation Abstracts (in press).

- (1962b), The comparative morphology of the chloride secreting cells of three species of Fundulus as revealed by the electron microscope. Anat. Record, 142 : 267-268.

Porter, K. R. (1953), Olservations on a submicroscopic basophilic component of cytoplasm, J. Exp. Med., $97: 727-750$.

- (1961a), The ground substance; observations from electron microscopy, in The Cell, ed. by J. Brachet and A. E. Mirsky. Academic Press, Ine., New York, vol. 2, pp. 621-675.

- (1961b), The endoplasmic reticulum: some current interpretations of its forms and functions, from Biol. Struct. Function, $1: 127$.

- (1961c). The sarcoplasmic reticulum: its recent history and present status, J. Biophys. Biochem. Cytol., 10, suppl.:219-226.

- - and C. Bruni (1959), An electron microscope study of the early effects of 3'-Me-DAB on rat liver cells, Cancer Res., 19:997-1010.

$\longrightarrow$, and - $-(1962)$, Comparative fine structure of slow- and fast-growing hepatomas, Program, 8th Intern. Cancer Congr., Moscow.

___ and G. E. Palade (1957), Studies on the endoplasmic reticulum. III. Its form and distribution in striated muscle cells, J. Biophys. Biochem. Cytol., 3:269-300.

cells cultured from mammary carcinomas of a milk factor strain. J. Exp. Med., 88:15-23.

- and E. Yamada (1960), Studies on the endoplasmic reticulum: its form and differentiation in pigment epithelial cells of the frog retina, J. Biophys. Biochem. Cytol., 8:181-205.

, et al. (unpublished observations). 
Reger, J. F. (1961), The fine structure of neuromuscular junctions and the sirenplasmic reticulum of extrinsic eye muscles of Fundulus heteroclitus, J. Biophys. Biochem. Cytol., 10:111-121.

Revel, J. P. (1962). The sarcoplasmic reticulum of the bat cricothyroid mucte, J. Cell Biol., $12: 571-588$.

Salpeter, M. M.. and M. Singer (1960). The fine structure of mesenchymatous cells in the regenerating forelimb of the adult newt Triturus, Develop. Biol., 2:516534.

Schjeide, O. A.. and M. R. Urist (1956), Proteins and calcinm in serums of entrogen. treated roosters. Science, 124:1242-1241.

Sedar. A. W. (1961a). Electron microscopy of the oxyntic cell in the gastric glands of the bullfrog (Rana cateshiana). T. The non-acid-secreting gastric mucosa. J. Biophys. Biochem. Cytol., 9:1-18.

(1961b), Electron microscony of the oxyntic cell in the gastric glands of the bullfrog. Rana catesbiana. II. The acid-secreting nuncosa, J. Biophys. Biochem. Cytol., 10:47-57.

Siekevitz. P., and G. E. Palade (1960a), A cytochemical study on the pancreas of the guinea pig. Y. In vivo incorporation of leucine-1. $\mathrm{C}^{1+4}$ into the chyotryp. sinogen of varions cell fractions. J. Biophys. Biochem. Cytol., 7:619-630.

- and — (1960b). A cytochemical study on the pancreas of the guinea pig. VI. Release of enzymes and ribonncleic acid from ribonucleoprotein particles. J. Biophys. Biochem. Cytol.. $7: 631-644$.

Sjöstrand, F. S. (1953), Electron microscopy of mitochondria and cytoplasmic double membranes, Nature (London). 171:30-31.

Slantterback. D. B.. and D. W. Fawcett (1959), The development of the cnidoblasts of Hydra. An electron nicroscope study of cell differentiation. J. Biophys. Biochem. Cytol., 5:441-452.

Smith, D. S. (1961), The structure of insect fibrillar flight muscle. A study made with special reference to the membrane systems of the fiber, J. Biophys. Biochem. Cytol., 10. suppl.:123.

Sotelo. J. R.. and K. R. Porter (1959). An electron mirrosope study of the rat ovum. J. Biophys. Biochem. Cytol.. 5:32 i-34l.

Stenram, U. (1953), Basophilic rods in the liver cell cytoplasm of rat, Acta Anat.. $18: 360$.

Waddington, C. II.. and M. M. Perry (1960). The ultra-structure of the developing eye of Drosophila, Proc. Roy. Soc. (London). B, 153:155-178.

Watson, M. L. (1955), Nuclear envelope. J. Biophys. Biochem. Cytol., 1:257-269.

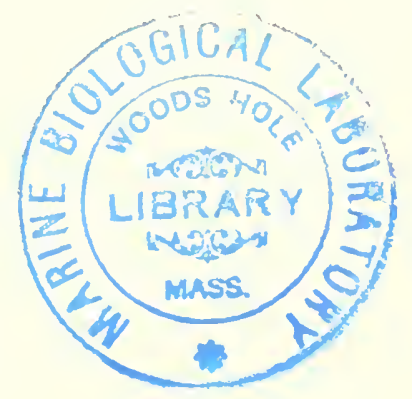





\section{Does Preformed Cell Structure}

\section{Play an Essential Role}

in Cell Heredity?*

Tracy M. Sonneborn $\dagger$

Department of Zoology Indiana University, Bloomington, Indiana

\section{Introduction}

This ehapter raises and attempts to answer a simple, fundamental question that is commonly ignored. Does the structure or organization of a cell, aside from that of its chromosomes, play an essential role in the determination of the structure of its cell progeny? This question is a timely one. The underlying simpler and hasic questions of the nature of the gene and gene aetion, it is widely helieverl, will soon be essentially solved and the time will be ripe for equally concen-

* Contribution No. 716 from the Department of Zoology. Indiana Univer:ity.

$\dagger$ The author gratefully acknowledges the invaluable collaboration of Dr. Ruth V. Dippell in the researches reported in the first half of this chapter. The inventigations were supported by grants from the American Cancer Society (E80 and E81D). the Atomic Energy Commission (AT(11-1).235), the Rockefeller Foundation. and In. diana University. 
trated attacks upon problems at the next higher levels of complexity. Foremost among them are the problems of the nature, development, and inheritance of structure at the higher supramolecular and microscopically visible levels within the cell.

The simplest working hypothesis to guide thought and investigation on these problems, and one which scems to have wide current appeal, is that higher levels of structure within the cell, above that of the polypeptide product of the cistron or gene, are accounted for by three factors: the physicochemical properties of reactants, their random collisions, and the ionic and molecular constitution of the cell "soup" in which the collisions occur. These factors are held to determine how gene products are built up into multipolypeptide enzymes and structural proteins, how multienzyme systems come together in proper sequential arrangement, how enzymes and substrates come together and yield further products, how smaller ribosomes combine to form larger ribosomes, and so on. The "self-assembly" hypothesis in its most extreme form thus ultimately traces the building of all cellular structure to molecular contributions from milieu and genes and to random collisions of previously unarranged reactants. While some molecular biologists, at least in oral discussions, seem to have great confidence in the full adequacy of the hypothesis, others adopt it tentatively with the express purpose of seeing how far it can be carried, how much structure can be accounted for without invoking additional factors. That some degree of structure can already be explaincd in this way seems evident. The question then is: Do we now know, or can we discover, whether the hypothesis is sufficient to account for all cell structure?

Doubts have long existed, espccially among students of the ciliated protozoa (Sonneborn, 1951, 1960; Wiesz, 1954; Ehret, 1960; Tartar, 1941, 1961), as to the sufficiency of so simple a hypothesis in the light of evidences for the essential role of a fourth factor, a specific preformed organization of the cell or its parts. This organization seems unable to arise de novo by gene action in any noncellular milieu or unorganized cell "soup." Moreover, a nucleus from a cell of one species often fails to make its own kind of cell when introduced into an organized cell of a closely related species. Decisive further evidence for an essential role of preformed cell structure in the inheritance of cell structure will be presented in the first half of this chapter. In the second half, some important literature will be considered in relation to our work and an attempt will be made to search for the underlying gencralities and the mechanisms involved.

Satisfactory experimental analysis of the genetic function of pre- 
existing cell structure requires a cell that possesses con-picnous, constant, normal organizational features. However, it also obviou-ly requires a cell with readily available or producible hereditary valriations of its normal features. Finally, the cell should be amenable to standard breeding analysis and other analytic procedures. Few, if any. cell types possess the needed combination of qualifications to the degree exhibited by the ciliated protozoan, Paramecium anrelia. Within this species, stock 51 (of syngen 4) and its derivatives are especially suitable because of the availability of adequate nuclear and cytoplasmic markers and an array of varied experimental tricks useful for decisive experimental analysis. This material was therefore used.

Attention was directed to the characteristic pattern of cortical organelles and its experimental modifications. The first and most exhaustively studied modification was the doublet cell, which possesses two complete sets of cortical structures. Doublets and other cortical variations in various ciliates, including Paramecium, have been studied from a number of points of view by many workers (see page 198). Some of their conclusions are closely similar to the ones reached in the present study, the unique feature of which is the completeness of the essential genetic analysis and some aspects of the seareh for generalities and mechanisms. Preliminary abstracts of some of the present work have been published by Somneborn and Dippell (1960a: 1961a, b, c; 1962).

\section{The Partern of Cortical Strueture in Paranecium anrelia}

\section{A. The cortival patcen in normal singlets}

Most of the features of the cortical pattern of $P$. aurelia, which were followed in this investigation, are shown in Fig. 11 of the dorsal (aboral) and Fig. $1 B$ of the ventral (oral) surfaces of a typical normal cell. The most conspicuous features of the dorsal surface are two large dots on the same meridian or not more than a few meridians apart. These are the pores of the contractile vacuoles. Normally. the anterior pore is further from the anterior pole than the posterior pore is from the posterior pole. The most conspicuous features of the ventral surface are all on one meridian. the oral meridian. Near the middle of this meridian is a large oval or comma-shaped depression, the vestibule, at the base of which is the clear, open mouth technically, the buccal ovcrture). Anterior to the mouth is a long, narrow, clear area -the preoral suture-extending from the mouth forward and left to 
the anterior pole. (The direetions right and left will always refer to the animal's right and left of the oral meridian which is considered to be the midventral line.) Posterior to the mouth is a long line, the eytopyge or eell amus, which lies on the postoral suture. The latter is the posterior half of the oral meridian, extending from the mouth
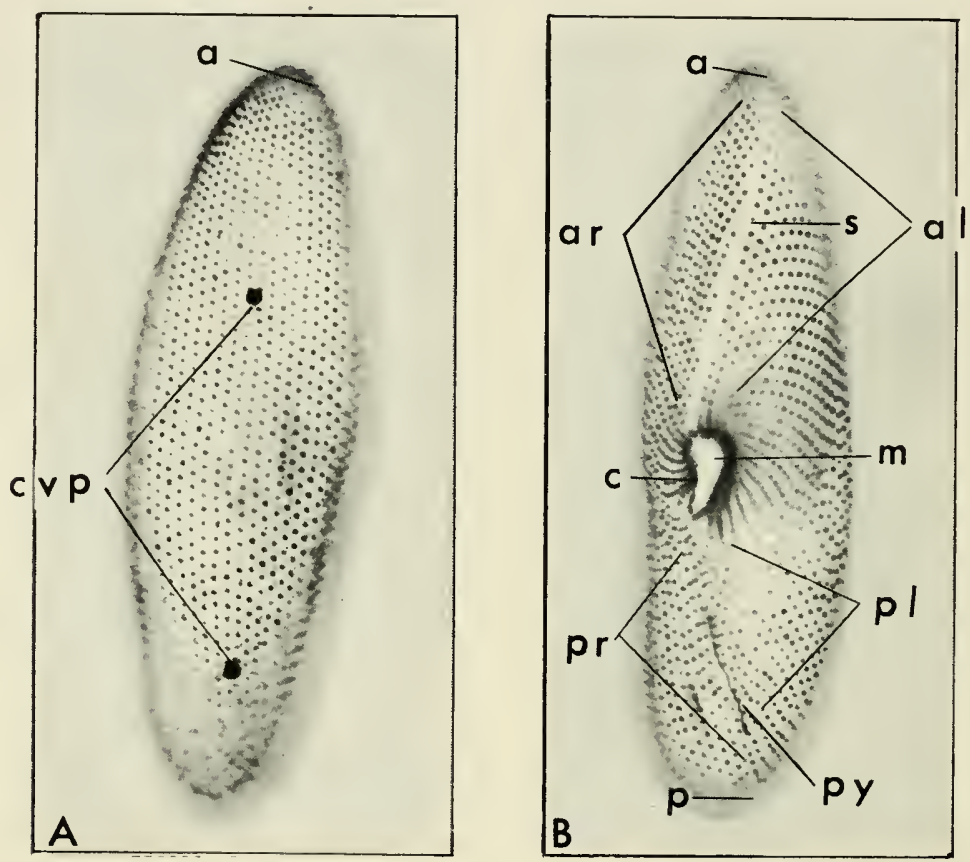

FIG. 1. Photographs of $P$. aurelia prepared by the silver impregnation technique. $A$. Dorsal or aboral surface. $B$. Ventral or oral surface. Magnification: $730 \times . a$, anterior pole; $a l$, anterior left kinety field; $a r$, anterior right kinety field; $c$, circumoral or vestibular kinety field; $c v p$, contractile vacuole pore; $m$, mouth; $p$, posterior pole; $p l$, posterior left kinety field; $p r$, posterior right kinety field; $p y$, cytopyge; $s$, preoral suture.

posteriorly and to the left toward the posterior pole. Unlike the preoral suture, the postoral suture is not a clear area but only a line of close juncture between two different surface patterns (see below).

Although the contractile vacuole pores and the three parts of the oral meridian (preoral suture, mouth, and cytopyge) are the most conspicnous features of the cortical pattern, the rest of the cortex exhibits a beantiful eonstancy of finer patterning marked by regularly oriented rows of dots much smaller than those representing the 
two contractile vacuole pores. Each dot represents one cilium and its base or kinetosome; each row of dots represents a row of kinetosomes. i.e, a kinety. In order not to interrupt the account of normal cortical pattern, I an goingr to describe at onee the way the kineties are grouped into eluacteristically patterned areas. Much of this description will be readily followed on Figs. $1 A$ and $1 B$; but part will at this point have to be taken on faith until I explain more fully (on pares 170 and 171) some of the details of cortieal strueture, the cytological technique used in preparing the specimens for study, and just what the dots on the photographs are.

There are six major groupings of kineties into characteristic fields: one dorsal and five ventral. The whole dorsal surface is a great field of longitudinal and parallel kineties, except where they converge near their ends to the anterior and posterior poles (which do not exactly coineide with the ends of the midlongitudinal axis of the body). The following five main ventral fields are on the sides of the oral meridian: (1) The anterior right field is composed of kineties that are nearly parallel to the preoral suture. (2) The anterior left ficld is composed of kineties that are almost perpendieular to the preoral suture. (3) The circumoral field lies in the vestibule and is composed of arched kineties paralleling the edge of the mouth. In ventral views the vestibule is seen on edge, making its kineties appear so elose together as sometimes to give the impression of a heary ring around the mouth. (4) The posterior right field is composed of kineties that extend parallel to the cytopyge line. (5) The posterior left field includes kineties that meet the eytopyge at an acute angle. Adjacent fields are not sharply set off from one another except where they meet the oral meridian. Thus the two anterior fields arade into the cireumoral field and the latter grades into the two posterior fields, especially in the region between the posterior end of the mouth and the anterior end of the cytopyge. Likewise, the distinetive patterns on the right and left of the oral meridian grade into the simple interpolar pattern on the dorsal surface. The five ventral fields and the gullei together will he referred to as the oral segment.

By far the most complex structure of the ventral surface is its internal extension beyond the mouth into the fumel-shaped gullet or eytopharynx (Fig. 2A). Figures $2 B$ and $2 C$ show what appear to be 13 kineties, of which a large part of the gullet is composed. (This appearance may he deceptive in the light of the stulies of Firet and Powers (1959), whose descriptions sugrest that the number and orientation of the wullet kineties may be quite different from the superficial appearanees.) Parallel to the right margin of the mouth, at the junc- 
ture between vestibule and gullet, is a single kinety, the endoral kincty. The left side of the gullet is composed of two groups of four rows of kinetosomes each, the dorsal and ventral peniculi. The dorsal side of the gullet is made up of a group of four rows of kinetosomes, the quadrulus. Between quadrulus and endoral kinety, the right side of the gullet is composed of what is called the ribbed wall (Ehret and Powers, 1959), believed to consist of an unknown number of highly
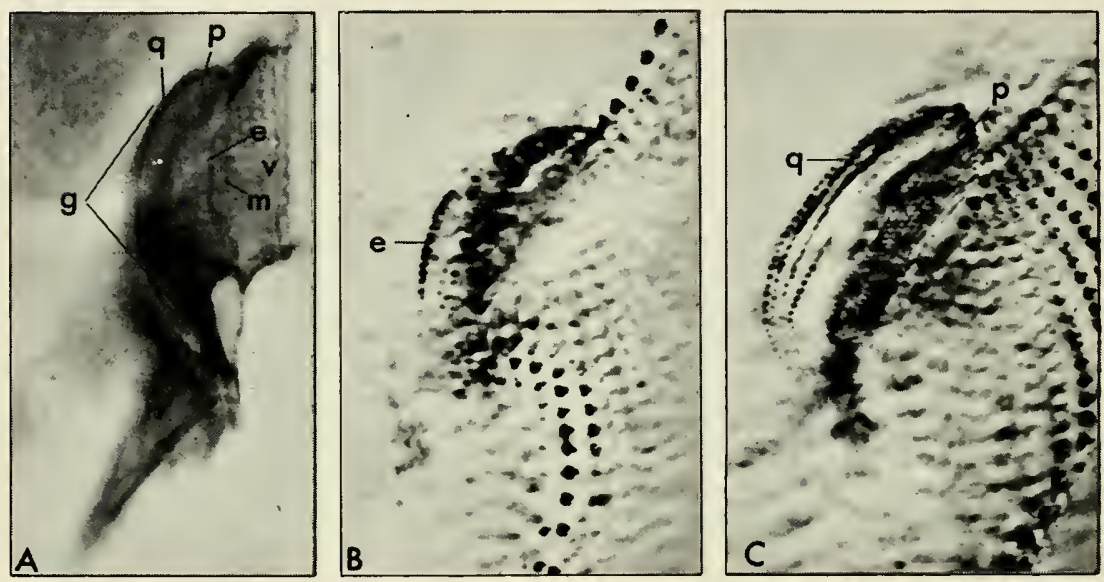

FIG. 2. The oral apparatus of $P$. aurelia. A. Vestibule $(v)$, mouth $(m)$, and funnel-shaped gullet $(g)$, viewed from right side, in specimen prepared by modified Regaud hematoxylin technique. The positions of the unseen gullet kineties are indicated by the letters used to symbolize them in $B$ and $C$. $B$ and $C$. Two focal levels of silver preparation of oral apparatus viewed from its right side; photographed with bright-field objective and phase contrast condenser. Magnification: $2,100 \times . B$. High focal level showing endoral kinety $(e)$ on right side at juncture with vestibule. $C$. Low focal level showing quadrulus $(q)$ of dorsal surface of gullet and the two peniculi ( $p$ ) of the left side of gullet. The two peniculi are so close together as to look like one structure.

modified kinetics. The ribbed wall is located to the observer's left of the endoral kinety in Fig. $2 B$, but it does not regularly show with the technique employed and is missing from this photograph.

The orientation of the kineties, for example, those in the left anterior field, sometimes seems ambiguous in the photographs, yet microscopic examination leaves no doubt. This requires some explanation, which can best be given by some further information on the composition of the cortex and its relation to the dots in the photographs. The cortex is a gelated surface layer 1 to 2 microns thick. (As 
used here, cortex is synonymous with cetoplasm. Some authors use the term "pelliele" in the same sense; others use it only for the outermost part of the cortex.) For present purposes, we need only to explain how the orientation of a kinety is recognizable. It is defined loy several features. In the first place, trichocysts alternate with one or two kinetosomes in the anteroposterior direction along a kinety. Seeond, a kinetodesmal fiber passes from the kinetosome to the right and anteriorly. Third, on the right side of each kinetosome for longitudinally disposed pair of kinetosomes) is another strueture known as the parasomal sae (Ehret and Powers, 1959). The kinety, its anteroposterior direction, and its right-left orientation are unambiguously defined hy these criteria, as mieroseopic examination of any short part of a kinety cleariy reveals.

The photographs printed here do not show all of these orienting features. The kinetodesmal fibers never appear. The position of the trichocysts is shown only irregularly because the fainter and smaller dots marking their positions (see Fig. $1 A$ at edge) are at a slightly different optical level from the larger, darker dots marking the positions of the kinetosomes. When the latter are in sharp focus, the former are either in poor focus or out of focus entirely. However, the photographs often show a blurred, faint, broken line partially connecting the dots in the same kinety and thus showing the direetion of the kinety. This serves to remove ambiguity in interpreting kinety direction, as for example in the anterior left field on Fig. $1 B$.

What then are the dots on the photographs? They are silver deposits resulting from the use of a modification of the wet-silver impregnation technique of Chatton and Lwoff (1930). Each of the heavier dots marks the position of one or two eilia (and kinetosomes) and one parasomal sac. With the phase contrast condenser the dot ean he resolved into its two or three components; the parasomal sac is always on the right and the one or two kinetosomes are always on the anteroposterior line of the kinety. As Dippell (1962) has shown, these dots are deposited on the body surface; they are not within the cortex. They mark the positions where the eilia and trichoeysts meet the body surface.

\section{B. The cortical pattern in doublets}

The structural features of the normal single animal are all present in duplicate in doublet animals (Fig. 3). The two sets of structures are in homopolar orientation with $180^{\circ}$ separating each pair of homologous structures: the two contractile vacuole neridians, the two oral 
meridians, and the two sets of 5 kinety fields adjacent to them. Between the two sets of structures, there is no partition. They appear to converge at a single anterior pole and a single posterior pole near the ends of the longitudinal axis. As one looks to the animal's right from the upper oral meridian in Fig. $3 A$, one sees first the usual three right kinety fields (anterior, circumoral, posterior) on the extreme
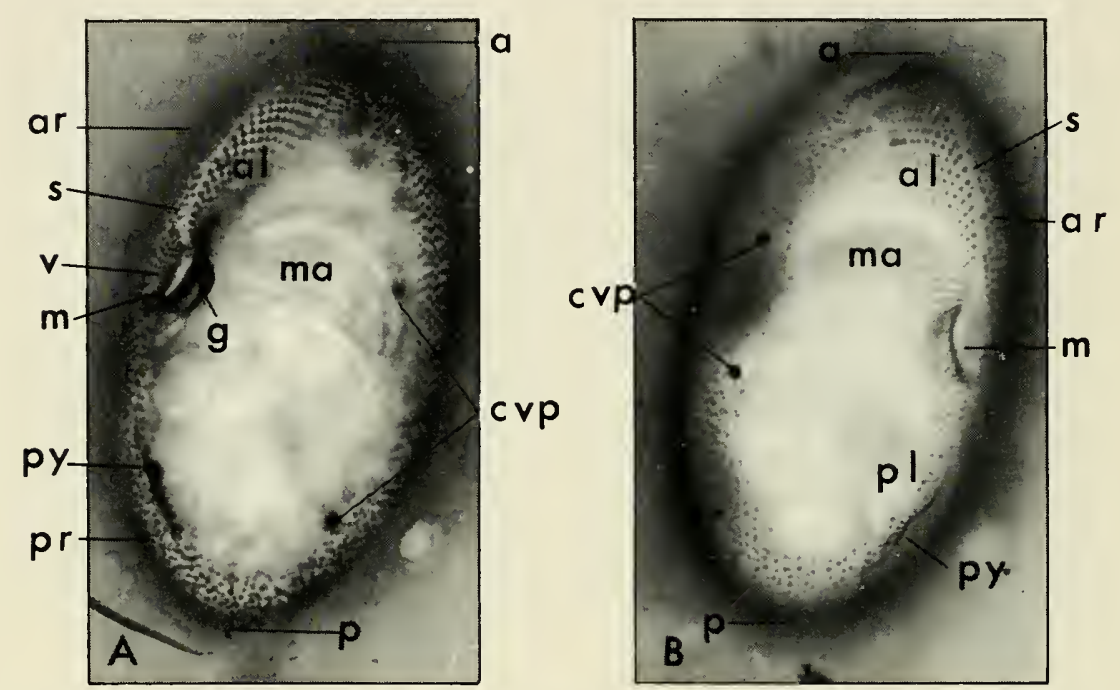

FIG. 3. Doublet animal at two focal levels: $A$, surface at upper focal level; $B$, surface at lower focal level. Silver preparation. Note that on $A$ (upper surface) the animal's right is the observer's left; but on $B$ (lower surface) the animal's right is the observer's right. $a$, anterior pole; $a$, anterior left kinety field; $a r$, anterior right kinety field; cvp, contractile vacuole pore. (The third dot on each contractile vacuole pore meridian is an artifact.) $g$, gullet; $m$, mouth; $m a$, macronucleus; $p$, posterior pole; $p r$, posterior right kinety field; $p l$, posterior left kinety field; $p y$, cytopyge; $v$, vestibule with right circumoral kinety field.

left side of the photograph. Continuing to the animal's right, by focusing down on the left from Fig. $3 A$ to $3 B$, interpolar dorsal kineties come into view and in their midst is the contractile vacuole pore meridian (or few meridians). This wide dorsal kinety field grades into the three left kinety fields (anterior, circumoral, posterior) which border on the second oral meridian seen near the right edge of $F i g$. $3 B$. The whole sequence of areas is again repeated in passing further to the right around to the starting oral meridian: the second set of right kinety fields is on the extreme right of Fig. $3 B$; continuing to 
the right now means focusing up to the right edge of Fig. $3 A$, where the dorsal field and contractile vacuole pores appear: the foens is too deep to show the rest of the dorsal field; hut, at the end of the circuit, the anterior left kinety field is in focus beside the starting point, the first oral meridian.

Internally, there is a common endoplasm witlout partition and usually only one macronucleus. In newly formerl doublets, which arise from a fusion of conjugants, there are two maeronuclei. After a relatively short time, these give way to a single macronueleus in the later progeny. Normally, the macromucleus of a singlet occupies a position close to the gullet with its major axis extending longitudinally; in doublets, the maeronueleus usually lies elose to both gullets, making its major axis transverse (Fig. $3 A$ ).

\section{The Basis of the Hereditary Difference between Singlet and Donblet P. aurelia}

As has long been known, singlets and doublets reproduce true to type through fissions (with relatively rare exeeptions that will be mentioned later). Both kinds of cells also reproduce true to type through repeated autogamies and through repeated conjugations, each with its own kind. Thus, the singlet and doublet are not merely hereditarily diverse; they show a high degree of stability through sexual as well as asexual reproduction.

In order to discover the basis of this hereditary difference, the obvious thing to do is to eross the two types of eells and carry ont a typical Mendelian analysis. As is well known (Sonneborn, 1947), conjugation in $P$. aurelia is a process of reciprocal cross-fertilization leading normally to genotypic irlentity between mates; hut there are oceasional failures leading instead to double self-fertilization (eytogamy). Therefore, in critical genetic work, the mates must be marked with different alleles in order to know whether reciprocal eross-fertilization actually occurred. Thus in our work on the breeding analysis of doublets and singlets, several unlinked pairs of alleles were always employed. The following account is confined to exconjugant clones in which the phenotypes, with respect to the marker wenes, demonstrated that normal cross-fertilization had oceurred.

Crosses of doublets by singlets regularly yielded clones of singlets from the singlet conjugants of each nating and a clone of doublets from the doublet conjugant of rach mating, in spite of the fact that both kinds of F1 elones had identical genotypes. These results indicate that the differenee between singlets and doublets is not the to a 
difference in nuclear genotype. However, in order to leave no possibility of reasonable doubt about this conclusion, the breeding analysis was carried further by backcrosses and by crosses between, and autogamy within, Fl clones. All results agreed. No segregation of singlets from doublets occurred in these generations from parents of either type. All exconjugant clones from singlet parents, regardless of genotype, were composed of singlet cells; and all exconjugant clones from doublet parents, regardless of genotype, were composed of doublet cells. Clearly, genotypic differences here had nothing to do with the hereditary difference between singlets and doublets.

The exclusion of genotypic differences suggests a cytoplasmic basis for the hereditary difference between singlets and doublets. A direct test of this possibility involves obtaining and detecting cytoplasmic transfer between conjugants (Sonneborn, 1950, pp. 119, 120, 127). Normally there is no detectable transfer of cytoplasm between mates although it sometimes occurs spontaneously in certain stocks. It is readily inducible, however, by subjecting conjugants for a short time to specific immobilizing antiserum. This establishes a cytoplasmic bridge in the region where gamete nuclei pass across, i.e., just to the right of the mouths. The bridge persists after separation has occurred at all other points, but it may eventually disappear, freeing the mates. The degree of persistence and breadth of the bridge are ronghly proportional to the amount of cytoplasm transferred. When bridges are broad, flow of cytoplasm between mates can be directly seen. Transfer of cytoplasm can also be detected indirectly by use of the cytoplasmic marker, kappa, the visible cytoplasmic particle that determines the hereditary killer trait. Each killer cell carries hundreds of kappa particles in its cytoplasm. Cytoplasm which flows from a killer to a sensitive conjugant carries kappa with it; consequently, the cells of the clone from the sensitive mate bear kappa and are killers. If cytoplasm bearing kappa is not introduced in this way into the sensitive mate, the cells of the clone it produces lack kappa and are sensitive.

Free flow of cytoplasm between mates had led to phenotypic identity of the resulting clones with regard to all previously studied hereditary traits that had been slown by breeding analysis not to be due to genotypic differences (Sonneborn, 1943; 1954a; Sonneborn and Lesuer, 1948). Its effect on the inheritance of the singlet versus doublet difference was therefore tested by using kappa and the killer trait as a cytoplasmic marker in addition to gene markers and by inducing cytoplasmic bridges between mates by the antiserum method. As shown in Figs. 4I and 4II, reciprocal crosses were made with respect to which kind of mate bore kappa and was a killer: kappa-bearing 
singlet killers were crossed to kappa-free doublet sensitives; and kappa-bearing doublet killers were crossed to kappa-free singlet sen-itives.

Again, as in the experiments reported above, singlet mates produced singlet clones and doublet mates produced doublet clonce, regardless of whether cytoplasmic transfer had occurred (Figs. 4I $\beta$ and $4 \mathrm{II} \beta$ ) or not (Figs. $4 \mathrm{I}_{\alpha}$ and $4 \mathrm{II} \alpha$ ). Even when the bridge was broad enough to see free cytoplasmic flow through it and to assure thorough mixing of the cytoplasms, eventual separation of the mates, followed hy their reproduction, yiclded clones showing the same result. Never before in our experience had we encountered results suggesting the paradoxical conclusion that a hereditary difference was neither genotypic nor cytoplasmic in basis. Accordingly, new possibilities had to be considered and subjected to analytical test.

First of all, possibilities of nuclear determination by mcchanisms other than genotypic differences were considered. One such possibility was nuclear differentiation. Earlicr studies (Sonneborn, 1947, pp. 293, 306-307) on the inheritance of mating types had shown that macronuclei of identical genotype, arising from products of a syncaryon at conjugation or autogamy, could become permancutly fixed to control one or the other of two alternative traits. lut that this differentiation persists through conjugation and autogamy when new macronuclei arise by "macronuclear regeneration." i.e.. by regeneration from a fragment of the prezygotic macronucleus. This knowledge was used to test whether the singlet-doublet alternative was determined by a comparable macronuclear differentiation.

Figure 5 diagrams the design of the experiment. Matings of doublets with singlets were induced to form broad cytoplasmic bridges by exposure to antiserum, as set forth above. This permitter the singlet and doublet mates to exchange some fragments of their prezygotic macronuclei, for these are carried across by the cytoplasm when the bridges are broad. In order to get the fragments to regenerate into macronuclei, all of the conjugants were from stocks that were homozygous for gene am. Homozy gotes for this gene yicld after conjugation a high percentage of first-fission products which lack macronuclei developed from the syncaryon, but which possess fragments of the prezygotic macronuclei (Sonneborn, 1954b: Nol,ili, 1961a). The fragments in such cells regenerate into macronuclei while segregating at random to the daughter cells formed during the next several fissions. These products of the fissions were isolated and grown into clones. The clonal phenotypes revealed whether the macronuclei were descended from a syncaryon (heterozygous for marker genes) or from 


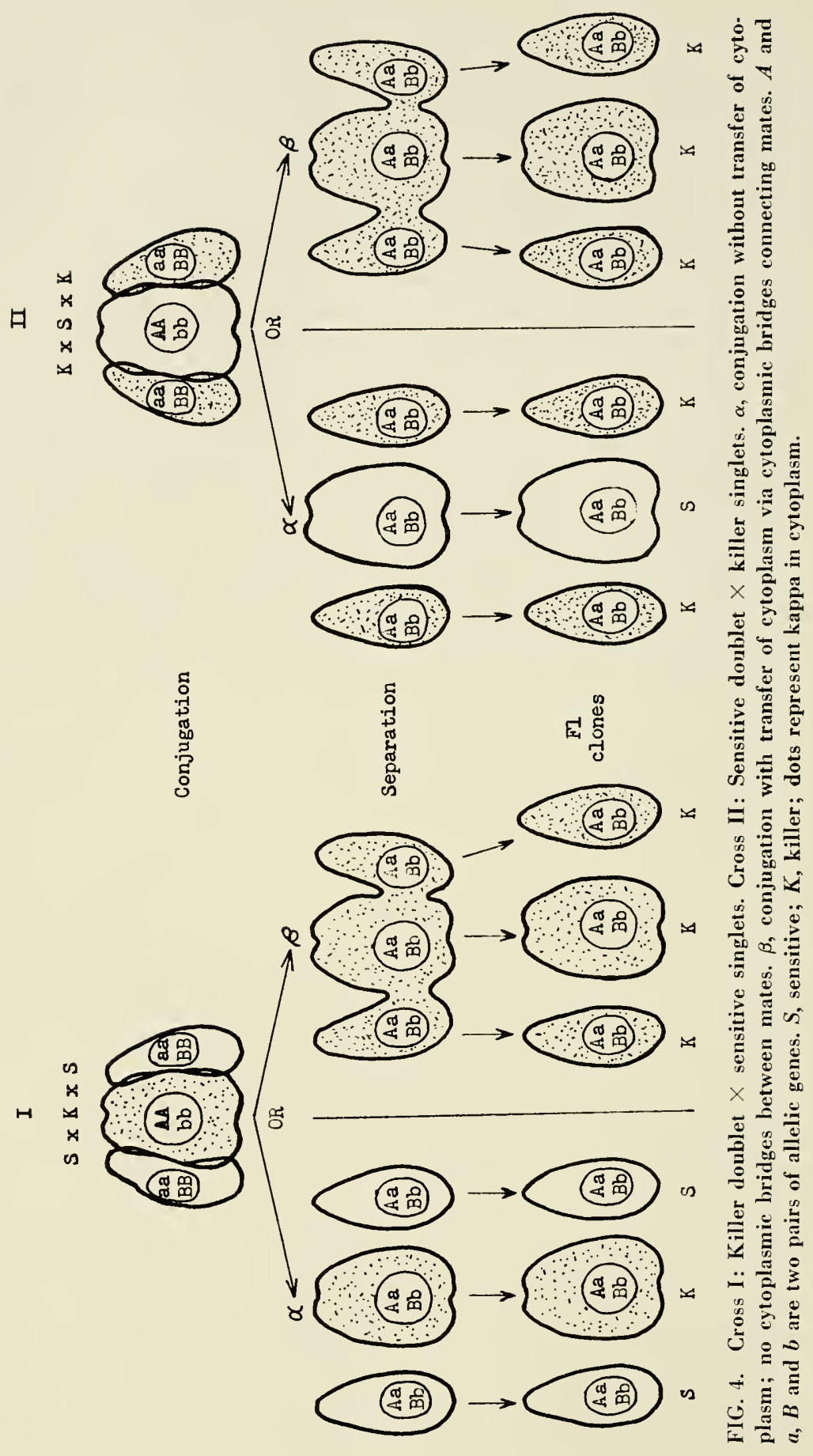




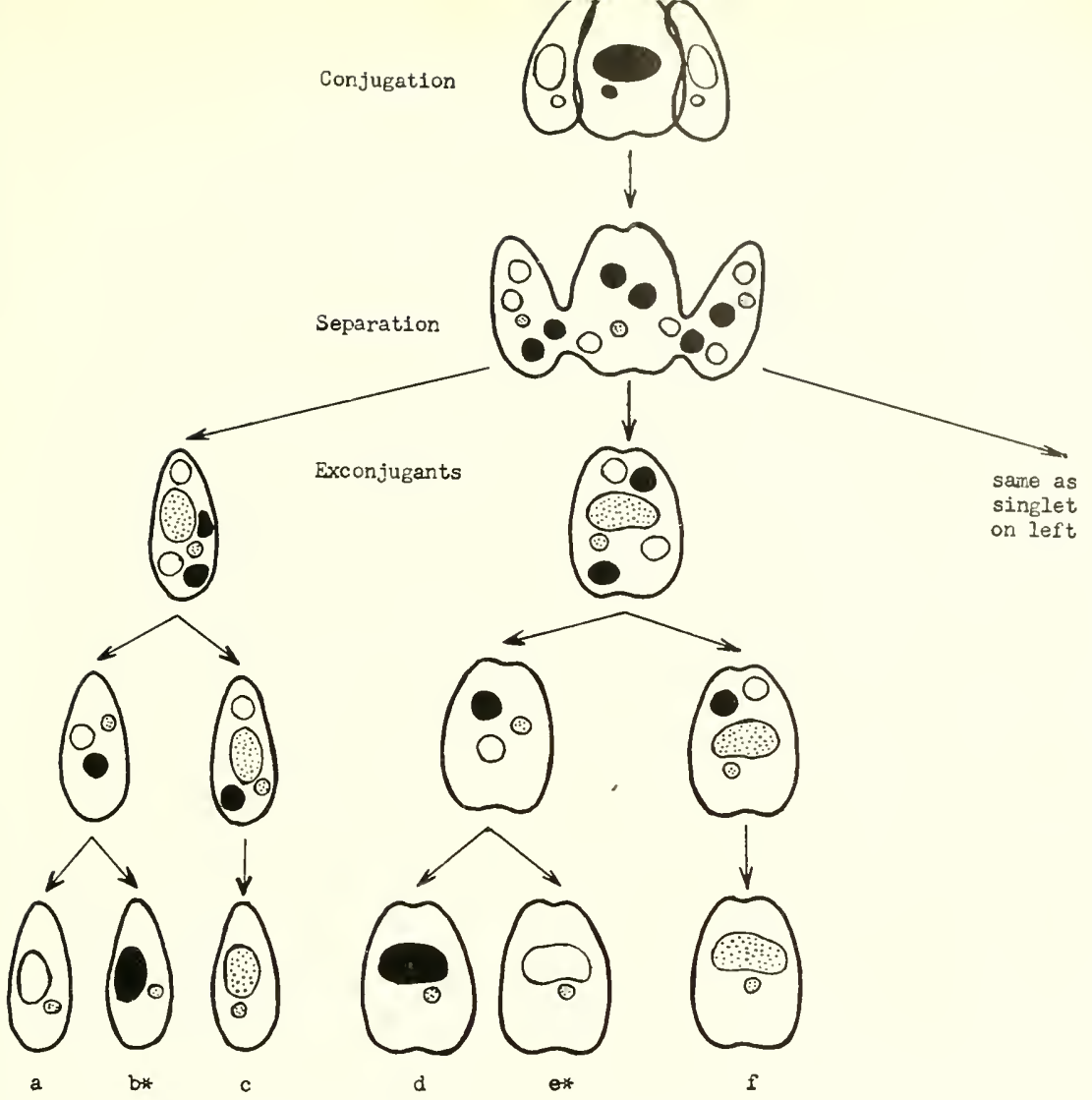

FIG. 5. Diagram of experiment to test whether macronuclear differentiation is the basis of the singlet-doublet difference. Hollow symbols represent nuclei originally in singlet parents; solid symbols represent nuclei originally in cloublet parents; stippled symbols represent hybrid nuclei formed at fertilization and their deriva. tives. The largest nuclei are macrontclei; the smallest are micronuclei; intermediates are fragments of the prezygotic macronuclei. The diagram is simplified by showing only a few of many fragments of a prezygotic macronucleus; actually the many fragments are not completely segregated until several fissions later.

$a$, singlet subclone with macronucleus regenerated from fragment of singlet prezygotic macronucleus.

$l^{*}$, singlet subclone with macronucleus regenerated from fragment of doublet mate's prezygotic macronucleus.

c. singlet subclone with macronucleus of normal kind, developed from product of fertilization nucleus.

$d$, doublet subclone with macronucleus regenerated from frigment of doublet prezygotic macronucleus.

$e^{*}$, doublet subclone with macronucleus regenerated from fragment of singlet mate's prezygotic macronucleus.

$f$, doublet subclone with macronucleus of normal kind, developed from product of fertilization nucleus.

$b^{*}$ and $e^{*}$ are the critical cases; their functional unclei (macromuclei) are derived from their mate's prezygotic functional macronuclei.

All types (a through $f$ ) have hybrid micronuclei, but these do not affect the phenotypes. The latter correspond to the macronuclear genotypes. 
a fragment of the prezygotic macronucleus (homozygous for marker genes); and, if the latter, whether from a prezygotic macronucleus of a singlet or doublet conjugant (homozygous for different alleles). This is possible in spite of the fact that all clones have heterozygous micronuclei, because the micronuclear genotype has no detectable effect on the phenotype; the latter corresponds regularly to the genotype of the macronucleus (Sonneborn, 1946).

The experiment was designed to reveal whether the singlet-doublet alternative would prove to be correlated with the source of the macronucleus. The answer should be most clearly provided by two of the six obtainable types of clones, $a$ to $f$, shown in Fig. 5. These two, marked with asterisks, are types $b$ and $e$. Clones of type $b$ are descended from singlet conjugants but possess macronuclei regencrated from a fragment of the prezygotic macronucleus of doublet conjugants. Clones of type $e$, reciprocally, are descended from doublet conjugants but possess macronuclei regenerated from a fragment of the prezygotic macronucleus of a singlet conjugant. Both types $b$ and $e$ should change character, from singlet to doublet and from doublet to singlet, respectively, if the basis of the difference between singlets and doublets lies in a fixed macronuclear differentiation. That did not happen. Type $b$ clones were composed of singlets in spite of possessing macronuclei derived wholly from doublets; type $e$ clones were composed of doublets in spite of possessing macronuclei derived wholly from singlets. Macronuclear differentiation thus seems to be excluded as the basis of the singlet-doublet difference, unless macronuclear fragments can be redifferentiated, and that has not been found to occur in any previous work.

The same conclusion is indicated by the character of clones of types $c$ and $f$ in Fig. 5. These are descended from singlet and doublet conjugants, respectively, that had exchanged cytoplasm (as indicated by transfer of macronuclear fragments, which can pass across only through a broad cytoplasmic bridge), and that had developed new macronuclei from products of syncarya. During this development, macronuclei are known to be subject to differentiation by the action of nuclear products in the cytoplasm (Sonneborn, 1954a). But in the case of clones of types $c$ and $f$, the cytoplasms present in the cells of both types were thorough mixtures of the cytoplasms of doublets and singlets. Such mixed cytoplasms, in all previously studied cases, often differentiate the ncw macronuclei in accord with the newly introduced cytoplasm. But this failed to happen in the present experiment. All clones of types $c$ and $f$ remained truc to their parental conjugant's character; i.e., those from singlet conjugants $(c)$ produced singlet 
clones and those from doublet conjugants $(f)$ produced doublet clones. This evidence thus supports that in the preceding paragraph which excluded macronuclear differentiation as the basis of the singletdoublet difference.

Another conceivable nuclear basis for the singlet-doublet difference lies in nuclear size. Without making measurements, it is obvious that doublets carry larger macronuclei than singlets. Do the larger nuclei determine larger cells with more cortical structures? If so, is the size of the nucleus an inherent property of the nuclei? The cxperiments which tested the hypothesis of macronuclear differentiation provided the answer. Mere inspection, without measurement, showed that when a fragment of macronucleus from a doublet regenerated in a singlet (type $b, \mathrm{Fig} .5$ ) it grew into a macronucleus of normal size, i.e., the size characteristic of singlets; and that, when it regenerated in a doublet (type $d, F i g .5)$, it grew to the large size characteristic of doublets. Conversely, when a macronuclear fragment from a singlet regenerated in a doublet (type $e, \mathrm{Fig} .5$ ), it grew into a macronucleus of the size characteristic of doublets; but when it regenerated in singlets (type $a$, Fig. 5), it grew to the size characteristic of singlets. The size of the macronucleus is not a cause of, but a response to, the size of the cell, as has also been reported in Stentor (Tartar, 1961).

The same conclusion follows from other results in clones homozygous for the am gene. As shown in row II of Fig. 6, this gene often yields very unequal macronuclear division at fission (Sonneborn, 1954b; Nobili, 1961a, b). Some cells receive very small pieces of macronucleus (rows II and III, Fig. 6). These small pieces grow into macronuclei of the size characteristic of the type of cell that bears them, regardless of whether the macronuclei were originally derived from singlets or doublets (row IV, Fig. 6). The observations described in this and the preceding paragraph thus effectively exclude macronuclear size as a determinant of the difference between singlets and doublets.

I have not been able to imagine any other possible mechanism of nuclear control of the difference between singlets and doublets. Therefore, attention was redirected back to possible cytoplasmic determination. The test that had been applied (page 174) was one which could reveal an effect of the freely moving cytoplasm, the fluid culoplasm, alone. It could not test an effect of the rigid, nonmobile 1 to 2 micron thick outer layer of cctoplasm, the cortex of the cell, containing nearly all the structures which distinguish singlets from doublets. As the only obvious remaining untested part of the cell, the cortex seems to be or to contain the genetic basis of the difference hetween 
singlets and doublets. However, so potentially important a conclusion should obviously not be left to stand upon mere apparent exclusion of alternatives; it requires the strongest of direet evidence. Such direet evidence might be sought by investigating the genetic consequences of adding and removing cortical parts alone. Would grafted extra cor-

I

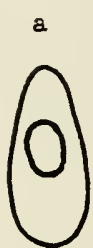

$\mathrm{b}$

II
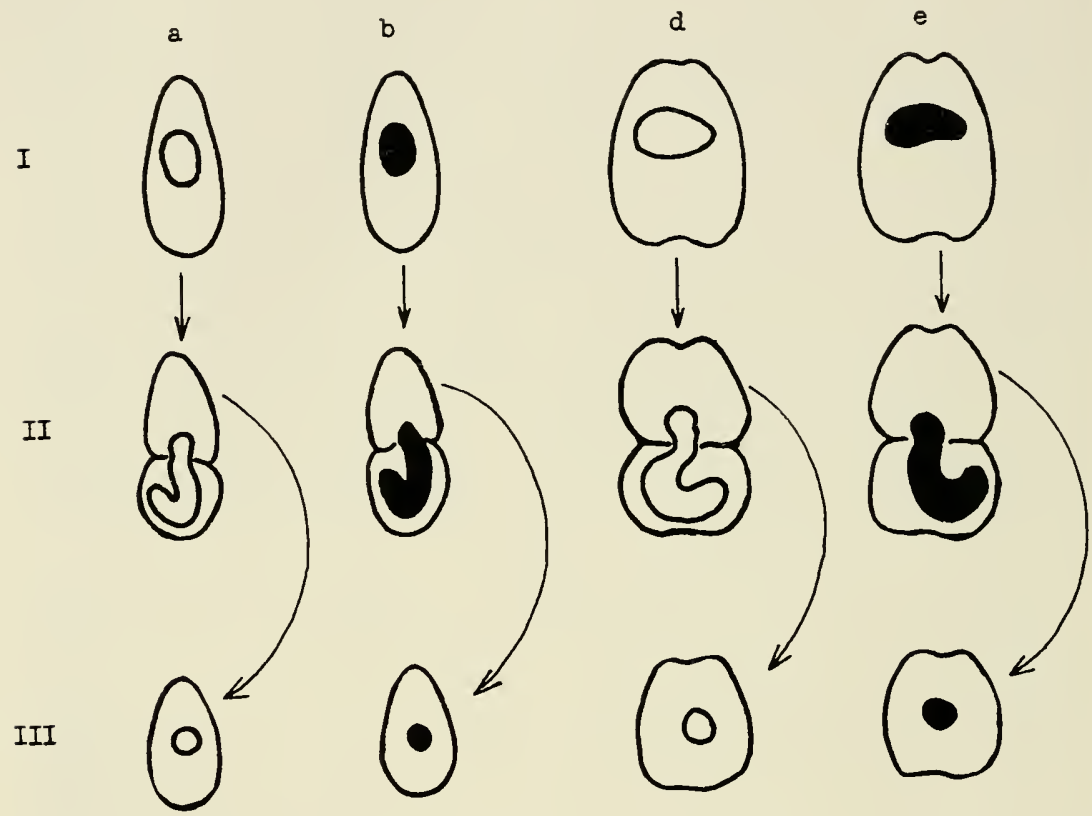

IV
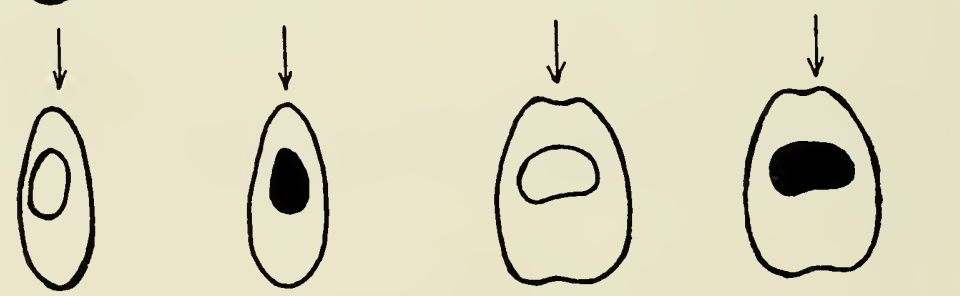

FIG. 6. Diagram showing the celluIar determination of nuclear size independently of nuclear origin. $a, b, d$, and $e$ are the same as in Fig. 5 ; solid macronuclei derived from macronuclei of doublets; hollow macronuclei derived from macronuclei of singlets. I and IV are adult cells before and after a fission, respectively. II slows fission with unequal macronuclear division, an effect of homozygosis for the recessive gene, am. III represents the fission products that received much less than balf of the dividing macronucleus. The small piece of macronuclens, regardless of its origin (see Fig. 5) from singlets (hollow) or doublets (solid), grows into a normal-sized macronucleus in singlets and into an oversized macronucleus in doublets. 
tical parts be reproduced in the progeny? Would deleted cortical parts be regenerated, or would the progeny also lack them? Answers to these questions, together with the results of the breeding analysis set forth ahove, should leave no doubt as to whether genetic autonomy is possessed by the cell cortex and its parts.

The difficulty in trying to answer these questions in Paramecium is that this organism has thus far seemed to be a poor material for the needed sort of operations. Although the body ean be cut in various ways, removal of cortical parts alone has met with little or no success and grafting has never succeeded. However, as has so often happened in the past, paramecia themselves frequently accomplish what the experimenter is unable to do. In effect, they themselves performed grafting operations and brought about losses of cortical parts.

In two instances following conjugation, a paramecium grafted onto itself a piece of cortex from its mate. The first case (Fig. 7) was of course the most exciting one. A doublet mating with two singlets was briefly exposed to immobilizing antiserum in order to induce cytoplasmic bridge formation (Fig. $7 A$ ). The doublet never separated from one of the singlets; the other singlet, however, separated except for the induced cytoplasmic bridge (Fig. $7 B$ ). The singlet remained long united to the doublet, but eventually separated (Fig. $7 C$ ). The doublet and its still-attached other singlet mate eventually died, but the free singlet lived. When first observed after separation, it bore a very conspicuous extra piece. as shown in Fig. $7 \mathrm{C}$. Its doublet mate at that time showed a corresponding nick. as if a piece were missing. The singlet, in breaking away from the doublet, had apparently taken along a piece of the doublet's cortex. Instead of growing rapidly and dividing within about 11 hours, as is normal for exconjugants, this singlet failed to grow for two days. During that period, its extra piece flattened out, making the posterior part of the body distinctly wider (Fig. 7D). Then the abnormal animal grew and reproduced (Fig. $7 E$ ). From one (but not the other) of the two products of the first fission arose a clone obviously different in form from either singlets or doublets (Fig. $7 F$ ). When samples of this clone were observed, after preparation by the silver impregnation technique, we found to our amazement and delight a new hereditary type that went far toward answering our question about the autonony of cortical parts.

These animals (Fig. 8) were intermediates between singlets and doublets. Like doublets, they had two complete oral segnents: two vestibules, mouths, and gullets; two anterior and posterior sutures; usually two eytopyges: and two sets of the five typieal associated kinety fields i anterior right and left, cireumoral, and posterior right 
and left). Unlike doublets, however, these two oral segments were not $180^{\circ}$ apart. Instead, the two mouths were $90^{\circ}$ or less apart and of course there was much less separation between the left kinety fields of the right segment and the right kinety fields of the left segment. Further, the anterior and posterior sutures of the left oral segment curved to the right insteal of to the left, mceting the sutures of the right oral segment at common poles. In many of these cells a third cytopyge appeared between the two on the postoral sutures. The

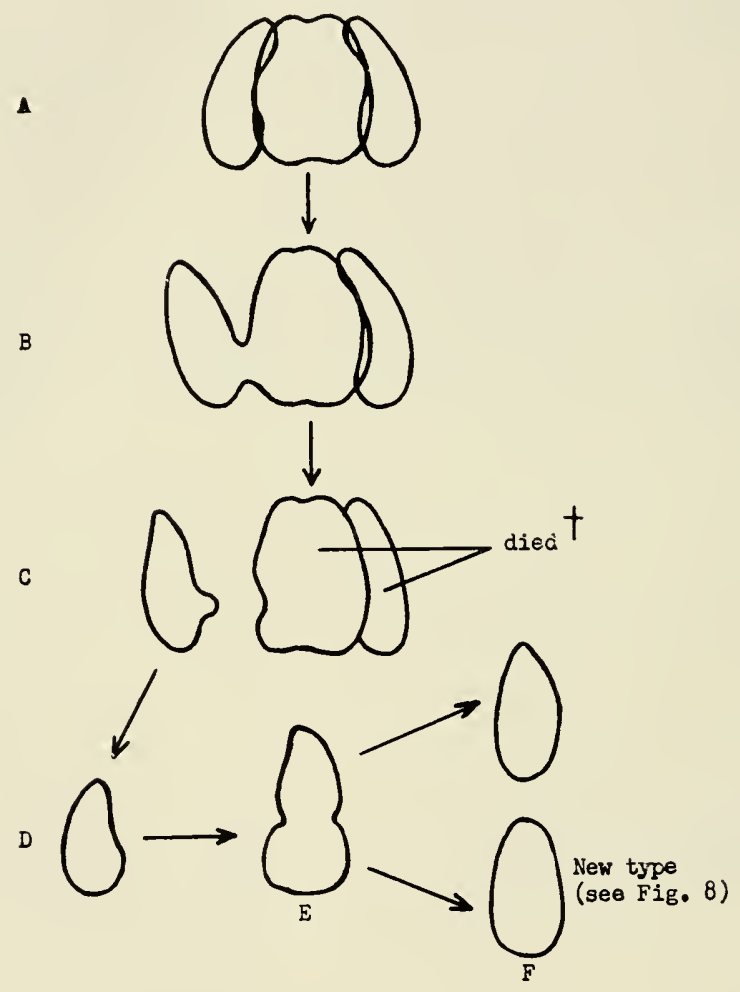

FIG. 7. Diagram of origin of the new type of animal shown in Fig. 8. A. Exposure to antiserum of two singlets conjugating with a doublet., $B$. Only one singlet separating, but with cytoplasmic bridge joining it to doublet. $C$. This singlet separated, but bore a hump. The nick in the doublet indicates that the source of the hump was a piece of cortex from doublet mate. $\dagger$ indicates death of doublet and other singlet; these never separated. $D$. The singlet one day later: hump "assimilated"; posterior half of body enlarged. $E$. First fission. $F$. One of the two daughter cells is a new cell type. NOTE: It is not known whether the new type came from the posterior or anterior product of this fission, only that one product produced a clone of the new type and the other did not. 
structures of the rest of the body were single: there was a single dorsal surface with the usual solitary narrow segment bearing contractile vacuoles. These features of the new cell type were as a rule faithfully reproduced during successive fissions.

This new hereditary cell type is theoretically decisive. A piece of paroral cortex, pulled off of one ccll and incorporated on the surface of another cell, has led to the development and inheritance of an entire supernumerary oral segment from pole to pole. In other words, genetic autonomy of a delimited part of the cell cortex has been demonstrated by the consequences of a natural graft of a small piece of cortex.

Further, observations on the cytopyge in the new cell type gave a clue to its developmental and genetic determination. Unlike the normal situation, the third cytopyge is not located on a postoral suture; but like the normal situation, it is located at the juncture of right and left postoral kinety fields. A third juncture of this sort exists in these cells as a result of the positions of the two oral segments: the left postoral field of the right oral segment abuts on the right postoral field. of the left oral segment. And there the third cytopyge appears in spite of the absence of a postoral suture and in spite of the reversal of right-left relations. The development and position of the cytopyge are thus correlated with localized structural features, the border between two specific different cortical fields.

The sccond cxample of "cortical picking" was the reciprocal of the one just described. The doublet conjugant robbed its singlet mate of a paroral piece of cortex. The singlet failed to grow and died. The doublet developed a third oral segment close to one of its two preexisting segments. This too was inherited, but reversion to the doublet condition occurred with considerable frequency.

The preceding examples indicate that an interpolar segment of cortex, when integrated into a cell, bchaves with a high degree of genetic autonony. Because growth of Paramecium is in the longitudinal direction, the question arises as to whether genetic autonomy is possessed only by one or more entire meridians from pole to pole. The answer to this question is provided by a type of clone which has arisen independently several times and in more than one way. Clones of this type show that some parts of an interpolar segment can be inherited while other parts of the same segment are lacking. In other words, genetic autonomy is not restricted to entire longitudinal segments, but holds also for parts of a segment along the anteroposterior axis.

Animals of this type (Fig. 9), have two oral segments $180^{\circ}$ apart, but only one of them is complete. The other oral segment lacks vesti- 
bule, mouth, gullet, and the typical circumoral kinety ficlil, lut possesses all other structural features of an oral segment, i.c.. the preoral suture with its right and left kinety fields and the postoral suture with its eytopyge and right and left kinety fields. Between the complete and incomplete oral segments are two aboral surfaces also

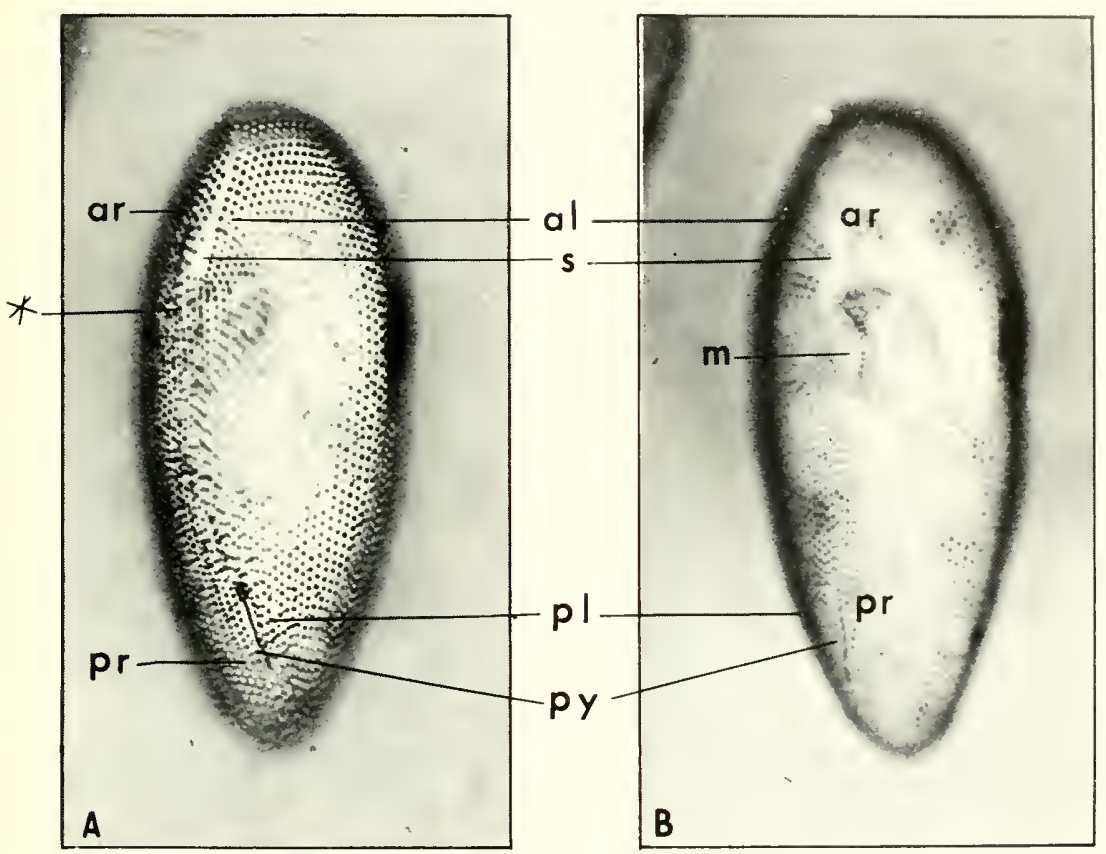

FIG. 9. Doublet lacking vestibule, mouth, and gullet of one oral meridian, but retaining rest of the meridian. Two focal levels of silver preparations of same cell. $A$. Surface with incomplete oral meridian at upper focal level. B. Surface with complete oral meridian at lower focal level. (As before, the animal's right and left are the same as the observer's on the lower surface but are reversed on the upper surface.) al, anterior left kinety field; ar, anterior right kinety field; $m$, mouth; $p l$, posterior left kinety field; $p r$, posterior right kinety field; $p y$, cytopyge; s, preoral suture; *, area where vestibule, mouth, and gullet are missing.

$180^{\circ}$ apart, each with its segment bearing contractile vacuole porcs. This incomplete doublet, lacking only the middle parts of one oral segment, reproduces true to type. Clearly, the smallest autonomons cortical part is less than an entire normal interpolar segment.

A number of other hereditary cortical variations have been obtained: triplets, quadruplets, a much increased number of contractile 
vacuole pores and meridians, and various hereditary disturbances in the development, growth, and relative movement of cortical parts during fission. We shall not go into these in this ehapter, although each eontributes further evidence of the genetic autonomy of cortical parts and further insight into how cortieal structures are reproduced.

The features of eortical reproduction which lear importantly on the present problems, will become evident from a comparative examination of how the main components of the highly structured oral segment are reprodueed in singlets, doublets, and incomplete doublets. Each of the struetures of this segment-the vestibule, mouth, and gullet of the oral apparatus and the sutures, the kinety patterns, and the cytopyge--follows the same rules of reproduction in all three kinds of cells. The differences among the cell types reveal what is essential and what is nonessential for the reproduction of various parts.

We can undertake to give here only some of the salient features of the reproduction of the parts of the oral segment. Actually the story is still not fully known in spite of careful study by many investigators. Among the early signs of reproductive aetivity, three are outstanding (Fig. 10). (1) A field of new kinetosomes appears near the posterior and right margin of the mouth (Fig. 10A). This is the rudiment of the new oral apparatus, destined to pass to the opisthe, the posterior product of fission. (2) Many new kinetosomes appear in the kineties of the left wall of the vestibule and in a zone extending to the left from the vestibule (Fig. 10B). (3) Within this area the kincties break to form the cleavage line ( $\mathrm{Fig} .10 \mathrm{~B}$ ), which begins between the left posterior edge of the old month and the left end of the rudiment of the new oral apparatus. The cleavage line continues around the body

FIG. 10. Formation of the oral rudiment in the fission of singlets, doublets, and one type of incomplete doublet. Silver preparations.

$A$. Singlet. Rudiment of new oral apparatus forming along the right side and posterior end of the mouth and vestibule of the old oral apparatus.

$B$. Singlet. Two focal levels showing the new oral rudiment which is beginning to be shifted posteriorly by elongation of vestibular kineties.

$C$ and $D$. Two focal levels of doublet. $C$, surface at upper focal level; $D$, surface at lower focal level. Both oral meridians and adjacent areas are undergoing the same developments as the one oral meridian and its adjacent areas in the singlet in $B$.

$E$ and $F$. Two focal levels of incomplete doublet lacking one vestibule, mouth, and gullet. $E$, surface at upper focal level showing the oral meridian that lacks vestibule, mouth, and gullet. A cleavage line extends from this meridian almost all the way around the body. $F$, surface at lower focal level with complete oral meridian; new oral rudiment extends slightly posterior to fission line.

Symbols for Fig. 10 are given in the legend for Fig. 12. 

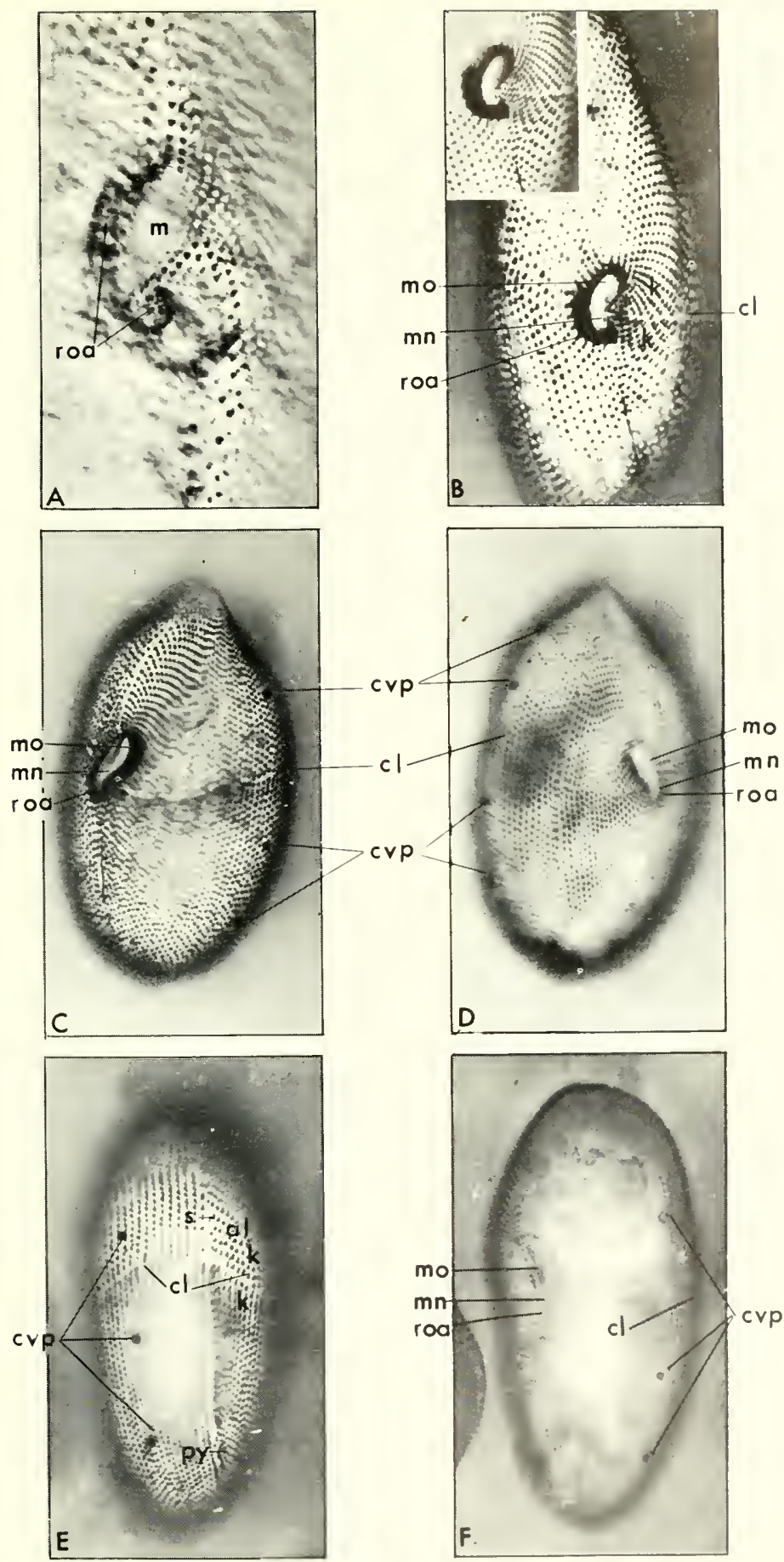
and eventually ends in the right wall of the vestibule at the anterior end of the rudiment of the new oral apparatus.

Exactly the same processes occur in doublets, as appears in Figs. $10 \mathrm{C}$ and $10 \mathrm{D}$. What happens on the one oral segment of singlets happens on both oral segments of doublets. The same is true for the two oral segments in incomplete doublets possessing two adjacent oral segments but only one dorsal field. Of special significance is what takes place in incomplete doublets that lack only the vestibule, mouth, and gullet on one of their two oral meridians (Figs. $10 E$ and $10 F$ ). The complete oral segment behaves as already described for the oral segments of singlets and doublets. The incomplete oral segment does not form a rudiment of a new oral apparatus; but the ofher two processes-increase in kinetosomes and formation of the cleavage line - occur nevertheless. The cleavage line starts on the left of the defective oral meridian at the place where the missing vestibule, mouth, and gullet should be and passes to the left until it reaches the right edge of the mouth on the complete oral meridian. And the cleavage line that began on the left of that oral meridian passes to the left until it meets the incomplete oral meridian on its right side. Hence the increase of kinetosomes and formation of the cleavage line are independent of the presence of vestibule, mouth, and gullet. And a rudiment of a new oral apparatus appears where and only where an oral apparatus already exists. Thus only one arises in singlets, two in complete doublets, two in incomplete doublets possessing two complete oral meridians, but only one in incomplete doublets possessing an oral apparatus on only one of their two oral meridians.

The main feature of reproduction of the oral segments in the next stages in fission is elongation of the kineties in which new kinetosomes were earlier packed close together. When the cleavage line reaches the right wall of the vestibule, many new kinetosomes appear there. The elongation of the kineties anterior to the cleavage line on both sides of the old oral apparatus has the effect of pushing posteriorly both ends of the rudiment of the new oral apparatus. This places the new rudiment, which is organizing into an oral apparatus, entirely posterior to the old oral apparatus $(\mathrm{Fig} .11 A)$. Unequal growth places the new rudiment to the right $(\mathrm{Fig} .11 \mathrm{~B})$. The same elongation of kineties occurs on both oral meridians of doublets; and wherever there is a rudiment of a new oral apparatus, it is thereby carried posteriorly and to the right. Figures $11 \mathrm{C}$ and $11 \mathrm{D}$ show this stage on both oral segments of a complete rloublet.

The further elongation of kineties occurs differentially in groups, according to a definite pattern which results in the formation of typi- 

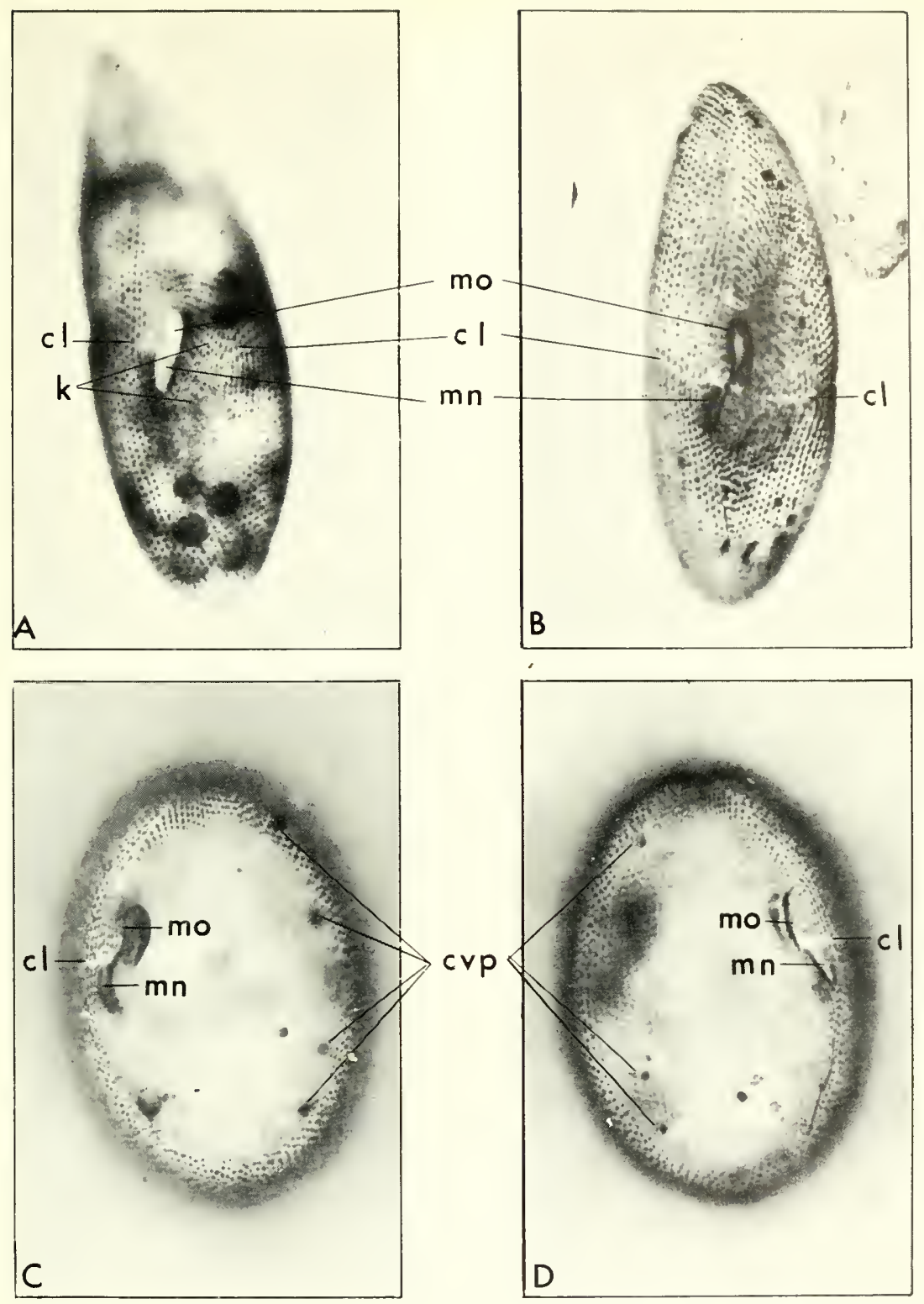

FIG. 11. Separation of the new oral rudiment from the old oral apparatus in the fission of singlets and doublets. Silver preparations.

$A$. Singlet. New oral rudiment shifted to position directly posterior to old oral apparatus.

$B$. Singlet. New oral rudiment posterior and to the right of old oral apparatus.

$C$ and $D$. Two focal levels of doublet animal. $C$. surface at upper focal level. $D$, surface at lower focal level. Note that both oral meridians show nearly the same stage as the one oral meridian of the singlet in $B$.

Symbols for Fig. 11 are given in the legend for Fig. 12 . 
cal kinety fields. The kineties anterior to the cleavage line begin to elongate before those posterior to the line; in this region, those on the left of the oral meridian elongate more than those on the right. Figure $12 A$ shows an early stage of this process and Fig. $12 B$ a late stage. The result is to establish the typical posterior right and left kinety fields between the old oral apparatus and the cleavagc line. The juncture of the two new kinety fields is the new postoral suture. There the new cytopyge is destined to be formed, but it is not yet present.

As Fig. $12 \mathrm{~A}$ shows, considerable kinety elongation occurs anterior to the cleavage line before any can be detected posterior to the line. Later, the kineties posterior to the cleavage line begin to elongate (Fig. 12B). This takes place differentially, but in reversed relations; i.e., the kineties on the animal's right of the new oral apparatus

FIG. 12. Reconstruction of new kinety fields in the fission of singlets, doublets, and one type of incomplete doublet.

$A$. Singlet. New oral apparatus still at cleavage line. Between the level of the old oral apparatus and the cleavage line, the kineties have elongated, more on the left than on the right, thus starting the formation of new posterior right and left kinety fields.

$B$. Singlet. Anterior to the cleavage line, the two new posterior kinety fields have almost been completed by further elongation of kineties, more on the left than on the right. Cytopyge is not yet developed at the juncture of the right and left fields (postoral suture line). At this stage, the kineties posterior to the cleavage line have also begun to elongate, much more on the right than on the left, beginning the formation of the new anterior right and left kinety fields. The right kineties, by elongating up above that part of the cleavage line which is connected with the anterior part of the new oral apparatus, are converting this part of the cleavage line into the new preoral suture.

$C$ and $D$. Two focal levels of doublet in a stage of fission between that of the singlets in $A$ and $B$. $C$, surface at upper focal level; $D$, surface at lower focal level. The areas on the sides of both oral meridians show the same developments as for the areas adjacent to the single oral meridian in singlets. $C$ shows the earliest beginnings of the new preoral suture; i.e., the kineties to its right are just beginning to elongate.

$E$. Upper surface of an incomplete doublet showing the oral meridian that lacks a vestibule, mouth, and gullet. Same stage of fission as the $\operatorname{singlet}$ in $B$; formation of the preoral suture from part of the cleavage line by elongation of right kineties up above part of it.

Symbols for Figs. 10, 11 and 12: $a l$, anterior left kinety field; ar, anterior right kinety field; $c l$, cleavage line; $c v p$, contractile vacuole pore; $k$, area of increase in number of kinetosomes; $k e$, area of elongating kineties; $m$, mouth; $m n$, mouth of new oral apparatus; mo, mouth of old oral apparatus; $p l$, posterior left kinety field; $p r$, posterior right kinety field; $p y$, cytopyge; pyo, cytopyge open (to discharge undigested food); roa, rudiment of oral apparatus; $s$, preoral suture; $s c l$, preoral suture forming from part of cleavage line. 


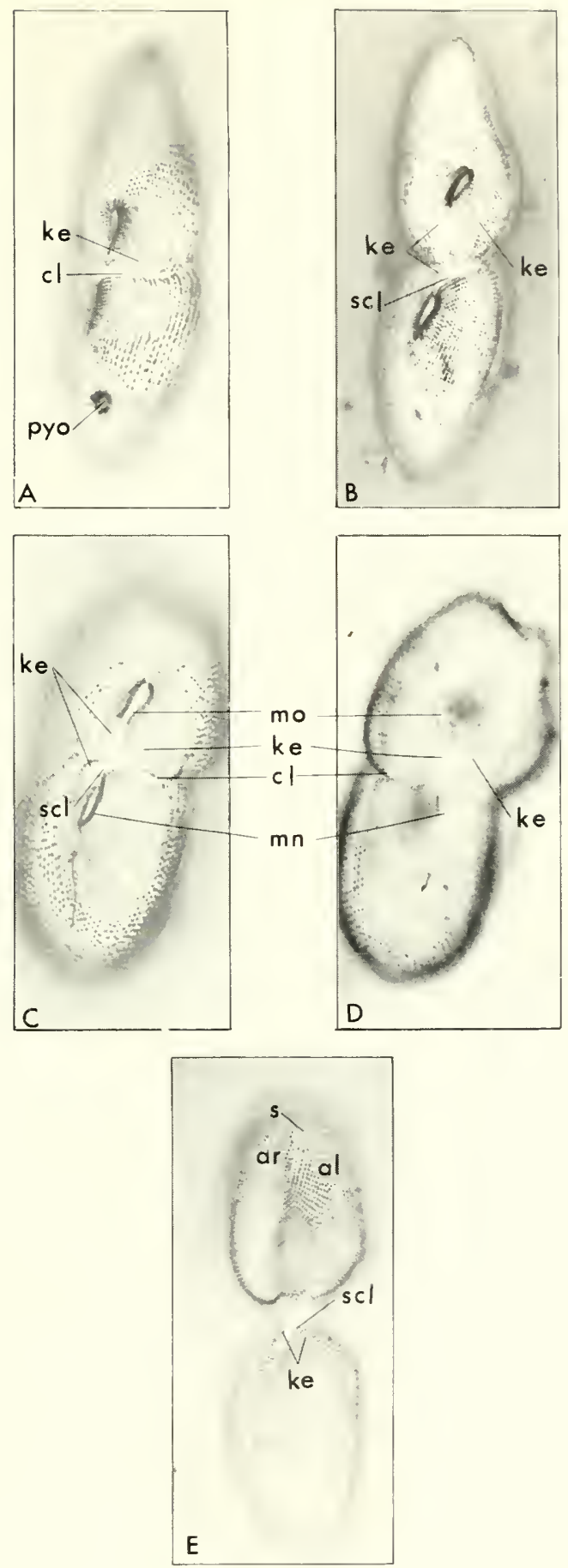


elongate much more than those on its left. The result (Fig. 12B) is to establish the typical anterior right and left kinety fields in an area of new growth between the new oral apparatus and the main part of the cleavage line. I had to say "main part" because, as appears in Fig. 12B, part of the cleavage line-the part that was at first immediately on the left of the oral meridian-becomes the new preoral suture. This happens, as a consequence of the growth of the right kineties up and to the left, so that they come to lie anterior to the part of the cleavage line which is still connected to the anterior edge of the new oral apparatus.

Exactly the same processes occur in doublets and incomplete doublets wherever there is an oral meridian. Figures $12 C$ and $12 D$ show them occurring on both oral meridians of a doublet in a stage of fission intermediate between that of the singlets of Figs. $12 \mathrm{~A}$ and $12 \mathrm{~B}$. Figure $12 C$ is a particularly good picture of the beginnings of the elongation of the right kineties posterior to the cleavage line: they are already penetrating into the cleavage line and marking off the earliest trace of the prospective new preoral suture. Figure $12 E$ shows that these definite patterns of kinety elongation take place around the oral meridian even when it lacks a vestibule, mouth, and gullet. The new preoral suture line forms posterior to the cleavage plane as a result of the elongation of the right kineties into the cleavage line and around that part of it destined to become the preoral suture.

Thus far only the normal or regular processes in singlets, doublets, and incomplete doublets have been described. They reveal much about how cortical cell heredity is accomplished. More is revealed by observations on exceptions to this course of events, by failures of certain processes to oceur, and by the origin of certain structures under conditions not expected from the preceding account of normal events. Only some of the more important exceptions will be mentioned in this paper.

Two principal kinds of failures in the occurrence of expected processes have been noted. On the one hand, certain groups of kineties that normally elongate have failed to do so or have done so to a less than normal extent. In some cases, the vestibular and nearby kineties have failed to elongate and, as a consequence, the rudiment of the new oral apparatus fails to grow apart from the preexisting oral apparatus. This may be dependent upon the prior failure of new kinetosomes to appear in these kineties; but the cause of these failures is still obscure. Often, but not always, correlated with but slight elongation of these kineties is failure of the new gullet to invaginate: its kineties remain up on the body surface more or less posterior to 
the preexisting vestibule, mouth, and gullet. We have not previously mentioned this invarination process, which has been noted by Ehret and Powers (1959), and the other details of the transformation of the rudiment into a functional normal oral apparatus because much is still obscure. But invagination of the gullet. the rudiments of which develop in the cortex near the old mouth-vestibule juneture, is part of the story. This invagination may also be corrclated with clongation of kineties, possibly, at least in part, those of the rudiment itself.

The other main kind of failure is the failure of the rudiment of vestibule, mouth, and gullet to form and develop even when a preexisting oral apparatus is present. Two examples can be eited. First, it can happen in complete doublets and it thus results in the oxigin of incomplete doublets. Significantly, this failure is preceded and accompanied by certain other aberrations. The number of kinetics between the oral segment and the contractile vacuole pores to its right is much reduced, from about 25 to about 8 to 15. The preoral suture is much shorter and correspondingly the vestibule, mouth, and gullet are much more anterior; i.e., they are located at its basc. In correlation, the postoral suture is much longer than normal. The cytopyge is more variable in size, often being short and much further than normal from the posterior end of the preoral suture. When these relations exist, the vestibule, mouth, and gullet on such an oral meridian are sooner or later destined to be irreversibly lost in the progeny. The dislocation of parts that precedes and accompanies this loss suggests an essential determinative role of localized regional interactions in the formation of the oral apparatus. To this we return later.

The second example is failure of ineomplete oral meridians, and of one of two closely placed oral meridians, to persist and be reproduced at autogamy and conjugation. At present this is just a brute fact which has not been studied as to details. even to the extent of knowing whether it invariably happens. No such failure occurs when two complete oral meridians are far apart.

A different type of failure appears in some cells of doublets that have two oral meridians less than $90^{\circ}$ apart. At fission. the cleavage line may be inhibited or appear late in the region between the two mouths (Fig. 13A). Correlated with this, the kineties in that region often fail to elongate to the normal extent. Consequently, in the course of successive fissions, the number of kineties between the two oral meridians is progressively reduced, sooner near the poles than near the equator, bringing the polar cnds of the anterior and postcrior sutures together further and further toward the equator (Fig. 13A). Eventually the two preoral sutures are reduced to one in this way 
and the same is true for the two postoral sutures and eytopyges; but the two vestibules, mouths, and gullets may still he present (Fig. $13 B$ ). In this condition, the latter can still be reproduced (Fig. 13B); but eventually even the two vestibules, mouths, and gullets become one in the progeny. This is one way in which eells with two oral
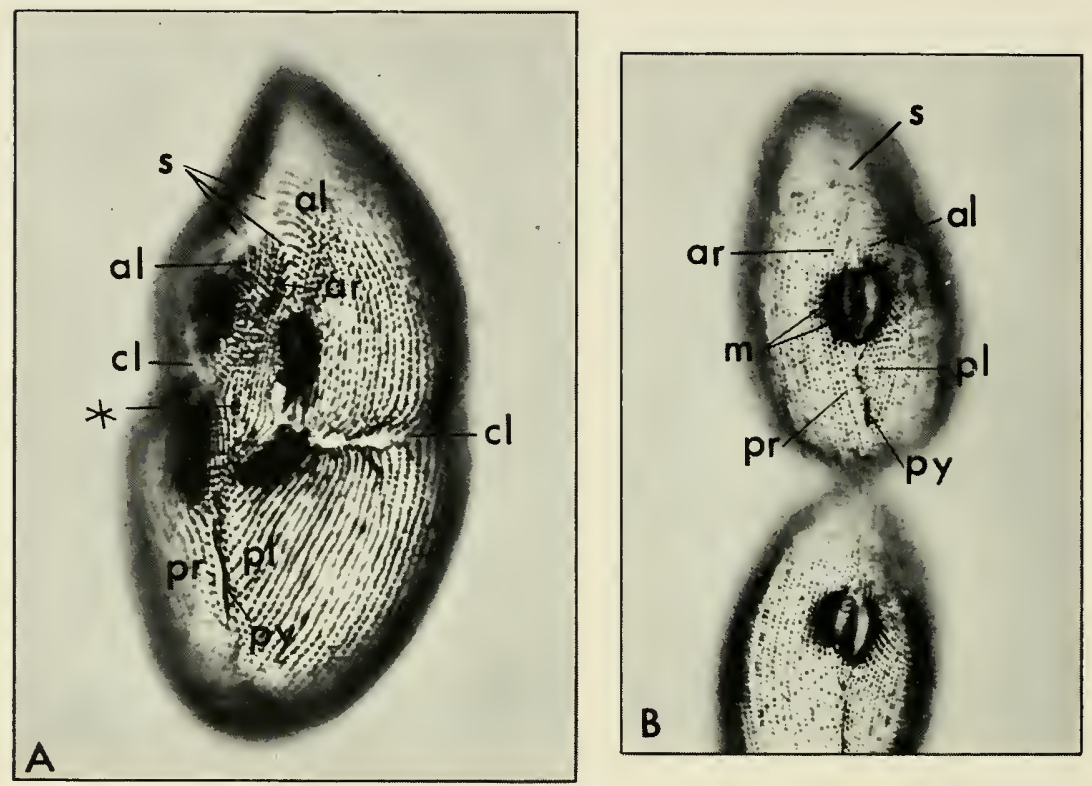

FIG. 13. Two stages $(A$ and $B$ ) in the fusion of oral meridians in a line of descent that had the two oral meridians less than $90^{\circ}$ apart.

$A$. Fission stage: the two new oral apparatuses have formed and separated from the old ones. Each oral meridian has a short preoral suture flanked by right and left kinety fields. Less than halfway to the anterior pole the two preoral sutures meet and proceed to the pole as a single suture flanked by its right and left kinety fields. The two oral meridians have still shorter independent postoral sutures (in the opisthe, of course) before they meet and proceed to the posterior pole as a common suture flanked by a single right and a single left posterior kinety field. There is but one cytopyge; it lies on the common postoral suture. A cleavage line appears to the right of the right oral meridian and (in typical wide form) to the left of the left oral meridian, but it is totally absent between the two oral meridians.

$B$. A late fission stage of another animal in the same line of descent. The entire suture line (preoral and postoral) is single. The only residue of doubleness appears in the vestibules, mouths, and gullets, both sets of which have reproduced.

$a l$, anterior left kinety field; $a r$, anterior right kinety field; $c l$, cleavage line; $m$, mouth and vestibule; $p l$, posterior left kinety field; $p r$, posterior right kinety field; py, cytopyge; $s$, preoral suture; *, area between vestibules where kineties have not cleaved. 
meridians can produce proseny with only onc. Their reproductive autonomy is guaranteed only when the two oral meridians are 90 or more apart. That is why it has proved impossible to oltain and maintain multiplets of an order higher than quadruplets. It is also evidence that important interactions and interferences oceur when corresponting replicate structures are unduly close together, suggesting-as we shall later discuss more fully-that interacting gradients play an important part in cortical morplogenesis and heredity.

In addition to losses in the ways just described, new structures may possibly arise de novo. For example, origin of a new oral apparatus at a place where none preexisted possibly oceurred as an exception. although this is still elouder with uncertainties. It will be recalled that we twice observed the origin of a whole new oral segment following the "natural grafting" of a piece of cortex from near the oral region of a mate (page 181). Unfortunately, exactly what the grafter piece contained remains unknown. Thus far the event has occurred too rarely to be fully studied in its early stages. But it is clear that no more than a short region of the oral segment, if any, conld have been grafted; and that from the graft developed an entire oral segment with all five typical associated kinety fields, as well as vestibule, mouth, and gullet. From the comparison of the behavior at fission of complete and incomplete oral meridians given above (page 186), we may be sure that, in order to do what it did. the graft must have contained an essential component. or all that was necessary for the formation of a new oral apparatus and also for the independent determination of a cleavage line, localized increase in kinetosomes. and localized differential elongation of kineties. That the graft might have lacked many or all of the gross structures of the supernumerary oral apparatus and its associated regions is sugested (hut not proved) by two facts. First, one product of the first fission lacked them. Second. in many other eiliates new oral structures arise far from the prexist. ing ones, indicating a less obvious mechanism of production than one depending upon proximity to the preexisting oral structures themselves. Perhaps something else normally associated with. lut -eparable from, the oral apparatus in Paramecinm is the basic determincr of formation of restibule, mouth, and gullet. If so. this-or part of itbut not the oral struetures themselves, may have heen in the active grafted piece: in which ease, the gross struetures would have arisen de novo, i.e., indirectly. muler the influence of a particular. different local cortical pattern.

Such a mode of origin is eertainly involved in the formation of the eytopyge. As pointed out, it arises at the juxtaposition of the posterior 
right and left kinety fields. Normally, this juxtaposition is on the postoral suture, but when two oral meridians are not more than $90^{\circ}$ apart, a third juxtaposition with reversed right-left relations exists betwcen them, and there a third cytopyge arises, in the absence of a third oral segment or any part of it (page 182). This suggests that cytopyge formation is determined by interaction between these two kincty fields or the cortical regions in which they are located.

This, together with analyses in other ciliates to be discussed later, makes more credible the possibility considered above in relation to the consequences of "natural grafts," of de novo origin of the oral apparatus by results of interaction between other juxtaposed diverse kinety fields or cortical regions. Ehret and Powers (1959) have also pointed out this possibility. Indeed, virtually the whole oral meridian from pole to pole, as well as the juncture between vestibule and gullet, is a series of junctures between visibly diverse cortical patterns, which would be more than ample to account in principle for all the determinative actions in morphogencsis and cell heredity correlated with the oral segment and its parts, if indeed such actions are the essential ones involved.

In the light of the preceding account, a preliminary summarization of the main relations may be attempted. In general, new oral segments are formed where and only where oral segnents or their decisive correlated cortical pattern junctures preexist. The rudiment of a new oral apparatus likewise arises where and only where an oral apparatus or its cortical determiner precxists. The preexisting oral apparatus and the parts of the oral segment beside and anterior to it pass to the proter, the anterior product of fission; the new rudiment and the parts of the oral segment beside and posterior to it pass to the opisthe, the posterior product of fission. Both proter and opisthe form new halfbodies. Except for the new oral rudiment, formation of these new parts involves: localized and differential (in space and time) increase in the number of kinetosomes in preexisting kincties; formation of the cleavage line by breaks in the kineties starting on the left at the oral meridian and procceding around the body to the oral meridian; the elongation of the kineties (spacing the originally crowded kinetosomes) according to a definite space-time pattern which creates the new kinety fields; specific elongation of the right circumoral and neighboring kineties of the developing opisthe forward into the cleavage line and to the left, so as to create a new preoral suture in the opisthe from part of the cleavage line; induction of specific new developments at junctures of specific cortical regions-certainly the induction of a cytopyge where new posterior right and left kinety 
fields abut and possibly induction of vestibule, month, and gullet in a comparable way.

In all these normally correlated events, only a few major types of processes seem to be taking place: localized increase in the number of kinetosones; localized elongation of kinetics in a refinite space-tine pattern; and progressive differentiation of particular new formations into definite structures. That there is a decisive developmental and genetic role of preformed structure in these processes is evident from the correlations, which have repeatedly been pointed out, between supernumerary and reduced cortical parts and the numbers of new parts that arise during fission. Between the old and the newly formed parts there is no evidence of a simple, direct. template-like. cansal relationship. Reproduction of cortical structures is typically very indirect, involving a complex, dynamic series of events. But these events are normally correlated in space with the locus of visible cortical differentiations. Usually, when the localized patterns are present, even in supernumerary and abnormal positions, the corresponding developmental events occur: when they are lacking, the events fail to occur. Remarkable is the fact that such localization of origin and development of parts and even of differential growth occurs within the confines of a single cell.

The major remaining problems are to identify the nature of the particular cortical patterns correlated with and presumably determining the particular pattern changes that lead to the development of new structures, and to discover the nature of the interactions that appear to occur between diverse local regions. Whatever these may be, the end result is two from one. two new cortical patterns normally identical with and essentially dependent upon the original one, both when the original is a typical singlet and when it deviates in any one of several ways from the typical singlet organization. In other words. the processes we have been describing at the gross level of microscopic visibility are the processes underlying cell heredity of the cortex and its highly differentiated parts in Paramecium aurelia.

\section{Literature. Discussion. and Conclusion}

Are the conclusions reached from our study of one stock of one species of ciliate of limited or general applicability? How should they be modified, if at all, in the light of related work and thomerht on other organisms? These questions would of course be appropriate in regard to conclusions based on the study of any onc organisu. perlaps sepecially when that organism is unicellular and a ciliate, for these oryan- 
isms differ greatly among themselves and are in some ways unique. We would believe conclusions to be fundamental only if they were found to be applicable to multicellular as well as to micellular organisms. Such a search for the fundamental is the object of this discussion section. Previous pertinent work on doublets and other cortical variants in ciliates will be considered first; then related work on multicellular organisms: and finally, the general conclusions to be drawn on the role of cortical structure.

\section{A. Dowblets and other cortical variants in ciliates}

The inheritance and morphogenesis of doublets have been studicd in a number of genera of ciliates in the course of the last 40-ord years. Most of this work has been critically and thoughtfully reviewerl from several points of view in a series of papers by Fauré-Fremiet (1945; $1948 \mathrm{a}, \mathrm{b} ; 1950 ; 1954)$. All studies show that doublets reproduce true to type during fissions; but to the question "How long can they do this?" the answer is not so simple. Many workers found that cultures begun with doublets eventually end up with only singlets present (for example, Chatton, 1921, on Glaucoma; Sonneborn, 1932, on Colpidium; Fauré-Fremiet, 1948a, on Lencophrys; Tartar, 1954a, on Stentor; Hanson, 1962, on Paramecium). Does this mean that the "inheritance" of this cortical variation is limited and that eventually the nuclear genotype prevails by restoring the normal singlet condition? While even limited inheritance would be of some significance, the full genetic import of cortical variations depends in part upon the degree to which they persist during reproduction. What then is the genetic significance of the reversion of cultures of doublets to singlets?

Donblets have been reported to give rise to singlets in several ways. A commonly olsserved way is for a depression to arise between the two sets of organelles at the anterior end and gradually to deepen in the course of successive fissions until it reaches the fission plane, which then cuts off two singlets and a doublet (Margolin, 1954). There are also some minor variations of this process. Another very different process is asymmetric reduction of the number of kineties and the distance on one side between two corresponding meridians such as the two oral meridians (Fauré-Fremiet, 1948a). This leads to eventual interaction between, and loss of onc of, the two sets of structures (see page 193 above). Once this process starts in a subline, it cannot be reversed by selection. A thind process is resorption of the 
two sets of organelles and replacement by one new set (Fanri-fremiet. 1945; Tartar, 195ta). Still other proceses have heen olserved.

The question is whether, by one proces or another. douldots are destined inevitably to revert to singlets. The answer is "Vo." Ipparent ultimate mass reversion has been shown to be due to one or more of several canses which hy no means involve 100 per cent revorion or even a high rate of reversion. Chatton (1921) pointed out that the singlets which arose with low frequeney in Glancoma multiplierl faster than the doublets and simply overgrew the culture. This has been confirmed in a number of other ciliates, for example. for Colpidium hy Sonneborn (1932). As he pointed out the same result would occur eren in the absence of differential reproductive rates, but more slowly, beeause doublets keep produciny singlet- oceasionally. while the latter do not revert to doublets. Thi- one-way change learls to higher and higher proportions of singlets in the culture. Chatton (1921), Margolin (1954), and Thlig (.1960) have further shown that the rate of singlet production by doublets depends upon the eultural conditions: conditions that permit rapid multiplication reduce the frequency of reversion. Uhlig, aseribing Tartar's (1954a) limiterl maintenance of donblet Stentors to suboptimal cultural conditions. steceeded in maintaining them for humbreds of fissions and apparentiy could do so indefinitely. Indeed, under appropriate conditions, doublets have been maintained indefinitely by culling out the revertant singlets (Dawson. 1920, on Oxytricha: Sonneborn. 1932. on Colpidium: Uhlig, 1960, on Stentor; the present work on Paramecium; and by others on other ciliates). Moreover. Somneborn (1932) showed that selection for morpholowically more "perfect" or symmetrieal doublets in Colpidium could reduce the frequeney of reversion from one in seven line-days to zero in 864 line-rlays. Doublets are not destined inevifably to revert to singlets: aside from ocea-ional produetion of singlets. they can in general keep reprodueing true to type by fissions indefinitely.

However, occasional production of singlets is genetically important in two respects. First, exceptions to doublet self-reproduction are useful. as teratological phenomena usually are. in revealing some of the processes involved in the normal maintenance of type foe page 192). Second. the fact that revertant singlets and their doublet sister lines of deseent carry products of division of one and the same ancestral nucleus implies strongly that the difference between the two cell types conld hardly be due to a genotype difference in their murlei (Sonnehorn. 1932). 
One report of limited persistence of doublets, not due to reversions at all, requires special mention. Calkins (1925) noted that a doublet clone of Uroleptus mobilis lost the capacity to conjugate. The singlets that arose in the clone regained this capacity. Becanse Uroleptus exhibits a clonal life cycle ending eventually in death in the absence of conjugation, the doublet Uroleptus was doomed to extinction. No other case of this kind has ever been found. Doublets do conjugate and this has made possible study of the inheritance of the doublet condition through fertilization, especially in Euplotes and Paramecium.

Both in Euplotes patella (Kimball, 1941) and in Paramecium aurelia (Sonneborn, 1942, and the present paper) doublets can conjugate with doublets; doublets of $P$. aurelia also undergo autogamy. The doublet condition persists in both the exautogamous and exconjugant progeny. In both genera, doublets were also crossed to singlets (Kimball, 1941; Powers, 1943; Sonneborn, 1942), with the same results as reported in the present paper. Genic markers showed that the doublets had been fertilized by their singlet mates (Powers, 1943). Although genetic analysis of the hasis of the difference between singlets and doublets was carried no further than this, the results-as far as they go-are in complete harmony with ours. Botlı singlet and doublet exconjugants reproduced true to type in spite of having identical genotypes.

That no genotypic difference distinguishes singlets from doublets is also indicated by the modes of origin of doublets. In some genera, the two products of fission of a normal singlet reunite to form a doublet, as was first noted by Chatton (1921) for Glaucoma. In this case, the fission is abortive; the two daughter cells remain united by a cytoplasmic bridge and the opisthe moves up alongside of the proter in homopolar orientation. In other genera, such as Colpidium (Sonneborn, 1932), the abortive fission may by further replication of parts form a multiple monster from which eventually both homopolar doublets and normal singlets may pinch off. In Paramecium (Sonneborn, 1942) doublets arise from a pair of conjugants by the formation of a cytoplasmic bridge which spreads in the main posteriorly. The first fission then yields two singlets from the anterior part of the fused exconjugants and a doublet from the posterior part. The details of origin show minor variations from pair to pair. The two conjugants that yield a doublet are of identical genotypes (as a result of the mating, if not prior to it). Thus, in all three of these modes of doublet origin, the two components of a doublet are genotypically identical 
with each other and with singlets of the same clone or clones. The point is even more striking in Stentor loublets: they can be proilueed by experimentally relocating parts of one cell (Tartar, 196]: Thlic. 1960 ).

The production of doublets from parts of one cell or by fission or conjugant fusion of two identical cells, the origin of suldelones of singlets from doublets, and the limited breeding resulis from eroses of singlets by doublets, all argued strongly for the absence of pertinent nuclear differences between the two types of cells before our present study proved the point heyond reasonable doubt hy exhaustive analysis.

The role of the cortex and its parts in determining the hereditary difference between singlets and doublets. as well as in determining the production and ordering of the diverse localized cortical parts. has also long been studied in many ciliates (Fauré-Freniet, 1945-1954). Most of these studies are based upon. stimulated hy, or related to the kinetosome theory, which can therefore serve as a point of departure for the following discussion.

To Lwoff (1950) we are indebted for a suecinct, documented, thoughtful, and influential account of the kinetosome theory. This theory is concerned with the genetic and morphogenetic properties of kinetosomes and kineties. The basic genetic feature of the theory is its attribution of genetic continuity to the kinetosomes. Kinetosomes are held to arise only by division of preexisting kinetosomes. The genetic continuity of kineties is held to be due to the retention of products of kinetosome division in the same row. We shall consider the morphogenetic features of the kinetosome theory after discussing the genetic feature.

The genetic continuity of kinctosomes is accepted by some modern workers, rejected by others. Mazia (1961) argues, as well as ean be argued from what is now known, that kinetosomes reproduce thenlselves from a germinal part. His evidence is largely derived from studies of centrioles; hut centrioles are kinetosomes, according to the kinetosome theory, and this is supported by their similar fine strueture (De Harven and Bernhard, 1956). On the other hand. Ehret and Powers (1959) contend that definite proof of kinetosomal self-reproduction by division is lacking. The mere appearance of a new kinctosome beside an old one is not proof; and no one has yet demonstrated in a new kinetosome material contributed by a preexisting kinetosone. Ehret and Powers suspect that minute unit elentents formed deep in the cell (in Paramecium) migrate to the surface and there frow 
into a unit of cortical strueture, the eiliary corpusele, which develops kinetosomes and other parts. Definite proof or exclusion of one or the other view is still lacking.

This uncertainty about the self-reproduction of kinetosomes has obvious but limited implications for the geneties of cortical organization. The structures and processes with which we are concenned are at higher levels than that of kinetosomes and the way they arise. They include the ways in which kinetosomes are grouped in more eomplex struetures, as well as the seemingly simpler ereation of fields with characteristically positioned and oriented kineties. The problem of the origin, development, and inheritance of structure at this level is independent of the answer to the question of the origin and produetion of individual kinetosomes.

The morphogenetic aspects of the kinetosome theory are far more important for present purposes. Local differences in cortical structure in other ciliates, as in Paramecium, involve variations in the spaeing, orientation, differentiation, and relative growth rates of kincties and groups of kinetosomes. It is therefore of basic importance to know whether such variations are inherent in the constituent kinetosomes and kineties or whether they are imposed upon them by other features of the local milieu. On the choice between these alternatives, the kinetosome theory is not firm. Lwoff (1950) recognized both of them and seemed to favor the latter. In other words, he thought it to be more likely that the kinetosomes and kincties were indispensable instruments of cortical differentiation, rather than that they might be the eause of it. Others have come out strongly for the causal interpretation (Wiesz, 1951). Fauré-Fremiet (1945-1954) repeatedly considers the possibilities in varied lights; he sometimes scems to lean toward the one, sometimes toward the other interpretation. Because the ehoice between these alternatives is fundamental for our theme, the main types of evidence bearing on it will now be considered.

The first type of evidence comes from observations of the normal course of events. Any particular structure normally arises at a particular spot marked either by a certain pattern of kineties or by association with the same kinety. This is well illustrated by the normally constant locus of origin of a new oral apparatus. As the most prominent set of cortical structures, it has been studied most. In many eiliates, such as Tetrahymena, it always arises in association with a particular interpolar kinety designated as kinety No. 1 or the "stomatogenie" kincty. In Paramecium, the endoral kinety (page 170), by the right edge of the nouth, is held by some to be the stomatogenic kinety (Roque, 1956h; Porter, 1960, at least in part). Their views 
imply that this localization of the presumed material souree of the new mouth and gullet is the basis for the regular appearance of the-e struetures close to the old one and for the dependenee of a new oral apparatus on the presence of a preexisting one. Fauré-Fremiet 19541 refers to this confinement of the stomatogenie kinety within the oral apparatus as the basis for its "autonomization." Here then is one view, based mainly upon the normal course of fission, of why and how new structures are determined by preexisting structures: a particular kinety determines a partieular cortieal strueture.

The second type of evidence comes from experimental interferences with the normal situation and leads in the main to opposite conchsions. The most extensive and intensive work has been done on Stentor (Tartar, 1961; Uhlig. 1960). Normally, only the apical end of the new oral apparatus (ealled the peristomial primordium, the primordium, or the anlage) arises in association with a particular kinety; the basal end extends across several kineties. Thus, the peristomial primordium normally arises in a definite fixed position marked by a particular kinety pattern. In pigmented species of Stentor, the kineties regularly alternate with pigmented stripes. Because the latter are more conspieuous, deseriptions are commonly given in terms of the stripes. On the midventral surface there is a zone of narrow ramifying stripes flanked on the left by broad interpolar stripes. The apical end of the primordium arises on this border and the basal part within the ramifying zone.

Is this normal position of origin of the primordium dne to the inherent properties of one or more kineties in that region? Nearly 60 years ago Stevens (1903) removerl the ventral half of the borly of Stentor, within which lay the ramifying zone, and a considerable region on both sides of $i t$, and found that the peristomial primordium was nevertheless formed. This has subsequently been repeatedly confirmed. Eventually, Tartar (1956) discovered what visilhle physieal conditions were necessary for the formation of the peristomial primordium. The pigment stripes in the ramifying zone are the narrowest on the body. Around the body to the right from this zone the stripes hecome progressively broader: they are thus lroadest on the other side of the ramifying zone. Tartar showed that relocations of hody parts yielded primordia only where artifieial junctures between wide and narrow stripes were malle. For example, when the ventral half of the hody is removed. the ent edges of the dorsil half join, making a new juneture between narrow and wide stripes. and there a primordium arises and develops.

Experiments such as this-and many variations of it have been 
performed, mainly on Stentor (Tartar, 1961; Uhlig, 1960) and on Blepharisma (Suzuki, 1957) - show clearly that no kinety or kinety field is alone cndowed with the capacity to be the site of formation of the complex peristomial primordium. This can happen anywhere around the whole circumference of the body when a juncture of contrast in stripe (and kinety) widths is set up by cuts and/or grafts. Apparently any kinety or group of kineties can serve as the site of primordium formation. The kineties can be no more than instruments of morphogenesis; they are not its cause.

What then is the cause of specific morphogenesis? Tartar's results seem to prove that the origin and development of the peristomial primordium is determined by interaction between adjacent narrowand wide-striped cortical areas. As he and Uhlig (1960) note, the visible gradation of stripe widths around the body is the visible expression of a gradient with its extremes meeting on the ventral surface where the apical end of the primordium normally arises. They showed, however, that not all artificially produced junctures of different stripe widths serve to induce primordium formation. If two junctures of unequally diverse stripe contrasts are created, the lesser contrast may fail to induce a primordium, especially if it is close to the greater contrast. Even if only one juncture exists and the stripe contrast is extremely slight, it may fail to induce. There are thus degrees of interaction at junctures correlated with difference in the gradient levels, and degrees of inhibition of primordium formation diffusing in gradient fashion from a major juncture. Another index of gradient action is the delineation during fission of new fine stripes in the finestripe ramifying zone: the number of new stripes decreases with distance from the broad-stripe region.

The Stentor work shows that the anteroposterior position of the primordium and the differentiation of its parts are determined by another gradient extending from the foot or base toward the apex. This gradient, for example, determines where the prinordium bends to the right across the fine-stripe ramifying zone. Further, the differentiation of a mouth at the base of the primordium depends upon the presence of a foot. Supernumerary feet in abnormal positions induce the formation of supernumerary mouths in abnormal positions; absence of a foot results in failure to form a mouth. Altogether, then, the origin and development of the peristomial primordium depend upon the interactions between the two gradients.

Two facts already mentioned give a most important clue to the general nature of operation of the first gradient. Although an adjacent wide stripe zone is essential, all the new formations appear either at 
the juncture or within the fine stripe zonc. The apical end of the primordium appears at the juncture; its basal portion and the new fine stripes arise within the fune-stripe zone. This strongly surgests that the broad-stripe zone acts as an inductor, its active principle(s) passing into and acting upon the narrow-stripe zone, which beluaves as if it were a competent responder to the inductor. W' should recall here that supernumerary inductor-response systems are partitioned at fission so that multiplets reproduce true to type indefinitely under favorable cultural conditions (Uhlig. 1960).

Thus far, decisive evidence that the determinative conditions are confined within the cortex has not been given. The euts and grafts in Stentor and Blepharisma can hardly be expected to be limited absolutely to the cortex. The cortex merely contains the geographical markers correlated with the olserved events. Tartar (1961). however, reports in a preliminary way another kind of operation on Stentor which points to a decisive role of the cortex. He made an incision and withdrew all or virtually all of the endoplasm, leaving cortex and nucleus. Such an operation was promptly followed by the restoration of the endoplasm, normal growth, and normal reproduction. Conversely, Tartar also stripped off the entire cortex. leaving endoplasm and nucleus. These cells became spherical, presumably developed a surface membrane (because the remaining cytoplasm was retained), and lived for some time; lont they failed to regencrate cortex or to develop further, eventually dying. However. if a piece of cortex was left on the endoplasm. it gradually spread around the latter, reconstituted the visible markers of its gradients, and eventually regenerated and reproduced normally. These cxperiments indicate that a small piece of cortex possesses or creates at least an essential part of the morphogenetic gradients and that the cortex docs not arise in the absence of preexisting cortex. Unfortmately, as Tartar realizes, the experiments fall short of being completely decisive. The cortex might simply be proviling certain mechanical or osmotic properties essential for normal cellular functioning, including the production of cortex itself.

The experimental analyses on Stentor (and on Blepharisma) provide beautiful models of the roles in morphogenesis and cell heredity of gradients, presumably in the cortex, and of inductor-response systems in the cortex. The question is: Are these models generally applicable to ciliates or are they limited to ecrtain gencra, for example, those which show an extraordinarily well-developed capacity for regeneration? Uhlig (1960) warns of the possibility of linited applicability and calls for direct evidence from a variety of ciliates. 
Although operative analyses of the sort carried out on Stentor have not been performed on Paramecium, there is nevertheless much to indieate that fundamentally the same models may apply, as will now be set forth.

The existence of cortical gradients in Paramecium and morphological evidences of their direction are slown by three lines of evidence. First, the position of lateral spines, a type of abnormality studied by Jennings (1908), shifts with the growth and division of the paramecia. The nearer the spines are to the ends of the body, the less their position shifts per fission cycle; the greatest shifts oceur when a spine is near the equator. This indieates that growth is greatest in the equatorial zone and decreases toward the poles. Second, slow growth at the poles is further indicated by the relatively slight restoration of cut ends at a single fission; several fissions are required to complete regeneration of polar parts (Tartar, 1954b and others). Third, the greatest increase of kinetosome number during fission oceurs near the equator; there is less and less with increasing distanee from the equator. Thus all three lines of evidence point to a growth gradient which is high near the equator and which decreases toward both poles.

Paramecium, like Stentor, also possesses sharp juxtapositions between areas exhibiting different kinety patterns. The oral meridian, virtually from pole to pole, is a line of juxtaposition between markedly diverse kinety fields on its right and left (page 169). There may even be differences on the two sides of the line in distance between rows of kinetosomes, those on the left usually being greater than those on the right. But this difference, if extensive measurements confirm it, is much less than the corresponding difference in Stentor. Much more striking is the difference on the two sides of the mouth. The vestibular kineties are very closely packed and run parallel to the rim of the month; the adjacent kineties forming the gullet not only are differently spaced (some closer, some further apart) but are mostly oriented in a different direction. Ehret and Powers (1959) point out two other differences on the two sides of the vestibule-gullet juncture: hexagonal versus rhomboidal patterns of their "eiliary corpuseles" and one or two versus four kinetosomes per repeating unit.

The important question is whether one or more of these abrupt junetures of visibly diverse cortical patterns has morphogenetic significance. The postoral juncture on the two sides of the eytopyge clearly does, as we have shown (page 184). It will be reealled that the morphogenetic action at the postoral juncture is independent of right-left relations, as was also found to be true for primordium 
production at the narrow- and fine-stripe juncture in Stentor lTartar, 1961). These observations appear to indicate that the interactions in both cases are dne to an inductive influence from the one region (wide-striped in Stentor) which spreads both to the right and to the left. Normally, only the region on one side is competent to respond in both cases: lut when eompetent regions are on both siles at once. both sides respond concurrently. That a competent responding area must be present for the response to oceur is shown ly the normal limitation of the response to one side. So far as I am aware, present knowledge of the crtopye does not permit a choice as to whether the left kinety area is the inductor and the right the competent responder. or the reverse. Perhaps the discovery of induction at the juncture, even when the juncture is not on an oral merielian and when the right-left relations are reversed. will inspire successul efforts to resolve the remaining questions.

With regard to the possible morphogenetic role of the cortical pattern juncture between vestilule and gullet in Paramecium. resolution of the altemative interpretations is rendered especially diffeult. The position where the anlage of the new oral apparatus is first seen $i s$ very elose both to the cndoral (stomatogenic?) kinety and to the juncture of the strongly marked differences in cortical pattern. Attempts to test which of these structural landmarks. if either. is decisive for the appearance of the anlage of a new oral apparatus could follow either of two paths. First. the earliest beginning of the anlage could be studied to sec if it is in fact physically contignous with the endoral kinety. Roque (1956b) and Porter (1960), neing the silver method, claim that it is; Ehret and Powers (1959). nsing phase and electron microscopy, claim that it arises several microns from this region.

Sccond. attempte might be made to separate the cndoral kinety from the vestibule-gullet juncture. This would not he easy. perhaps not possible, to do surgically: however. repetitions of certain experiments, plus eytological controls. might accomplish the tark. One such experiment was Hanson's (1955) destruction of the ability to form a gullet on onc oral meridian of a doublet by exposing the area of the right posterior restibule-gullet juncture on that meridian to a fine beam of ultraviolet irradiation. Cytolocical study accompanying such an experiment should reveal whether cortain struetures such as ihe endoral kinety were destroyed. Hanson did not have eytolowical controls and did not even know whether the rest of the orat meridian persisted in progeny that lacked one vestibule, mouth. and gullet. Perhaps they were like om incomplete doublets that harl this oral segment except for restibule. mouth, and gullet. Anotlire type of 
experiment that might yield the necessary information is induction of "picked" cortex (page 181). Cytological study should reveal whether the effective picked pieces contain an endoral kinety, a vestibule-gullet contrast juncture, only one part of that system, or merely some pattern of cortical structure which is decisively different from that of the area into which it is implanted.

While awaiting decisive evidence as to the possible roles of the endoral kinety and vestibule-gullet juncture, the available facts concerning the general situation point to a tentative choice. Kineties genetically differentiated for the production of oral apparatuses (or for any other visible structure) do not exist in the decisively analyzed ciliates. Instead, interacting gradients, visibly expressed as juxtaposed different cortical areas, have proved to be determinative. In Paramecium, the determination of at least one structure-the cytopygeoccurs in the same way. In the absence of contrary decisive evidence in any ciliate and in the light of supporting evidence for the principle of interacting gradients in all well-analyzed cases (including one in Paramecium), tentative rejection of the interpretation of genctically differentiated kineties, including the endoral kinety of Paramecium, seems justified. For the same reasons, tentative adoption of the principle of determination of morphogenesis by interacting gradients or fields seems justified, even when they are not correlated with visible pattern junctures, as in the ciliate Glaucoma (Frankel, 1960a, b, 1961).

Up to this point, the problem under discussion has been the part played by the cortex in the perpetuation through fissions of its own specific pattern of differentiation. However, the discussion has proceeded upon a tacit assumption which now necds to be made explicit and to be suljjccted to careful scrutiny. Tacitly it has been assumed that the processes of morphogencsis at fission partake of an all-or-none character. Either a structure develops or it doesn't. And this is determined by the interactions of a few primary gradients at junctures of gradient contrast. So relatively simple a model is a good first approximation, but the impression of its adequacy comes from putting aside a large class of facts which will now have to be examined.

To begin with, the reader will find on page 193 an account of a series of cortical deviations from a complete doublet type which led to eventual complete and irreversible loss of vestibule, mouth, and gullet on one of the two interpolar oral segments of doublets, leaving all other landmarks of this segment. A number of stages in the loss were observed. The process thus occurred gradually over a series of successive fissions. Observations of comparable progressive cortical 
losses over a number of fissions were earlier reported by FauréFremiet (1948a) for Leucophrys patula: asymmetrie reduction in the number of kineties led inevitably to loss of one set of cortical struetures from doublets. Likewise. Hanson (1962) has noted progressive changes. Localized irradiation of one oral apparatus of a doublet with a fine beam of ultraviolet infliets damage on the exposed oral apparatus and on the capacity to produce new ones on that meridian at fission. Both of these kinds of damage. without further irradiation. ean independently lead to greater or lesser abnormality over the course of a considerable number of fissions until one or the other of two stable conditions is reacherl: complete loss of one oral apparatus and the capacity to produce one on that oral meridian, or complete normality.

Observations like these are important in at least two respects. First, they show that morphogenesis and cell heredity of particular cortical struetures are not all-or-none phenomena. The initiation of a cortical strueture is only the first step in its ereation. Initiation alone does not assure complete normal development. For the latter. other factors are involved. Apparently, there is a sequence of such factors, the operation or effeet of later factors in the sequence being dependent upon the normal or abnormal results of the operation of earlier factors in the sequence. The nature of these factors and of their operation in ciliates is almost totally unknown, although initial attempts to understand them have been made by Fauré-Fremiet (1948a) and Hanson (1962).

Second, observations of these sorts, by providing an example of progressive eortical changes over a series of suceessive fissions, may provide a connection in principle between the short-term phenomena of eell heredity and morphogenesis and the long-term progressive ehanges in morphogenesis and cell heredity, extending over hundreds of successive fissions, that constitute the clonal life cycle of immaturity, maturity, senescence, and death (Maupas, 1888; Calkins, 1926a: Sonneborn, 1954e; Jennings, 1944). Among the events of elonal aging is an increasing frequeney of abnormalities of cortical structures and of alnormalities in the processes of production of cortical structures at fission (Sonneborn and Schneller, 1955; Sommeborn and Dippell, 1960b), including final failure to form at fission an oral apparatus (Dippell, 1955). The basic mechanisms underlying this one-way progression away from "normality" (i.e., the condition in young elones) may be similar to those operating in the progression toward complete loss of one set of oral organelles from doublet. Further analysis of either may throw light on both. 
Obviously ciliates would long ago have become extinct were there not also reversals of the unirlirectional, progressive, degenerative clonal age changes in morphogenetic processes. Return to the starting point is required for survival. This is commonly accomplished in ciliates at the time of the fertilization processes. In Paramecium, for example, conjugation and autogany are the only occasions on which a preexisting oral apparatus involutes, disappears, and is replaced by a new oral apparatus (Hertwig, 1889; Roque, 1956a; Porter, 1960). The new one arises in the same manner as at fission, but it remains in the cell in which it arises. At the same time, the cilia on part of the ventral surface of the two conjugants are lost and later regenerated (Hiwatashi, 1955). Replacement of the corresponding kinetosomes (or ciliary corpuscles) and comparable replacements on the rest of the surface have not yet heen reported. In view of the initiation of a new life cycle at fertilization and of the evidence for progressive age changes in the cortex, a delibcrate and careful search for more extensive renewal of the cortex at the time of fertilization might prove fruitful. In any case, it is clear that at least some cortical changes form not merely a sequence, but a cycle. Similar cyclic returns to the starting point are associated in some ciliates with encystment and with "physiological regeneration," a disappearance of some old organelles, and their regeneration.

Cyclic return to the starting point is also shown during the asexual reproduction of parasitic ciliates with multiple hosts (Lwoff, 1950). Markedly different cortical patterns are characteristic of the period of association with different hosts. One pattern leads regularly to the next in correlation with a definite and regular sequence of hosts. The sequence of cortical changes and hosts leads back to the starting point. It too is not merely a sequence, but a cycle.

These observations on the cycles of cortical changes in the course of the lives of multihost, parasitic, asexual ciliates and of free-living sexual ciliates are of great significance for any general theory of the role of the cortex. They show that, in ciliates, cortical morphogenesis and heredity are not-as is commonly supposed - normally limited to the regular bipartition and reconstruction of exactly the same cortical pattern fission after fission, but are progressive-in part, very slowly progressive-sequences of changes forming a closed cycle back to the starting point. This larger view of the cortical events in ciliates provides a model of what would have to be involved in multicellular organisms if the cortex played in them a role of importance contparable to the role it plays in ciliates. 


\section{B. Multicellular orgamisms and cortical erolution}

Double animals, parabiotie twins. and the like are-as everyone knows-commonplaces of the experimental embryology of Metazoa. But they are not reproduced. This is because the individual cells are not changed and reproduction is from a single cell or a fusion of two cells. Only the pattern of cellular association is altered. However, the cellular association itself functions genetically in the asexual reproduction of certain Metazoa and these can form hereditary doublets as stable as those in ciliates. Sonneborn (1930) obtained two differently oriented doublets of the Rhabdocoel turbellarian, Stenostommm incaudatum. Each reproduced true to type indefinitely through asexual reproduction. These eases are particularly instructive not only because they are in Metazoa, but especially because detailed comparison with the doublets in ciliates reveals so much about the basic similarities. In both the eiliates and Metazoa, the gross reproduction true to type involved indirect, dynamic processes quite independent of any template processes of replication per se. In both, the basis lay in the perpetuation of a new combination of the number and the arrangement of parts which were indirectly self-reproducing. In both, the perpetuation depended upon inductor-response systems of morphogenesis with complex development of the hereditary structural parts in each generation. The ehief difference lay in the units of organization: cells and tissues in the case of the Metazoa. parts of the cortex of a single cell in the case of the ciliates.

What do the Metazoa have to tell us about the role of the cell cortex? The literature of experimental embryology of higher animals is replete with evidences of the importance of the cell cortex. It plays decisive roles, for example, in cell "recognition" during reaggregation of dissociated cells (Moscona, 1957), in organizer and inductor actions and the response to them by competent cells (Weiss, 1939), in the mosaic of determinative regions of the ega (Dalcy and Pa-teels, 1937. 1938: Curtis, 1960), and presumably in the whole distinctive nolecular organization of each cell type ( 1 Teiss. 1962. and hi-earlier papers on molecular ecology and related natters). The conclusions set forth above as to the existence and roles of gradients, ficlols, interactions between parts, and movement or differential growth in ciliate norphogenesis and cell heredity liave their connterparts in the older and much more extensive experimental embryolowical studies on Mrtazoa.

Recently Curtis (1960) has demonstrated the corticaf localization 
of the determinative parts of the pattern of the mosaic egg of Xenopus. In such eggs, the different parts of the egg cortex are segregated into different cells during cleavage, presumably in the absence of growth or further cortical developments. When growth and further development begin, the cells endowed with diverse cortices appear to follow different lines of cortical development (ef. Sonneborn, 1960). Juxtaposition of cells with different cortical patterns leads to organizer and inductor-response reactions. The parallels to regionally diverse cortical parts in ciliates, and the interactions between those that are adjacent, are too obvious to be labored. The main difference between unicellular and multicellular organisms in these respects is in the nature of the differentiated and interacting units: different regions of the cortex of one Protozoan cell correspond in principle to the cortices of different cells in the Metazoa (Fauré-Fremiet, 1954).

Finally, in Metazoa as in Protozoa, the cortical patterns and events undergo a progressive self-directed sequence of changes, during the clonal life cycle in the latter and during the individual life cycle in the former. In both, one change leads to the next and the sequence becomes a cycle by a return to the starting point. In the ciliates, any cell (after immaturity and before advanced senescence) can undergo fertilization (or encystment or physiological regeneration) and return to the cortical starting point. Likewise all cells capable of division may be able to do this in certain plants (Steward, 1961). Only certain cells can do it in the Metazoa. In the Protozoa and the Metazoa, the return may be rapid and normally confined to a cell that has undergone fertilization or one specialized to undergo it. The many parallels suggest that the roles of the cell cortex and the principles of their operation may be fundamentally alike in unicellular and multicellular animals.

This basic similarity implies an evolutionary development of cortical specificities; and the considerable degree of antonomy of cortical parts suggests a corresponding degree of independence in their evolution. This is strongly indicated by the existence of a number of genera of flagellates and ciliates (for example, Giardia, Teutophrys) in which the animals appear morphologically to be doublets or higher multiples of the animals of other genera (Faure-Fremiet, 1945). Within this limited group, the evolution of genera clearly runs parallel to the laboratory production of hereditary doublets and multiplets.

In general, there is no doubt about the existence of cortical evolution in the ciliates. The whole taxonomy of this group hinges upon cortical characteristics (Corliss, 1961). However, nearly all of the gross morphological features of ciliates are cortical features. The 
important point is whether the evolutionary changes in the corter were due to genomic ehanges, independent cortical changes, or parallel series of independent but selectively correlated changes in genome and cortex. No direct evidence on these alternatives is available or is likely to be obtained. If cortical changes other than mere losses or additions of parts (for example. shifting the position of the oral apparatus from equator to pole, a type of difference that distinguishes certain ciliate taxa) could be produced and shown to be autonomonsly inherited, then independent cortical evolution would be indicated. Thus far, nothing like this has been accomplished in the laboratory or seems likely to be. I am inclined to favor the possibility of parallel. independent, and selectively correlated evolution of genome and cortex, for it has well-established precedent in the parallel evolution of genome and plastids in Oenothera (Stubbe, 1960; Cleland, 1962 ).

Some of the main trends in cortical evolution are hoth obvious and instructive. Zooflagellates, from which the ciliates crolved, are an enormously varied group. The progression from simplest to most complex is outstandingly accompanied by corticalization of an increasingly large number and variety of kinetosomes and their associated structures. In the simplest flagellates, these are unitary, simple, and for the most part deep in the endoplasm. The centriole is in them the key kinctosome. While it may be compound in structure, it is associated with both spindle fibers and the one or few flagella. In somewhat less simple flagellates, there are one or few kinetosomes and more complex and more numerous fibrous structures. such as cresta, axostyle, and costa, in addition to spindle fibers and flagella. The kinetosomes, as well as most of the other parts, still lie deep in the endoplasm. In the more complex flagellates, several changes oceur: the number of kinetosomes increases greatly, they concentrate more and more upon association with flagella, and they lie prevailingly near the surface of the body. Finally, in the opalinids the cortex of the anterior pole or apex of the cell reaches its fullest development as a sort of organization center, with a ring of apical kinetosomes organizing longitudinal kineties. In the eiliates these longitudinal kineties become independent of the apical region and the cortex of the equatorial region becomes the center of growth and organization.

The original internal location of kinetosomes and other parts in Zooflagellates and their evolutionary migration to the cortex support Ehret and Powers" (1959) view of the internal origin of kinetosomes (or of eiliary corpuseles) in the ontogeny of Paramecium. But other aspects of the evolutionary picture do not support their view that the cortex of Paramecium is composed solely of packed ciliary corpuseles, 
aside from trichocysts. Flagellates have a cortex even when the kineto. somes lie in the endoplasm; it may be little more than a limiting membrane system. Perhaps the outermost membranes of Paramecium are homologous with the outer membranes of flagellates. The wellknown inducible shedding of the pigment-containing "pellicle" in Blepharisma (Nadler, 1929) and Stentor (Tartar, 1961) without loss of essential nonreplaceable cortical components, taken in connection with Tartar's earlier cited result on the irreplaceability of the Stentor cortex, seems to weigh against that part of the Eliret and Powers (1959) conception which reduces the entire cortex to elements having internal origin.

The account just given indicates that new parts were added to the cortex during the evolution of the Protozoa. Knowledge is lacking as to whether certain cortical parts or the whole cortex is the seat of the gradients and physiological diversities that direct the course of morphogenesis and the processes which result in the inheritance of cortical characteristics. In the Metazoa, as we have seen, gross morphological differentiation of the cortex has largely disappeared; but the underlying determinative physiological differentiations of the cortex are present in highly developed form, as Curtis's (1960) experiments demonstrate. This leads to the guess that the basic genetically and morphogenetically important part of the cortex is not the part that is unique to the Protozoa, the part bearing the morphologically visible differentiations.

\section{The role of preformed cortical structure}

The question with which this chapter began-whether the structure of a cell (aside from that of its chromosomes) plays an essential or nonessential role in the determination of the structure of its cell progeny-has been answered unambiguously by experiment al analysis. Such structure may play little or no part in many essential intracellular activities which depend only on the physicochemical properties, amounts and random collisions of newly imbibed food (in the broadest sense), and newly produced direct and indirect products of gene action. On the other hand, our study of Paramecium-in general agreement with a number of other studies-shows that preformed cortical differentiations are essential for their own reproduction. Certain visible cortical structures failed to arise de novo when they were initially lacking. Experimental modifications of the visible cortical organization were perpetuated during cell reproduction. Thorough breeding analysis, combined with other accessory modes of 
analysis, proved that the difference between two hereditary cortical types, singlets and doublets, was not due to any genic, nuclear, or endoplasmic difference. Finally, natural grafts of a picec of cortex showed that it was decisive in morphogenesis and cell heredity. The autonomy and genetic significance of cortical structure was thus fully estahlished.

We then tried to pin down just what cortical structure is genetically autonomous and just how this genetic autonouny is achieved. Conspicuous cortical structures, like kinetosomes, kinetics, and groups of kineties, to which a causal role in morphogenesis and cell heredity has often been attributed (and still is, in many quarters), are clearly not genetically fixed as to their developmental and genetic roles. They are one instrument, not the cause, of morphogenesis and cell heredity. They are responsive to, and express visibly, the more basic, underlying causal cortical structure. This finer structure, probahly at the molecular level, is the basis of the genetically and morphogenetically decisive interactions we have described as occurring hetween juxtaposed diverse cortical areas which are the seats of gradients of structure and action.

What are the determinative molecular species, configurations, and modalities in the cortex? At present this remains almost or quite completely unknown, not only in ciliates but in all organisms. FauréFremiet (1950, 1954) has put forth stimulating suggestions based upon the general geometrical parallels between kinctics and macromolecules such as polypeptides and polysaccharides. He points out that both exhibit similar symmetry, polarity, and other polymeric features. He suggests that the properties of the visible structures are consequences of the comparable properties of the constituent and/or surrounding cortical macromolecules. This suggestion is attractive, but alone it of course does not account even in principle for the modalities of morphogenetic processes and their genctic conseruences.

How can we in general bridge the gap between the (unknown) molecular structure of the cortex and the morplogenetic and genetic processes which surely are linked to it? Speculation about the anwwer to this question cannot he entircly free; it must be limited to conform with a good deal of pertinent knowledge. In particular, it must conform with what is known about nuclear functions. The cistrons or genes make polypeptides, proteins, enzymes, and indirectly the products of enzymic activities. Some of these doubtless enter into the composition of the cortex of the cell. Differences between allelie eistrons or genes would therefore be expected to result in molecular differenecs in the cortex and thus to determine at least some cortical differences. 
Preer (1959), Maly (1958, 1960), Sonneborn (unpublished), and Hanson (1962) have indeed found in Paramecium genic or nuclear differences that determine differences in visible cortical structures or in their morphogenetic processes. These findings have to be accommodated in reasonable speculations about the decisive determinative molecular organization of the cortex and the modalities of its action.

Perhaps the main clue-aside from the demonstrated fact that the cortex is essential and determinative-lies in information bearing on the limits of nuclear action. It should be obvious, but commonly is not recognized as such, that the nuclens alone cannot make its corresponding cell or any cell at all (Sonneborn, 1951). This is not merely because the rest of the cell provides a limiting membrane with the function of regulating ingress and egress of materials, for there are regionally diverse decisive areas in the cortex of a single cell. The decisive contribution of the cell cortex is thus its specific organization. Specificity of cytoplasm is correlated with that of the nucleus, for chromosomes in the cytoplasm of a closely related species often cannot function normally and are injured or destroyed (Levine, 1953; Hennon, 1962). This implies that there must be, for cellular existence, a delicate correlation between genotype and plasmatype which is lethally disrupted by relatively minor changes in either and which slowly co-evolves (see above). This intricate intracellular coordination, the result of ruthless long selection, offers little hope that man could ever devise a noncellular milieu in which a nuclens could operate so as to make its own cell or any cell at all.

These considerations leave but few sorts of speculative possibilities for the mode of operation of the cortex. On the one hand, the diverse parts of the cortex might be the seat of production of certain molecules not directly or indirectly producible by the action of genes (and food) alone. However, there is at present, so far as I am aware, no evidence for the production by cells of specific molecules independently of those taken in as food or formed directly or indirectly by genic action. On the other hand, the diverse parts of the cortex (and other preformed cytoplasmic structures) might be the seat of specific absorption and orientation of molecnles derived from the milieu and genic action. This alternative is more in harmony with present knowledge. Preexisting cortical structure would then play its essential part by determining where some gene products go in the cell, how these combine and orient, and what they do (Sonneborn, 1951; Tartar, 1961). Apparently such specific assemblies conld confer new properties upon molecular groupings. A contemporary example of such origin of new properties appears to be provided by transfer 
RNA's. Their triplets appear to be capable of uniting effectively with their complementary triplets in messenger RNA only after the transfer RNA's have combined with their amino acids. Otherwise the mes. senger could be clogged witl blanks. In like manner, one may suppose that the gene products which unite with molecules of the cortex acquire specific activities as a result of the mion. The varions developmental and genetic events which are regionally localized in different parts of the cortex may thus be dependent upon specific molecular combinations between newly formed molecules deriving from the genes and preexisting molecular patterns already present in the cortex.

This conception further agrees with the contemporary view that function is intimately connected with molecular structure. Preexisting structure determines processes that lead to different structures and different processes in sequences that are self-determined at every step and that lead back cyclically to the starting point. This dymamic interplay of structure and process contrasts with the static view of an unchanging, persistent, fundamental ground substance or organization of the eytoplasm which always underlies the developmental and regenerative capacities of the cell (Calkins, 1926b: Ephrussi, 1952; FauréFremiet, 1950: 1954; Harrison, 1945). Present knowledge rather indicates a cyclically changing scene dependent at every level on preexisting structure, from the preformed enzymes and ribosomes that are indispensable for renic replication and action to the organized cortical fields, gradients, and localized inductor-response systems required for morphogenesis and hereditary transmission of cortical strueture and action systems.

At this stage in discovery, we can only formulate the systems in such general terms. The much more difficult task for the future is to define and specify in molecular terms the decisive structures, gradients, and inductor-response systems and to reveal how specific absorption, orientation. and activation of migratory molecules leads to visible morphogenesis and genetie stability of cell organization.

\section{References}

Calkins, G. N. (1925), Uroleptus mobilis. V. The history of a double organism, J. Exp. Zool., $41: 191-213$. (1926a). Biology of the Protozoa, Lea \& Febiger, Philadelphia. (1926h). Organization and variation in Protozoa. Sci. Monthly, 22:341-351. Chatton. E. (1921), Réversion de la scission chez les Ciliés. Réalisation d'individus distomes el polyenergides de Glancoma scintillans se multipliant indéfiniment par scissiparité. Compt. Rend. Acad. Sci, 173:393.

. and A. Lwoff (1930), Imprégnation. par diffusion argentique, de l'infracilia- 
ture des Ciliés marins et d'eau douce, après fixation cytologique et sans dessication, Compt. Rend. Soc. Biol., 104:834.

Cleland, R. E. (1962), Plastid behavior in North American Euoenotheras, Planta, $57: 699-712$.

Corliss, J. O. (1961), The Ciliated Protozon, Pergamon Press, New York.

Curtis, A. S. G. (1960), Cortical grafting in Xenopus laevis, J. Embryol. Exp. Morphol., 8:163-173.

Dalcq, A., and J. Pasteels (1937), Une conception nouvelle des bases physiologiques de la morphogénèse, Arch. Biol. (Paris), 48:667-710.

— ents" de Child, Bull. Acad. Méd. Belg. 6 e Sér., 3:261-308.

Dawson, J. A. (1920), An experimental study of an amicronucleate Oxytricha. II. The formation of double-animals or twins, J. Exp. Zool., 30:129-157.

De Harven, E., and W. Bernhard (1956), Étude au microscope électronique de l'ultrastructure du centriole chez les Vertébrés, Z. Zellforsch. Mikroskop. Anat., Abt. Histochem., $45: 378-398$.

Dippell, Ruth V. (1955), Some cytological aspects of aging in variety 4 of Paramecium aurelia, J. Protozool., 2 (Suppl.) :7.

(1962), The site of silver impregnation in Paramecium aurelia, J. Protozool., 9 (Suppl.) : 24.

Ehret, C. F. (1960), Organelle systems and biological organization, Science, 132 : 115-123.

- and E. L. Powers (1959), The cell surface of Paramecium, Intern. Rev. Cytol., 8:97-133.

Ephrussi, B. (1952), Nucleo-cytoplasmic Relations in Microorgamisms, Oxford University Press, Fair Lawn, N.J.

Fauré-Fremiet, E. (1945), Symmétrie et polarité chez les Ciliés bi- ou multicomposites, Bull. Biol. Fr. Belg., 79:106-150.

(1948a), Doublets homopolaires et régulation morphogénétique chez le Cilié Leucophrys putula, Arch. Anat. Microscop. Morphol. Exp., 37:183-203.

- (1948b), Les mécanismes de la morphogénèse chez les Ciliés, Folia Bio. theoretica, 3:25-58.

— (1950), Problème moléculaire de la morphogénèse, Ann. Biol., 26:361-379. (1954), Les problemes de la différenciation chez les protistes, Bull. Soc. Zool. Fr., 79:311-329.

Frankel, J. (1960a), Morphogenesis in Glaucoma chattoni, J. Protozool., $7: 362-376$.

- $(1960 \mathrm{~b})$, Effects of localized damage on morphogenesis and cell division in a ciliate, Glaucoma chattoni, J. Exp. Zool., 143:175-194.

- (1961), Spontaneous astomaty: loss of oral areas in Glaucoma chattoni, J. Protozool., 8:250-256.

Hanson, E. D. (1955), Inheritance and regeneration of cytoplasmic damage in Paramecium aurelia, Proc. Nat. Acad. Sci. U.S.. 41 : 783-786.

- (1962). Morphogenesis and regeneration of oral structures in Paramecium aurelia, J. Exp. Zool., 150:45-68.

Harrison, R. G. (1945), Relations of symmetry in the developing embryo. Trans. Conn. Acad. Arts and Sci., 36:277-330.

Hennon. Sally (1962), A cytological and embryological analysis of the nuclear changes occurring in a lethal amphibian hybrid (Rana sylvatica female by $R$. pipiens male), Dissertation, Indiana University. 
Hertwig. R. (1899). Üher die Conjugation der lufusorien. Abhandl. h. bayer. Ahul. Wiss., II CI.. 17:151-233.

Hiwatashi. K. (1955). Studies on the conjugation of Paramecium caudatum. V'1. On the nature of the union of conjugation. Sci. Rep. Tohoku U'niv, 4tl ser., Biology, $21: 207-218$.

Jennings, H. S. (1908). Heredity, variation and evolution in Protozoa. I. The fate of new structural characters in Paramecium. in connection with the problem of the inheritance of acruired characters in unicellular organisms. J. Exp. Zool., $5: 577-632$.

- (1944), Paramecium bursaria: life history. I. Immaturity, maturity and age. Biol. Bull., 86:131-145.

Kimball, R. F. (1941), Double animals and amicronucleate animals in Euplotes patella with particular reference to their conjugation. J. Exp. Zool.. 86:1-33.

Levine. M. (1953). The interaction of nucleus and cytoplasm in the isolation and evolution of species of Paramecium. Evolution, $7: 366-385$.

Lwoff, A. (1950). Problems of Morphogenesis in Ciliates, John Wiley \& Sons, Inc.. New York.

Maly, R. (1958). Eine genetische bedingte Storung der Zelltrennung bei Parame. cium aureliu, Z. Vererbungslehre, 89:397-121.

(1960). Die Normalisierung genetisch bedingter Defekte der Zelltremung bei Puramecium aurelia durch Sauertoffmangel und Kohlemmonoxyd. Z. V'erer. bungslehre, $91: 226-236$.

Margolin, P. (1954), A method of obtaining amacronucleated animals in Parame. cium aurelia, J. Protozool.. $1: 174-177$.

Maupas. E. (1888). Recherches expérimentales sur la multiplication des infusoires ciliés. Arch. Zool. Exp. Gen. (2), 6:165-277.

Mazia, D. (1961), Chapter 2, in The Cell, erl. by J. Brachet and A. E. Mirsky. Academic Press, Inc., New York, vol. 3, pp. 77-394.

Moscona, A. (1957). The development in titro of chimeric aggregates of dissociated embryonic chick and mouse cells, Proc. Nat. Acal. Sci. U.S. 43:181-194.

Nadler. J. E. (1929). Notes on the loss and regeneration of the pellicle in Blephar. isma undulans, Biol. Bull.. 56:327-330.

Nobili, R. (1961a), L'azione del gene am sull'apparato nucleare di Paramecium aurclia durante la riproduzione vegetativa e sessual in relazione all età del clone ed alla temperatura di allevamento degli animali. Caryologia, 14:13-58. (1961b). Variazioni volumetriche del marronucleo e loro effetti netha ripro. duzione regetativa in Paramecium utrelia, Atti Soc. Toscana Sci. Nut. (Ser. B): 217-232.

Porter, E. D. (1960), The buccal organelles in Parnmecium aurelin during fiscion and conjugation. with special reference to the kinetosomes, J. l'rotozool., $7: 211$ 217.

Powers, E. L. (1913), The mating types of double animals in Euplotes patella. Am. Midland Naturalist, 30:175-195.

Preer. J. R. (1959). Nuclear and cytoplasmic differentiation in the Protozoa. in Developmental Cytology; ed. by Dorothea Ruduick. The Ronald Press Company. New York, pp. 3-20.

Roque. Madeleine (1956a). Lévolution de la ciliature lucrale peudant l'antoganie et la conjugai on chez Puramecium aurelia, Compt. Rend. Acrul. Sri., 242:25922595. 
(1956b). La stomatogénèse pendant l'antogamie, la conjugaison et la division chez Paramecium aurelia, Compt. Rend. Acad. Sci., 243 :1564-1565.

Sonneborn, T. M. (1930), Genetic studies on Stenostomum incaudatum. II. The effects of lead acetate on the hereditary constitution, J. Exp. Zool.. 57:409-439.

(1932), Experimental production of chains and its genetic consequences in the ciliate protozoan, Colpidium campylum (Stokes), Biol. Bull., 63(2):187211.

(1942). Double animals and multiple simultaneons mating in variety 4 of Paramecium aurelia in relation to mating types. Anat. Record, 84(4) :29-30.

- (1943), Gene and eytoplasm. I. The determination and inheritance of the killer character in variety 4 of Paramecium aurelia, Proc. Nat. Acad. Sci. U.S., 29:329-338.

(1946), Inert nuclei: inactivity of micronuclear genes in variety 4 of Paramecium aurelia, Genetics, $31: 231$.

(1947), Recent advances in the genetics of Paramecium and Euplotes. Advan. Genet., $1: 263-358$.

- (1950), Methods in the general biology and geneties of Paramecium aurelia, J. Exp. Zool., 113:87-148.

(1951), The role of the genes in cytoplasmic inheritance, in Genetics in the 20th Century, ed. by L. C. Dunn, The Macmillan Company. New York. chap. 14.

- (1954a), Patterns of nucleoeytoplasmic integration in Paramecium, Caryologia, vol, suppl.:307-325.

_ (1954b), Gene-eontrolled aberrant nuclear behavior in P. aurelia, Micr. Gen. Bull., $11: 24-25$.

- (1954c), The relation of autogamy to senescence and rejuvenescence in Paramecium aurelia, J. Protozool., 1:38-53.

- (1960), The gene and cell differentiation, Proc. Nat. Acad. Sci. U.S., $46: 149$ 165.

— , and Ruth V. Dippell (1960a), The genetic basis of the difference between single and double Paramecium aurelia, J. Protozool., 7 (Suppl.) :26.

- and - (1960b), Cellular ehanges with age in Paramecium, in The Biology of Aging, ed. by B. I. Strehler et al., AlBS, Washington, D.C.. p. 285.

- and - (1961a). The modes of replication of cortical organization in Paramecium aurelia, syngen 4, Genetics, 46:899-900.

in Paramecium aurelia, syngen 4, Genetics, 46:900.

$\longrightarrow$, and - (1961e), The limit of multiplicity of cortical organelle systems in $P$. aurelia, syngen 4, Am. Zool., $1: 390$.

$\longrightarrow$, and (1962), Two new evidences of cortical autonomy in syngen 4 of Paramecium aurelia, J. Protozool., 9 (Suppl.) : 28.

- and Arlene Lesuer (1948), Antigenic characters in Paramecium aurelia (variety 4): determination. inheritance and induced mutations, Am. Natural. ist, $82: 69-78$.

- and Myrtle V. Schneller (1955), The basis of aging in variety 4 of Para. mecium aurelia, J. Protozool., 2 (Suppl.) :6.

Stevens, Nellie M. (1903), Notes on regeneration in Stentor coeruleus, Arch. Entwickslungsmech. Org., 16:461-475.

Steward, F. C. (1961), Growth induction in explanted cells and tissues: metabolic and morphogenetic manifestations, in Synthesis of Molecular and Cellular 
Structure, ed. by Dorothea Rudnick. The Ronald Prens Company, New York. chap. 8, pp. 193-246.

Stubbe, W. (1960). Untersuchnngen zur genetische Analyse des Plastoms von Oenothera, Z. Botan., 48:191-218.

Snzuki, S. (1957), Morphogenesis in the regeneration of Blepharisma undulans japanicus Suznki, Bull. Yamagata Unir.. Nat. Sci., 4:85-192.

Tartar. V. (1941), Intracellular patterns: facts and principles concerning patterns exhibited in the morphogenesis and regeneration of ciliate Protozoa, Growth 5 (suppl.) : 21-40.

(1954a), Reactions of Stentor coeruleus to honoplastic grafting. J. Exp. Zool., 127:511-575.

(1954b). Anomalies in regeneration of Paramecium, J. Protozool., $1: 11-17$.

(1956). Grafting experiments concerning primordium formation in Stentor coeruleus, J. Exp. Zool.. $131: 75-122$.

(1961), The Biology of Stentor, Pergamon Press, New York.

Uhlig, G. (1960). Entwicklungsphysiologische L'ntersuchungen zur Morphogenese von Stentor coeruleus. Arch. Protistenk. 105:1-109.

Weiss, P. (1939), Principles of Development, Holt, Rinehart and Winston. Inc.. New York.

Weisz, P. B. (1951), A general mechanism of differentiation haned on morpho. genetic studies in Ciliates. Am. Naturalist, 85:293-311.

- (1954), Morphogenesis in Protozoa, Quart. Rev. Biol., 29:207-229.

(1962). From cell to molecule, in The Molecular Control of Cellular Activity, ed. by J. M. Allen. McGraw-Hill Book Company, Inc., New York, chap. I, pp. 1-72. 



\title{
Microenvironmental
}

\author{
Influences in \\ Cytodifferentiation
}

\author{
Clifiord Grobstein \\ Department of Biological Sciences \\ Stanford University, Stanford, California
}

My objective is to present some facts which suggest that the materials between, and normally closely associated with, the surfaces of cells may be important in controlling cytodifferentiative behavior. Since cytodifferentiation and organismal diversification are opposite faces of the developmental coin, controls for the one must underlie the regularities of the other. There is a large body of information indicating that cytodifferentiation is sensitive to extrinsic influence. However, my emphasis here is not on extrinsic factors generally. but on those which reside in the immediate vicinity of the cell. in the largemolecular materials which are produced by the cell or its close neighbors and which may continuously interact with their source subsequent to production. It is in these terms that I define what is referred to in this discussion as the microcnvironment.

I shall limit myself to consideration of two of the several available 
sources of information on the developmental role of microenvironment-embryonic induction and the reaggregation of dissociated cells. The information which I shall summarize raises the interesting possibility that there are important relationships among the mechanisms of aggregation, induction, and cytodifferentiative control.

Embryonic induction long has been recognized as relevant to cytodifferentiative control-because it involves developmental dependency -the differentiative course of one group of cells in the embryo is different depending upon whether or not it comes into association with a sccond group. The possibility of microenvironmental effects is raised because the association between the two tissues normally is extremely close.

In lens induction by optic vesicle, for example, the morphological association is so close, as judged by histological sections and by efforts to separate the two mechanically, that mechanisms have been proposed (Weiss, 1958) which assume direct surface-to-surface contact of the cells involved. These assumptions were supported by the finding that interposition of such materials as cellophane between the lentogenic epithelium and the optic vesicle completely blocks the induction (McKeehan, 1951). In recent years, however, evidence has been accumulating that actual contact is not required in certain inductive systems, providing the interspace between has suitable properties. It appears, nonetheless, that even under these circumstances there is a limit to the separation distance across which the reaction can proceed. I should like, first, to recall some of the evidence which seems to justify these statements.

Let me begin by introducing the experimental system which has so far been most useful in our laboratory. It involves the rudiment of the definitive kidney or metanephros of the mouse. In the 11-day embryo the rudiment consists of two components, the outer metanephrogenic mesenchyme and the inner ureteric bud. It is important to recall that the ureteric bud branches to form the collecting ducts of the kidney, while the outer mesenchyme contributes the glomeruli and secretory tubules. If the intact rudiment is placed under suitable conditions in vitro, each component undergoes continued morphogenesis in sufficiently normal fashion to be recognized in the developing culture and in subsequent histological sections (Figs. 1 to 6). If the rudiment is first treated with trypsin, however, and the ureteric bud removed, the metanephrogenic mesenchyme alone entirely fails to undergo kidney-type morphogenesis under the same culture conditions. If the separated mesenchyme is recombined in culture with ureteric bud, or with the dorsal region of embryonic spinal cord, 
rudiments of secretory tubules appear (Fig. 7). These facts, together with others previously gathered on kidney development in the intact organism, demonstrate that epithelial tubule formation by nephrogenic mesenchyme is dependent upon an outside contribution. Normally this is assumed to be provided by the ureteric bud: experimentally it can also be supplied by dorsal spinal cord.

For reasons of convenience, it is the combination of dorsal spinal cord and metanephrogenie mesenchyme which has received most attention. When a fragment of cord is included among fragments of metanephrogenic mesenchyme, seeretory tubule rudiments appear in the mesenchyme after 30 to 40 hours of ineubation. It is important to note that these rudiments do not appear generally in the mesenchyme but only in immediate association with the surface of the spinal cord. I say "immediate association" now; when the observation was first made the relationship suggested "contact." I note this to emphasize that the system under consideration shows the usual character. istic of intimaey in embryonic induction.

Having such an inductive system under reasonable control in vitro, the next question is the one of separability of components. It turned out that if dorsal spinal cord and metanephrogenie mesenchyme were cultured "back to back" on a highly porous membrane filter (millipore), secretory tubule rudiments appeared in the metanephrogenie mesenchyme immediately opposite the spinal cord (Fig. 8). I say "immediately opposite" to emphasize again that the tubules do not appear just anywhere in the mesenchyme; they form as close to the cord as they can under the circumstances, separated only by the thickness of the membrane filter. The filter used in the early experiments was approximately 20 microns thick, with average pore diameter in the vicinity of $1 / 2$ micron. By examining sections with the optical microscope, particularly under phase conditions, it was possible to discern materials penetrating into the filter. Electron microscopy showed that some of this material, at least, was eytoplasmic-so one could not say with eertainty with this filter that a 20 -mieron separation between cell surfaces was achieved. Subsequent experiments, however, with filters of lesser porosity (in the vicinity of 0.1 mieron), showed that eytoplasm-free separation of at least 20 microns can be achieved without blocking the induction, though the intensity is reduced.

This last point, the reduction of intensity at 20 microns by membranes of porosity in the vicinity of 0.1 micron, raises a red flag to easy assumptions that separability implies free diffusion and indefinite mobility on the part of the active materials. The eaution is 
emphasized by measurements made on the transmission distance of the inductive activity, even using higher-porosity filters whieh allow relatively free entry of eytoplasmic processes into the interspace. Measurements were performed by interposing either single filters of different thickness or multiple layers of filters of the same thickness (Figs. 9 and 10). When the response, expressed either as thickness of the metanephrogenic layer or as occurrence of tubules, was plotted
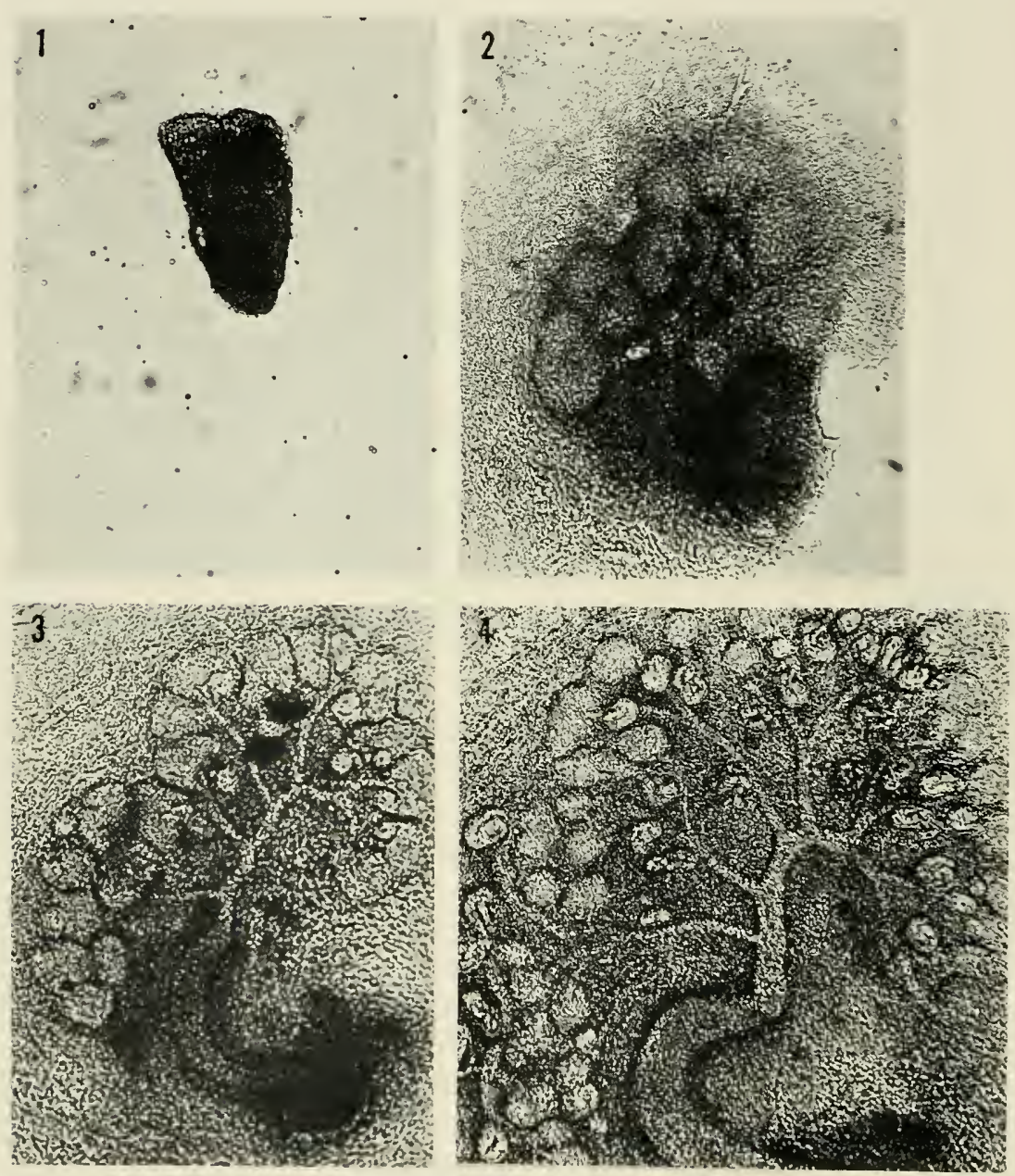

PLATE I. Developing metanephric rudiment of the 11-day mouse embryo in vitro. ( $\times 38.4$.$) FIG. 1. Immediately after explantation. FIG. 2. On the second day. FIG. 3$. On the fourth day. FIG. 4 . On the seventh day. 


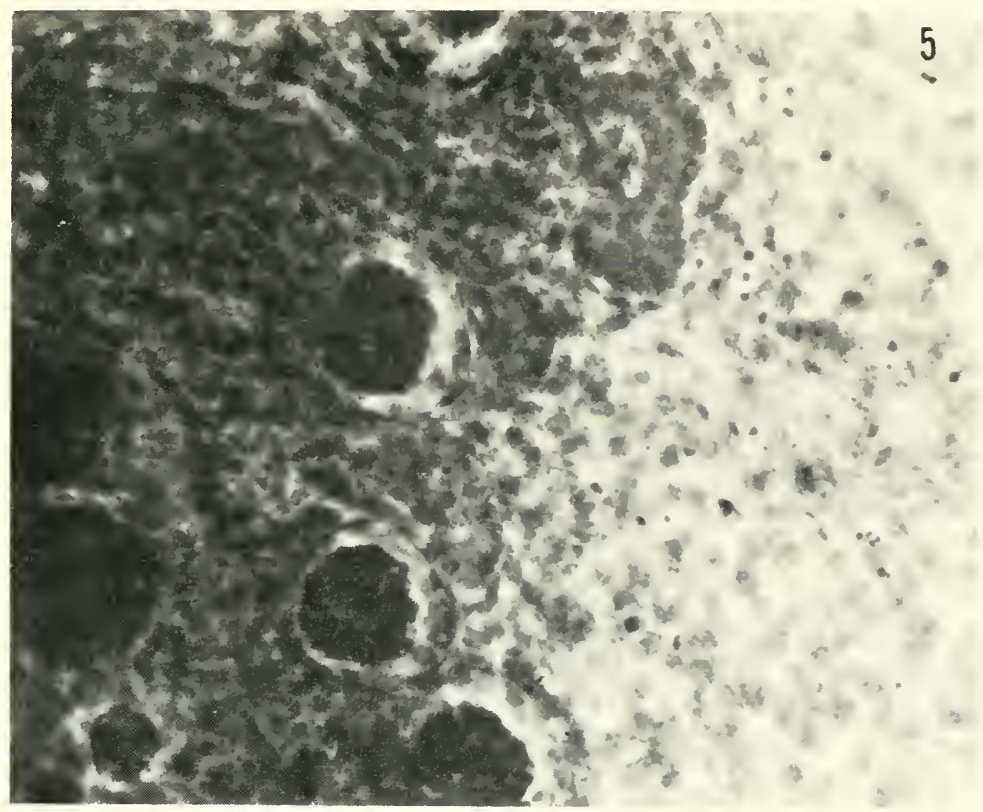

6

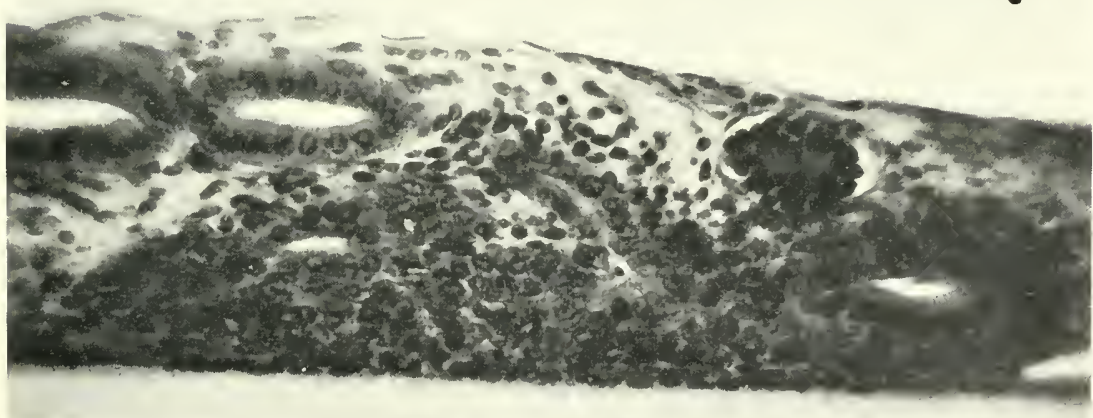

PLATE II. Metanephros of the 11-day mouse embryo cultured for 8 days on a millipore filter platform. Note glomeruli and epithelial tubules. FIG. 5. Fixed and stained whole mount. FIG. 6. Fixed and stained section.

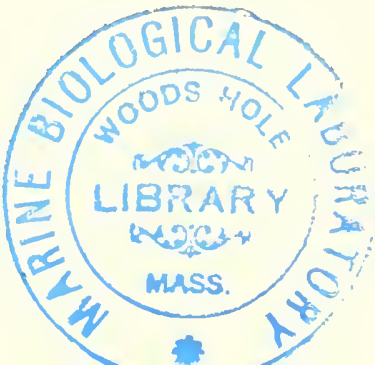




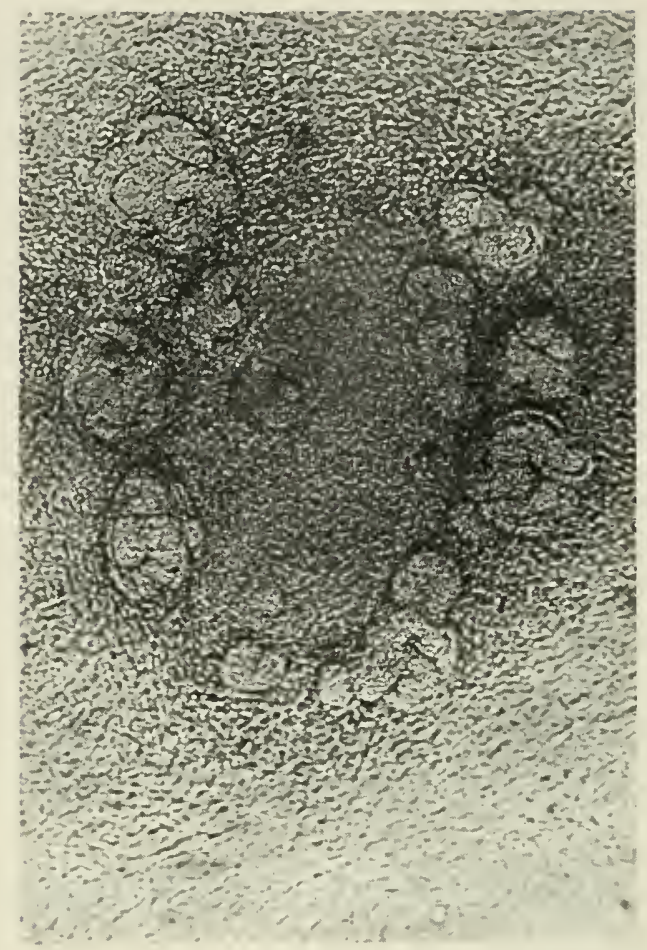

PLATE III. FIG. 7. Dorsal spinal cord in metanephrogenic mesenchyme. Note induced tubules surrounding cord.

against intervening distance, an "inductive activity" curve was obtained (Fig. 11). This declined sharply beyond about 30 microns and reached the level of nondetectability, by the criteria used, at 60 to 80 microns. The close association of induced structure to inductive source thus appeared not to be based on a requirement for surface-to-surface contact, but on limited transmission distance in active form of the inductive material. Stated in another way, we seem to be dealing with materials which are not of the cell surface itself, but which normally are closely associated with it. In turn, this would imply that such surface-associated, microenvironmental materials are important in controlling differentiative processes.

We would, of course, like to know very much more about these

PLATE IV. Transfilter induction by dorsal spinal cord of epithelial tubules in metanephrogenic mesenchyme. FIGS. 8, 9. Positive effect with two filter layers. FIG. 10. Absence of effect with four filter layers. 


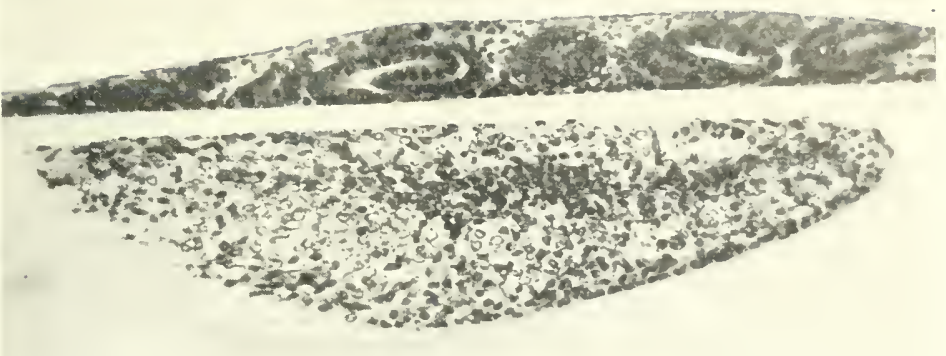

8
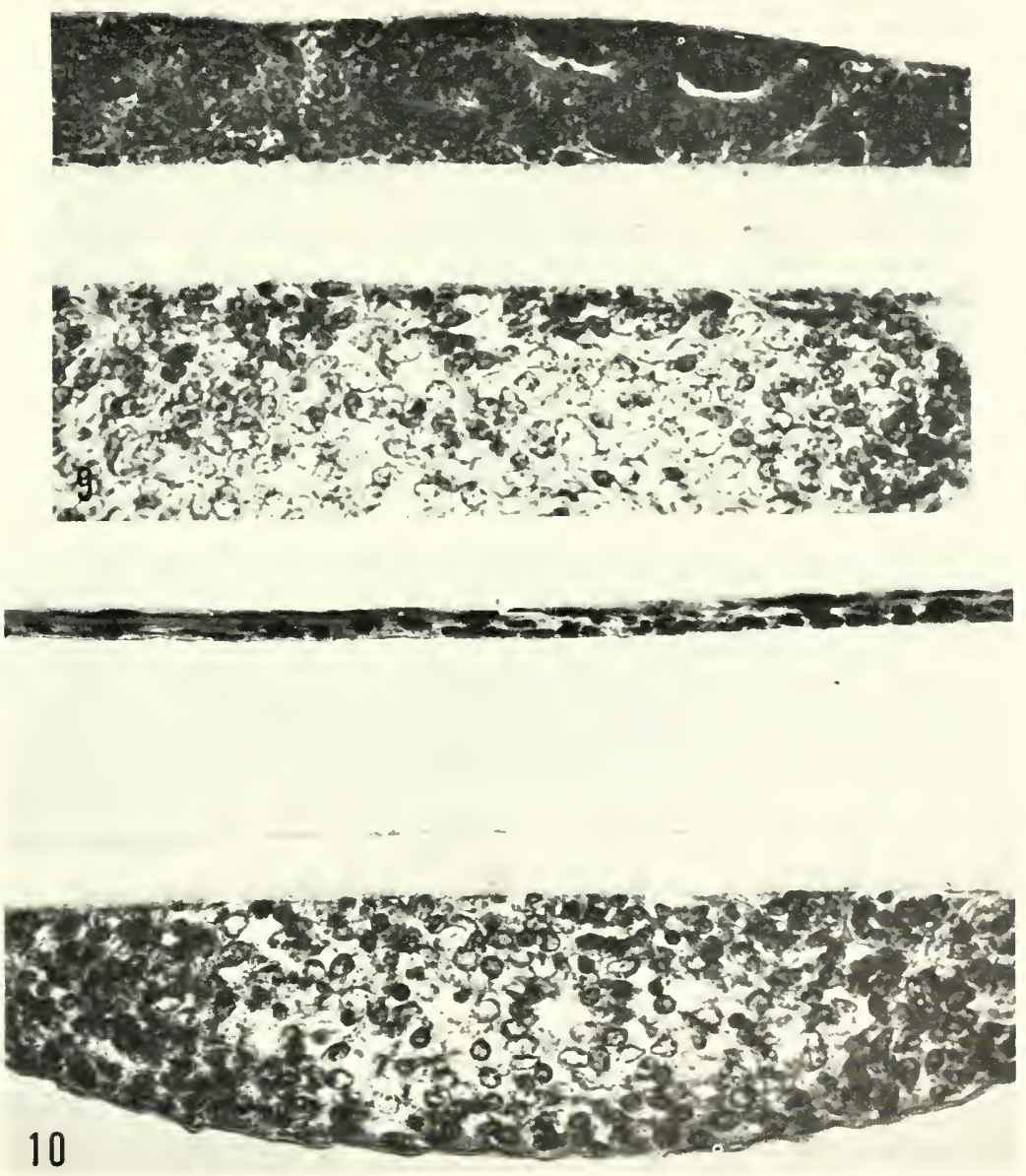
matcrials, how they are produced and how they operate. It seems clear that essential components of the material are large-molecular. This is suggested by the restraining effect, already mentioned, of filter porosities in the 0.1 micron range. Sieving in terms of molecular size is not by any means the only nechanism by which the filter may restrain mobility, but it is noteworthy that 0.1 micron is quite large in terms of molecular dimensions. Moreover, cellophane blocks the inductive effect. This can be shown by simply intcrposing cellophane

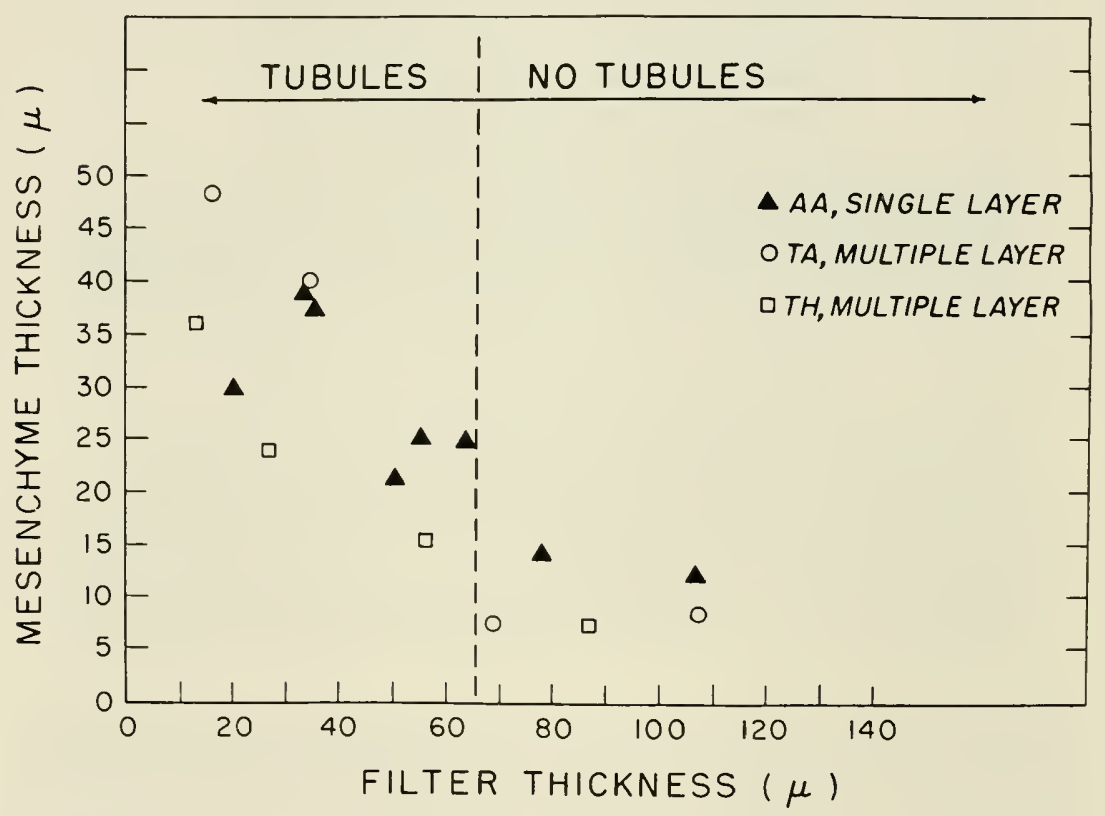

PLATE V. FIG 11. Effect of separation distance (filter thickness) on metanephro. genic mesenchyme thickness and tubule formation. $A A, T A, T H$, filters of different porosity and thickness. Each point represents an average of four or five cases.

between the interactants, but it is shown more dranatically by making use of the multiple-filter technique, as in the measurement of transmission distance. If a threc-layer assembly is used, the middle layer of which consists of cellophane with a small hole (Fig. 12), a localized induetion is obtained only immediately over the hole (Fig. 13). This seems to say not only that the cellophane is "opaque" to the activity, but that it comes through the small pinpoint hole to form a "bright" spot on the opposite sidc. It is interesting that this "shadowing" effect of cellophane is not only what would be expected 


\section{FILTER-CELLOPHANE ASSEMBLY}
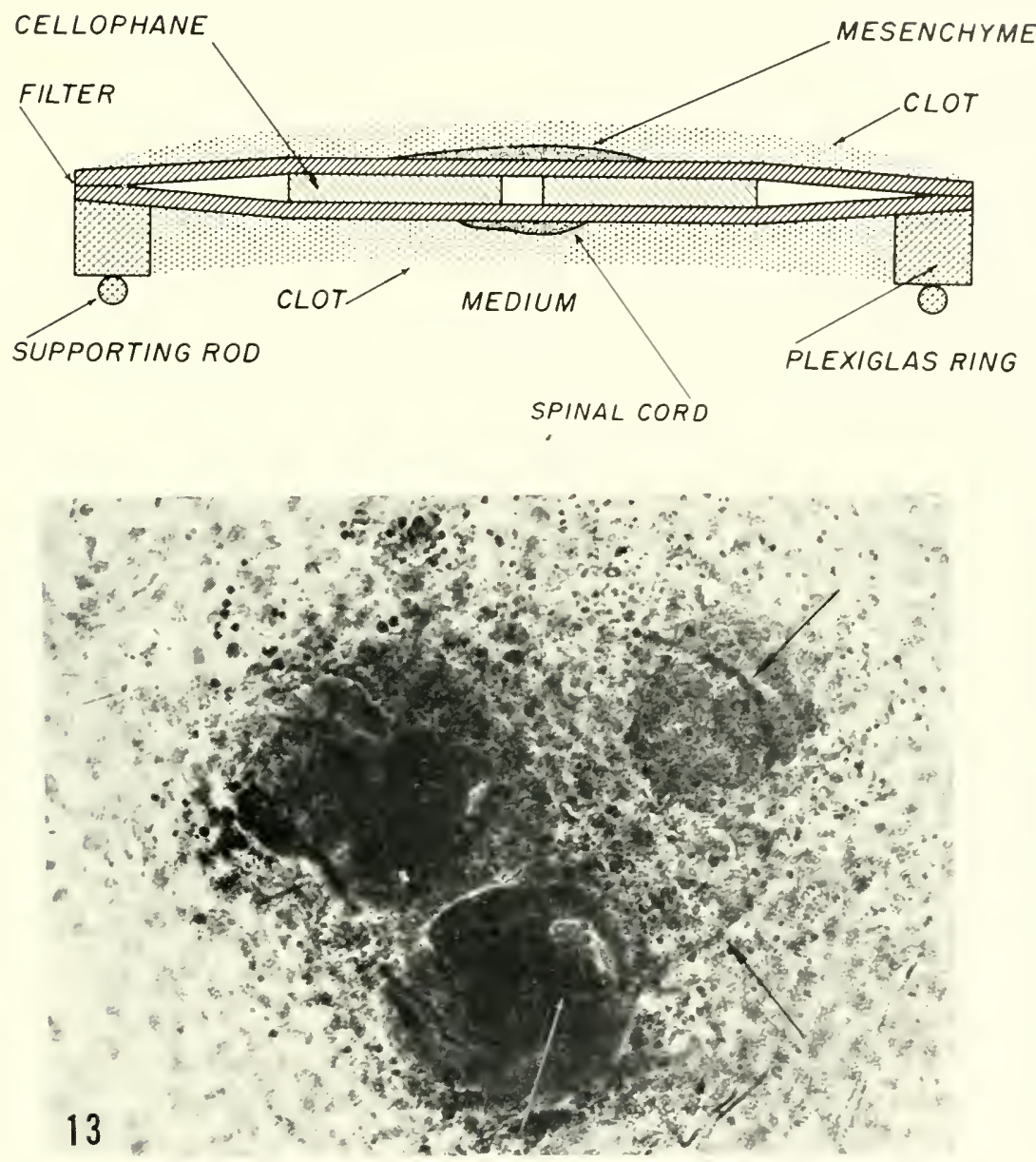

PLATE VI. FIG. 12. Diagram of cellophane with small hole interposed between inductive interactants. FIG. 13. Fixed and stained whole mount. Note edge of hole in rellophane marked by arrows, epithelial rudiment, forming. 
of large molecules, but it suggests that mobility of the material is primarily vertical in the filter substance with little lateral component. This is in conformity with what is believed by the manufacturers to be the structure of the filters used. It may be an important characteristic for obtaining the transfilter inductive effect, since it would tend to reduce dilution of materials in the interspace hy the general environment.

It also scems clear that protein is a constituent of the interspace material. At an early stage in the study of the transfilter effect, it was noted that the filter interspace between the tissues in sections differed
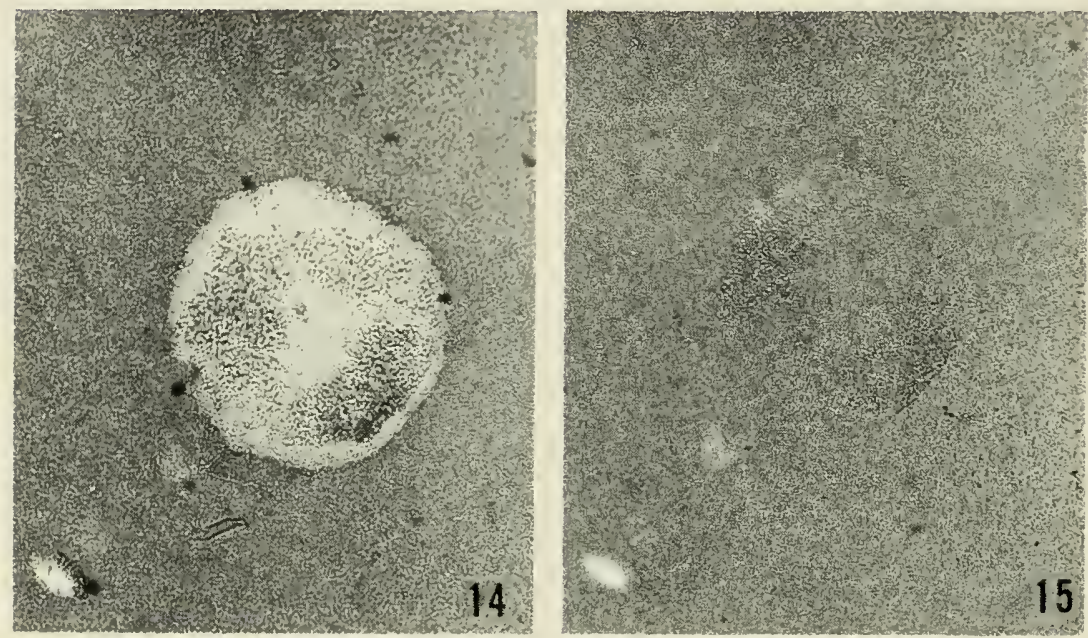

PLATE VII. Residual spot in filter. FIG. 14. Before exposure to trypsin. FIG. 15. After exposure to trypsin.

slightly in staining and optical properties from the filter lateral to the tissues. This led to studies of spinal cord incubated on filters in the absence of metanephrogenic mesenchyme, in an effort to detect inductive activity or material "secreted" by the spinal cord into the filter. Such preparations, after incubation for 20 to 24 hours, were fixed in alcohol-formalin. The spinal cord was found to be tightly cemented to the filter, so tightly that it could be removed only by scraping and fragmentation. When virtually all of the tissue had been scraped away, a translucent spot was left, clearly different from the surrounding filter (Fig. 14). The spot stained occasionally but variably with the periodic acid-Schiff procedure. When spotted filters 
were placed in trypsin, the spot gradually disappeared over a 10 minute interval (Fig. 15). Curiously, the spinal cord could he removed from the filter relatively easily before fixation, and such filters following fixation showed no sign of a spot. In general. the behavior suggested deposition in the filter of a mucoid slime. Neither unspotted filters, howcver, nor spotted filters following carcful washing to remove fixative had any inductive effect on metanephrogenie mesenehyme subsequently added.

The impression that protein is a constituent of the interspace material is strengthened by recent autoradiographic studies in which dorsal spinal cord was labeled by exposure to tritiated amino acids, before being put into culture on the membrane in the presence or absence of metanephrogenic mescnchyme. After varying periods of ineubation, the cultures were fixed in aleohol-formalin, sectioned, and processed for autoradiography. The presence of silver grains in the overlying radiation-sensitive film marks the location of the tritinm and, because tritium emission has low energy and a short emission path, the resolution of the method is high. Dorsal spinal cord becomes very heavily labeled during incubation for 2 hours in the tritiated amino acid solution. This labeling, presumably primarily of proteins in the tissue, is indicated by marked blackening of the film immediately over the cord (Fig. 16). More interesting, however, is the fact that in cultures incubated for 24 hours there is evident radioactivity in the filter interspace beyond the tissue, as well as in the metanephrogenic mesenchyme on the opposite side. Grain counts over the filter gave values 7 to 16 times background count, and these indications of radioactivity were limited to the general region previously identified as the "spot." It thus appears that administration of labeled protein precursors to the spinal cord deposits label in the filter in a form fixable by alcohol-formalin. It remains to be demonstrated that the tritium-labcled material and the trypsin-sensitive material are one and the same, but it will be more surprising if they are not than if they are.

Using the grain-counting procedure, it is possible to get an estimate of the amount of labeled material with increasing distance from the spinal cord. For this purpose labeled cord was incubated on a thicker filter, 125 to 150 microns, to provide a distance greater than that which inductive activity will eross. After incubation for varying periods such cultures were autoradiographed, and counts were made on suecessive 13-micron ranks across the thickness of the filter. Omitting details, it is clear that radioaetivity falls off sharply in the first 60 microns and approaches background in the vicinity of 100 microns 
(Fig. 17), when higher-porosity filters (about 0.5 micron) are used, and declines very much more rapidly when lower-porosity (about 0.1 micron) filters are used. The impression is that there is quite good agreement between the distribution of label and of inductive activity with distance.

It is interesting that the gradient of label exists not only in the filter but in the surrounding clot in which the tissue is embedded (Fig. 18). In fact, as one looks at the autoradiogram, one notes first

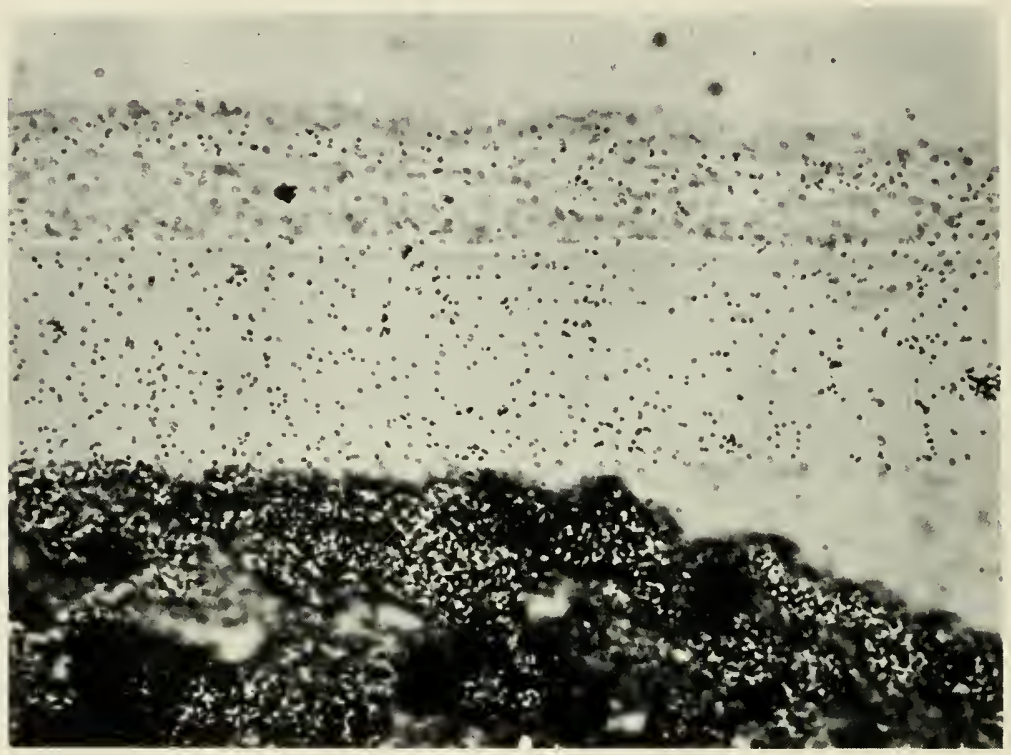

PLATE VIII. FIG. 16. Autoradiogram of transfilter culture involving dorsal spinal cord (below), heavily labeled by exposure to tritiated amino acids. Note grains above filter and over metanephrogenic mesenchyme on opposite side of filter.

the dense and reasonably sharply bounded "picture" of the dorsal cord, and then becomes aware-particularly knowing the result of the grain counts-that there is a much less dense "halo" of grains grading off around it.

Recent data obtained by Willian Koch, a graduate student in our laboratory, indicate that the label observed in the filter is noncellophane-passing. He has repeated the experiment referred to above involving two filter layers with intervening cellophane. He finds label in the filter on the dorsal cord side of the cellophane, but none in the cellophane or in the filter on the opposite side. Under these circum- 
stances label is found in the metaneplrogenie mesenchyme but at reduced levels in comparison with noncellophane cultures. This label presumably represents nonfixable small molecular material which passes cellophane.

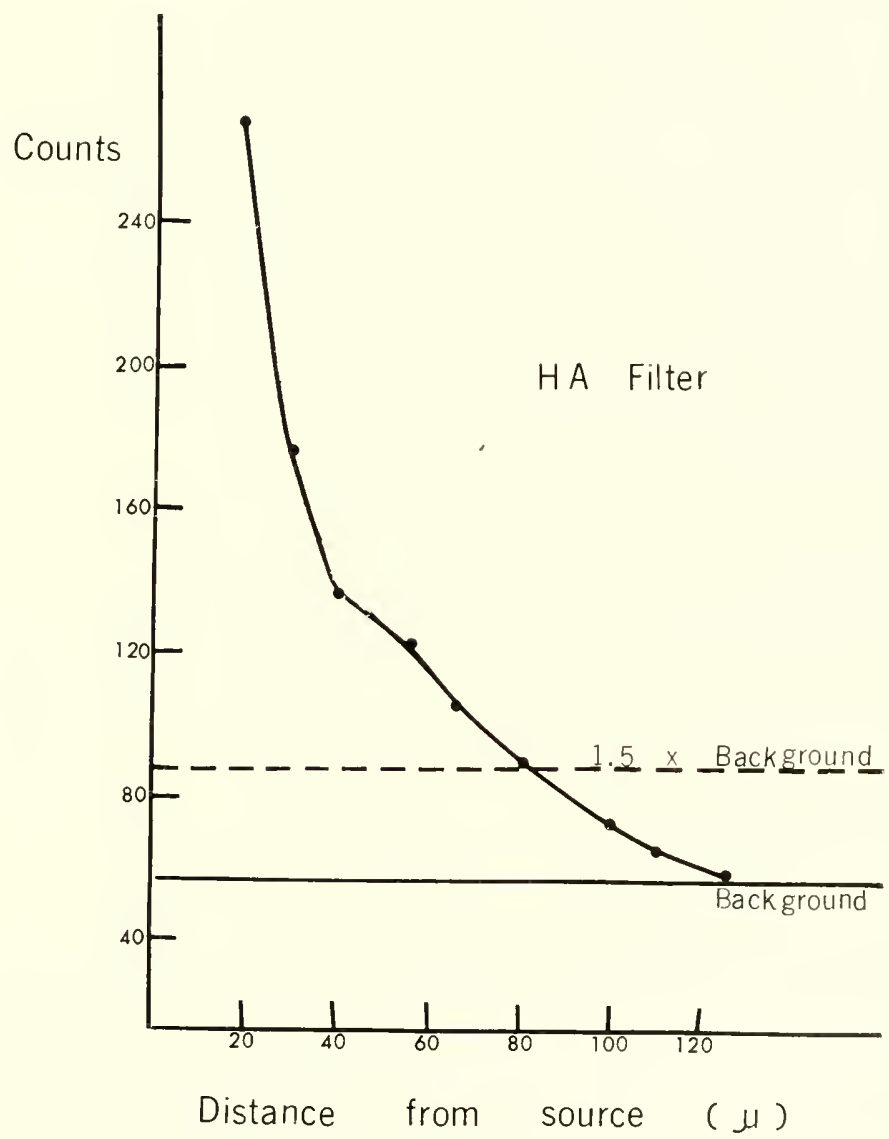

PLATE IX. FIG. 17. Curve of grain counts across thick filter with increasing distance from spinal cord source labeled with tritiated amino acids.

The entire body of data can be explained on the assumption that dorsal spinal cord produces at free surfaces a protein-containing material which moves into the enviromment over a limited distance. Among its components this material includes one or more which is inductively active. It is important to note that though inductive activity conforms with the distribution of label. labeling does not necessarily indicate 
inductive activity. Labeled metanephrogenic mesenchyme, for example, puts label into the filter and across it into unlabeled dorsal cord, though no known inductive activity moves in this direction. Moreover, label is present in the filter after incubation times as short

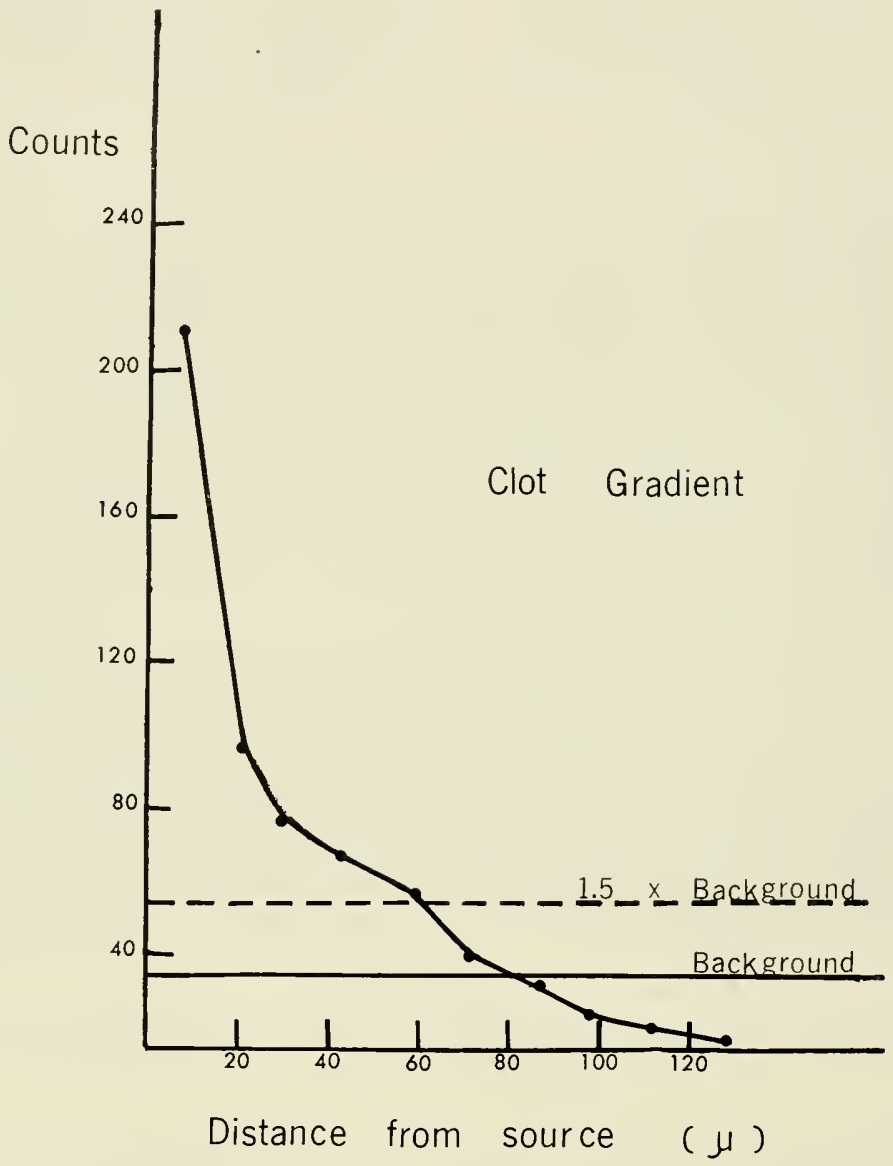

PLATE X. FIG. 18. Curve of grain counts with increasing distance in clot sur. rounding dorsal spinal cord labeled with tritiated amino acids.

as 3 hours, but definitive changes in the metanephrogenic mesenchyme are not known to occur until 24 to 30 hours. Kecping these reservations in mind, it is safe only to say that inductive activity appears to be associated with a kind of "halo" of large-molecular material, including protein, which exists in the immediate vicinity of dorsal spinal cord. 
These results fortify the notion. carlier advancerl by Baitsell (1925), Weiss (1933), Huzella (1941), and others, that microcnvirommental materials produced by cells have important developmental signifieance. Additional support is afforded by data from the second major line of investigation to which I referred earlier-the reaggregation of dissociated cells. This phenomenon was studied first. among animals. in sponges and other relatively uncomplieated invertebrates. More recently it has been under investigation in slime molds. in amphibia, and even in higher vertebrates. Observations on reaggregating mouse and chick cells in the last several years, reported by Moscona (1960), are particularly relevant and striking. Moscona finds that at an early stage in the reaggregation of freshly dispersed chick embryonic cells a transparent mmeoid material. "evidently an exudate of cellular origin," makes its appearance. The reaggregating cells appear to move within fine strands of this material, which collects on introduced cotton fibers and on the glass floor of the vesscl and appears to be the "immediate substratum or microenviromment" for migration and aggregation. Staining reactions and susceptibility to enzymatic digestion suggest that the material probably is a mucoprotein.

Freshly disaggregated cells produce considerable quantities of mueoid: it can he accumulated in strands or ropes by gently swirling reageregating cells toward a central vortex. Cells which are grown as monolayer cultures for a period of time undergo change in the quality. and reduction in the quantity, of the mucoid matcrial they produce. Concomitantly, aygregative behavior and cell cohcrence gradually decline. Thus, dissocrated monse embryonic skin cells. after more than 10 days in monolayer eulture, form only small clusters, even when they are swirled into proximity or centrifugally packed to favor agaregation. Such clusters show very limited histogenesis and differentiation. The aggregation and histogenesis are little affected when the cells are intermixed with freshly dissociated chick or monse precartilage cells (heterotypic), but are markedly improved on intermixing with freshly dissociated chick skin cells (homotypie). Under the latter conditions the mouse cells are found grouped together and participating in the formation of follicle-like structures.

The decline in agcregability and histogenesis with culturing described by Moscona recalls and illuminates an observation made some years ago on embryonic mouse salivary rudiments in vitro. The salivary rudiment is a two-component strueture like the metanephros and, similarly. the components ean be separated by trypsin treatment. When the two components are recombined immediately, the inner 
epithelial one continues the dichotomous branching characteristic of normal morphogenesis. When, however, the mesenchymal component is cultured over a 20-day period, its capacity to support the dichotomous branching of freshly isolated epithelium gradually declines. Accompanying the decline there is a change in the outgrowth pattern of the mesenchyme, from sheet-like behavior with cohesive boundary to increasingly dispersive hehavior with individually migrating fibroblast-like cells at the boundary (Fig. 19). Here a behavioral change, which may well conform with Moscona's observation of decline in aggregability and production of extracellular material, is accompanied by altered morphogenetic effect on the associated dependent epithelium.

Note that in Moscona's experiments aggregative and differentiative behavior are simultaneously altered during the period in monolayer culture. This is, of course, in conformity with many observations that culturing, under conditions which promote cell dispersal, tends to be antidifferentiative (Grobstein, 1959). A well-documented example of this has just been reported by Holtzer et al. (1960). They examined chondrocytes freed from already formed cartilage. Over a period of 10 days of culture in a disposed state, these cells lost all detectable cartilage properties, as judged by their ability to incorporate $S^{35}$ or to form recognizalble matrix when returned to conditions under which freshly dissociated cells undergo chondrogenesis. Although changes in aggregative behavior were not stressed in the study, it is interesting that freshly liberated chondrocytes on a clot spontaneously aggregate within 24 hours and show little spreading tendency. After several passages in culture, while the differentiative properties were declining, the cells failed to aggregate spontaneously, forming a thin, rapidly spreading sheet.

There is, therefore, good reason to suspect a relationship between the mucoid, microenvironmental material and differentiation. Results reported by Wilde (1960) may offer the most direct demonstration to date that such a relationship actually exists. Working with 1 to 15 cells from early amphibian embryos in restricted, microdrop nutrient environments, he found that under particular conditions none of the cells differentiated. When, however, the microdrops containing similar cells also included "the opalcscent, slightly viscous material which poured off the cells in the disaggregating fluid," differentiation of the cells was normal and similar to that seen in organotypic cultures of the source tissue. Wilde reports further data, involving combination of cells with extracellular material from heterotypic sources, suggesting that the material may not only be necessary for differentiation but 

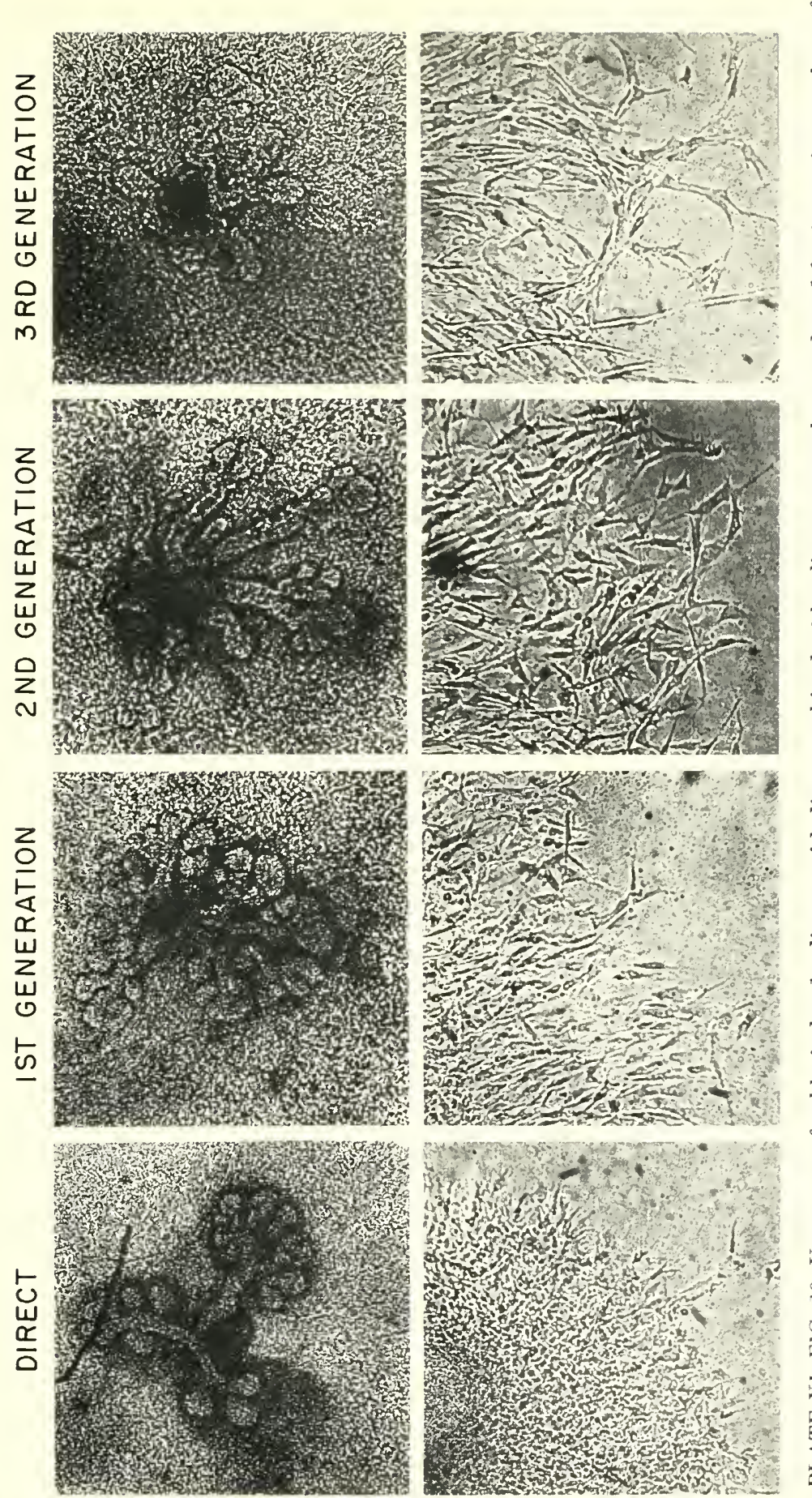
may contain informational cues as to direction of differentiation. Chemical data on the nature of Wilde's material, particularly in relation to Moscona's and to the conditioned medium of Niu (1956), will be awaited with great interest.

What do these facts add up to? Certainly not to definitive statement about the mechanisms of induction, of aggregation, or of cytodifferentiative control: They point, rather, to continued examination of the couplings among these three phenomena, with emphasis on the possibility that they share a common basis in microenvironmental large-molecular materials. If it be assumed that these materials simultaneously are cell product and cell controls-both for the source cells and their immediate neighloors-they would then provide the basis for "external feedback" and a common matrix underlying the integral character of many multicellular systems. How such materials operate, if they do, in controlling intrinsic cellular activities is not at all clear. In some fashion they must mesh with intracellular control mechanisms radiating outward from the replicative genetic code. A number of models are available from which to choose. They might operate completely superficially, as "gatekeepers" on a permease model or the modified molecular ecology model of Weiss. They might carry "instructions" more deeply into the cell, to interact with the genetic sites themselves, with messenger materials, or with cytoplasmic synthetic sites. Or, an idea which attracts me particularly at the moment, they might operate at or close to the cell boundary, modifying the many subtle factors which influence polymerization and complexing of monomers synthesized deeper in the cell. Whatever is the answer, and most likely there will be more than one, when we have it we shall be one step closer to rationalizing the mutual operation of replicative and regulative factors in the control system of the cell.

\section{Heferences:}

Baitsell, G. A. (1925). On the origin of the connective-tissue ground-substance in the chick embryo. Quart. J. Microscop. Sci.. 69:571-590.

Grobstein, C. (1959), Differentiation of vertebrate cells, in The Cell, ed. by J. Brachet and A. E. Mirsky, Academic Press, Inc., New York, vol. 1, pp. 437-496.

Holtzer, H., J. Ablott, J. Lash, and S. Holtzer (1960), The loss of phenotypic traits by differentiated cells in vitro. 1. Dedifferentiation of cartilage cells, Proc. Nat. Acad. Sci. U.S., 46:1533-1542.

Huzella, T. (1941), Die Zwischenzellige Organisation, Verlag von Gustav Fischer. Jena.

McKeehan, M. S. (1951). Cytological aspects of embryonic lens induction in the chick, J. Exp. Zool.. 117:31-64.

Moscona, A. A. (1960), Patterns and mechanisms of tissue reconstruction from dis- 
sociated cells. in Developing Cell Systems and Their Control, ed. by D. Rudnick, The Ronald Press Company, New York.

Niu, M. C. (1956), New approaches to the problem of embryonic indurtion. in Cellular Mechanisms in Differentiation and Grouth, ed. by D. Rudnick. Prince. ton University Press. Princeton. N.J.

Weiss. P. (1933). Fuuctional adaptation and the role of ground substances in devel. opment, Am. Naturalist, $67: 322-340$.

(1958), Cell contact, Intern. Rev, Cytol., $7: 391-123$.

Wilde, C. E. (1960). Factors concerning the degree of cellular differentiation in organotypic and disaggregated tissue cultures. Colloq. intern. sur la Cult. Organo-typique (in press). 



\section{Differentiation}

\section{and Morphogenesis}

\section{in Insects}

Carroll M. Williams

The Biological Laboratories

Harvard University, Cambridge, Massachusetts

Diversity is introduced into biological systems by the slow-paced events of organic evolution and by the swift unfolding of the individual life. In the diversifications which shape the egg into an organism, what we see is the implementation at the cellular level of speciesspecific information inherited from the preceding generation. We may think of the genes as supplying a kind of "construction manual" which is translated into action during the course of development. But the construction manual itself is the product of trial-and-error testing in the lives of tens of thonsands of individuals over enormons periods of time. Therefore, the two kinds of diversifications. developmental and evolutionary, come together in the management of genetic information-its genesis. implementation, and testing in the careers of the individual and the species. 
The construction manual (to continue the analogy) is "read" by the individual cells, which in all but the earliest embryonic stages are numbered in the millions. From a fairly carly stage in embryonic development we can separate these cells into a series of cytological types-muscle, nerve, epithelium, and so on. What begins as a unity rapidly becomes a multiplicity of vastly different forms and functions.

All these cells, as far as we know, continue to possess a full set of genes, corresponding to the construction manual for the organism as a whole. And yet, during the course of embryonic development, the construction "erew" resolves itself into clones of diverse cell types, which (in the manner of bricklayers, plumbers, and eleetricians) make use of only their own specifie assignments in the eonstruction manual.

\section{The central dogma}

In the interpretation of these happenings we come face-to-face with a series of concepts which everyone will recognize as a central dogma of present-day biology. At the risk of recapitulating what has gone before, let me briefly review this theory.

The hereditary information of the genes is coded in the nucleotide sequence of DNA, presumably in the form of a series of three-letter words made up of the letters A, T, G, and C. At any one time, much and perhaps most of this genetic information is not at the disposal of the synthetic centers of the cell. In one way or another a certain fraction of the DNA is repressed and therefore unexpressed. Under appropriate conditions, specific genes or gene combinations are derepressed. At these particularly activated sites, the coded information of the DNA is transferred to newly synthesized RNA in the form of a series of three-letter words made up of the letters $A, U, G$, and $C$. This so-called "messenger RNA" then passes to the cytoplasm. It enters the ribosomes and each of its three-letter words is used to code the precise position of one of the 20 kinds of amino acids in newly synthesized protein. Once the amino acids have been properly positioned in the peptide chain, the molecules of protein automatically fold into their distinetive so-called "tertiary structure." The protein thereby attains its characteristie enzymatic activity, as dictated by its amino acid sequence and overall shape. And since most, if not all, of the reactions of the cell are catalyzed by enzymes, it is alleged that all happenings in the cell are a sequel to the synthesis of specific enzymes. 


\section{Control of genctic information \\ in microbial systems}

The central dogma has, more recently, been extrapolated to account for the moment-to-moment control of enzyme synthesis in nicrobial systems. This extrapolation takes the following form (Jacoh and Monod. 1961; Jacoly and Wollman, 1961) :

There are certain enzymes which are necessary for the survival of the cell at all times. for example, all the enzymes which lic on the main pathways of intermediate metabolism and encrgy transformations. These so-called "constitutive enzymes" are continuously synthesized-a state of affairs which signals the activity of the corresponding gencs. By contrast. there are a large number of other enzynes which are needed only under certain conditions and circumstances. These "inductive enzymes" are not synthesized until they arc needed: therefore, the genes for their synthesis are ordinarily maintained in a state of chronic repression.

The theory tries to account for the ability of specific metabolites to induce the synthesis of specific enzyme systems. It is postulated that the synthetic reactions for groups of enzymes serving a given biochemical pathway are programmed by a collection of genes which are under the control of a single "operator gene," the whole complex being known as an "operon." But under most conditions the operator gene is in combination with a specific "repressor substance." and the corresponding operon is thereby repressed.

Each repressor substance is the synthetic product of a particular "regulator gene." The repressor substance is freely diffusible. If all goes well, it combines with and represses its specific target. But on its way to the operator gene, the repressor substance is subject to inactivation if it encounters and combines with a substrate of the particular enzyme system that is repressed. In this case the operator gene escapes from repression and can go ahead and activate the collection of genes in its operon. So, in this indirect manner, a given substrate induces the synthesis of an appropriate enzyme systcm.

It is also proposed that certain regulator genes produce inactive repressor substances which can lye activated only by combination with specific small molecules. This accounts for the ability of metabolic end products to suppress the on-going synthesis of spccific enzyme systems.

In this bird's-eye view of the theory, one cannot fail to be inpressed by the increasing attention that centers on mcchanisms of control. 
Whereas it formerly sufficed to think of genes that program the synthesis of specific enzymes, it is now necessary to postulate several categories of genes whose sole purpose is to control and modulate other genes. If this system of control secms unnecessarily complex, one is well advised to reflect on the metabolic pathways for a miniature molecule such as acetic acid. What if the controlling mechanisms of a cell turn out to be as intricate as the "metabolic maps"?

\section{Mierobes versus higher organisms}

The central dogma is based on studies of microbes and their viruses. Therefore, the question may well be asked whether it has any bearing on developmental processes in the higher and more pretentious forms of life.

At this point I must confess that I find the concept of regulator genes and operator genes-not to mention the rather mysterious "episomes"-strikingly reminiscent of McClintock's genetic "controllers," including "activators," "modulators," and "dissociators," which werc described in 1951 (for review see Brink, 1958). So, the pertinence of these concepts has already been documented in at least one "higher organism," the corn plant.

Despite all this duplication in terminology, I believe that the new point of view has much to tell us about the management of genetic information in animal cells and that a judicious application of its principles call promote a great leap in what may prove to be the forward direction.

As a first and somewhat hesitant step toward this objective, I propose to consider how the new theory, derived largely from studies of bacteria and viruses, may be applied to certain aspects of insect growth and metamorphosis.

\section{Differential gene activity in giant chromosomes}

In the banana orchards of Brazil there lives a mosquito-like fly called Rhynchosciara angelae. The female of this insect oviposits a cluster of some $150 \mathrm{eggs}$, all of which hatch simultaneously a few days later. The larvae then assemble into a compact mass and crawl around together as a slug-like object.

The lives of the 150 larvae are wonderfully synchronized. Over a period of a month or so, they grow at the same rate, molt at the same 
time, pupate in synchrony, and some days later they all emerge as arlult flies within a few minutes of one another. Therefore, as one would hope and as Brener and Pavan (1955) have confirmed, the activities of their cells and tissues show a degree of synchronization that is mmatched in any other metazoan. Each larvan in effect, is equivalent to the next: so, in principle, one can design experiments in which the same individual is sacrificed 150 times.

As is the practice in most dipteran insects, the growth of larval Rhynchosciara takes place solely by cell enlargement, the chromosomes heing duplicated again and again without any cell division. Ordinarily, this would lead to a vast increase in chromosome number. However, in Rhynchosciara as in most Diptera, the daughter chromatids ro not separate following replication. Instearl. they align themselves side by side to form compact, ribbon-like or cable-like chromosomes up to 16,000 times larger than ordinary chromosomes.

Within the giant chromosome each chromatid is a much-coiled structure, the tightness of the coil dictating a periodic structure which stains more intensely than do the adjacent loosely coiled regions ( $\mathrm{Ris}$ and Crouse, 1945). And since the daughter chromatids pair "qene for gene," the net result is that cach giant chromosome can he recognized under the compound microscope, not only by its overall size and shape, but also by the pattern of its crosshanding.

In Rhynchosciara there are four giant chromosomes in the nucleus of each larval cell. The total number of crossbands is in the thousands: in Drosophila melanogaster (where the number has been counted) there are 5,072, corresponding, it is alleged, to the number of gene loci (Bridges, 1942). By taking advantage of the giant size of the chromosomes, one may inquire as to whether a full and complete set of genetic material is distributed to the various cell types during embryonic development.

In Rhynchosciara, as in Chironomus, the answer to this question is clear-cut. In such diverse ceils as those of salivary glands, midgut. rectum, seminal vesicles, and Malpighian tubules. one can identify. not only a full complement of giant chromosomes, but also the characteristic fine structure in homologous parts of homologous chromosomes (Berger, 1940; Slizynsky, 1950; Beerman. 1952: Paran and Breuer, 1952).

On more detailed cytological examination. one finds that the giant chromosomes of each type of cell are distinguisher by the swollen appearance or "puffing" of certain specific bands. This is apparently due to the uncoiling of the chromatids at these localized places-a 
process which, more rarely, may proceed to the formation of enormous rosette-like projections called "Balbiani rings" (Beerman, 1952; Mechelke, 1953; Becrman and Bahr, 1954).

Cytochemical studies suggest that the projections from the chromosomes consist of unraveled DNA (Becrman, 1952, 1959; Gall, 1958). Moreover, the individual "puffs" prove to be the sites of intensive synthetic activity, especially of RNA (Beerman, 1952; Pavan and Breuer, 1952; Ficq and Pavan, 1957; Gall, 1958). It is difficult to avoid the conclusion that the puffing phenomenon is, in fact, a caricature of the de-repression of specific gene loci and the coding of messenger RNA.

In general, one can say that the pattern of puffing is uniform thronghout a single tissue, but it differs from that in other tissues of the same individual (Beerman, 1952, 1959; Mechelke, 1953; Breuer and Pavan, 1955). Each tissue is, of course, engaged in synthetic operations peculiar to itself-a fact which is apparently reflected in its pattern of puffing.

If attention is centered on a single tissue, say, the salivary glands, it is worth inquiring as to whether the chromosomal puffs undergo any systematic change during larval life. Because of the precise synchronization within each brood of larvae, Rhynchosciara is obviously the perfect animal for this type of study (Breuer and Pavan, 1955). However, similar investigations have been carried out with considerable success on the salivary glands of the Chironomidae (Beerman, 1952, 1959; Mechelke, 1953).

Just prior to pupation, the salivary glands show a pronounced change in their synthetic activity, in that the clear secretion which they previously produced is replaced by a brownish fluid which is now synthesized for the first time. In cytological preparations of salivary glands, the new synthetic acts are signaled by striking changes in the pattern of puffing in the giant chromosomes. Most of the puffs that had been prominent during larval life now collapse, the DNA strands apparently being folded back into the chromosome to re-form conlpact bands (Breuer and Pavan, 1955). Meanwhile, new puffs are formed at a series of other specific loci.

There is a comprehensive body of evidence to show that the change in the secretory activity of the salivary glands is promoted by the same endocrine agents that control the metamorphosis of the animal as a whole. As we shall later consider, pupation is the response to an increasing titer of "ecdyson" and a decreasing titer of "juvenile hormone." Therefore, by injecting ecdyson into immature larvae, one can 
establish the endocrine conditions which favor precocious pupation. The question arises as to the behavior of the giant chromosomes under these conditions.

Experiments of this type have been performed on Chironomus by Clever and Karlson (1960). Two hours after the injection of ecdyson, the pattern of puffing in the salivary glands shows a changeover from larval to pupal type. Clever and Karlson conclude that the primary effect of ecdyson is to alter the activity of specific genes and that this action is documented in the giant chromosomes.

\section{HNA and the synthesis of sill:}

In Nigeria and certain other parts of Africa, there occurs a lepidopteran called Epanaphe moloneyi whose mode of life bears a certain resemblance to that of $R$ hynchosciara. Here again, the larval stages are gregarious. They move about on the food plant as "processionaries," spinning a thread of silk to guide themselves back to their common nesting place. When the larvae are full grown, the entire group of 100 or more individuals collaborate in spinning a large silken chamber almost the size and shape of a football. Within this chamber, each larva finally spins its own separate cocoon and pupates. After about a month of adult development, the pupae are transformed into moths which escape from the cocoons.

Interest in the Epanaphe silkworm stents from the fact that its silk consists essentially of two amino acids, glycine $(42.5$ moles \%) and alanine ( 53.1 moles \%), thereby qualifying as the simplest of naturally occurring proteins (Lucas et al., 1958).

The silk is synthesized and secreted into the lumen of the silk gland by a monolayer of epithelial cells which form the distal regions of the two glands. These cells are extremely rich in ribosomal RNA-a fact which probably accounts for their rapid synthesis of what is essentially a single, diagrammatically simple protein. If the ribosomal RNA is responsible for coding the glycine-alanine sequence in Epanaphe silk, this fact should signal itself in certain predictable peculiarities in the ratios of the four bases in $\mathrm{RNA}$ : namely, very high ratios of guanine to adenine and of uracil to cytosine (Speyer et al., 1962) .

YCas and Vincent (1960) have tested this proposition by jonrneying to Africa, collecting large numbers of Epanaphe silkworms, and isolating the RNA from the silk-secreting part of the silk gland, as well as from a number of other tissues and organs.

The answer was clear-cut. The base ratios encountered in the silk- 
secreting cells showed no correlation with the peculiar features of the synthetic product and, in fact, did not depart from those encountered in the other tissues that were examined.

As Ycas and Vincent (1960) point out, this implies that the "bulk RNA" of the ribosomes does not contain the genetic information which codes the amino acid sequence in silk. This finding is completely in line with that obtained on microbial systems where, as previously mentioned, genetic information is continuously transmitted to the ribosomal "factories" by a ccrtain short-lived messenger RNA which makes up only a tiny fraction of the total RNA.

\section{Metamorphosis of the Cecropia silliworm}

In the case of giant chromosomes of Rhynchosciara, we considered the evidence for gene repression and de-repression as well as the cytological picture of the synthesis and coding of what appears to be messenger RNA. Then from a study of Epanaphe we learned that the ribosomes are "ignorant" synthetic centers to which genetic information is apparently conveyed in the form of messenger RNA. I now propose to consider the harnessing of genetic information to specific morphogenetic acts. And for this purpose I hasten to introduce our final performer.

In fields and forests of eastern North America there occurs a handsome silkworm whose outstanding properties as an experimental object entitle it to rank alongside Rhynchosciara and Epanaphe. Taxonomists continue to amuse themselves by changing the scientific name of this insect; therefore, let us simply call it the Cecropia silkworm.

The eggs are oviposited in early summer on any of a number of common trees and shrubs. Ten days later they hatch into little spinose caterpillars which grow rapidly, punctuating this growth by a series of four larval molts. By transforming leaves into silkworm, they increase their mass some 5,000 -fold and finally hecome mature fifthinstar larvac.

Through the workings of hormonal factors which we shall shortly consider, there comes a day when the bchavior of the mature silkworm suddenly changes. It ceases to feed, having already built up within its own tissues a stockpile of molecules to sustain the 10 remaining months of life. After a period of random locomotor activity, it begins to spin a cocoon around itself. Work on the structure continues for 2 days, during which time a silk thread, nearly a mile long, is transformed into a complicated edifice. 
The completion of the cocoon signals the beginning of a new and even more remarkable sequence of events. On the third day after the cocoon is finislied, a great wave of death and destruction sweeps over the internal organs of the caterpillar. The specialized larval tissues break down. But meanwhile, certain more or less discrete clusters of cells, tucked away here and there within the body, begin to grow rapidly. nourishing themselves on the breakdown products of the dead and dying larval tissues. These are the "inaginal dises" which throughout larval life have heen slowly enlarging within the caterpillar. Their spurt of growth now shapes the organism according to a new plan. The specialized structures of the caterpillar are swept away and replaced by new organs arising from the imaginal discs. In addition, some of the less specialized larval tissues, such as the epidermal layer of the abdomen, are transformed direetly into pupal tissues. Finally, the old larval cuticle is shed to unmask an essentially new organism, the pupa. All these charges normally take place within the snug confines of the cocoon.

Once the pupa has formerl, there is an abrupt halt to the events which during a period of 8 weeks have transformed the ege into a larva and the larva into a pupa. During the months that follow, the insect persists in a kind of suspended development-an ohligatory dormancy termed "pupal diapanse." The insect overwinters in this state of developmental standstill.

\section{Endocrine control of motamorphosis}

The pupal diapause proves to be the result of an endocrine deficiency, namely, a failure of the hrain to secrete a "brain hormone" required for the continuation of development ( Williams, 1946). The brain hormone is the synthetic product of 26 neurosecretory nerve cells (Williams, 1952a). For reasons that are not understood, the brain's newrosecretory cells are somehow turned off at the time of pupation. In order to get turned on again. they require several months of exposure to low temperatures-a need which is obviously met in the overwintering pupa (Van der Kloot. 1955: Williams, 1956b). When the chilled pupa is returned to a warmer temperature (as normally happens in the spring of the year). the brain secretes its hormone and adult development begins.

By appropriate experiments, it is possible to show that the brain hormone does not exert its effect througliout the insect as a whole. Its primary function is to activate another endocrine organ. the "pro- 
thoracic glands" (Williams, 1952b, 1958). And it is this second endocrine organ which then secretes the growth hormone itself-a molecule which has been isolated and crystallized and called "ecdyson." The hormone is a water-soluble, heat-stable, heterocyclic ketone with the provisional formula $\mathrm{C}_{18} \mathrm{H}_{30} \mathrm{O}_{4}$ (Butenandt and Karlson, 1954; Karlson, 1956).

When exposed to ecrlyson, the pupal tissues, after 8 months of developmental standstill, are promptly stimulated to intense morphogenetic activity. The result is a predictable pattern of death and birth at the cellular level as the specialized tissues of the pupa make way for the equally specialized tissues of the adult moth (Williams, 1961a). Spectacular changes occur throughout all parts of the insect: in the head, the formation of compound eyes and feather-like antennae; in the thorax, the molding of legs, wings, and flight muscles; in the abdomen, the shaping of the genitalia and, internally, the exorbitant growth of ovaries and testes. And in the newly formed skin we can witness the strangest behavior of all-the extrusion and transformation of tens of thousands of individual cells into the colorful but lifeless scales so typical of moths and butterflies (Stossberg, 1938).

After 3 weeks of adult development, the process is complete. The full-fledged moth escapes from the cocoon and unfurls its wings.

\section{The genetic construction manual}

This summary of the life history of the Cecropia silkworm brings us back to the concept of the genetic "construction manual" mentioned at the outset. In the case of the Cecropia silkworm, as in all insects that undergo a complete metamorphosis, the construction manual is obviously divided into three distinct chapters.

The first chapter tells how to make the egg into a larva. The second chapter gives directions for the destruction of the larva and the reworking of the same materials into a pupa. The third and final chapter tells how to reshape the pupa into an adult moth. This analogy serves to emphasize that the sequential polymorphism of insect metamorphosis involves the decoding and acting out of what is little short of successive batches of genetic information (Snodgrass, 1954; Wigglesworth, 1961a). Perhaps the day is not far distant when we may speak of "larval operons, pupal operons, and adult operons"-collections of genes which are sequentially brought into play to build and rebuild the insect on the unchanging foundation of the constitutive enzymes prerequisite for life at all stages.

Though these overall happenings are amazing enough, it is well to 
recall that the metamorphosis of the animal as a whole is a mosaie of metamorphoses at the level of the individual cells. And here we eome face-to-face with the most baflling phenomenon of all. It turns out that the individual cells at an early stage in embryonie development are "determined" or "programmed" for the speeifie sequence of differentiations which days, weeks, or months later they will act out in the future larva, pupa, and adult. In this sense, the eonstruetion manual is more akin to the script of a three-act play in which the individnal eells are east in individual roles.

\section{Metamerplosis of slin implants}

The programming of cells is particularly well illustrated in the experiments first performed by Kähn and Piepho (1938, 1940) and subsequently continued in great detail by Piepho and his students at Göttingen (Piepho, 1938a, b; 1943).

If a tiny fragment of skin is cut from a eaterpillar and implanted into another eaterpillar of the same or even of a different speeies, the implant not only survives but undergoes a complieated career of growth and metamorphosis in synchrony with that of the host.

The first thing that happens is that the epithelium of the implant grows around to close on itself to form a cyst-a hollow ball with walls only one cell thick. Curiously enough, this growing around occurs in such a manner that the cutieular surface of the epithelium always faces inward to form a lining to the eyst.

Days or weeks later, when the host larva undergoes a larval molt, so does the little hollow ball of cells. The eutieular lining is shed into the lumen and each eell now seeretes a new larval enticle. This shedding and re-forming of larval cuticle is repeated over and over again as long as the host is undergoing larval molts. If the implant is removed prior to the pupation of the host and re-implanted into a sequence of immature larvae, there is apparently no limit to the numbers of larval molts that it ean undergo (Piepho, 1943; Piepho and Meyer, 1951). So, as far as its cells are coneerned, the larval molts correspond to the use and re-use of the eoded instructions for synthesizing and secreting a larval cuticle.

But, in the normal course of events, sooner or later the host metamorphoses to a pupa. So docs the implant. The larval cuticle is east off into the lumen of the cyst and each cell now seeretes an overlying island of pupal cuticle. The cyst, in short, has pupated. Manifestly, each eell is now tapping information that had previously been repressed, presumably within its own ehromosomes. Still later, when 
the pupal host transforms into an adult, the cyst casts off its pupal cuticle and secretes an adult cuticle covered with scales and hairs. Here again, it is necessary to conclude that each epithelial cell is de-repressing a fresh assortment of genetic information.

This experiment teaches us two things. The metamorphosis of the implant shows that each cell possesses a definite repertoire of morphogenetic information-a sequential program which it is able to act out even in the semi-isolated situation. And in the synchronization between the behavior of implant and host, we are reminded once again of the control and coordination which is exercised by hormones.

\section{Endocrine control of genetic information}

On the basis of present knowledge, the programming and prepatterning of the cellular community is little short of incomprehensible. The endocrine control of metamorphosis is, by contrast, a far simpler problenı which has begun to clarify itself.

We have seen that the prothoracic gland hormone, ecdyson, is the growth hormone of insects. In its absence, the insect lapses into a state of developmental standstill. When it is again secreted, diapause is terminated and growth is resumed.

When ecdyson is secreted and acts with little or no opposition, it causes the cells to undertake synthetic acts accompanied by the derepression and utilization of fresh genetic information (Williams, $1961 \mathrm{a}, \mathrm{b})$. We have illustrated this action in the case of the giant chromosomes of Chironomus (Clever and Karlson, 1960). The larval cells pupate; the pupal cells undergo adult differentiation. So, to revert to an earlier analogy, it is ecdyson that prompts the cells to proceed from one chapter to the next. Therefore, it is necessary to conclude that ecdyson acts directly or indirectly on the nucleus to cause the de-repression of genetic information which can then be implemented by the cytoplasm in new synthetic acts.

At this point I call attention to a minor technicality-the successive instars of the larval life. During the larval period the insect is somehow stabilized as a larva. It grows and molts and grows and molts. The Cecropia silkworm, as we have seen, increases its mass 5,000-fold during the five larval instars. But it fails to metamorphose until the end of the fifth instar.

It is easy to show that ecdyson is the necessary stimulus for larval growth and molting. But somehow there is at work a conservative force which opposes change, which blocks "growing up" without interfering with growth in an unchanging state. 


\section{The jurenile hormons}

This conservative force proves to be yet another hormone, the socalled "juvenile hormone." As demonstrated by Wigglesworth (1936), the juvenile hormone is secreted by a tiny pair of cephalic glands, the corpora allata.

The action of juvenile hormone is to modify the cellular response to ecdyson-to suppress new synthetie acts without interfering with the use and reuse of the information already at the disposal of the cells (Williams, 1959, 1961a. b). If this "brake" on progressive differentiation is removed by the excision of its source in the corpora allata, then the immature larva reacts to ecdyson by undergoing metamorphosis into a midget pupa and adult (Bounhiol, 1938; Fukuda. 1944; Williams, 1961a.b). What we witness, in short, is the precocious acting out of the life plan.

Under normal conditions and circumstances, pupation becomes possible late in larval life when the corpora allata undergo a progressive loss of their endocrine activity. Ecdyson now acts in the presence of low concentrations of juvenile hormone to cause the de-repression of the fresh genetic information for constructing the pupa (Williams, 1961b). But in many insects one can reapply the "Jorakes" by implanting active corpora allata obtained from younger larvae. When juvenile hormone is supplied, the mature larva can postpone its metamorphosis and continue to grow as a larva. The net result is that the insect after one or more extra larval instars finally transforms into a giant pupa and adult (Wigglesworth, 1954).

Equally spectacular is the effect of juvenile hormone on the transformation of a pupa into an adult moth, a phase of metamorphosis which normally takes place in the presence of ectyson and what appears to be the total absence of juvenile hormone. If juvenile hormone is supplied by the implantation of active corpora allata, the pupa is prevented from turning into an adult moth. To varying degrees, as dictated by the concentration of juvenile hormone. the formation of the adult moth is inhibited. In the presence of a sufficiently high titer of juvenile hormone, the pupa responds to eedyson by molting into a second pupal stage (Williams. 1959).

By the use of the pupal assay, the juvenile hormone has been extracted and extensively purifier. It proves to be a water-insolulle oil containing numerous methyl and methylene functions and what appears to be a lactone ring (Williams, 1956a. 196la). Meanwhile. the German investigator, Schmialek (1961). has been able to mimic the action of juvenile hormone by the injection of the 15-cartion 
unsaturated alcohol, farnesol (Wigglesworth, 1961b). The same is true for the 20-carbon unsaturated alcohol, phytol, according to unpublished results of experiments which I have performed in collaboration with John Law. However, in our experience, these well-known chemicals are only about one-thousandth as active as the juvenile hornone itself.

Despite persistent uncertainties as to the chemistry of juvenile hormone, we can state with considerable assurance that the function of the hormone within the living insect is to block the flow of fresh genetic information from nucleus to cytoplasm (Williams, 196la, b). By analogy with the simpler and more accessible microbial systems, we find no dearth of mechanisms which could account for the conservative action of juvenile hormone. It could affect one or more systems of positive or negative feedback concerned with the repression of specific regulators, operators, or operons; it could interfere with the flow of messenger RNA from nucleus to cytoplasm; it could selectively block the utilization of this information in the synthetic factories.

This much we can say with confidence. Juvenile hormone somehow prevents the cytoplasm from receiving or acting on fresh instructions whose ultimate source must be the coded genetic information of the nucleus. Meanwhile the hormone fails to interfere in any way with the use and reuse of the information already at the disposal of the cytoplasm. In the presence of juvenile hormone a cell can read and reread the same chapter in the construction manual. But it cannot press on to the next chapter.

\section{Insects and microbes}

So, in this brief excursion into entomology, we find that the insects obey and in some instances illuminate a number of concepts of developmental biology derived fron studies of microbial systems. These concepts, without exception, have to do with the management of genetic information-its de-repression and flow from its source in the hereditary material to its implementation in specific synthetic actsmore particularly, the synthesis of specific enzymes and structural proteins.

In insects as in microbes, it is increasingly clear that cells do not continuously express all the potentialities inherent in their genetic equipment. At any particular eross section of time, most cells are in a highly repressed state.

A bacterial cell synthesizes only those enzymes that are needed and 
refrains from synthesizing those which are not needed. The decision not to synthesize a new enzyme is passive in the sense that it involves a continuation of the repressed state of the corresponding gene or genes-a further withholding of the genetic information prerequisite for the synthesis. An affirmative decision to undertake the synthesis of a new enzyme is active in that it involves the de-repression of the corresponding genes and a flow of the appropriate genetic information to the synthetic centers of the cell.

A bacterial cell is equipped, not so much with a "construction manual" as with a "cookbook" - a collection of recipes for the management of any number of energy-rich molecules which it may encounter. Therefore, its genetic equipment is delicately tuned to the exigencies of the environment. In a bacterial cell the countdown on the synthesis of a new enzyme must be counted in milliseconds.

Anyone familiar with the elegant organization of animal cells is entitled to the view that a bacterium is a nondescript object. The cells of a louse are, by comparison, of outstanding beauty. But a far more important distinction is that an animal cell, say, the egg of an insect, has a vastly complicated charge on life. Its method of making another egg is, in the least, a roundabout process.

A central dogma of experimental embryology has been the concept of the totipotent egg-a cell that starts out doing everything and in the course of embryonic development gives rise to a progeny which specializes and differentiates by doing less and less. The microbes have disenchanted us from this point of view. It now appears that the egg is a highly repressed and specialized cell. It is specialized for reproduction, for cloning itself to establish the "critical mass" of the blastoderm (Grobstein, 1959). Even the molecules of yolk seem, for the most part, to have been synthesized elsewhere and "injected" into the ovum prior to fertilization (Bonhag, 1958; Telfer, 1961; Hisaw, 1962 ).

Unlike the bacterial cell, the egg can scarcely allow itself to be at the disposal of the molecules of the environment. Therefore, it commonly envelops itself with one or more shells and membranes to become a self-contained system. Meanwhile, the genetic plans for the embryo must be speedily programmed.

Here we trip over the phenomenon of "embryonic determination," which is encountered in its extreme expression in the so-called "mosaic eggs" of the Diptera and Lepidoptera. The cells of the very early cubryo are somehow programmed for a series of future differentiations which they and their progeny will undertake, not only in the embryo, but also during suecessive phases of metamorphosis. And 
in the acting out of these various and sundry programs, the entire community of cells will be paced and coordinated by certain endog. cnous molecules which, as enclocrine agents, will give stop-and-go signals reminiscent of the "controlling elements" in bacterial systems.

It is clear that the programming of cells has to cio with sequential gene action-the "taping" of the individual cells for a subsequent "playback." In the concrete case of the higher insects, it is a process that anticipates the future of the individual life and predicts with utmost precision the chemical engineering of larva, pupa, and adult.

\section{IRefprences}

Beerman. W. (1952), Chromomerenkonstanz und spezifische Modifikationen der Chromosomenstruktur in der Entwicklung und Organdifferenzierung von Chironomus tentans, Chromosoma, 5:139-198.

- (1959), Chromosomal differentiation in insects, in Developmental Cytology, ed. by D. Rudnick, The Ronald Press Company, New York, pp. 83-104.

- and G. F. Bahr (1954). The submicroscopic structure of the Balbiani-ring. Exp. Cell Research, 6:195-201.

Berger, C. A. (1910). The uniformity of the gene complex in the nuclei of different tissues, J. Heredity, $31: 3-4$.

Bonhag, P. F. (1958), Ovarian structure and vitellogenesis in insects, Ann. Rev. Entomol., 3:137-160.

Bounhiol, J. J. (1938), Recherches expérimentales sur le déterminisme de la métamorphose chez les Lépidoptères, Bull. Biol. France et Belg. Suppl., 24:1199.

Breuer, M. E., and C. Pavan (1955), Behavior of polytene chromosomes of Rhyn. chosciara angelae at different stages of larval development, Chromosoma, 7:371385.

Bridges, P. N. (1942), A new map of the salivary gland 2L-chromosome, J. Hereditv, $33: 403-408$.

Brink. A. (1958), Mutable loci and development of the organism, J. Cellular Comp. Physiol., 52, Suppl. 1:169-195.

Butenandt, A., and P. Karlson (1954), Ueber die Isolierung eines Metamorphose. Hormons der Insekten in kristallisierter Form. Z. Naturforsch., 9b:389-39l.

Clever, U., and P. Karlson (1960), Induktion von Puff-Veränderungen in den Speicheldrüsenchromosomen von Chironomus tentans durch Ecdyson, Exp. Cell Res., 20 :623-626.

Fisq, A., and C. Pavan (1957), Autoradiography of polytene chromosomes of Rhynchosciara angelae at different stages of larval development, Nature (London), 180:983-984.

Fukuda, S. (1944), The hormonal nechanism of larval molting and metamorphosis in the silkworm. J. Fac. Sci., Univ. Tokyo, Sect. IV, 6:477-532.

Gall, J. G. (1958), Chromosomal differentiation, in McCollum Pratt Symposium on the Chemical Basis of Development, ed. by W. D. McElroy and Bently Glass, Johns Hopkins Press, Baltimore, pp. 103-135.

Grobstein, C. (1959). Differentiation of vertebrate cells, in The Cell, ed. by J. Brachet and A. E. Mirsky, Academic Press, Inc., New York, vol. 1, pp. 437-496. 
Hisaw, F. L. (1962). The evolution of endocrine adaptations of the ovarian follicle, Oregon State University Symposium, 1961 (in press).

Jacob, F., and J. Monod (1961), Genetic regulatory mechanisms in the synthesis of proteins, J. Mol. Biol., 3:318-356.

- and E. L. Wollman (1961), Sexuality and the Genetics of Bacteria, Academic Press, Inc., New York.

Karlson, P. (1956), Biochemical studies on insect hormones, Vitamins and Hor. mones, 14:227-266.

Kühn, A., and H. Piepho (1938), Die Reactionen der Hypodcrmis und der Ver. sonschen Drüsen auf das Verpuppungshormone bei Ephestia kïhniello. Biol. Zentr., $58: 12-51$.

—_ and — (1940), Über die Ausbildung der Schuppen in Hauttransplantaten von Schmetterlingen, Biol. Zentr., 60:1-22.

Lucas, F., J. T. B. Shaw, and S. G. Smith (1958), The silk fibroins, Adv. in Protein Chem., $13: 108-243$.

Mechelke, F. (1953), Reversible structurmodifikationen der Speicheldrüsenchromosomen von Acricotopus lucidus, Chromosoma, 5:511-543.

Pavan. C.. and M. E. Breuer (1952), Polytene chromosomes, J. Heredity, 43:150157.

Piepho, H. (1938a), Wachstum und totale Metamorphose an Hautimplantaten bei der Wachsmotte Galleria mellonella L., Biol. Zentr., 58:356-366.

(1938b), Üher die Auslösung der Raupenhäntung, Verpuppung und Imaginalentwicklung an Hautimplantaten von Schmetterlingen, Biol. Zentr., 58: 481-495.

- (1943). Wirkstoffe in der Metamorphose von Schmetterlingen und anderen Insekten, Naturwiss., $31: 329-335$.

- , and H. Meyer (1951), Reaktionen der Schmetterlingshaut auf Häutungshormone, Biol. Zentr., 70:252-260.

Ris, H., and H. Crouse (1945), Structure of the salivary gland chromosomes of Diptera, Proc. Nat. Acad. Sci. U.S., $31: 321-327$.

Schmialek, P. (1961), Die Identifizierung zweier im Tenebriokot und in Hefe vorkommender Substanzen mu Juvenilhormonwirkung. Z. Naturforsch, 16b: 461-464.

Slizynsky, B. M. (1950), Chironomus versus Drosophila, J. Genet., 50:77-79.

Snodgrass, R. E. (1954), Insect metamorphosis, Smithsonian Misc. Collections, 122 (9) :1-124.

Speyer, J. F., P. Lengyel, C. Basilio, and S. Ochoa (1962). Synthetic polypeptides and the amino acid code, II, Proc. Nat. Acad. Sci. U.S., 48:63-68.

Stossberg, M. (1938), Die Zellforgänge bei der Entwicklung der Flïgelschuppen von Ephestia kühnielia, Z. Morphol. Oecol. Tiere, 34:174-206.

Telfer, W. H. (1961), The route of entry and localization of blood proteins in the oocytes of saturniid moths, J. Biophys. Biochem. Cytol., 9:747-759.

Van der Kloot, W. G. (1955), The control of neurosecretion and diapause by physiological changes in the brain of the Cecropia silkworm, Biol. Bull., 109: 276-294.

Wigglesworth, V. B. (1936), The function of the corpus allatum in the growth and reproduction of Rhoduius prolixus (Hemiptera), Quart. J. Microscop. Sci., 79:91-121.

(1954), The Physiology of Insect Metamorphosis, Monographs in Experimental Biology, no. 1, Cambridge University Press, London and New York, pp. 1-152. 
(1961a), A tentative synthesis, in Symposium No. 1, Royal Entomological Society, London, ed. by J. S. Kennedy, pp. 103-113.

(1961b), Some observations on the juvenile hormone effect of farnesol in Rhodnius prolixus Stal (Hemiptera), J. Insect Physiol., $7: 73-78$.

Williams, C. M. (1946), Physiology of insect diapause: The role of the brain in the production and termination of pupal dormancy in the giant silkworm Platysamia cecropia, Biol. Bull., 90:234-243.

(1952a), Morphogenesis and the metamorphosis of insects, Harvey Lectures, 47:126-155.

- (1952b), Physiology of insect diapause. IV. The brain and prothoracic glands as an endocrine system in the Cecropia silkworm, Biol. Bull., 103:120 138.

(1956a), The juvenile hormone of insects, Nature (London), 178:212-213. (1956b), Physiology of insect diapause. X. An endocrine mechanism for the influence of temperature on the diapausing pupa of the Cecropia silkworm, Biol. Bull., $110: 201-218$.

(1958), Hormonal regulation of insect metamorphosis, in McCollum Pratt Symposium on the Chemical Basis of Development, ed. by W. D. McElroy and Bently Glass, Johns Hopkins Press, Baltimore, pp. 794-806.

(1959), The juvenile hormone. I. Endocrine activity of the corpora allata of the adult Cecropia silkworm, Biol. Bull., 116:323-338.

- (1961a), Insect metamorphosis: An approach to the study of growth, in Growth in Living Systems, ed. by M. X. Zarrow, Basic Books, New York, pp. 313-320.

(1961b), The juvenile hormone. II. Its role in the endocrine control of molting, pupation, and adult development in the Cecropia silkworm, Biol. Bull., $121: 572-585$.

Yčas, M., and W. S. Vincent (1960), The ribonucleic acid of Epanaphe moloneyi Druce, Exp. Cell Res., 21 :513-522. 


\title{
Growth and
}

\section{Differentiation in}

\section{the Nervous System"}

\author{
Rita Levi-Montalcini \\ Department of Zoology \\ Washington University, St. Louis, Missouri
}

In the course of divergence of cell lineages and blocking out of different systems from early products of division of the fertilized egg cell, the nervous system is one of the first to assert its differentiation. The thickening of the ectoderm along the middorsal line of the embryo is a barely noticeable event among the many developmental processes which take place at the same time. It is, however, a major event in the history of the nervous system, which has dissociated itself from the

* The work described in this paper was supported in part by grants from the National Institute of Neurological Diseases and Blindness, Public Health Service. Bethesda, Md., and from the National Science Foundation, Washington. D.C.. and by a contribution from the American Cancer Society to Washington University. St. Louis, Mo.

The microphotographs were made by Cramer Lewis, Department of Illustration, Washington University Medical School, St. Louis, Mo. 
adjacent epithelial tissues and no longer shares their fate. From that moment, two major processes set in, to transform the thin neural plate in that complex structure known as the vertebrate nervous system: The one is the gross shaping of the brain and of the spinal cord which results from intense proliferative activity and from massive cell movements; the other is the elahoration of a multitude of nerve centers and of the wiring which interconnects these centers in the general framework of the central nervous system. Obviously no sharp line can be drawn betwcen these two processes, since they occur simultaneously and the first sets the stage for the second, but they can be singled out and analyzed as two distinct aspects of the same developmental process.

The analysis of the factors involved in the shaping of the brain and the determination of its regional differences has been a favorite object of embryologists ever since Spemann and Mangold discovered the organizing potency of the upper blastoporal lip in amphibians. The molding of the brain and of the spinal cord texture in a myriad of cell aggregates, the formation of fiher tracts, and the outgrowth of peripheral nerves are instead the object of analysis of the neurologist, who explores the developing nerve centers as a clue to the understanding of their ultimate structure and function.

To the biologist who is preoccupied not with the function in the nervous system, but with the more general problems of growth and differentiation, the developing nervous system offers an unequaled field of exploration, for there he finds cell populations differentiating along divergent lines in restricted temporal and spatial dimensions.

To the writer, who shares with the neurologist the interest in structure and function in the nervous system, and with the biologist the curiosity in growth and differentiative processes, the intricacies of the nerve structures represent a never-ending object of wonder and exploration. In the following pages only a few of the manifold aspects of this problem will be considered. The selection is guided by personal experience and interest in some specific developmental aspects rather than by a logical sequential line.

At first we shall consider the devclopmental mechanisms which operate in the early segregation and differentiation of nerve centers. Then we shall discuss the effects produced on sensory nerve cells by changes inflicted to their peripheral fields of innervation. Finally we shall report on the growth response of sensory and sympathetic nerve cells to some recently discovered nerve growth factors. The similarities and differences between the response of sensory cells to nerve growth factors and to an increased field of innervation will offer an 
opportunity of discussing one of the most obscure and yet important aspects of growth and differentiation in the nervous system-the control mechanism exerted by extrinsic factors on these processes.

\section{Derelopmental Mechanisms in the Central Nerrous System}

The following analysis is based on the study of the developing nervous system of the chick embryo, which has been our favorite object of investigation during the past years. A few observations performed on the nervous system of a mammalian embryo (mouse) show that the developmental processes in birds and mammals follow a similar pattern.

\section{a. First differentiative phase}

The band of thickened ectoderm along the middorsal line of the chick embryo has folded into a neural groove and the neural groove has changed in turn into a neural tube, before the cylindrical-shaped cells which form the tube show any sign of their essence. In the head region, differential growth of the walls results in the shaping of the tube in three vesicles. The further elaboration of these vesicles in the main brain regions will not be discussed here. Rather we shall consider the differentiative waves which sweep the neural tube along its rostrocaudal axis and lay down the building blocks of brain and spinal cord nerve centers.

It may be worth mentioning that this first and the following differentiative processes would perhaps have never come to the attention of the neurologist, were it not for the discovery by Cajal, toward the end of the past century, of the unusually high affinity of differentiating nerve cells for silver salts. The silver technique introduced by Cajal offers an invaluable tool to detect the early differentiated nerve cells, which stand out in sharp relief for their dark brown color on the pale background of the undifferentiated cells.

The nenral tube has barely formed, when a swarming of neuroblasts takes place from the ventromedial lining of the central canal to the lateral aspect of the tube. In the head region, where this differentiative process first starts, the slender migrating neuroblasts are the forerunner of the diencephalic-mesencephalic main nuclear aggregates and of the motor cephalic nuclei. This process has been described in detail in previous publications $(1,2,3)$ and will not be considered here. In the spinal cord, the neuroblasts build up a continuous column in a ventrolateral position. The further differentiation 
of this column and the segregation of its different components involve a series of developmental steps which have been analyzed in detail (4) and will be summarized here. In this initial phase of their maturation, the neuroblasts move as isolated units. They cover the short distance between the central canal and the lateral edge of the neural tube by means of ameboidic movements of their bodies, which glide between the parallel and tightly packed rows of undifferentiated cells. As soon as they reach the ventrolateral area of the tube, they assemble together in a column which increases in size as new units join the ones which have already settled. This process continues till the fourth day. A similar migratory movement takes place also from other more dorsal sectors of the ependyma around the central canal. The neuroblasts originating from these segments do not gather in a column but take position as isolated units or small cell groupments along the dorsolateral edge of the neural tube. They give origin to the associative and commissural neurons, which establish links between the two halves of the spinal cord and between rostral and caudal segments of the tube. At the end of the fourth day of incubation, this early differentiative phase is practically completed in the brain centers and in the rostral segments of the spinal cord, while it is still in progress but near completion in the thoracic and lumbosacral segments which mature later, according to the rostrocaudal gradient of differentiation. The subsequent phase, between the end of the fourth and the eleventh day of incubation, represents the most dynamic period in the developmental history of the spinal cord and brain centers of the chick embryo. It is in this period that the apparent homogeneous population of early differentiated nerve cells breaks down at some levels and is swept away in a few hours, while at other levels it splits in morphologically and functionally distinct cell agglomerates; some of the cells continue their differentiation in situ while others migrate in compact columns or cell rows to settle in regions at considerable distance from the ones where they first underwent maturation. Numerous instances of such migratory processes were described in different segments of the spinal cord, brain stem, and higher brain centers $(4,5,6)$. Here we shall outline only the main developmental patterns of differentiation of nerve centers and present some considerations on the mechanism of these differentiative processes.

\section{b. Second differentiative phase}

At the end of the fourth day of incubation, the spinal cord in the chick embryo exhibits a deceptively simple architecture. A compact 
column of neuroblasts extends from the cervical to the sacral segnent. It is easily identified as the motor column from its position as well as from the direction of the axons which gather in small nerve bundles and emerge from the neural tube as motor roots. The associative and commissural neurons mentioned above give origin to slender fiber tracts; the commissural fiber tract marks the borderline between the compact core of undifferentiated cells which still represent the main component of the neural tube and the differentiated neurons collected in the lateral columm. A detailed description of this process is presented in a previous publication (4); here we shall briefly outline the developmental patterns of the motor system at the cervical, brachial, and thoracic levels.

\section{Regional Patterns}

Cervical Segment. The cervical lateral motor column undergoes a dramatic and massive degeneration between $4 \frac{1}{2}$ and 5 days of incubation; in these few hours about three-fourths of the reuroblasts which form the column disintegrate and are swept away by macrophages which gather in the area (4). The combined use of three different techniques-silver impregnation, vital stains, and standard histological techniques-gave a complete picture of this striking process. At 5 days the column is reduced to about one-fourth of its previous width. The surviving cells form the slender medial columm which innervates the trunk muscles at that level (Fig. lc).

The significance of this extensive and short-lasting disintegrative process in the cervical segment of the spinal cord is obscure. We are not aware of the occurrence of similar mass destruction taking place under normal conditions in other scctions of the developing nervous system, although we described two other instances of cell disintegration in the cervical and thoracic spinal ganglia of the chick embryos in stages between 5 and 6 days (7). Considerations presented in the previous publication (4) suggested the possibility that the disintegrating cells at the cervical level might represent an abortive preganglionic center. The experiments performed to test this hypothesis will be presented after discussion of the differentiative pattern in otber spinal cord segments.

Brachial and Lumbosacral Segments. In both segments the spinal motor column segregates into a large lateral component which imnervates, respectively, the anterior and posterior linbs, and into a mediolateral column of the same width and position as the column described at the cervical level. This column is also present at the thoracic and 


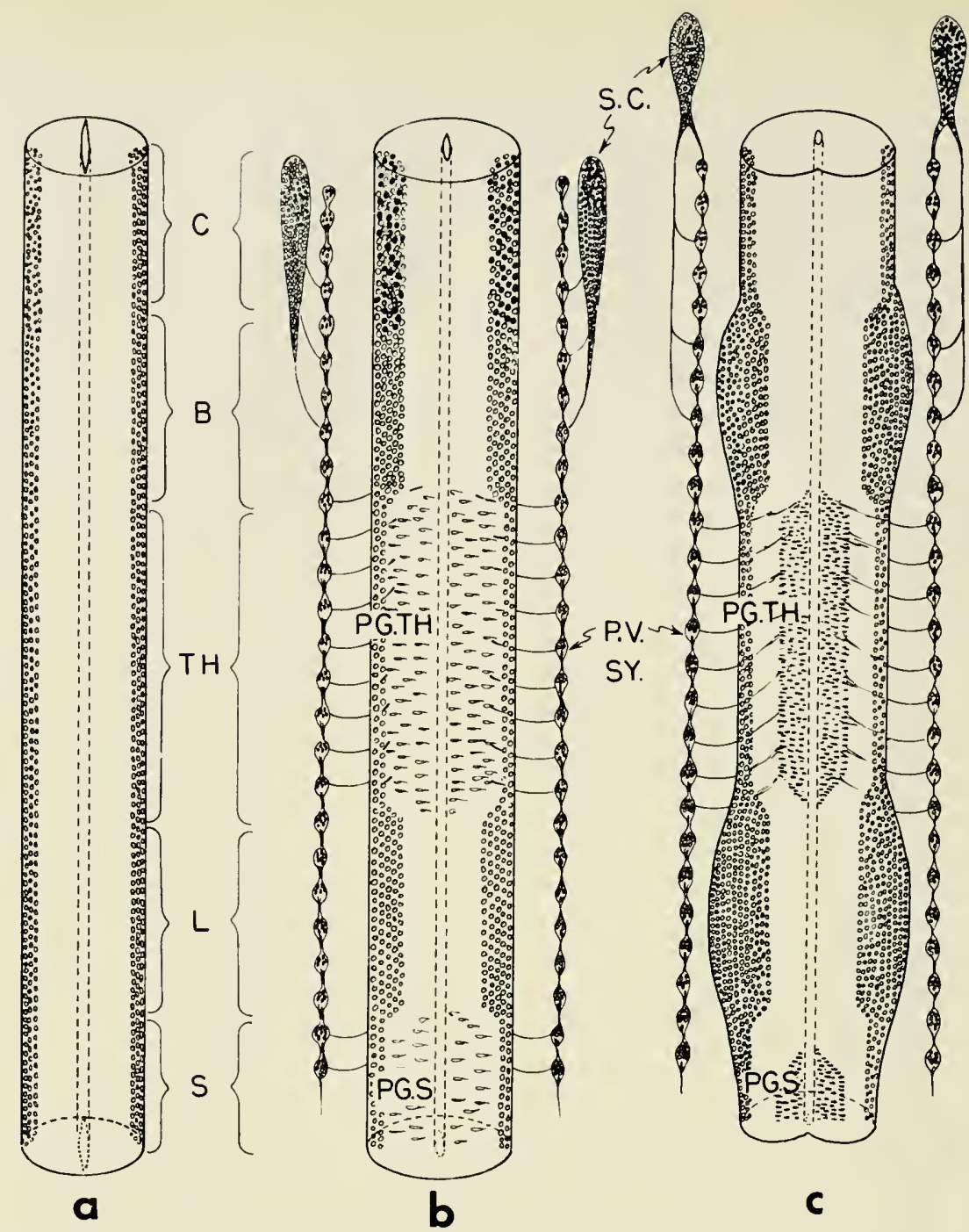

FIG. 1. Diagrammatic illustration of the emergence of regional differences from a morphologically uniform system in the spinal motor column of the chick embryo. (a) 3.day embryo: The motor column is of uniform width from the cervical to the sacral level. (b) 5-day embryo: The majority of the differentiating neuroblasts in the cervical segment of the motor column undergo degeneration. They are represented as solid black circles. In the thoracic and sacral segments the migration of the preganglionic columns is under way. (c) 8-day embryo: The degenerated nerve cells in the cervical segment of the motor column have disappeared. The remaining nerve cells in this segment form the slender medial motor columns. Note the size increase of the brachial and lumbar motor columns innervating the limbs. In the thoracic and sacral segments, the two preganglionic columns have reached their definitive position adjacent to the central canal. The two slender columns in a peripheral position represent the medial motor columns. C, cervical level; B. brachial level; L. lumbar level; PG.S. preganglionic sacral center; PG.TH, preganglionic thoracic center; P.V.SY, paravertebral sympathetic ganglia; S, sacral level; S.C, superior cervical ganglion; TH, thoracic level. 
sacral level. In all segments it serves the same function-innervation of the trunk musculature (Fim. 1).

Thoracic and Sacral Segments. In both segments two massive migratory movements take place between the middle of the fourth and the end of the seventh day of incubation. The following description is based on the analysis of this process at the thoracie level. Cell movements in the sacral segment present similar features and therefore will not be discussed.

Before describing the migratory movement, it is of interest to consider the motor column, which has barely formed and which consists at 4 days of neuroblasts of similar size and shape in a random distribution. The duality of this apparently homogeneous population becomes manifest if one inspects the peripheral distribution of their nerve fibers. The majority of these fibers end in contaet with the primordia of the sympathetic ganglia at the two sides of the spinal cord, whereas only a small fiber contingent is directed toward the trunk museles. It is therefore evident that the motor column consists of a mixed population of preganglionic and somatomotor nerve cells. In later developmental stages the two populations are topographically well distinct from each other: The preganglionic column is located in birds in a dorsomedial position adjacent to the central canal while the somatomotor column has a medioventral position and is identified as the medial motor colımn.

The segregation of the two cell populations is foreshadowed by a ehange in the texture of the newly formed motor column. At $41 / 2$ days about three-fourths of the entire cell population assembles in compact and parallel rows of newroblasts oriented toward the eentral canal (Figs. 1 and 7 ). A migration of these cells starts immediately after, while the remaining cells continue their differentiation in situ. They form the medial motor column.

The progrcssion of the migratory cells during the three following days is diagrammatically represented in Fig. 1 and needs no further comment. The intense silver affinity of the migrating cells and the slowness of the entire process, which was studied in close time series of embryos between the fourth and the end of the seventh day, gave the possibility of exploring all the aspects of this movement, which results in the active dislocation of thousands of differentiated nerve cells from their early ventrolateral position to their terminal scttlement dorsal to the central canal (Figs. 1, 8, and 9).

At the end of the seventh day the migratory movement is completed, and one can easily identify in the cells which gather in two 
distinct nuclei adjacent to the central canal the cells of origin of the preganglionic motor centers (Figs. 1, 10, and 11).

\section{An Experimental Analysis of the Regional Patterns in the Cervical and Thoracic Spinal Cord Segments}

The hypothesis (sce page 265) that the disintegrating nerve cells in the cervical segment of the spinal cord might represent an abortive visceral column was tested by transplanting the cervical segment of the spinal cord from 2-day chick embryo to the thoracic level of hosts of the same age $(8)$. The thoracic segment of the host was extirpated and the transplant inserted in its place. In performing this operation, Shieh wanted to test the hypothesis mentioned above, by providing the "abortive cells" with the possibility of establishing connections with the sympathetic ganglia. The operation presents technical difficulties and only a few embryos survived till the seventh day. In the few specimens examined, Shieh observed the formation of a preganglionic motor column similar to the one which forms at the thoracic level. He also observed a large number of degenerating neurons. These results suggest that at least a number of the cells that normally undergo degeneration at the cervical level survive in the transplant and build a preganglionic motor column with the same mechanism as normally occurs in the thoracic level. These experiments, if confirmed by others now in progress, will support the hypothesis that an abortive preganglionic center is present in the cervical level of the spinal cord. They would also give evidence of the flexibility of differentiative patterns in the central nervous system.

\section{Mass Migration in Other Sectors of the Central Nervous System}

Between the fifth and the eleventh day, the brain stem and the suprasegmental brain structures are the stage of an incessant and yet highly organized movement of differentiated nerve cell populations. We shall consider below the main features of these movements, as they appear in the developing nervous system of the chick embryo.

Migratory Movements in the Brain Stem. The early continuous motor column (see page 265) segregates at first in the primordia of the XII, XI, X, VII, V, IV, and III nuclei. Each of these centers segregates in turn in the following days into two or more cell groupments through more or less complex migratory movements of its components.

At some levels, movements in opposite directions take place at the same time, or two cell populations, moving along slightly divergent 
paths, merge and segregate again, each to pursue its specific course. In all instances the migrating cells are well differentiated at the time they start their journey. Their slender, elongated bodies, dark-stained in silver preparations, detach sharply on the pale background of the undifferentiated cells, which still represent the major component of the brain stem at this stage. Each population is easily recognizable from adjacent populations by the different shade of its color in silverimpregnated material. All migrating cells trail their axon behind while moving toward their final location; the direction of the fibers represents in the mature organism a valuable guide to detect the route followed by a nerve center to reach its final destination.

It was the peculiar path traced in the brain stem by the axons of the accessory nucleus of the VIth nerve (Fig. 2) which suggested that its cells of origin have undergone a migratory movement in previous developmental stages. This movement was actually observed in embryos examined between the sixth and the eighth day of incubation.

During this period a considerable number of cells segregate from the main nucleus located near the midline on the floor of the fourth ventricle; they move in a straight line, one after the other in a single row in an oblique direction from their former mediodorsal position to their final ventrolateral location. The neuroblasts cut their way across the dense texture of the brain stem, which consists of closely packed rows of undifferentiated cells with their long axes oriented at $45^{\circ}$ with the axes of the migrating cells (Figs. $2 b, 2 b^{\prime}, 12$ ). Toward the middle of their journey the shifting population crosses and intermingles with the population of the facial nucleus, which is also moving from a laterodorsal to a ventrodorsal position (Fig. 12). The two populations dissociate at the beginning of the seventh day and each reaches its destination about 24 hours later (Figs. 2, 13).

Migratory Movement in the Third Nucleus. This movement, which was first described by Biondi (9), consists of the exchange across the midline of one of the four oculomotor nuclei with its partner of the opposite center. The exchange occurs between the two ventromedial nuclei; it starts at the end of the fifth day and is completed at 8 days. Since the two populations moving across the midlinc are of a considerable size, the traffic of the neuroblasts moving in the opposite direction and crossing each other is heavy. At 6 days a continuous irail of neuroblasts in different rows bridge the two oculomotor centers (Figs. 3 $b^{\prime}, 14$ ). When their final settlenent is completed at 7 days, the axons trailing behind make a ventral commissure on the midline (Figs. 3c', 15 ).

Migratory Movements in Suprasegmental Structures. In all supra- 


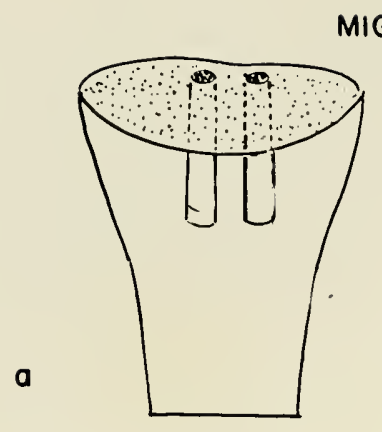

MIGRATION IN THE ABDUCENS
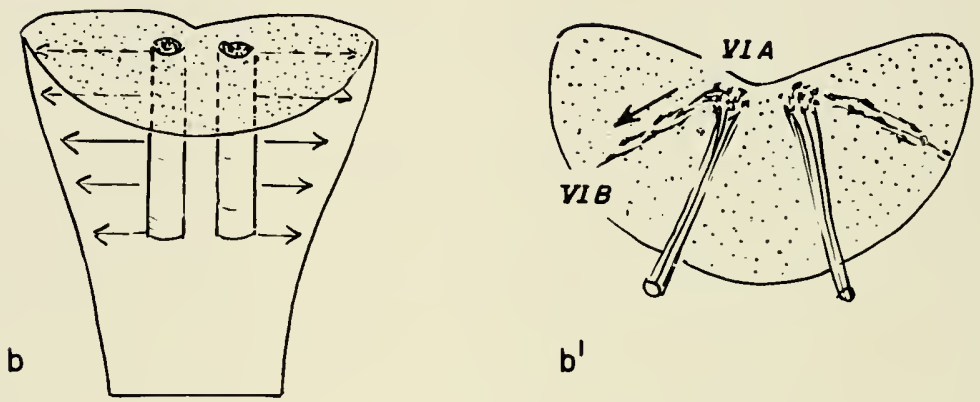

$\mathbf{b}^{\prime}$

\section{GDAYS}
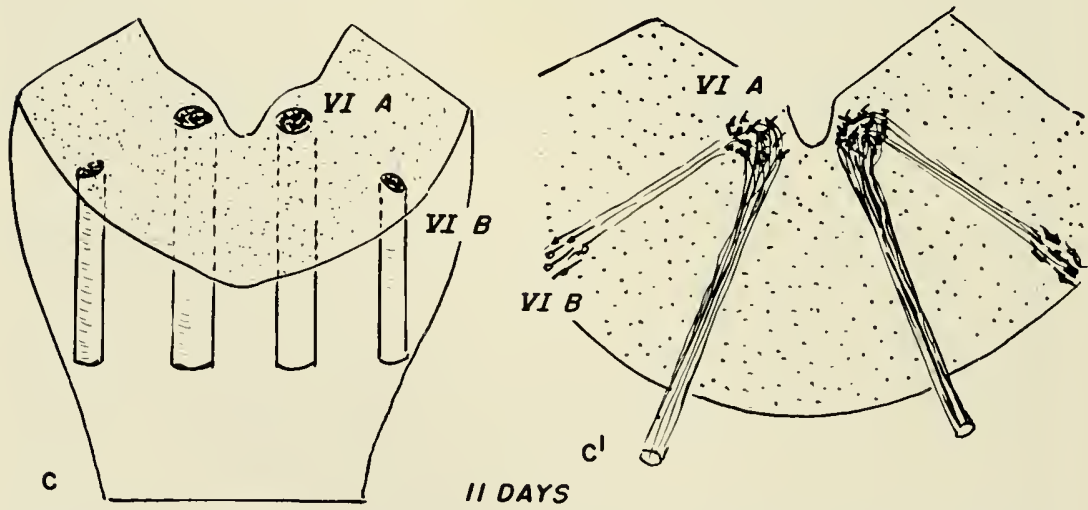

FIG. 2. Diagrammatic frontal and transversal representation of the segregation of the accessory nucleus from the main nucleus of the VIth nerve in the chick embryo. $a, b, c$ : stereographic views of the VIth nuclei at 5,6 , and 11 days. In $a$, the nuclei appear as two columns; in $b$, the arrows indicate the migration of neuroblasts from the main nuclei in a lateral direction; in $c$, the migration is completed and the two accessory columns are formed. $a^{\prime}, b^{\prime}, c^{\prime}$ : the same process as viewed in transversal sections. VI $A$, main nucleus; VI $B$, accessory nucleus. 


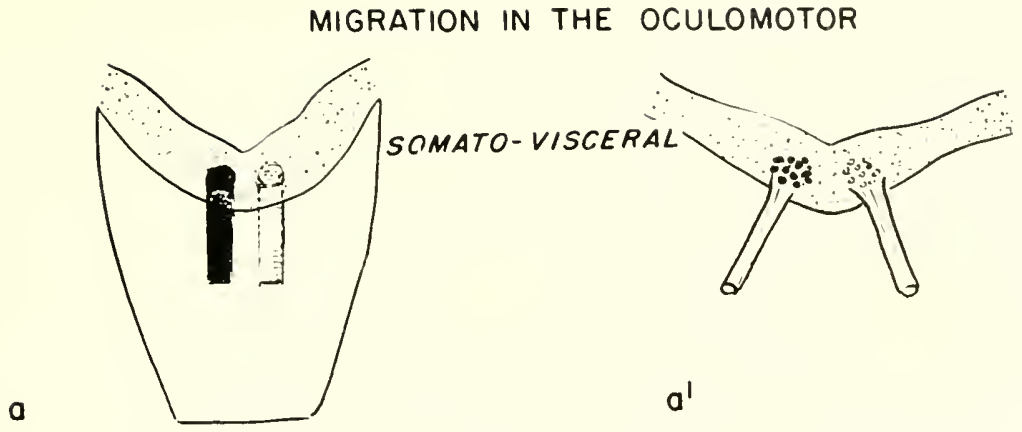

5 DAYS
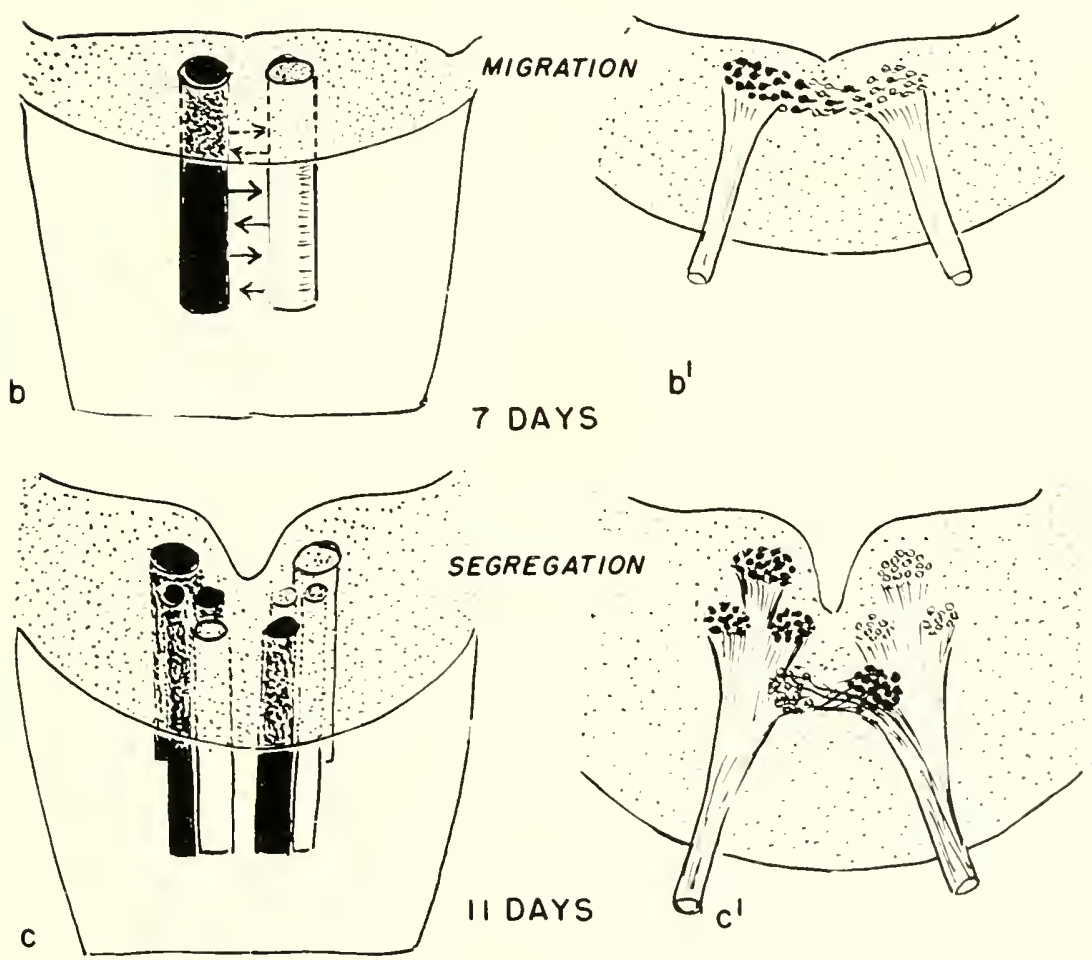

FIG. 3. Diagrammatic frontal and transversal representation of the segregation of the four nuclei of the IIIrd nerve and of the migration of the two ventromedial nuclei across the midline. Solid black. left oculomotor colnmn; white. right oculomotor column. $a, b, c$ : stereographic views in a frontal plane, $a^{\prime}, b^{\prime}, c^{\prime}$ : the same process as viewed in transversal sections. 
segmental structures, migration of differentiated ncrve cells plays an important role in the molding of nerve centers. These movements are more difficult to analyze than the ones in the brain stem since the active displacement of cell populations occurs at the same time as gross morphological changes in the shape of the brain. In the following discussion we shall outline only two of these movements, which oceur in the ccrebellar cortex and in the avian telencephalon.

Migratory Movements in the Cerebellum. The complex changes in size and shape in the Purkinje cells during their late differentiation were first described by Cajal (10) and nothing can be added to his exact analysis of the process. Until recently it had not been settled whence these cells originate and how they appear during the early developmental phases of their diffcrentiation [unpublished observations (11)]. We traced these cells in our series of avian brains in stages between 7 and 8 days of incubation. They appear as elongated neuroblasts in proximity to the deep subependymal gerninal layer. Since they react intensely to silver and exhibit the characteristic fusiform shape of cells in a migratory phase, it was easy to explore their position during the following days and trace their active displacement from the deep to the cortical cerebellar layer. During the early phases they are closely packed in dense cellular rows; as they reach the cortical layer they spread in a fan-like fashion and settle in the layer which will be known as the Purkinje layer in the fully developed organism (Figs. 4, 16 to 19).

The origin of the Purkinje cells from the germinal layer was recently described by Uzman (12), who utilized the technique of labeling the migrating cells with tritiated thymidine. His observations establish beyond doubt the migratory movements of these cells. This technique ean be very useful to detect the migratory movements in nerve cell populations. In future research both this technique and the silver method, which has the advantage of staining selectively the migrating cells, should be combined.

Migratory Movements in the Cerebral Hemispheres. The mass migration of one of the avian telencephalic centers was described in detail in a previous publication (6). Since it does not substantially differ from other migratory movements of differentiated nerve cells, we shall mention here only its main features.

The mass migration of the nucleus, which we designated as nucleus epibasalis centralis, starts at 8 days. It consists of two dense neuroblast columns moving along the lamina medullaris dorsalis. The cells exhibit the characteristic elongated shape of migrating neuroblasts and the intense silver affinity. One can trace the two moving columns and 

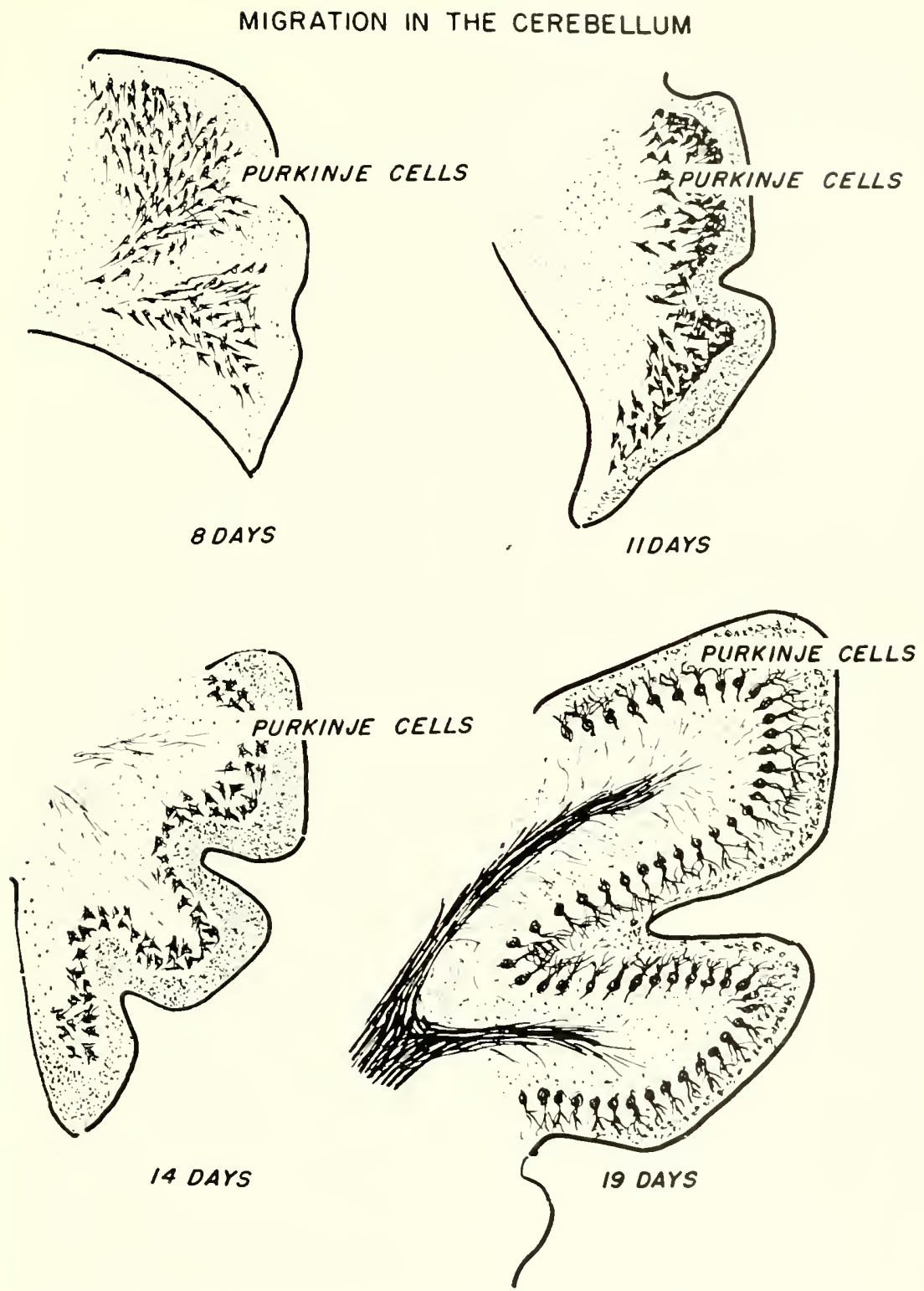

FIG. 4. Diagrammatic representation of the migratory movements of the Purkinje cells in the cerebellum of the chick embryo.

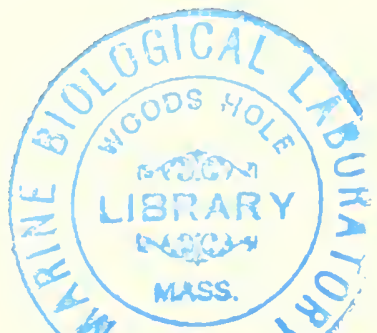


their progression in closely timed series till they have reached their final location in the central epibasal area at 12 days. Then the stationary cells lose their parallel alignment and become multipolar (Fig. 5).

In seeking for an explanation for these migratory movements, which resemble the organized and directed migration of a school of fish in a stream or of a colony of termites, we are faced with several questions: Why should differentiated cells engage in such long routes and settle down in areas so far removed from the ones where they first underwent their early differentiation? Which is the major motive force underlying and directing the migrating cell populations?

Similar questions were raised in connection with other cell movements such as the migratory movements of cells in developmental processes, the disaggregation and reaggregation of cell groupments intermingled at random in tissue culture, and the synergistic movements which play such a prominent role in the developmental cycle of slime molds. We shall consider bricfly the results of these investigations since the explanations offered in all three instances may have a bearing on our own problem.

Migratory patterns of chromatophores in Amphibia were investigated by Twitty and by Twitty and Niu $(13,14)$ in vivo and in vitro, with refined and precise techniques. The results of the experiments performed in vitro suggest that the cells move in response to mutual stimulation or repulsion mediated through the action of substances released by the cells.

Reaggregation patterns of suspensions of freshly dispersed embryonic cells in liquid culture medium were the object of detailed analysis by a number of investigators $(15,16,17,18,19)$. The early hypothesis by Moscona and Moscona (15), that cell exudates might have an orienting influence on the migration and aggregation of dissociated cells, found support in more recent investigations by Moscona (20). He observed that cells dispersed in a liquid medium frequently "appear to follow each other in clcarly discernible rows." Phasecontrast, time-lapse movies of similar cultures reveal that the cells move within fine strands of highly transparent slimy substance, evidently an exudate of cellular origin. The author suggests that the extracellular matrix might act as a cell-integrating system endowed with specific cell-directing activities.

The aggregative and migratory patterns of slime molds $(21,22,23)$ present a striking instance of cell movements under the controlling action of diffusible substances. The mechanism of the movement and the chemical nature of the agent acrasin, produced by some of the cells, lent themselves to a more precisc exploration than animal cells. 
Migration in Telencephalon
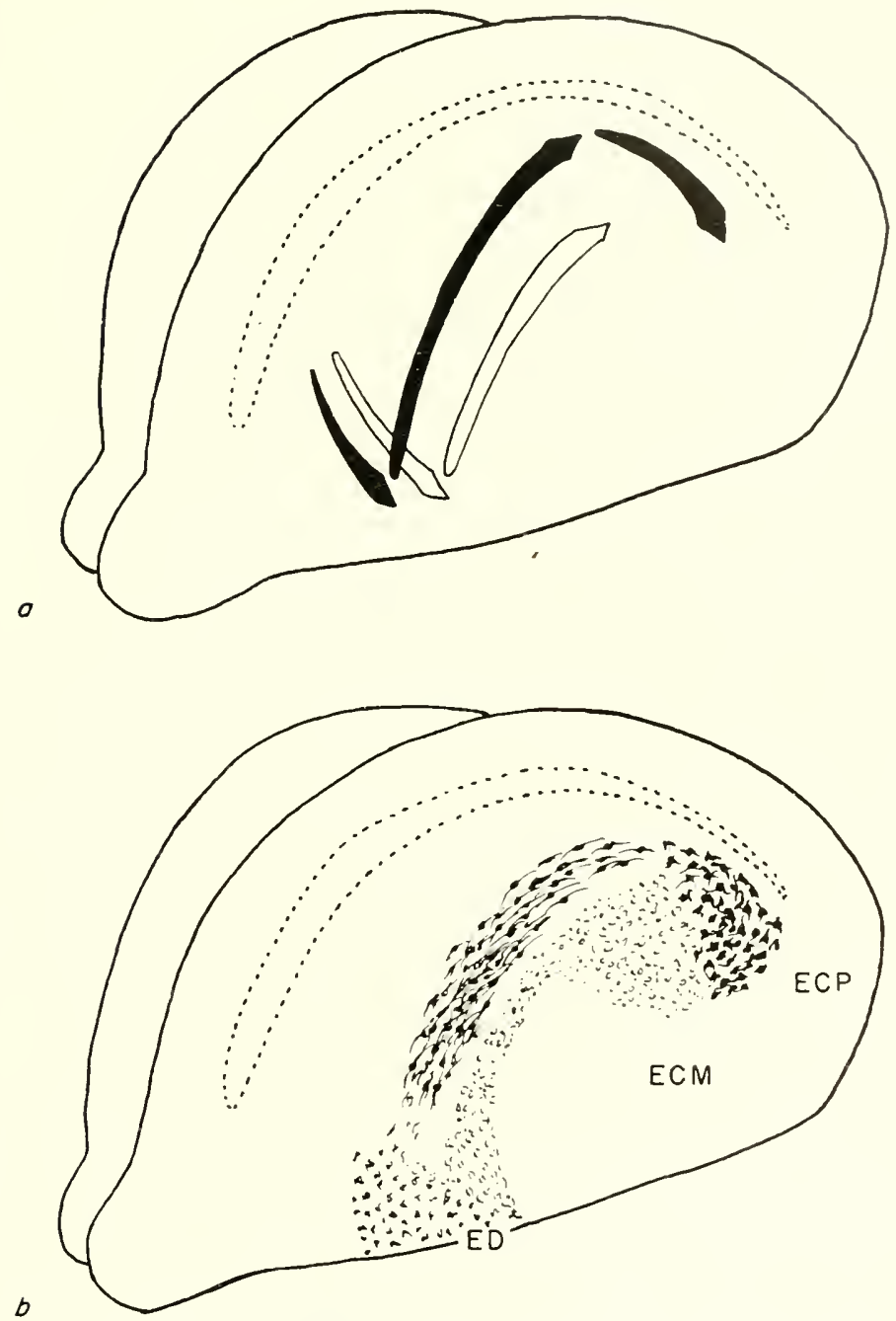

FIG. 5. Diagrammatic illustration of the migration of the epibasal central nuclei in the avian telencephalon. In $a$, the black and white arrows indicate the direction of movement of the two cell populations from their early formation at 7 days to the completion of the process at 12 days. In $b$, the two migrating populations are represented. ED, nucleus epibasalis dorsalis; ECM. nucleus epibasalis centralis. pars medialis; ECP, nucleus epibasalis centralis, pars posterior. 


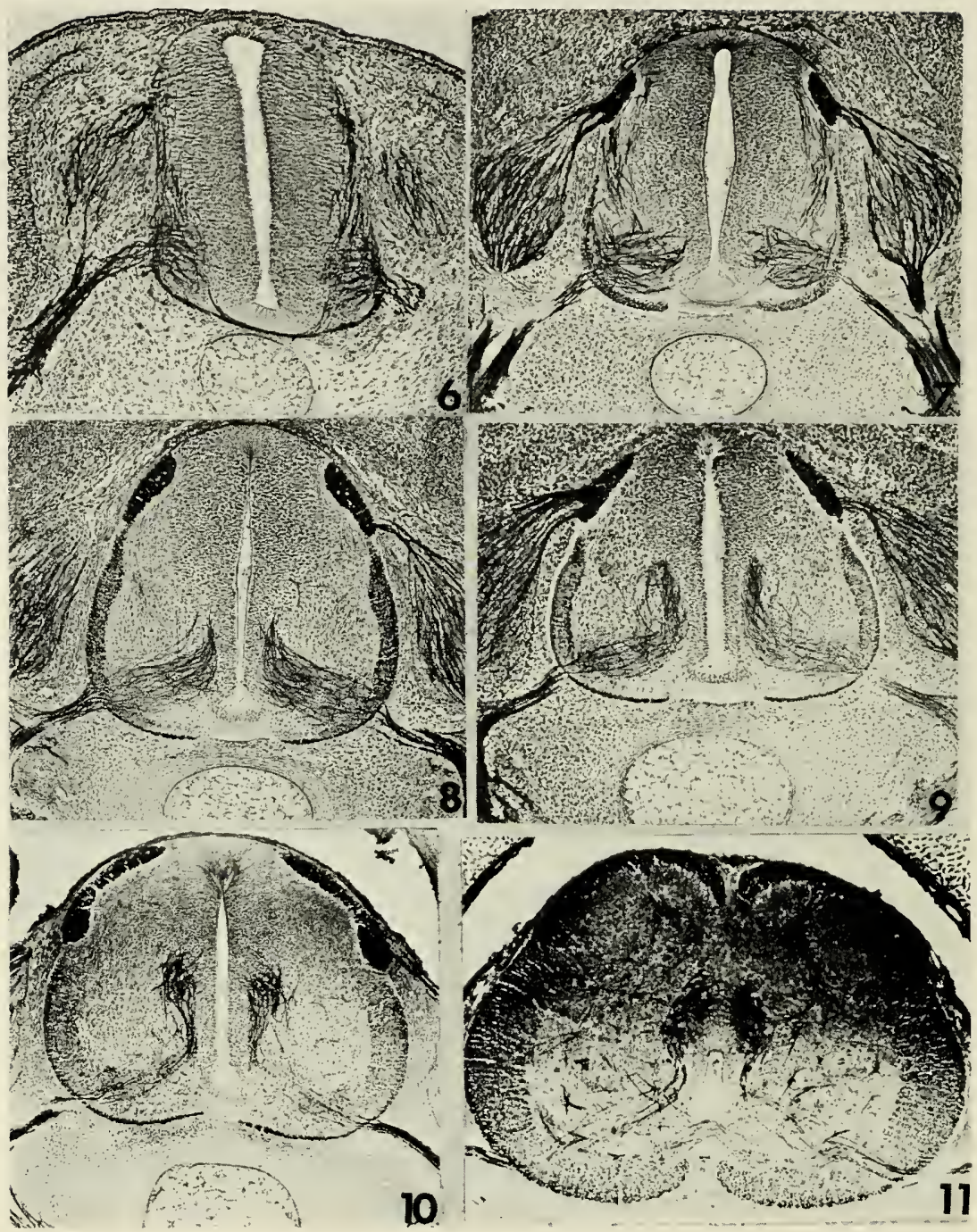

PLATE I. Figures 6 to 11 illustrate the formation and migration of the preganglionic thoracic column in the spinal cord of the chick embryo between 3 and 11 days. All sections are from material impregnated with the Cajal-De Castro silver technique. The microphotos in this and in the following plates are not retouched. FIG. 6. 3-day embryo. FIG. 7. 4-day embryo. FIG. 8. 51/2-day embryo. FIG. 9. 6-day embryo. FIG. 10. 7-day embryo. FIG. 11. 11-day embryo. See explanation in text. 
Growth and Differentiation in the Nervous System 277
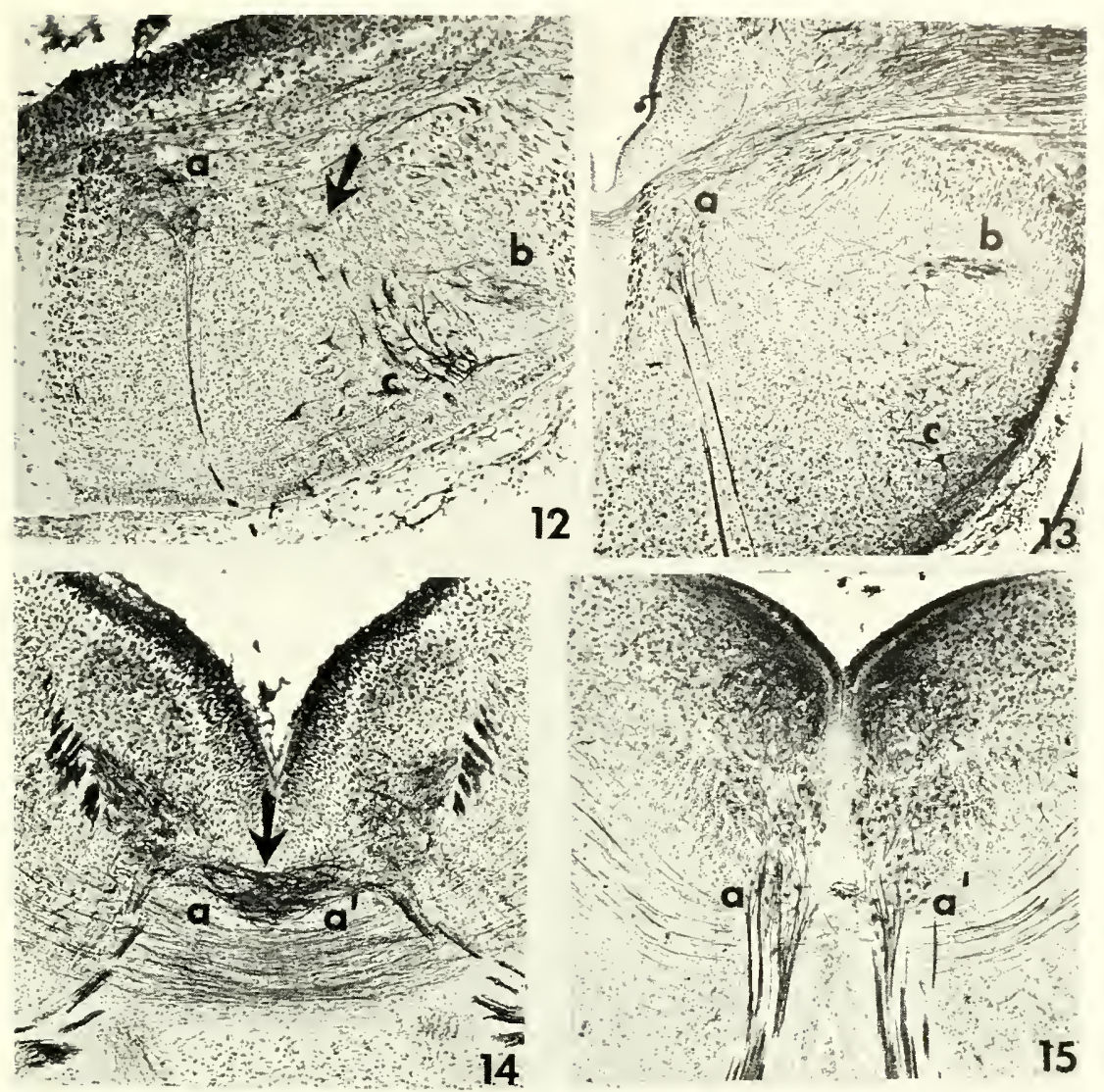

PLATE II. Fig. 12. Transverse section through the VIth nerve of a 6-day embryo. Arrow points to neuroblasts in the process of migrating from the main nucleus $(a)$ of the VIth nerve to the accessory nucleus $(b)$ of the same nerve. $c$, neuroblasts of the VIIth nucleus. FIG, 13. Transverse section at the sone level as Fig. 12. in an 11-day chick embryo. The migration of the accessory nucleus $(b)$ from the main nucleus $(a)$ of the Vlth nerve is completed. $c$, VIIth nucleus. Fig. 14. Transverse section through the nuclei of the HIIrd nerve at the mesencephalic level of a 6.day embryo. The arrow points to the two populations $\left(a\right.$ and $\left.a^{\prime}\right)$ as they cross the mid. line and move in opposite directions to join the nuclei of the contralateral IIIrd nerve. FIG. 15. 15-day embryo. Cross section at the same level as in Fig. 14. The two ventromedial nuclei of the Illrd nerve $\left(a\right.$ and $\left.a^{\prime}\right)$ are seen in their definitive contralateral position. Note the segregation of the oculomotor nerve cells in four nuclei. 
These last investigations gave definite support to the concept that diffusible agents control cell movements. Since these movements (as in the case of migrating nerve cells) occur simultaneously with other differcntiative processes, it is difficult to draw a line between the effects exerted by these agents on cell movements and on other aspects of cell differentiation.

In the case of the migratory movements in the central nervous system, we are under no illusion that the processes might lend themselves to a precise experimental analysis. Even though the hypothesis that the complex locomotion pattern of nerve cells might be directed by some agent released in the matrix by other cells or by the matrix itself is plausible, the demonstration would be extremely more difficult than in other situations where cell movements occur in more suitable environmental conditions. This conclusion should not discourage further attempts to explore the complex migratory patterns of ncrve cells, since this exploration will undoubtedly contribute to our knowledge of the developing nervous system. The results of the experimental analysis of the spinal cord by Shieh (see page 268) and results of experiments now in progress on the brain stem show that the migratory patterns can be altered by transposition or ablation of segments of the neural tube. They give evidence of the flexibility of these processes and indicate that environmental factors play a role in the differentiation of the central ncrvous system.

We shall devote the following section to the analysis of developmental and growth processes of nerve cells which early in life migrate out of the central nervous system and establish themselves in discrete cell aggregates known as sensory and sympathetic ganglia. This position is most favorable for exploring the cells under normal and experimental conditions. The results to be reported below show that these cells arc highly receptive to agents present in the medium not only during embryonic life but throughout all their life cycle.

\section{Itole of Peripheral Efiectors and treceptors in the Differentiation and Growth of Nerre Centers}

When in 1935 R. G. Harrison presented in the Croonian Lecture the results of his brilliant analysis of the developing nervous system of the amphibian (24), the newly opened field of experimental neuroembryology seemed to offer unlimited possibility to explore the nervous system and to uncover the mechanisms which operate in its differcntiation. 
Three aspects of this analysis impressed particularly the rearler of the Croonian Lecture and encouraged further experimentation along this line: (1) the extraorlinary tolerance of the embryo for any kind of surgical performance, ranging from restricted ablations to destruction of nost of its nervous structures: (2) the flexibility of the developing nervous system, which readily arlapts itself to any new situation and even accepts foreign tissues as peripheral receptors and effectors; and (3) the rapidity of the response of developing nerve centers to ehanges inflicted to their fields of innervation. The sitnation in the early thirties seemed to he rery similar to the situation which prevailed a few years earlice in the field of experimental embryology, when the discovery of embryonic induetion had transformed the static field of descriptive embryology into one of the most dynamic and promising areas of hiology. In the years which followed the publication of the Croonian Lecture, all possible avenues of this new ficld were explored. First the amphibian larvae and then the chick embryos submitted obediently to the glass or steel needle, which performed all kinds of ablation and transplantation experiments. Many times during the past years the results and perspective in this field have been considered $(25,26,27)$. We shall examine here only one of the most discussed problems of neuroembryology-the nechanism of control exerted by peripheral effectors and receptors on their associated nerve centers. Since the first experiments were performed ly Harrison, Detwiler, and their students $(24,28)$ a good deal has heen learned about the effects elicited by decreasing or increasing the peripheral field of innervation. while practically nothing has becn learned about the regulatory medianisms which operate under normal and experimental conditions. Fet it is the understanding of these mechanisms which is important if we wish to gain information on growth and developmental processes in the nervous systen.

In the past the attention has heen mainly focused on the differentiation of spinal ganglia. As a result we know today more about the differentiative pattern of sensory nerve cells than alout any other nerve cell. Most of the investigation centered on the chick cmbryo, which provides excellent material for normal and experimental analysis. We shall consider in the following section the results of this analysis, which recently received new impulse from the discovery of specific nerve growth factors well identified in their chemical and biological aspects. A closely related cell. the sympathetic nerve cell. will also he considered since its response to growth factors, which is even more impressive than the response of the sensory cell, sheds light on other facets of the problem under consideration. 

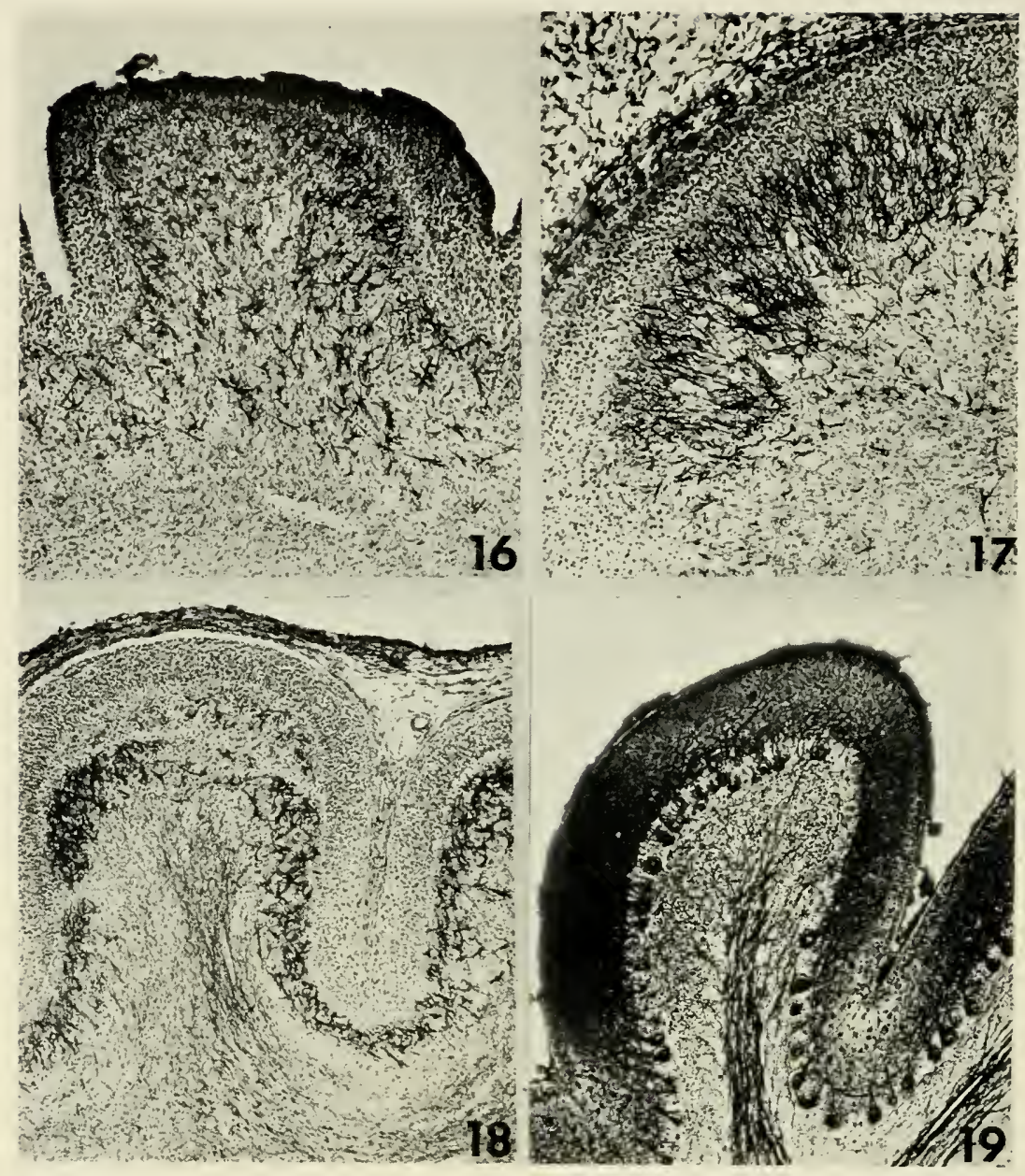

PLATE III. FIGS. 16 to 19 show the mass migration and progressive differentiation of the Purkinje cells in the cerebellum of embryos at $8,11,14$, and 19 days of incubation. See explanation in the text.

\section{Developmental pattern of sensory ganglia under normal and experimental condivions}

In 1934 and in 1939 Hamburger performed the first detailed analysis of the growth and differentiation of sensory ganglia in chick embryos under normal conditions and under the experimental conditions of unloading or overloading their peripheral field of innervation (29, 30 ). The extirpation of the limb bud at the stage of 3 days of incuba- 
tion or the implantation of an additional limb at the same stage provided the conditions for this investigation. He observed severe atrophy of the ranglia deprived of their peripheral field and noticeable size increase in the ganglia confronted with a larger than normal field of inuervation. His results were confirmed in subsequent investigations $(31,32)$. In 1943. while performing this analysis, we observed two distinct elasses of cells in the sensory ganglia (31). The presence in these ganglia of two populations differing from each other in cell size as well as in their location in the ganglia was first rlescribed by Hamburger in his early investigation of normal embryos and enulyryos deprived of one limb bud (29). We now observed that the two cell populations differ strikingly from each other also in their affinity for silver. The lateroventral population is the first to differentiate and is formed of large nerve cells which react intensively to silver from their first differentiation at 4 to 5 days to the end of the incubation period. The mediodorsal population does not show silver affinity till the end of the incubation period. The two cell groups, which we designated in a previous publication (32) as V-L and M-D from their position, differ therefore from each other in time pattern of differentiation, cell size, position, and silver affinity (Fig. 22). Recently a cytochemical difference between these two types of neurons was shown by Gerebtzoff, who investigated the acetyl-eholinesterase activity in different cells and fiber systems (33). Although the author called attention only to the different content of the enzyme in the fibers of the dorsal funiculi, his photographic documentation shows a clear-cut difference in the amount of the enzyme present in the two eell populations: The V-L but not the M-D eells show the presence of the enzyme (Fig. 23). The structural and chemical differences between the two types of sensory nerve cells come in sharp relief when the ganglia are confronted with changes in their field of innervation. In 1944 (31), we observed that the extirpation of the limb bud at 3 days of incubation results in an almost immediate breakdown and disappearance of most of the V.L cells, whereas the M-D cells persist in atrophic condition till the end of the incubation perior. In 1949 (32), we described a differential response of these two cell populations following implantation of an additional linb hud in 3-day-old embryos. Counts of the V-L nenrons in ganglia confronted with an enlarged field showed an increase of about 80 per cent of these neurons over the control eell population, whereas no changes were detected in the number of the M-D cells. Results to be presented in the following section gave evidence of a differential and opposite response of the two types of neurons when confronted with neoplastic tissue. 


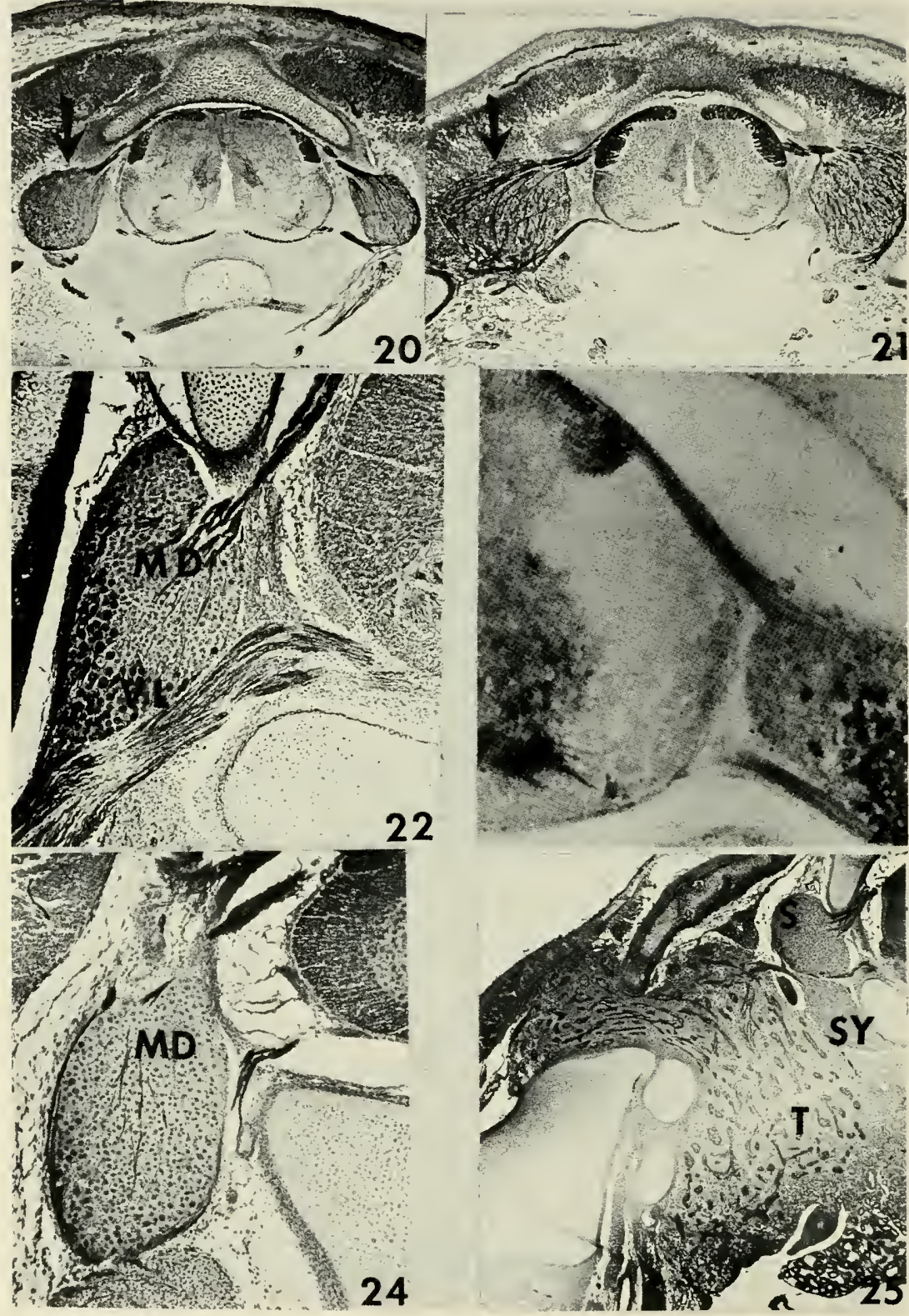

PLATE IV. Figures 20 and 21 represent transverse sections through the thoracic level of 10-day embryos. FIG. 20. Control. FIG, 21. Eubryo injected for 3 days with the purified salivary NGF. In both microphotos, arrows point to spinal 
A comparison of the effects ealled forth by extirpation of the limb primordia or by implantation of additional limb buds showed that in both instances all developmental processes of sensory nerve cells scened to be affected-the mitotic activity, the initial differentiation of sensory nerve eells, as well as their further growth (32).

Two hypotheses were advanced as to the mechanism of this control. Either (1) the peripheral field of innervation controls the growth processes of the associated nerve centers by releasing into the circulation some agent which selectively promotes the growth and differentiation of nerve cells tributary to that field, or (2) the periphery affects only those nerve cells which establish contact through their nerve fibers with the field of innervation. Both alternatives failed to explain satisfactorily all the effects evoked in the sensory ganglia by extirpation or transplantation of an additional limb. The hypothesis listed at (1) was in conflict with the observation that an increase or a decrease of the peripheral field of innervation affects only the sensory and motor centers whieh supply nerves to that area. The other alterna: tive, which consirlers the nerves as mediators between the end organs and the associated nerve centers, agrees better with these observations. It does not, however. explain other aspects of the growth response of the sensory ganglia to ehanges inflicter in their peripheral field of innervation. It was in fact found that the mitotic activity in these ganglia increases or decreases according to the extension of the area they innervate. Since dividing cells are obvionsly deprived of nerve fibers, these results cannot be accounted for as a direct effect of the periphery on individual nerve cells. The experiments to be reported in the following section suggest a more satisfactory explanation of the ahove results. They will therefore be reconsidered after presentation of the new findings.

ganglia. Note the increase in size of ganglia of the treated embryo. FIG. 22. Spinal ganglion of a control 11-day embryo. The two cell populations in the spinal ganglion $(M D$ and $(L)$ show the difference in their affinity for silver. FIG. 23. The acetylcholinesterase activity in the V.L nerve cells of the spinal ganglia in 10. to 11-day chick embryos. (Reproduced with the permission of M. A. Gerebtzoff from Fig. 32 in Cholinesterases, Pergamon Press.) FIG. 24. Spinal ganglion contributing nerve fibers to a fragment of mouse sarcoma 180 (not apparen in the picture). Same magnification as Fig. 22. Note the size increase of the $M D$ population. The I' $L$ population does not show in this section. FIG. 25. The massive invasion of an implanted fragment of mouse sarcoma 180 by nerve fibers from adjacent sensory and sympathetic ganglia. $T$, tumor; $S$, sensory ganglion; $S Y$, sympathetic ganglion. 


\section{Growth IResponse of Nerve Cells (o) a Diffusible Protein Agent}

The finding in 1948 by Bueker of a nerve growth stimulating effect of mouse sarcoma 180 on the sensory ganglia of chick embryos (34) may be defined as the ontcome of a fortuitous discovery and a calculated search. The results so much exceeded the expectation that the unprepared mind of the observer overlooked the exceptional magnitude of the response in the attempt to make it fit into the previously accepted schemes of growth and differentiation in the nervous system.

In transplanting a fragment of mouse sarcoma 180 in the body wall of 3-day chick embryos, Bueker wanted to test the effect of a rapidly expanding tissue on sensory and motor nerve cells. When he examined the embryos 5 days later he found in a number of cases that the tumor had become established and was invaded by sensory but not by motor nerve fibers. He also observed that the sensory ganglia contributing fibers to the tumor were enlarged in size as compared to the contralateral normal ganglia. No changes were observed in the motor column. The author concluded that the tumor clicited the growth response in the sensory ganglia by providing them with a larger field of innervation than their usual ficld. Since the effect appeared to be restricted to the ganglia sending nerve fibers to the tumor, the nerve fibcrs were considered as the mediators of the effect. The results and the conclusions therefore fitted well into the picture presented above of the effect of the periphery on associated nerve centers. A reinvestigation of this effect led to a different interpretation of the phenomenon.

\section{a. Hesponse of sensory embryonic nerve cells to implantation of mowse sareomas}

The response of the sensory ganglia to implantation of mouse sarcoma 180 or 37 was investigated in a close series of chick embryos ranging in age between 4 and 18 days (35). Ganglia adjacent to the transplant provide its neurotization with large nerve bundles, which branch in all directions inside the tumor (Fig. 25). At 11 days the ganglia appear three times larger than controls. 'The overgrowth is due to an increase in cell size and cell number of the M-D population, whereas no changes arc appareni in the V.L population, which does not seem to participate in the innervation of the tumor (Fig. 24). From the elcventh day to the end of the incubation period, the effect 
of the tumor on M-D cells gradually decreases in spite of the steady increase in size of the transplant, which at 18 days normally fills the abdominal cavity of the embryo $(36,37)$.

A series of investigations on the effects of mouse sareomas 180 and 37 on sensory ganglia of the chick embryo, explanted in vitro with the hanging drop technique, showed that the neoplastic cells elicit a remarkable growth effeet from the sensory cells (Figs. 32, 33). The effect consists of the outgrowth of a dense halo of nerve fibers from the ganglia adjacent to but not in contact with the tumor within the first 10 hours of eulture in vitro (38). The effeet is maximal if the ganglia are explanted from 7- to 9-dlay chick embryos. It decreases in ganglia explanted from older specimens and is no longer apparent in ganglia from 18-day chick embryo. The effects in vitro show therefore a parallelism with the effects elicited by the tumor in the embryo: In both instances the sensory cells appear to be receptive to the growth agent present in the neoplastic tissue only during a limited period of their growth.

The results of the in vitro experiments showed that the tumor evokes a response from the sensory ganglia even if no contaet is established between the two tissues. Experiments to be reported below show that a growth response can be elicited from the sensory ganglia in vivo by simply injecting diffusible agents into the yolk of developing embryos.

It was concluded from the aloove findings that a direct contact between nerve fibers and the tissue producing the growth agent is not necessary to elicit the increase in size and number of the M.D population in the sensory ganglia.

\section{b. Hesponse of semsory ganglia of chicl: cmbryos to alifusibla nerve growerh factors}

It was the substitution of the tissue eulture technique for the laborious and time-consuming technique of transplantations in the embryo which made possible an extensive search for nerve growth factors and also offered the possibility of investigating the biochemical aspect of the problem. Two potent nerve growth factors (NGF) discovered in snake venom and monse sulomaxillary salivary glands $(39,40,41,42)$ show striking biochemical similarities with the factor isolated from the tumor. In all three instances the agent isolated and purified hy Cohen was identified with a protein or a protein-bound particle (41). Here we shall consider the biological effects of the purified extract of 

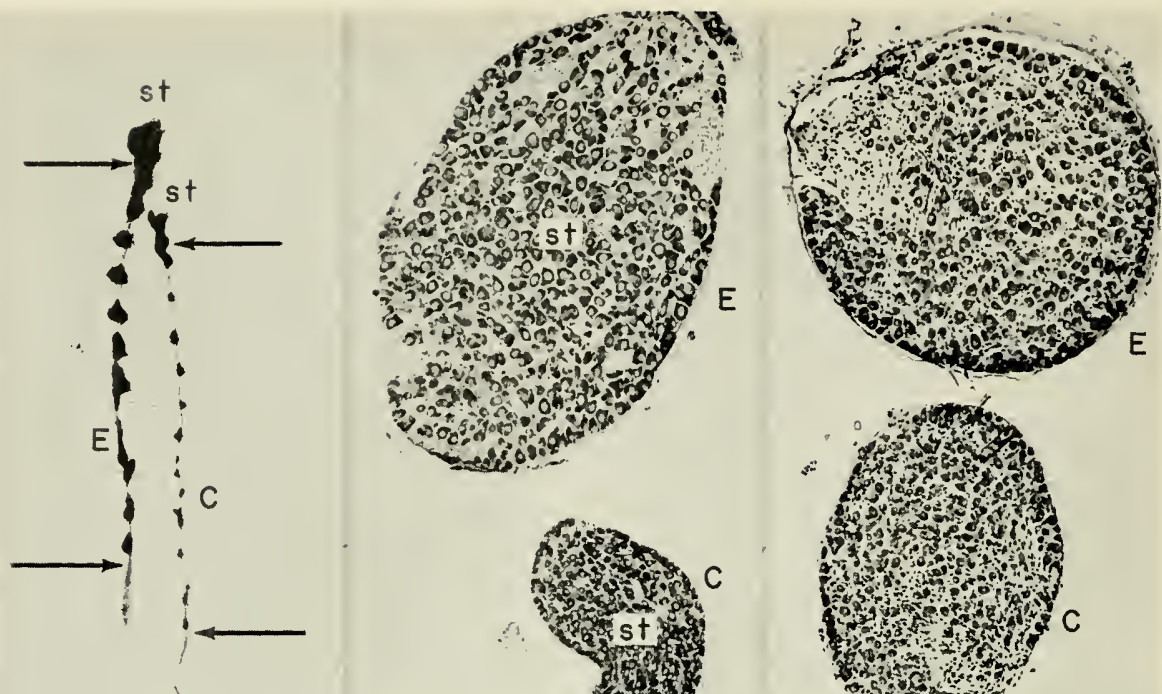

26
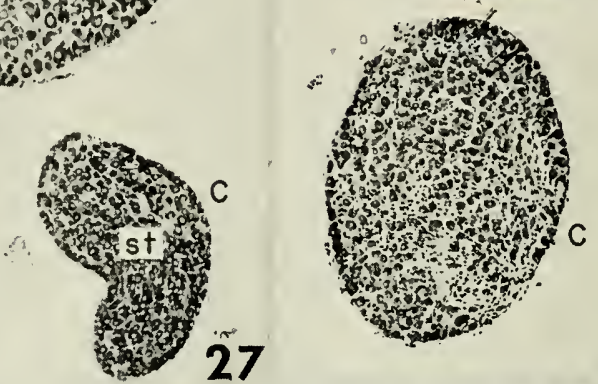

28
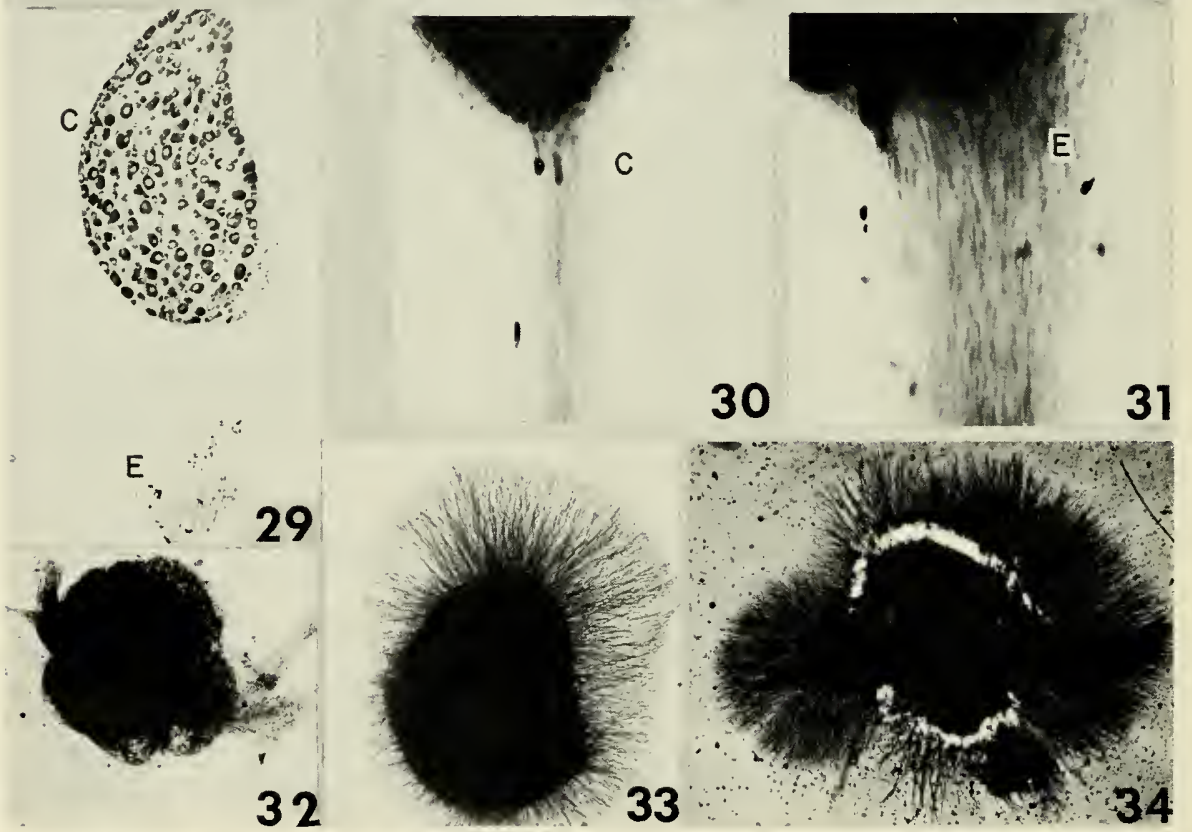

PLATE V. FIG. 26. Whole amounts of the sympathetic thoracic chain ganglia of experimental $(E)$ and control $(C)$ mice 19 days old. Experimental mouse injected with the NGF salivary factor from birth. ST, stellate ganglia. FIG. 27. Transverse section of stellate ganglia $(S T)$ in experimental $(E)$ and control $(C)$ ganglia of Fig. 26. Sections through levels indicated by upper arrows in both chains of Fig. 26. FIG. 28. Transverse section of superior cervical ganglia of two adult mice. $E$, mouse 
the mouse salivary glands on the sensory ganglia of chick embryos. Similar results were obtained by injecting the purified agent extracted from snake venom.

The addition to the culture medium of the purified protein extracted from the salivary glands or from the snake venom elicits the same nerve growth response as fragments of tumor or tumor extract. Both the snake venom and the mouse salivary wlands liarloor this agent in such a large amount that a very small quantity of the purified extracts is sufficient to evoke the in vitro effects. It was shown by Cohen that the purified salivary extract is active at a concentration of 0.01 gamma of protein per milliliter (41). This solution, when added to the medium of culture in the proportion of one part to one part of synthetic medium and one part of plasma, elicits a dense halo of nerve fibers from the explanted sensory ganglia. It was designated as one biological unit. A comparison between the potency of the tumor and the salivary gland extract indicates that the latter is about 6,000 times more potent on a dry weight basis than the tumor.

Daily injections of a few gamma of the purified protein isolated from mouse submaxillary salivary gland into the yolk of 6- to 10-day chick embryos call forth a growth response from the M-D population of sensory nerve cells, comparable to the response elicited by intra. embryonie transplants of mouse sarcomas (Figs. 20, 21). The size increase of this population has its counterpart in the hyperneurotization of the exteroceptive embryonic ficlds. Since no inerease in the V-L population was observed and no hyperneurotization of the museles is apparent, it is tempting to correlate these two populations with different fields of distribution. Further investigations are in progress to elueidate this point and to trace the distribution of nerves from the hypertrophie ganglia to their terminal structures.

injected for 1 week with the NGF salivary factor: $C$, control ganglion. FIG. 29. Transverse sections through superior cervical ganglia of 4 -month-old mire. $C$. control: $E$. mouse injected for 5 days after birth with the antiserum to the salivary NGF. FIGS. 30 and 31. Sympathetic nerve trunks of control and experimental chain ganglia of Fig. 26 at higher magnification. Low arrows in Fig. 26 indicate areas enlarged in Figs. 30 and 31. FIG. 32. Spinal ganglion of a $\vec{i}$-day-old chick embryo cultured in vitro for 24 hours. FIG. 33. Spinal ganglion as in Fig. 32. combined in vitro with a fragment of monse sarcona 180. Note the dense fibrillar halo. FIG. 34. Sympathetic ganglion of a human fetns 3 months old cultured for 24 honrs in a medium to which the NGF salivary factor was added. 


\section{c. Tesponse of sympathetic nerve cells of chick embryos to implantation of mouse sarcomas and to the injection of other nerve growth factors}

Since the beginning of this investigation in 1950 , we realized that the sympathetic ncrve cells are far more affected by the tumoral factor than the sensory nerve cells. While the size increase of the sensory ganglia adjacent to the transplant ranges between two and three times that of the controls, the size increase of sympathetic ganglia is four to six times that of the controls (42). Two factors may in part account for these differences: (1) The sympathetic nerve cells at variance with the sensory nerve cells are all receptive to the nerve growth factor; and (2) the effect is not restricted to a given period of their differentiation but continues till the end of the incubation time. As will be shown below, sympathetic nerve cells of mammals remain receptive to the growth factor throughout all life (Fig. 28).

In a number of cases the effects of the tumor are restricted to the sympathetic ganglia which establish contact with the neoplastic tissue through their nerve fibers (35). In the majority of the cases, however (about 85 per cent of the total number of embryos cxamined, which amounts to many hundreds), the entire sympathetic chain ganglia are strikingly enlarged (36). Nerve fibers emerging from the hypertrophic and hyperplastic glanglia overflow the adjacent viscera, which are not innervated in corresponding developmental stages in control embryos; they also enter and fill large blood vessels with thick nerve bundles. Fragments of tumor transplanted onto the chorioallantoic membrane of 4- to 6-day chick embryos elicit the same effects. In this last group of experiments, the tumor and the host share the circulation, but no direct contact is established betwen them.

Sympathetic ganglia from 9- to 11-day chick embryos, explanted in vitro in proximity to fragments of mouse sarcomas, produce a dense halo of nerve fibcrs similar to the halo produced by sensory ganglia (see page 285). The in vitro technique was also used to test the effects of the purificd extract of mouse salivary glands and of snake venom on the sympathetic ganglia of chick embryos. The injection of the purified cxtract of the salivary gland into the yolk of 6- to 10-day chick embryos evokes an overgrowth of the entire sympathetic chain ganglia and hyperneurotization of the viscera (43).

In summary, we may conclude that the M-D sensory neurons and the sympathetic nerve cells of the chick embryos are highly receptive 
to a growth factor present in mouse sarcomas, snake venom, and mouse submaxillary salivary glands.

Some of the results are of particular interest for the light they shed on the growth and differentiative processes of embryonic nerve cells. They show that the growth potentialities of these cells far exceed their growth range under normal conditions. Furthermore, they show that the active factor can reach the cells through the nerve fibers or through the circulatory system. The penetration of sympathetie nerve fibers into viscera and blood vessels normally impermeable to nerves. as well as the hyperneurotization of exteroceptive fields with sensory nerve fibers, shows that both the qualitative as well as the quantitative aspects of peripheral nerve distribution are not rigidly fixed in the embryo but that considerable deflections from the normal pattern are tolerated.

\section{d. Itespomse of sympathetic nerre cells of newborn and adult mice to the purified salieary NGF}

After the experiments in tissue eulture indicated that sympathetic ganglia of mammals (rodents and human fetuses) are receptive to the NGF, we tested its effeets in newhorn and then in adult mice. Daily injections of this agent in the amount of 2,000 biologieal units per gram of body weight in mice hetween the day of birth and the nineteenth rlay result in a six-time increase of the volume of these ganglia (42). The increase is due to a twofold increase in the cell population and a threefold increase in the size of nerve cells (Figs. 26, 27, 30, 31). A parallel inerease in the supply of sympathetie nerve fibers to the blood ressels, viscera, and hair was observed. In the adult, the NGF ealls forth increase in the size of individual neurons but no increase in their number.

\section{Distribution of the NGF in the organism}

Every time during the past years that we detected a new source of the NGF, we hoped to have at last identified its source in the organism. In no instance. however, was the evidence strong enough to implicate the tissuc as the "source" of the NGF. and the search is still in progress at the present time. One interesting and perhaps revealing observation was to find that the NGF is present everywhere in the organism (44). It is harbored in exceptionally high amount in the 
mouse salivary glands and in their homologue, the snake venom glands; it is present in lesser amount in the salivary glands of other rodents, which in turn seem to possess it in higher amount in the kidney (unpublished observations). It is present in embryonic tissues of chick embryo (45) and in granuloma tissue experimentally produced in different vertebrates (44). It is also detectable in the sensory and sympathetic nerve cells of embryonic birds and in the sympathetic cells of a variety of mammals, man included. A preliminary exploration indicates its presence in luman serum.

The functional significance of this agent in the growth and developmental processes of sympathetic nerve cells can hardly be questioned. We have evidence that in the mouse the sympathetic cells remain receptive to the NGF throughout life and it is conceivable (but still not proved) that this applies also to the same cells in other mammals (Fig. 34). Additional support in favor of the hypothesis that the NGF might play an essential role in the growth and differentiation of the receptive nerve cells came from experiments reported in detail elsewhere $(41,46)$, which slowed that the injection of this antiserum destroys selectively the sympathetic ganglia in newhorn mammals (Fig. 29).

\section{A re-evaluation of the role of extrinsic factors as controlling agents of growth and differendiation of nerve cells:}

Before attempting an evaluation of the results presented in the preceding pages, it may be of interest to consider how past interpretations were abandoned as new facts were discovered and as we gained a more precise picture of the phenomenon. We believe that the present information is still at best only partial and fragmentary; this belief and past experience suggest offering a working hypothesis rather than a conclusion in the following pages.

It will be recalled that at first the growth effects elicited by mouse sarcomas on the sensory ganglia of the chick embryo were compared to the effects elicited by implantation of an additional limb in the embryo (34). At that time, the similarities rather than the differences between the two effects were stressed. A reinvestigation and a more close inspection of the phenomenon resulted in a radical change of position. When it was discovered that the tumor elicits a generalized growth effect on the sensory and sympathetic ganglia of the embryo, the differences rather than the similarities between the effects of the 
tumor and the effects of an additional limb were stressed (37). We concluded that the tumor calls forth atypical responses which rannot be considered as merely an intensification of normal developmental processes. The question was then raised whether these exceptional effects were not due to some unique property of neoplastic tissues. This hypothesis, suggested in 1953 (37). was ruled out 3 years later when it was diseovered that snake venom harbors a nerve growth factor remarkably similar to the NGF of mouse sarcomas. When, 2 years later, it was found that the mouse submaxillary salivary glands also possess this factor. it was definitely establisherl that even normal structures can harbor the NGF. At the same time, the difference between the effects elicited by the implantation of a limb and the effects elicited by implantation of mouse sarcomas or by injection of the venom or of the salivary NGF seemed to eome into an even sharper relief than before.

The results obtained with these last factors established lieyond doubt that the specific protein ean avail itself of different routes to gain access to the nerve cells. While in experiments of transplantation of additional limbs we had only evidence of the role played by nerve fibers in conveying the message from the periphery to the nerve cells, now we were able to show that the NGF can utilize the nerve fibers (intraembryonic tumor transplantation); it ean utilize the circulatory channels (chorioallantoic tumor transplantation or injection of the NGF into the yolk): or it can diffuse in the medium, as proved by tissue eulture experiments.

A next step in the investigation was the discovery that the NGF is present in the receptive ne:ve cells and ean also be detected in other structures and body fluids. Of particular interest is the finding that it is present in the serum of mammals. man included, and that it is produced by undifferentiated structures such as eubryonic cells (45) and granuloma tissue experimentally produced in adult mammals (44).

The above results raised the question whether the NGF is produced in a special organ and from there sprearl in the organism, or whether it is normally produced by different types of cells. This question is still undecided, although we believe that the evidence is in favor of the second alternative. Since we have evidence that it is produced in anaplastic tumors and it is present in embryonic tissnes. We are ayain faced with the problem which we considered as definitely settled: Are the growth effects elicited by a transplanted additional limb entirely different from the effects elicited by the NGF disenssed ahove? In order to answer this question, one should have a more precise 
notion of the biochemical changes which take place in ganglia confronted with an enlarged peripheral field such as the one provided by an additional limb bud. We know that the mitotic activity increases and as a consequence more nerve cells are produced. The effect is restricted to the ganglia which contributc fibers to the graft. This is in fact the main difference between the effects elicited by a transplanted limb and an implanted tumor. There are, however, instances of moderately active tumors where the effect is restricted to the ganglia which send fibers into the neoplastic tissue. The difference is therefore more of a quantitative than of a qualitative order. The massive and generalized effects elicited by rapidly growing tumors, or ly injection of large quantities of the salivary NGF, represent exceptional events with no parallel in the normal development of the embryo. Under normal conditions, it seems conceivable that the peripheral end organs release small quantities of growth factors and that these factors may utilize the nerve fibers as channels of diffusion to the associated nerve centers. This hypothesis would explain the mitotic effects and at the same time would not be in conflict with the observation that the effects are restricted to nerve centers contributing fibers to the implanted organs.

In suggesting that the effects evoked by peripheral structures and by the NGF isolated from tumor, snake venom, and the mouse salivary glands might in ultimate analysis operate in a similar way, we wish to make clear that the growth factors necd not be the same in all experimental conditions examined above. It was in fact shown that the effects elicited by the transplantation of an additional limb are mainly apparent on the V-L sensory cells while the effects of the tumor and of the purified NGF are mainly and perhaps entirely restricted to the M-D cells and to the sympathetic ganglia.

A confirmation of the above hypothesis would come from the isolation of growth factors from peripheral structures with a specific effect on other nerve cells, such as the V-L sensory cells and the motor neurons. This is one of the problems we propose to investigate. The realization that it is a very difficult problem makes it more challenging and worth the efforts it will require.

\section{Ieferences}

1. J. F. Tello (1922), Les differenciations neuronales dans l'embryon du poulet pendant les primiers jours de l'incubation, Trav. Lab. Rec. Biol., Univ. Madrid, T., 2 I :1-93.

2. W. F. Windle and D. W. Orr (1936), Neurofibrillar development in the central 
nervous system of chick embryos up to 5 days incubation, J. Comp. Neurol., $63: 431,463$.

3. F. Visintini and R. Levi-Montalcini (1939), Relazione tra differenziazione strutturale e funzionale dei centri e delle vie nervose nell'embrione di pollo. Arch. suisses neurol. et psychiat., 43:1-45.

4. R. Levi-Montalcini (1950). The origin and development of the visceral system in the spinal cord of the click embryo. J. Morph., 86:253-284.

5. R. Levi-Montalcini (1942), Origine ed evoluzione del nucleo acressorio del nervo abducente nell'embrione di pollo, Acta Pontif. Acad. Sci., 6:335-345.

6. A. W. Jones and R. Levi-Montalcini (1958), Patterns of differentiation of the nerve centers and fiber tracts in the avian cerebral hemispheres. Arch, ital. biol., $96: 231-284$.

7. V. Hamburger and R. Levi-Montalcini (1949), Proliferation, differentiation, and degeneration in the spinal ganglia of the chick embryo under normal and experimental conditions, J. Exp. Zool.. $111: 467-502$.

8. P. Shieh (1951). The neoformation of cells of preganglionic type in the cervical spinal cord of the chick emhryo following its transplantation to the thoracic level. J. Exp. Zool.. 117:359-396.

9. C. Biondi (1910), Osservazioni sullo svíluppo dei nuclei d'origine dei nervi oculomotore e trocleare nel pollo. Riv. ital. neuropatol. Psichiatr., 3:302-312.

10. S. R. Cajal (1929). La charpente neurofibrillaire dans la cellule de Purkinje jeune. et son evolution, in Études sur la Neurogenese de Quelques V'ertebres, ed. hy Instituto de Estudios cientificos. Madrid, pp. 192-211.

11. R. Levi-Montalcini (unpuhlished observations).

12. L. L. Uzman (1960). The histogenesis of the mouse cerebellun as studied by its tritiated thymidine uptake, J. Comp. Neurol., 114:137-160.

13. V. C. Twitty (1944), Chromatophore migration as a response to mutual influences on the developing pigment cells. J. Exp. Zool.. 95:259-290.

14. V. C. Twitty and M. C. Niu (1954). The motivation of cell migration, studied by isolation of embryonic pigment cells singly and in small groups in vitro, J. Exp. Zool., 125:541-573.

15. A. Mosiona and H. Moscona (1952). The dissociation and aggregation of cells from organ rudiments of the early chick embryo, J. Anat., 86:287-301.

16. C. Grobstein (1954). Tissue interaction in the morphogenesis of mouse embryonic rudimcnts in vitro, in Aspects of Synthesis and Order in Grouth, 13th Symposium. Princeton University Press, Princeton, N.J.. pp. 233-268.

17. A. Moscona (195\%). The development in vitro of chimaeric aggregates of dissociated embryonic chick and monse cells, Proc. Nat. Acad. Sci. U.S., 43:181-194.

18. P. Weiss (1945). Experiments on cell and axon orientation in vitro: The role of colloidal exudates in tissue organization, J. Exp. Zool., 100:353-386.

19. P. Weiss (1958), Cell contact. Intern. Rev. Cytol., $7: 391-422$.

20. A. Moscona (1959). Patterns and mechanisms of tissue reconstruction from dissociated cells. in Developing Cell Systems and Their Control, ed. by Doro. thea Rudnick. The Ronald Press Company, New York.

21. J. T. Bonner (1947), Evidence for the formation of cell aggregates by chemo. taxis in the development of the slime mold Dictyostelium discoideum, J. Exp. Zool., $106: 1-27$.

22. M. Sussman (1952), An analysis of the aggregation stage in the development of the slime molds. Dictyosteliaceae. II. Aggregative center formation by mixture of Dictyostelium wild type and aggregateless variants. Biol. Bull., 103:446-457. 
23. M. Sussman and F. Lee (1955), Interactions among variant and wild type strains of cellular slime molds across thin agar membranes, Proc. Nat. Acad. Sci. U.S., $41: 70-78$.

24. R. G. Harrison (1935), The Croonian Lecture on the origin and development of the nervous system studied by the methods of experimental embryology, Proc. Roy. Soc. (London) B, 118:155-196.

25. V. Hamburger and R. Levi-Montalcini (1950), Some aspects of neuroembryology, in Genetic Neurology, ed. by P. Weiss, University of Chicago Press. Chicago, pp. 128-160.

26. V. Hamburger (1954), Trends in experimental neuroembryology, in Biochemistry of the Developing Nervous System, Academic Press. Inc., New York.

27. P. Weiss (1955), Nervous system, in Analysis of Development, ed. by Benjamin H. Willier. Paul A. Weiss, and Viktor Hamburger, W. B. Saunders Company, Philadelphia, vol. 7. pp. 346-401.

28. S. R. Detwiler (1936), Neuroembryology: An Experimental Study, The Mac. millan Company, New York.

29. V. Hamburger (1934), The effects of wing bud extirpation on the development of the central nervous system in chick embryos, J. Exp. Zool., 68:449-494.

30. V. Hamburger (1939), Motor and sensory hyperplasia following limb-bud transplantations in chick embryos, Physiol. Zool., 12:268-284.

31. R. Levi-Montalcini and G. Levi (1944), Correlazioni nello svilnppo tra varie parti del sistema nervoso. Commentationes Pontif. Acad. Sci., 8:527-568.

32. V. Hamburger and R. Levi-Montalcini (1949), Proliferation, differentiation and degeneration in the spinal ganglia of the chick embryo under normal and ex. perimental conditions, J. Exp. Zool., $111: 457-502$.

33. M. A. Gerebtzoff (1959), Cholinesterases, Pergamon Press, New York, pp. 1-195.

34. E. D. Bueker (1948), Implantation of tumors in the hind limb field of the embryonic chick and the developmental response of the lumbo-sacral nervous system, Anat. Record, $102: 369-390$.

35. R. Levi-Montalcini and V. Hamburger (1951), Selective growth stimulating effects of mouse sarcoma on the sensory and sympathetic nervous system of the chick embryo. J. Exp. Zool., 116:321-362.

36. R. Levi-Montalcini (1952). Effert of mouse tumor transplantation on the nervous system, Ann. N.Y. Acad. Sci.. $55: 330-343$.

37. R. Levi-Montalcini and V. Hanburger (1953), A diffusible agent of mouse sarcoma, producing hyperplasia of sympathetic ganglia and hyperneurotization of viscera in the chick embryo, J. Exp. Zool., $123: 233-288$.

38. R. Levi-Montalcini, H. Meyer, and V. Hamburger (1954), In vitro experiments on the effects of mouse sarcomas 180 and 37 on the spinal and sympathetic ganglia of the chick embryo. J. Exp. Zool., 116:321-362.

39. R. Levi-Montalcini and S. Cohen (1956), In vitro and in vivo effects of a nerve growth-stimulation agent isolated from snake venom. Proc. Nat. Acad. Sci. U.S., 42:695-702.

40. S. Cohen and R. Levi-Montalcini (1956), A nerve growth-stimulating factor isolated from snake venom, Proc. Nat. Acad. Sci. U.S., 42:571-574.

41. S. Cohen (1960). Purification of a nerve-growth promoting protein from the mouse salivary gland and its neuro-cytotoxic antiserum, Proc. Nat. Acad. Sci. U.S., $46: 302-311$.

42. R. Levi-Montalcini and B. Booker (1960), Excessive growth of the sympathetic 
ganglia evoked by a protein isolated from mouse salivary glands. Proc. Nat. Acad. Sci. U.S., 46:373-384.

43. R. Levi-Montalcini (1958), Chemical stimulation of nerve growth, in The Chemical Basis of Development, ed. by W. D. McElroy and Bently Glass, Johns Hopkins Press, Baltimore.

44. R. Levi-Montalcini and P. U. Angeletti (in press), Biological Properties of a Nerve.growth Promoting Protein and Its Antiserum. Pergamon Press, New York.

45. E. D. Bueker, I. Schenkein, and J. L. Bane (1960), The problem of distribution of a nerve growth factor specific for spinal and sympathetic ganglia. Cancer Research, $20: 1220-1228$.

46. R. Levi-Montalcini and B. Booker (1960), Destruction of the sympathetic ganglia in mammals by an antiserum to a nerve-growth protein, Proc. Nat. Acad. Sci. U.S., 46:384-391.

47. R. Levi-Montalcini and S. Cohen (1960). Effects of the extract of the mouse submaxillary salivary glands on the sympathetic system of mammals. Ann. N.Y. Acad. Sci., 85:324-341.

48. R. Levi-Montalcini and P. U. Angeletti (in press), Growth control of the sympathetic system by a specific protein factor, Quart. Rev. Biol. 



\section{Index}

Page references in boldface type indicate illustrations

Absorption bands, 2

Acetate thiokinase, 83, 84

Acetic acid, 32, 34, 46

Acids, acetic. $32.34,46$

alpha-amino, beta-ketoadipic. 38 amino, 10, 34, 72, 235, 236

isozymes. 113

deìta-amino-levulinic, 38

formic, 32,34

hydroxy, 34

succinic, $32,38.46$

ADP (adenosine diphosphate), 76, 78, 80 and ATP. 78

and pyruvate, 80

Aggregation, 224, 237. 240

Alanine, 249

Aldolases, 71, 73, 74, 76, 77 muscle, liver. yeast, $\mathbf{7 5}, 76$

Algae. photosynthesis. in blue-green. 17 (See also Blue-green algae) in marine, 17

Alleles, 173

Alpha-amino-beta-ketoadipic acid, 38

Amino acid sequences, 72

p.Aminobenzoate, 89

Ammonia, 3, 32, 33, 60. 61. 63

converted to urea. 59

irradiation, 47

x-ray identification, 33

Amplibia, 237

Androgen, endogenous, 151

exogenous, 151

Anticancer agents. 88
Antiserum, 175, 182

Arginase, 62. 63

Arginine phosphate, 55

Asexual reproduction, 173

Assay, pupal, 255

ATP (adenosine triphosphate), 18, 38

ADP-bound. 78

cleavage. 71, 77, 78, 81, 82, 85

phosphate by actosin, 87

syuthesis, 81

hydrolysis. 86

photoproduced. 25

pyrophosplate linkage, 19, 21, 22, 23, $24,26,27,29$

Autogamy, 175, 193

Autonomizatiou. 203

Autoradiography. 233. 234

Avian telencephalon, migration of epi. basal central nuclei, 275

Bacteriochlorophyll, 30 structure, 31

Balbiani rings, 248

Biochemistry and evolution. 45

Biology, developmental, 96

Biosynthesis, of coenzyme A by bacteria. 50

of purines. 48

Blue-green algae. 159

chloroplasts, 28

photosynthesis, 17

Brain, 263

Brain differentiation. 262 
Carbon, chemistry of, 2

hydro-, 13

methane, 14, 34

oxidized, 5

on Venus, Mars, 11

radioactive-11, 18

reduction cycle, 18, 19, 20

terrestrial surface, 4

Carbon compounds, of other planets, 11 synthesis of, 9

Carbon cycle in photosynthesis, 18, 21

Carbon dioxide, 11, 12, 19

reduction through carbon cycle, dark reartions, 19

light reactions, 19

Carbon-14, 18

Carbon-hydrogen-oxygen compounds, 6 in metabolism, 7

Carbon reduction cycle. 18, 19, 20 evolutionary history, 20

Carbonaceous compounds, 9, 10

Catalysis, 72

auto., 38

iron, 39

protein, 69, 70, 73

Catalysts, evolution. 37

rudimentary development. 36

Cecropia silkworm, 252

Cell (s), bacterial, 257

differentiation, 98

doublet (see Doublets)

enlargement, 247

epithelial, mouse, after castration. 153

heredity, 165, 205, 208-214

liver. estrogen stimulation, 151

movement, 278

nerve (see Nerve cells)

Paramecium, structure, 167

programming of, 258

structure, preformed, 165

synthesis, $243 \mathrm{ff}$.

Cellophane, 231, 235

Centrioles, 201

Chick embryo. nervous system, 263-265. 268, 277, 278

spinal column, 266

preganglionic thoracic column, 276

segregation, in 111 nerve, 271

in VI nerve, 270

thoracic level, 282

transverse section of $V 1$ nerve, 217

Chitin, 54

Chlorophyll, bacterio-, 30

converted phoro-, 30

structure, $\mathbf{3 1}$
Chlorophyll, structural relation to heme, 41

structure, 30,31

Chloroplasts, 27, 29

blue-green alga, 28

green alga, 28

guinea pig pancreas, 28

lamellar structure, 29

sonicate, 30

spinach, 29, 30

tobacco, 28

visible order, 36

Chondrocytes, 238

Chromatid, 247

Chromosomes, 214, 215

DNA in, 103

gene, 246

giant, 106, 247, 249

Diptera, 106

puffing in, 247

puffing patterns, 106, 107, 108, 248

RNA, 103

Ciliates, 196, 201, 210-212

cortical variants, 198

doublets, 201

Citrulline formation, 64

Clones, 174, 175, 178, 179, 181. 183, 184. $200,209,244,246,257$

phenotype, 173

Coenzyme A, synthesis, 51, 81, 84

Cofactor function, 76,78

divalent cation, 76

Collagen filaments, 36

Conjugation, 193

Construction manual, 243, 244, 253 genetic, 252

Cortex, 201, 205, 208, 211-213, 215

inductor response systems, 205

patterns, 197

Cortical differentiation, 197

Cortical evolution, multicellular organ. isms, 211

Cortical morphogenesis and heredity, 195

Cortical picking, 184

Cortical structure, preformed, 214

Coupling, 40

Cyst, pupated, 253

Cytochrome (s), production, 51

reduction, 25

Cytochrome $c, 87$

Cytodifferentiation, control. 224, 240 microenvironmental influences in, $223 \mathrm{ff}$.

Cytogany, 173

Cytological technique, 169 
Cytoplasm, 125, 126, 130, 136, 138, 144, 155, 159. 174. 205, 216, $21 \%$. 244

structure, 157

Cytoplasmic bridges. 175. 181

Cytopyge, 182, 184. 186. 194. 195, 207, 208

Dehydration, nonredoxed, 25

photoinduced. 24

Delta-amino-levulinic acid, 38

Determination, embryonic. $25 \%$

Developmem. embryonic. 244

Differentiation, 238

brain, 202

cell. 98

cortical, 197

ER in, 155

erythrocytes, 97

macronuclear. 113

melanocyte, 98, 103

molecular. 113

nervous system. 261. 278

nuclear, 109

and segregation. 262

Diffusion layer, 5

Diphosphopyridine nucleotide. 20,76 , 78 cofactor. 78

Diptera, giant chromosomes. 106

Diversification. gene, 243 organi:mal, 223

Diversity, in cytoplasmic structure. 144 in ER. 145. 146

in mitochondria. 122

protein. 95

subcellular. 121

DNA Ideoxyribonuclei" acid). 88, 97. 241

in chromosomes, 103, 104

replication. 106

Doublets. 167. 171, 172, 179-181, 184.

185. 188. 193, 198-201

ciliate. 201

done, 200

conjugants, 178

cortical variants. 198

fission. 190

killer, 176

kinety fields. 190

oral apparatus, 209

oral rudiment. 186, 189

Paramecium, 175

sensitive. 176

(See also Cellis),

DPNH-cytochrome reduction, 25
Drosophila, 106, 108

esterases in. 114

Erdy=on, 106, ] 108, 252, 254. 255

Ertoplasm, 171

Egg. totipotent. concept. 257

Egg mosaic, 257

Elarmobranchs. 62.63

Embryo, chick (see Chick embryo)

Embryonic determination. 257

Embryonic development, 244

Endoplasm. 173. 179. 205 (See also ER)

Energy, chemical. 20

electromagnetic. 20

in bacteria. 18

Gibbs free. 8

radioactive. 7

sources. earth. 7

, sunlightu. 8

Enolase, 73

Enzyme 1s1. 70. 89. 91. 166. 215, 21 \%

acetate thiokinase. 83.84

aldolases. 71, 73. 74, 76. 79

muscle. liver, yeast, 75,76

amino acid sequences. 171

$p$-aminobenzoate. 89

ratalyzing. 178

rofactors. 70

constitutive, 245

control, genetic, 88,89

dehydrogenases. 78

in Drosophila. 113

enolase. 73

est erase. 113

genetic and ontogenetic control. 1]3

ghtamine syuthesis, 82

hexokinase. 79

liydrolytic. 71,72

induced change. 88

inductive. 245

isozymes isee Isozymes |

mechanistic relations. 78

in microbial syatems. 245

papain. 73

phosphorylation. muscle contraction. 85

pyruvate kinase. $78-80$

resistance to antibiotics, 88,90

specificity, 82

synthesis, 245

tyro-inase. 101-103. 108

Episomes, 246

Epithelium. 238

lentogenic. 224

morphogenesis, 239 
Epithelium, salivary, 239

tubules, 227

ER (endoplasmic reticulum), 126, 128, $130,132,134,136,138,142,144$. $145,151-153,155,159,160$

differentiation, 238

diversity, 145, 146

modulation, 151

rough. 146,148

smootl, 147

structural continuities, 148

Erythroblasts, 142

Erythrocytes, differentiation, 97

Esterase, 113

Drosophila, 106, 108

evolution and biochemistry, 45

theory of, 1

Fatty acids. 34

Fertilization, 200

Filter, 232, 233

Fission, 186, 188, 195. 196, 198, 209. 210

abortive, 200

singlets and doublets, kinety fields, 190

oral rudiment, 185, 186, 189

Flagellates, 212, 213

zoo., 213

p-Fluorophenylalanine incorporation, 77

Formic acid, 32, 34

Galactogen, 54

Gene (s), 215, 243-245

am, 179

construction manual (see Construction manual)

diversification, developmental, evolu. tionary, 243

environmental effects, 98

function, 98

regulation of, 96

in giant chromosomes, 246

heterozygous, 175

inhibition or activation, 98

operator, 245, 246

products, 166

regulator, 245

repression, 242

Genetic information, control in microbial systems, 245

endocrine control, 254

nanagement of, 256

Genotype, 173, 175, 198, 200, 216

micronuclear, 178

Glaucoma, 198, 203-205, 208
Glomeruli, 227

Glucagon injection. 149

Glucolytic breakdown, 150

Glucose secretion, 149

Glutamine, 81

Glutamine synthetase, 82

Glutathione, 81

Glycine, 32, 34, 38, 46, 249

$\mathrm{x}$-ray identification, 34

Glycocyamine, 56,57

Glycogen, 34, 124, 136, 149, 155

Golgi complex, 130, 142, 144, 153, 159

Grain-counting procedure, 233, 235, 236

Greenhouse effect, 12

Hense. 41

structural relation to chlorophyll, 41

Hemoglohin, 52, 142

adult, 97

rlemical differences, 52

fetal, 97

gain mutation, 50

sickle-cell, 51

C. 52

S. 52

synthesis, 97

Heterocyclic pyrrole ring, 38

Histones, 104

cleavage, 105

Homarine, 54

Jlormone, juvenile, 255, 256

Hydrogen, 4, 9, 10

cluemistry of, 2

escape from earth, 5

irradiation, 47

oxidixed, 4

Hydrogen peroxide, decomposition, 38

Hydroxy acids, 34

Imaginal dises, 251

Induction, 224, 225, 228, 240

Inserts, differentiation, 243

growth, 246

metamorphosis, 246

microbes, $243 \mathrm{ff}$.

norphogenesis, 243

Insulin, 52

species specificity, $\mathbf{5 3}$

Invagination, 193

Irou, catalysis, 39

ferrous, 38

function, 38

Irradiation, ammonia, 47

hydrogen, 47

methane, 47

lsozymes, 72, 111, 113 
Isozymes, amino acid sequence. 113

aspaerokinase, 117

esterise. 113

lactate dehydrogenase, 112

LDH. 115

lysine. 117

molecular changes. 113

threonine, 117

transplantation, 115

(See also Enzymes)

Killer trait. 174

Kinetics, interpolar dorsal. 172

Kineto-ome (s), 186, 188, 192, 196, 210, 213,215

self-reproduction. 202

theory of. 201

Kinety. 171, 188. 192. 193. 195, 202. 207 elongation. 188, 192. 215

endoral. 170. 208

Kinety fields, 195

doublets. 190

fission. 190

singlets. 190

Kinety patterns, 186

Lactate dehydrogenases. 72. 76, 39

Lamellar cisternae. 159

ribosomes, 132, 142, 144, 153

Lamellar structure, chloroplasts, 29

Larva. cuticle. 253

Larval molts, 253

Lencophrys patula, 209

Limestone, 6

Limiting membrane, 216

Lombricin, 56

Lysosomes, 1.4

Macromolecules, 215

Macronucleus. 179

Mars, 12

Matrix, 125, 126, 128, 278

cytopla=mic. 134, 136, 140, 142, 151 . 159

Melanin, 101

in neural retina. 101 rhick. 102

in pigmented retina. 101, 103

tyrosinase synthesis, 101-103. 108

Melanoblasts, 98,101

Nelanocste, 98

dendritic. 98

differentiation. 98. 103

epithelial. 98

manmalian, 98

Melanogenesis, 98
Melanosome(-). 99. 101

formation. 101

pigmented retini, 102, 101, 105

in protein fibrils, 99

Meridian(s). 86. 192

oral. 190. 194

fusion, 194

Menenchyme, metanephrogenic, 224, 226, 230, 232

nephrogenic. 225

salivary, 239

spinal cord, 225, 228

ureteric bud, 224, 234

Metabolie maps, 246

Metamorphosis. endocrine control. 25l. 254

insect, 246

of skin implants, 253

Metanephric rudiment, 226

Metaneplrogenic layer, 226

Metanephrogenic mesenchyme, 224 , 226, 230, 232

Netanephros, 227

mouse, 224

Metazoa, 211. 212

Meteoric matter, 3

Methane. 32. 33

carbon.14. 34

irradiation. 47

x-ray identification, 33

Nicrobes, genetic control. 245

versus higher organisms, 246

and insects. $243 \mathrm{ff}$.

Microenvironment, 224, 228. 237

Mirrovesicles. 144

Migration. 237

nuclei, 275

Mitochondria, 124, 125, 128, 132 , $134,140.142,155,159$

diversity, 122

structural variations, 123

Molecule(s), autocatalysis, 46

catalysis, by heavy metals. 46

by organic compounds. 46

differentiation, 113

organic origin, 1

primeval and primitive, 32

synthesis. 46

Monolayer culture, 238

Multivesicular bodies. 144

Mutation. 1

gain. hemoglobin, 50

Nerve cells, growth response, 284

to diffusible protein agent. 285

migratory patterns, 278 
Nerve cells, sensory, 262

implantation of mouse sarcomas, 284,285

sympathetic, implantation of mouse sarcomas. 288

response to purified salivary NGF. 289

Nerve centers. differentiation and growth, 278

role of peripheral affectors and re. ceptors in, 278

sen-ory ganglia, 280. 281

Nervous system, central, 261

rhick embryo. 263

developmental mechanisms, 263, 278

differentiation, 261

first differentiative phase, 263

growth of, 261

mass migration, $268 \mathrm{ff}$.

Purkinje cells, 280

regional patterns. $265 \mathrm{ff}$., 268

second differentiative phase, 264

Neural tube, 265, 278

Neuroblasts, 263-265

NGF, 291, 292

distribution. 289

response in sympathetic nerve cells. 289

Nitrogen, 12

chemistry of, 2

excretion, 59,60

Nircleohistone, 106

Nucleotide, diphosphopyridine, 20, 76. 78

pyridine. $20-27$

sequence, 244

triphosphopyridine. 21

Nucleus, 179, 216

cellular determination of size, 180

cellular differentiation, 109

macromolecular fractions, dialyzed, 109,115

injected into fertilized eggs, 109

migration, 275

multiplication in foreign cytoplasm. 109

Octopine, 57

Opalinids, 213

Operon. 245

adult, 252

larval, 252

pupal, 252

Opisthe, 196

Optic vesicle, 224

Oral apparatus, 196
Oral apparatus, doublet, 209

meridian, 183, 190, 194

Paramecium, 170, 175, 209

rudiment. doublet, 186, 189 singlet, 186,189

Organelles, 198, 199, 209

Organic compounds. phosphate in, 10

Ornithine, 62

Orthophosphate, 38 converted to pyrophosphate. 40

Oxidation, of carbon. 5 of nitrogen. 5 phosphorylation, $25,26,72,86,87$ of surface elements, 6

Oxidation state, 5

Oxygen, atomic abundances relative to, 4

chemistry of, 2

free, 6

molecular, 22

Paramecium aurelia. 167, 168, 184, 206208. 210, 212-214, 216

cell structure, genetic function, 167

cortical strncture, 167

hereditary differences in singlets and doublets, 175

oral apparatus. $170,175,209$

Parasomal sac, 171

Periodic acid-Schiff procedure, 232

Petrolenm, 3

PGA (phosphoglyceric acid). 19

Phenotypes, 173

clonal, 175

Phosphagens, 55, 56

Plosphate, carbanyl, 62

rreatine, 55

in organic compounds, 10

Phowphorylation, aldolises, 71

enzymes, 81

oxidation, $25,26,72,86,87$

reversibility, 25

Photosynthesis, 16-18

in algae, 17

alkaline, 114, 115

acid diagram, 116

apparatus, 17

ATP, 25

in bacteria, 17

carbon cycle. 18, 21

evolution, 15, 17

in green plants. 17.27

mechanism, 17

modern. 16

primitive, 32

quantum conversion, 20 
Photosynthesis. schene, 23

subcellular, 17

submolecular. 17

Pla-maphore-i, in liver cells. 153

Pla-matype. 216

Polypeptides, synthesis, 97

Porphyrins. 40

biosynthesis, 39

generation, 36

Potassinm-40, beta rays. 32

Primordium (anlagen), 203-205

Protein(s). 233

catalytic. 69 ff. 73

clrenical activity, 35

diversity, 95

specific, origin, 95

structure, 35

tertiary, 244

synthesis, 97, 244

Prothoracic glands, 252

Pnffing phenomenon. de-repression. 248 in giant chromosomes, 247

Pupa. assay, 255

('yst. 253

diapause, 25]

operon, 252

Purines, biosynthesis, 48

coenzyme A. 50

P'urkinje cells. 280

migration in chick embryo. 273

Pyridine mucleotide, 20, 22, 24. 26, 27 reduced. 24

Pyrophosphate, 24

formation. 38

linkage. ATP. 19, 21, 22, 23, 2t, 26. 27. 29

nonphotosynthetic, 26

Pyruvate kimase artivity, 78,79

phomphoryl formation, 80

Quialruplets, 185

Quantum absorption. 18

Quantum conversion. 18

in photosynthesis, 20

Radiation. ionizing. cyclotron source. 34 $\mathrm{K}^{40} .38$

Radioactive carbon-11, 18

Rarlioactive energy, $\vec{\imath}$

Redox system, photoinduced, 22

Reduction cycle. arbon. 18-20 rarbon dioxide. 19

DPNA. 25

phosphate by ferrous iron. 40

Regeneration. maronuclear. 175

Replication. DNA in, 106
Repressor substance. 245

Reproduction, asexual. 173

Reptiles, clelonian, 60, 61

Rhynchosciura angelae, $246 \mathrm{ff}$. synchronization, 247,248

Ribosome(s), 97, 126, 128, 159, 166. 217. 24. 250

lamellar cisterna attached, J32, 142. 144,153

RNA in, 249

Ribulose diphosphate. 18, 19

RNA (ribonucleic acid). 97, 106, 217. 244

bulk. 250

in chromosomes, 103

messenger. 244, 250, 256

ribosomal. 249

synthesis, 240, 249

Rudinent, 196

ocal, 185, 186, 189

Sarcolemma. 149

Sarcoplasm, 149

Self-selection merhanism, autocatalytic, 38

Sensory nerve cells. 262, 284, 285

Seryl residue. $\mathbf{7 2}, 73$

Singlet(s). 179-181, 188, 197, 198, 200, 201

killer, 176

kinety fields, 190

oral rudiment. 186,189

organization, 197, 199

Paramecium, 175

sen-itive, 176

Solar material. 3

Solar matter, 4

spinal columm, which embryo, 266

regional differences, 266

Spinal cord, 232. 235, 236, 263, 264

mesenchyme. 225. 228

spinal ganglia, 283

Sponges. 237

SR (sarcoplasmic reticulum), 149 . 152

Stenostomum incaudatum, 211

Stentor. 198. 203-205, 214

Sulsstrates, 166

Sucrinic acid, 32, 38, 46

Sulfur. 3

Surfare pressure rate, 5

sutures, postoral. 19.1

preoral, 169

Simpathetir nerve rells, 288. 289

Symearyon, 175

Synthesis. arbon compounds. 11 
Synthesis, cell, $243 \mathrm{ff}$. coenzyme A, 81, 84 enzyme, 245

hemoglobin, 97

mechanism, 49, 50

molecular, 46

polypeptides, 97

protein, 97, 244

RNA, 240, 249

tyrosinase, 101-103, 108

urea, 62,65

Taurocyamine, 56,57

Teratological phenomena, 199

TPNH (triphosphopyridine nucleotide), 19, 21

photoproduced, 25

Transfilter inductive effect, 232

Trichocysts, 171

Triose phosphate, 18, 19

Triose phosphate dehydrogenase, 26

Triplets, 185

Trypsin, 224, 232, 233

Tyrosines, 74 release, 74
Ultraviolet, far, 32

Ultraviolet irradiation, 38,207

Urea, 58, 61, 63

ammonia converts to, 59

formation, 64,65

production, 59

synthesis, 62,65

in Xenopus laevis, 58

Ureogenesis, 62

Ureteric bud, 224, 225

mesenchyme, 224

Uric acid, 61

Vacuole(s), contractile, 193

meridians, 172

pores, 185, 186

Vestibular-gullet juncture, 207

Water, 3, 12, 32-34

X-ray identification, ammonia, 33 glycine. 34

methane, 33

Xenopus, 212

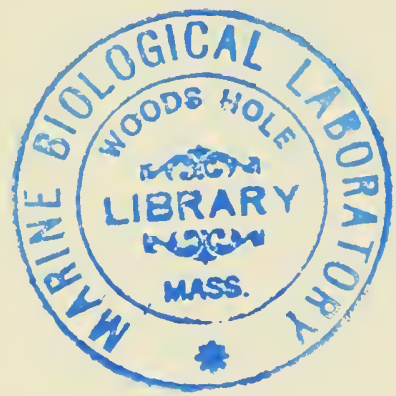









